\title{
A contextual model for planning continuing education programmes for university library practitioners in Vietnam
}

\author{
by \\ Hong Sinh Nguyen
}

Co-supervisors: Professor G. E. Gorman and Dr Daniel Dorner

A thesis submitted in fulfilment of the requirements for the degree of Doctor of Philosophy in Library and Information Management

School of Information Management

Victoria University of Wellington

New Zealand 


\begin{abstract}
Continuing education (CE) for library and information management (LIM) practitioners is an ongoing issue in the profession. In particular, due to the current significant changes in library and information services in the Vietnamese context, especially in university libraries, $\mathrm{CE}$ is a priority for enhancing the ability of practitioners and upgrading the capability of libraries to meet the demands of higher education as well as to meet the demands of socio-economic development of the country.
\end{abstract}

The purpose of this study is to provide a contextual model for CE that will assist providers and university libraries in designing and implementing more effective learning programmes for the practitioners. The study focuses on determining the factors affecting $\mathrm{CE}$, and on identifying and prioritising key learning needs among university library practitioners in Vietnam.

The study employed a preliminary model for CE based on the literature and developed specifically for the Vietnamese context as a framework to gather data. Ten individual interviews with university library managers, and 17 focus group interviews with operational staff were conducted. In addition, related documentary evidence from participating university libraries, relevant ministries and the central government were gathered and examined. Based on the obtained data the model was assessed and revised, and the learning needs for Vietnamese university library practitioners were identified and prioritised.

The study found five main factors significantly affect CE: social factors, professional factors, organisational factors, individual factors, and the nexus between the individual practitioner's and his or her organisation's needs. These factors also particularly affect triage, the process of identifying and prioritising learning needs for university library practitioners. In regard to learning needs, in this study specific areas of professional knowledge and skills are identified as the first priority and generic skills as the second 
priority for library operational staff while management knowledge and skills are identified as the first priority and professional knowledge and skills as the second priority for library managers.

These findings are useful for (1) government and professional organisations, university libraries and library managers in establishing relevant policies and activities to facilitate the CE of library practitioners, (2) CE providers in designing and implementing effective CE programmes, (3) practitioners in enhancing their learning pursuits.

Keywords: Continuing education, library and information management, university library practitioners, continuing education needs, Vietnam. 


\section{ACKNOWLEDGEMENTS}

My first and largest debt of gratitude goes to my supervisors, Professor Gary Gorman and Dr. Daniel Dorner, who have provided me with advice and assisted me whenever I experienced difficulties. Their supervision, empathy and kindness have encouraged me to complete this study.

I am extremely grateful to Liz O'Connor and Xiaodan Gao, learning advisors at Victoria Student Learning Support. Xiaodan spent several hours helping me practise my proposal presentation in my first year of PhD study. Liz provided useful feedback about my writing in my last two years of PhD study. I also enormously thank Louise Norton and Dr. Deborah Laurs for their assistance in editing this thesis.

I deeply thank the library directors and study participants in Vietnam. The directors supported me in conducting the research in their libraries and spent time sharing their ideas with me. The study participants enthusiastically took part in discussions and willingly shared their opinions with me. Without their cooperation and contribution, this study would not have been possible.

I would like to express my appreciation to others in the School of Information Management, especially Professor Pak Young, Dr. ChernLi Liew, Jean Grant, Tiso Ross and Peter Metham, who were very supportive throughout my study.

I am also indebted to Ms. Ngo Ngoc Chi, the former Head of the Library and Information Department at the University of Social Sciences and Humanities in Ho Chi Minh City, for giving me the opportunity to upgrade my academic degree.

I thank my Vietnamese friends in the Master of Library and Information Studies programme in the School of Information Management, especially Duong, Mai, Thoa, Vy and Phuong Mai, for their friendship during the years I have been in Wellington. I also 
thank my peers in the $\mathrm{PhD}$ programme, especially Lanthom, for sharing in my progress and difficulties.

My final and most heartfelt thanks go to my father and mother, Chi Hai and Anh Toi, who have shared my happiness and frustration and who have encouraged me with untiring support and unlimited belief in me. I dedicate this work to my loving parents. 


\section{TABLE OF CONTENTS}

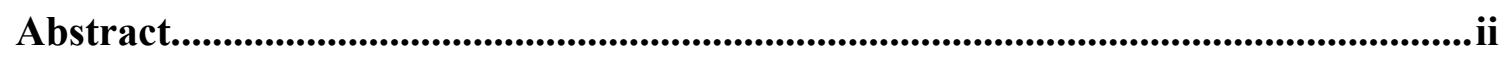

ACKNOWLEDGEMENTS .....................................................................................iv

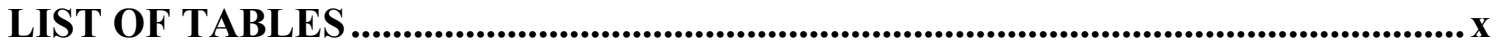

LIST OF FIGURES ......................................................................................................................

LIST OF APPENDICES .......................................................................................................xiii

LIST OF ABBREVIATIONS .................................................................................xiv

CHAPTER 1: BACKGROUND TO THE STUDY .........................................................1

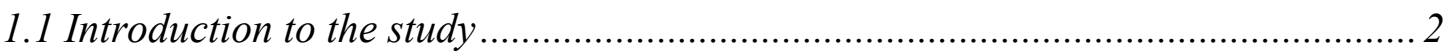

1.1.1 Statement of the problem......................................................................... 2

1.1.2 Research questions......................................................................................

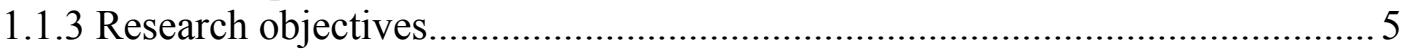

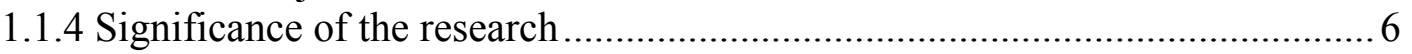

1.1.5 Research methodology ............................................................................. 7

1.1.6 Delimitations and limitations of the study ................................................. 7

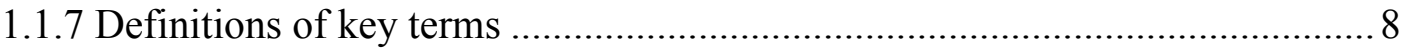

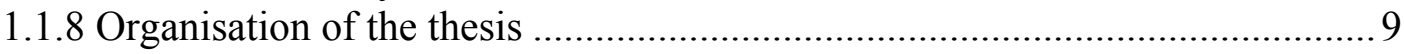

1.2 Background on library and information development in Vietnam ......................... 9

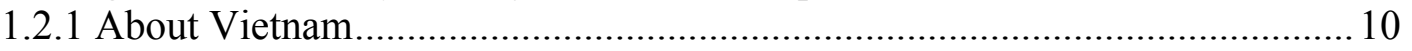

1.2.2 Historical background of library development in Vietnam .............................. 11

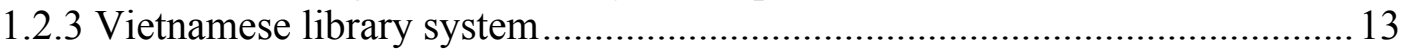

1.2.4 Library and information science education and CE activities in Vietnam ..... 18

CHAPTER 2: LITERATURE REVIEW AND PRELIMINARY MODEL...............20

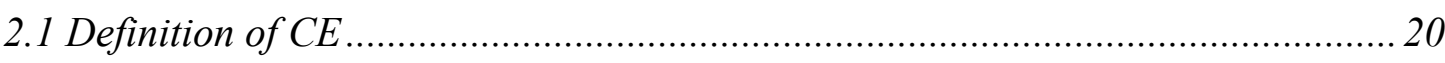

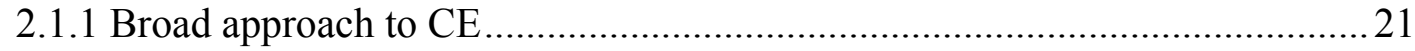

2.1.2 Specific approach to CE focusing on professions ………..............................2 22

2.1.3 Definitions of CE within the LIM profession .................................................2

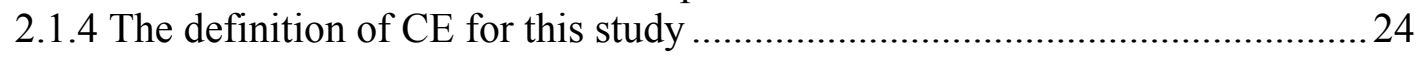

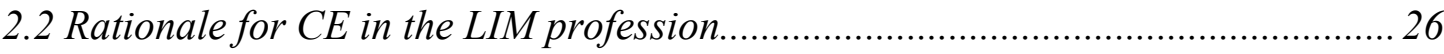

2.2.1 Overcoming the limitations of initial education and improving professional

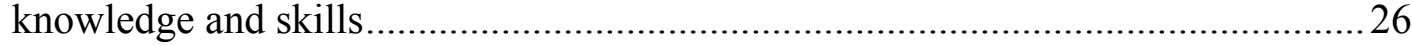

2.2.2 Keeping abreast of changes and surviving in a competitive workplace

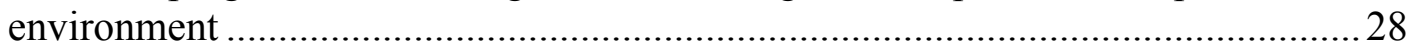

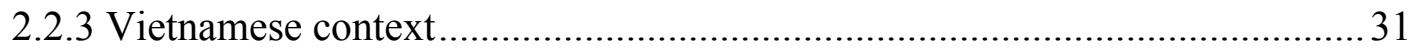

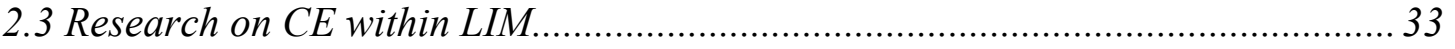




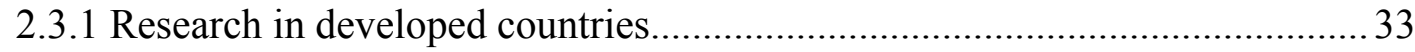

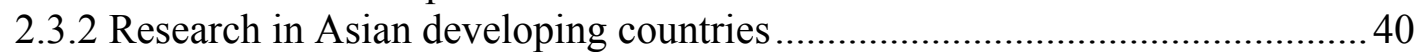

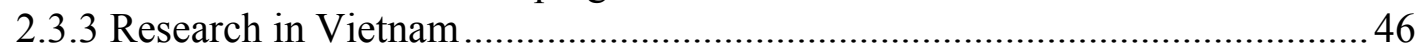

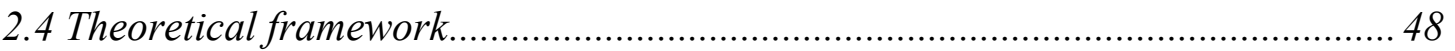

2.4.1 Factors affecting CE .............................................................................. 48

2.4.2 Overview of conceptual models of adult education and $\mathrm{CE}$ in the literature . 56

2.4.3 Review of the Performance Model in CE (Nowlen, 1988)..............................59

2.5 The preliminary model for CE for university library practitioners in Vietnam .... 66

2.5.1 Adaptation of factors affecting CE from literature ..........................................66

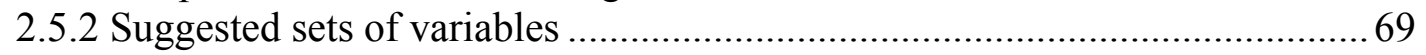

CHAPTER 3: RESEARCH METHODOLOGY ......................................................74

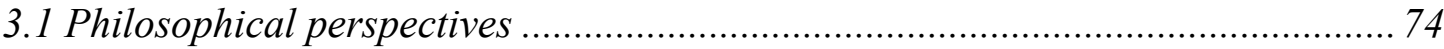

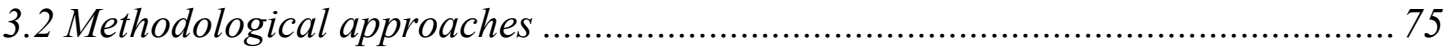

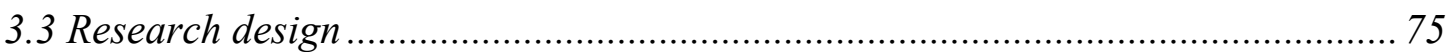

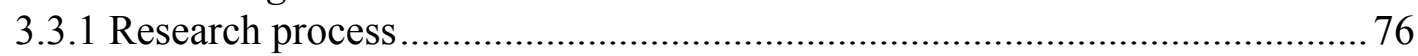

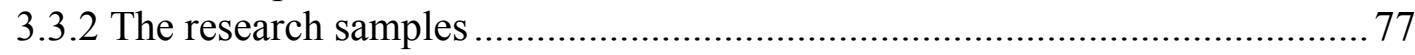

3.3.3 Data collection procedures....................................................................... 82

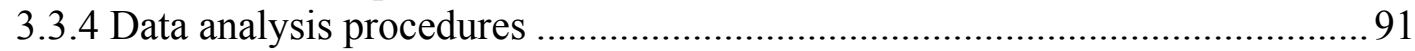

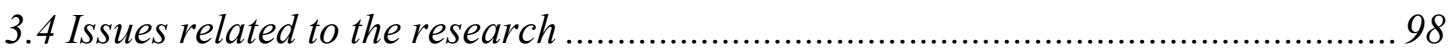

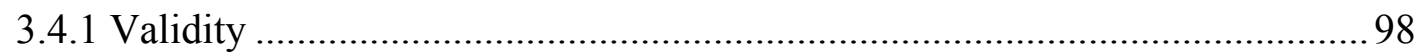

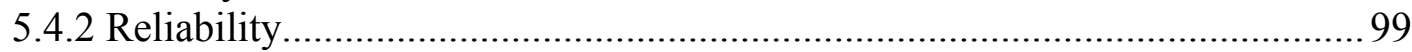

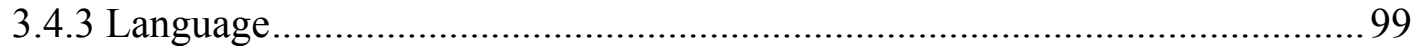

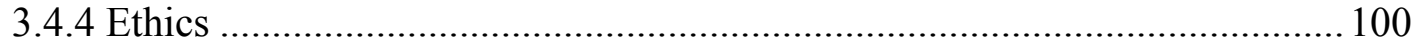

CHAPTER 4: DEMOGRAPHIC INFORMATION ................................................101

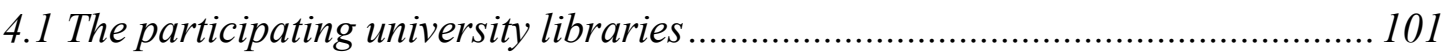

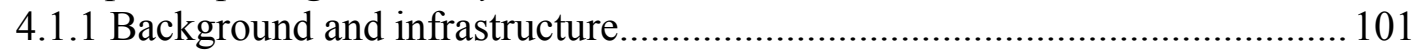

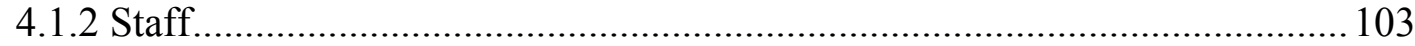

4.1.3 Library organisational structure …………………..................................... 104

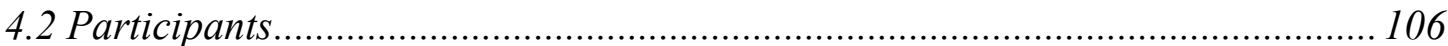

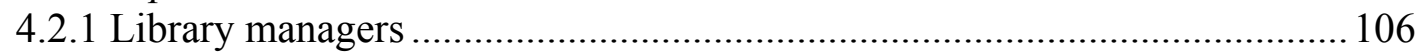

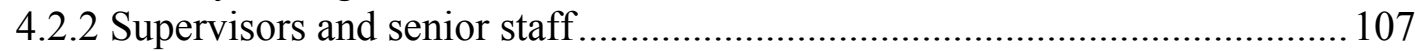

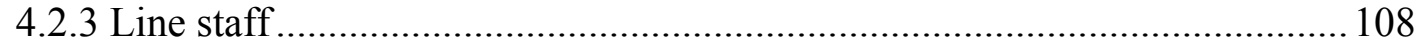

CHAPTER 5: SOCIAL, PROFESSIONAL AND INDIVIDUAL PRACTITIONER

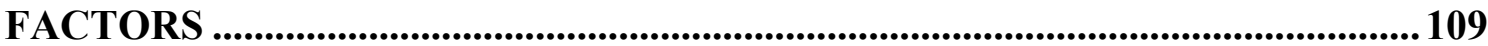

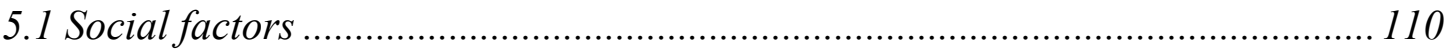

5.1.1 Society's perceptions of women's role ........................................................... 110

5.1.2 Society's views of library work ............................................................... 114

5.1.3 Society's perceptions concerning learning ………….................................. 120 


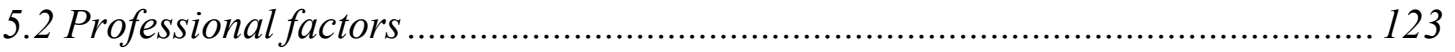

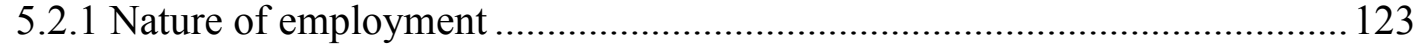

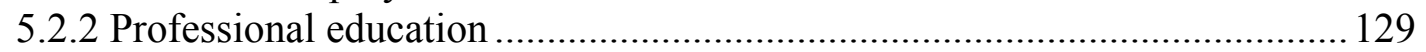

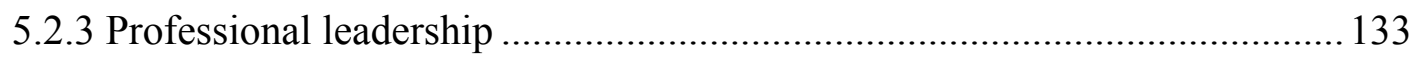

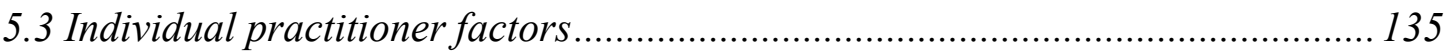

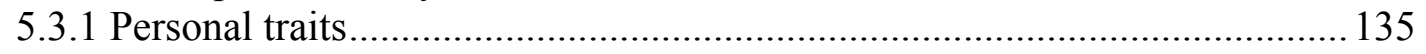

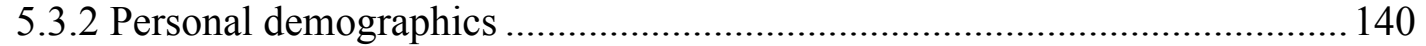

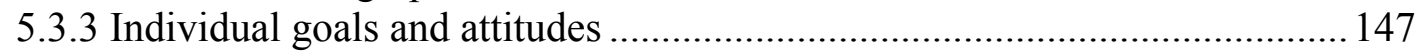

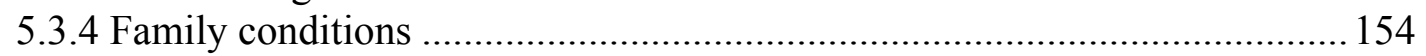

\section{CHAPTER 6: ORGANISATIONAL FACTORS AND PRACTITIONER AND} ORGANISATION NEXUS ......................................................................................... 159

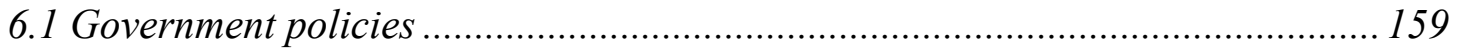

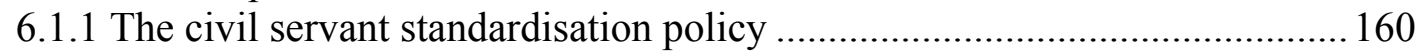

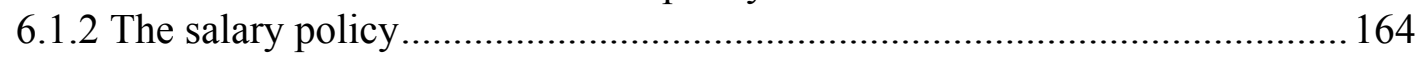

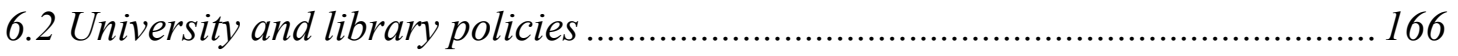

6.2.1 Library development plans ...................................................................... 166

6.2.2 Bonus and promotion policies ................................................................ 168

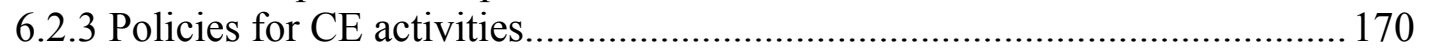

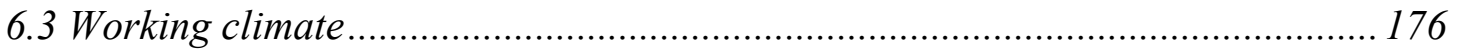

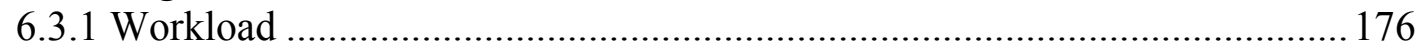

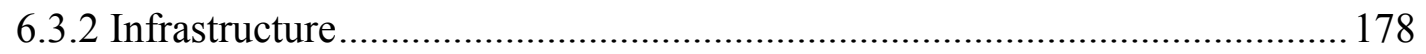

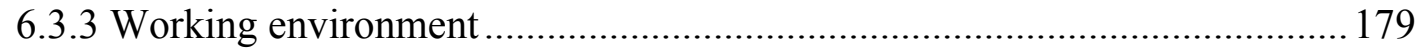

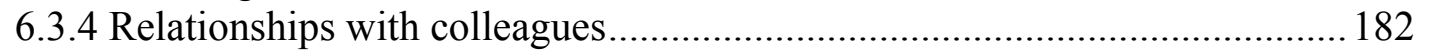

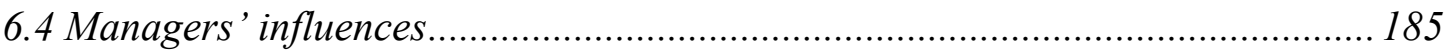

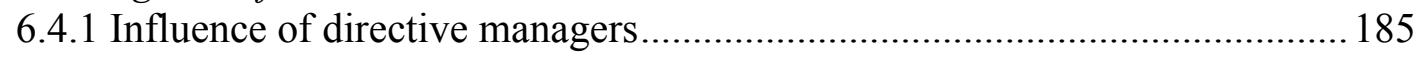

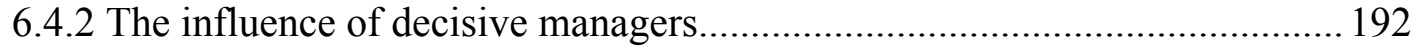

6.4.3 Influence of formalistic managers ............................................................. 195

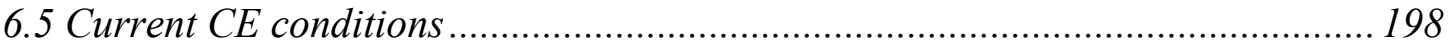

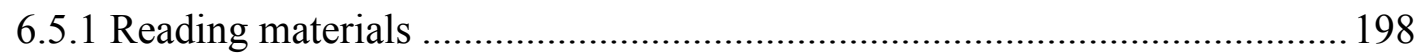

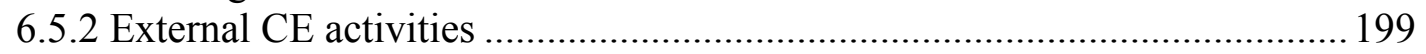

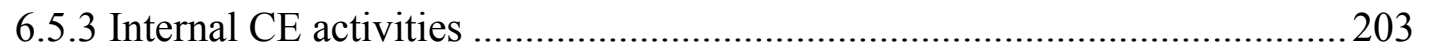

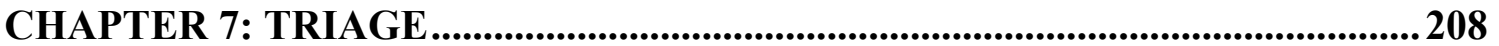

7.1 Identifying perceived learning content ………….......................................2. 210

7.1.1 Learning content identified in the documentary evidence.............................211

7.1.2 Learning content identified for operational staff from interviews.................221

7.1.3 Learning content identified for managers based on their perceptions ...........239

7. 2 Identifying preferred learning formats ........................................................... 245

7.2.1 Learning formats for operational staff......................................................24

7.2.2 Learning formats for library managers based on their perceptions ............... 249 


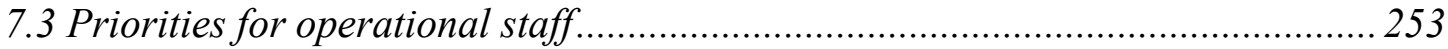

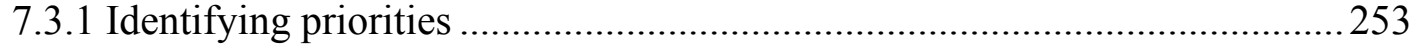

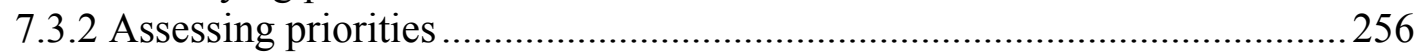

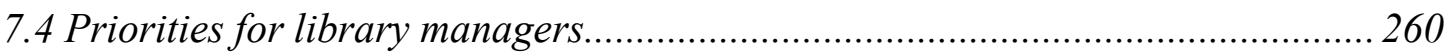

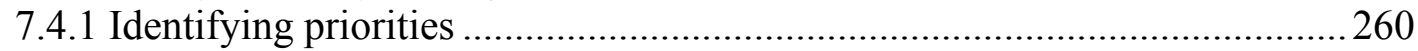

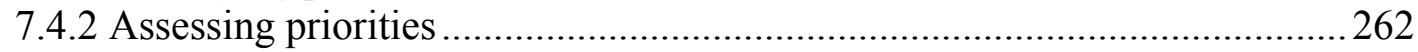

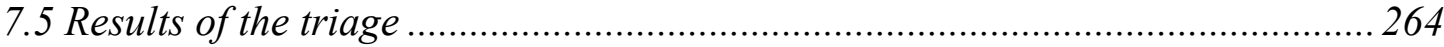

CHAPTER 8: MODEL REVISON AND CONCLUSION ................................. 271

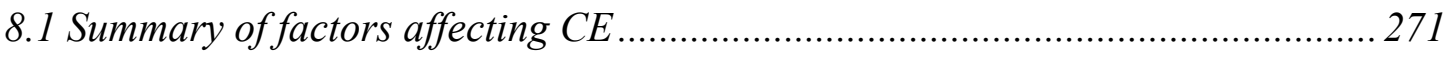

8.2 Model assessment and revision.................................................................... 277

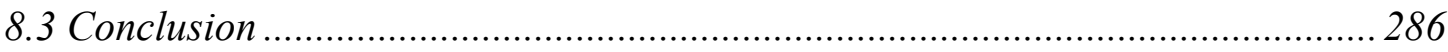

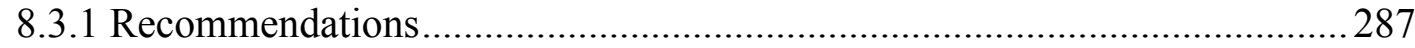

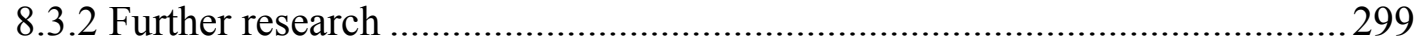

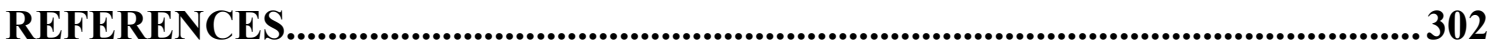




\section{LIST OF TABLES}

Table 2.1: $\quad$ Main factors in models of CE .................................... 57

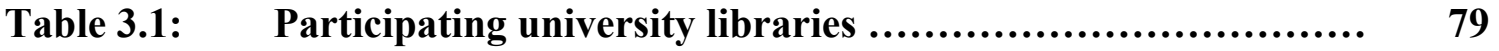

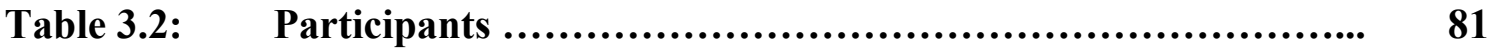

Table 3.3: $\quad$ Framework of data reduction ................................. 96

Table 7.1: $\quad$ Required learning content for operational staff identified in the 1993 Professional Criteria ................................ 213

Table 7.2: $\quad$ Required learning content for managers identified in the 1993 Professional Criteria ................................................ 214

Table 7.3: $\quad$ Expected learning content identified in the 2007 Library Development Plan ........................................... 216

Table 7.4: Review of learning content for operational staff in the documentary evidence ........................................ 218

Table 7.5: The most important learning content for operational staff in the documentary evidence ......................................... 219

Table 7.6: Review of learning content for managers in the documentary

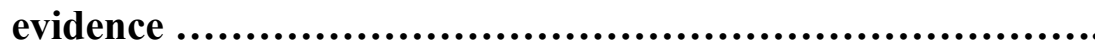

Table 7.7: The most important learning content for managers in the

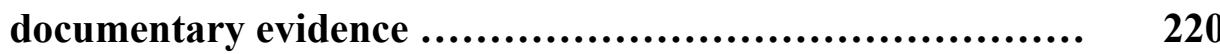

Table 7.8: $\quad$ Learning content for operational staff based on managers'

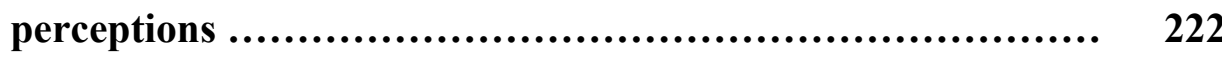

Table 7.9: $\quad$ Learning content for operational staff based on staff's $\quad 228$

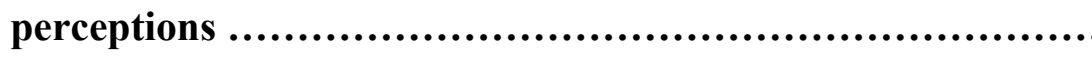

Table 7.10: Learning content for managers based on managers'

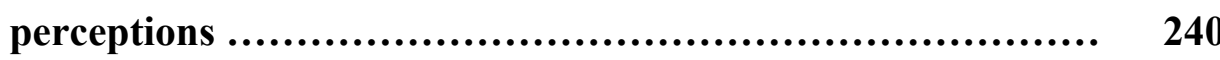

Table 7.11: Priority learning content for operational staff .................. 254 
Table 7.12: $\quad$ Priority learning content for managers ....................... 261

Table 8.1: $\quad$ Factors affecting CE for university library practitioners ...... 271

Table 8.2: $\quad$ Review of factors in the preliminary model and in the data ... 277 


\section{LIST OF FIGURES}

Figure 1.1: Map of Vietnam .............................................. 10

Figure 1.2: Vietnamese library system ......................................... 14

Figure 1.3: Organisational structure of public university libraries ......... 16

Figure 2.1: $\quad$ Factors affecting adult education and $\mathrm{CE}$ from the literature .. $\quad 56$

Figure 2.2: $\quad$ Performance Model ............................................... 60

Figure 2.3: Variables in the Performance Model ........................... 65

Figure 2.4: The adaptation of variables to the preliminary model for this

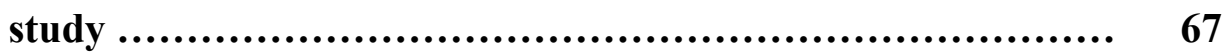

Figure 2.5: The preliminary model for CE for university library practitioners in Vietnam ...................................... 69

Figure 3.1: The research process ......................................... 77

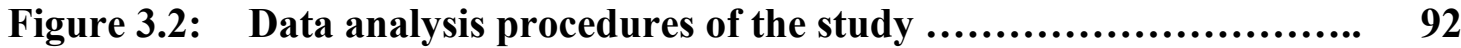

Figure 4.1: $\quad$ Organisational structure of participating libraries ............. 104

Figure 8.1: Revision of the Social environment factor ..................... 280

Figure 8.2: Revision of the LIM profession factor ....................... 281

Figure 8.3: Revision of the Organisations factor $\ldots . \ldots \ldots \ldots \ldots \ldots \ldots \ldots \ldots \ldots \ldots . \quad 282$

Figure 8.4: Revision of the Practitioners characteristics factor ............ 283

Figure 8.5: Contextual model for the CE of Vietnamese university library

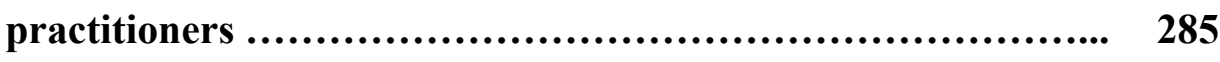




\section{LIST OF APPENDICES}

Appendix A: Information sheet and consent form for sample libraries ...... 320

Appendix B: Information sheet and consent form for individual

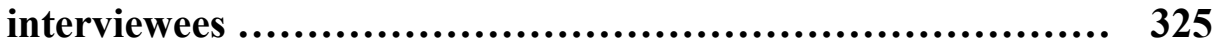

Appendix C: Information sheet and consent form for group focus

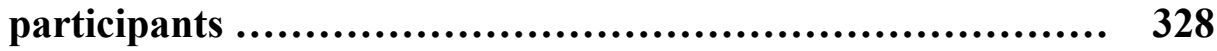

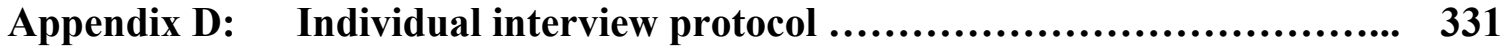

Appendix E: Themes for gathering evidence and sample of interview

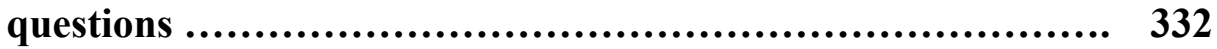

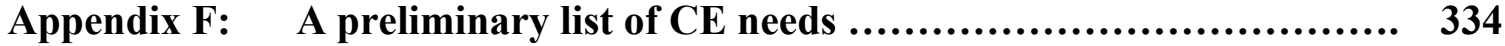

Appendix G: $\quad$ Focus group interview protocol ............................. 337

Appendix H: Handling problematic group behaviours ....................... 339 


\title{
LIST OF ABBREVIATIONS
}

\author{
AACR2: Anglo-American Cataloguing Rules, Second edition \\ BBK: $\quad$ Bibliotechno-bibliogracheskaja Klassfikacija \\ (Library-bibliographic classification) \\ CE: Continuing education \\ DDC: $\quad$ Dewey Decimal Classification \\ FESAL: $\quad$ Federation of Southern Vietnam Academic Libraries \\ IT: Information technology \\ LIM: $\quad$ Library and Information Management \\ MARC: $\quad$ Machine-Readable Cataloguing \\ MARC21: $\quad$ Format for bibliographic data \\ MOET: $\quad$ Ministry of Education and Training \\ NACESTI: National Centre for Scientific and Technological Information \\ OPAC: $\quad$ Online Public Access Cataloguing \\ VNU-HCMC: Vietnam National University-Ho Chi Minh City \\ VNU-HN: Vietnam National University-Ha Noi
}




\section{CHAPTER 1: BACKGROUND TO THE STUDY}

The need for continuing education (CE) in the professions is an ongoing issue and always topical. CE for practitioners was provided through apprenticeships and guild systems in the Middle Ages, and has become an informal adjunct of professional practice into modern times (Queeney, 2000). In the Library and Information Management (LIM) profession, $\mathrm{CE}$ is a constant important issue because of the profession's features, as Moyo (2002) noted:

The emerging information society, with information at its core has increased the pressure on librarians... to undertake continuing professional education to ensure that they have relevant skills and competencies to make them remain competitive in the information marketplace where there are many other players. (p. 230)

Since then, the LIM profession has operated in an environment of increasing information overload, of rapid developments in information technologies and of greater competition in the information market - all of which place greater pressure on LIM practitioners to upgrade their knowledge and skills if they are to remain relevant in the new information age.

In Western developed countries research on issues relating to CE in LIM has been undertaken since the 1960s. Over the past five decades Western authors have conducted many studies concerning theoretical and practical issues of CE for LIM practitioners. These issues include the value and scope of, and responsibility and motivation for CE. They also include models for development programmes, needs assessment, and the planning, implementation and evaluation of $\mathrm{CE}$ programmes. The past studies of $\mathrm{CE}$ have effectively guided and motivated CE activities in many Western countries, and CE has become a vehicle to support LIM practitioners facing changes in society, technology and the profession. 
However, CE has not been the subject of such comprehensive research in developing countries, including Vietnam. Although the Vietnamese Ministry of Culture and Information (2004b; 2007) considers CE to be a means to respond to the requirements of the profession, studies of this topic are lacking in Vietnam. Current CE programmes are unsystematic and conducted in isolation from one and other (Ngo, 2004; Nguyen, 2000b). Therefore, CE for LIM practitioners requires urgent attention from researchers in Vietnam.

The main purpose of this study is to identify and understand factors affecting CE for university library practitioners in Vietnam. This has been done by developing, assessing and then revising a contextual model for $\mathrm{CE}$ for university library practitioners. The revised model provides a framework for identifying, explaining and prioritising key learning needs that assists CE providers and university libraries to design and implement more effective CE programmes for university library practitioners in Vietnam.

\subsection{Introduction to the study}

To provide background to the study, this section outlines the research problem, research questions, objectives, significance and a brief description of the research methodology.

\subsubsection{Statement of the problem}

Due to the implementation of the Đổi Mới ${ }^{1}$ reform policies, Vietnam has progressed in many areas, especially in economics and education. Đổi Mói $i$ and the current five-year development plans of the Vietnamese government (Communist Party of Vietnam, 2001, 2006) emphasise developments in higher education. The total number of students in higher education in Vietnam increased from 893,754 in 2000 to 1,540,201 in 2007

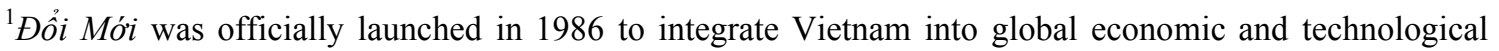
development, and to implement industrialisation and modernisation in the country. This reform process was characterised by two major aspects: 1) macro-economic stabilisation, market reforms and a gradual move away from central planning; and 2) a gradual opening up to the rest of the world through a more "open door policy".
} 
(Ministry of Education and Training, 2007). Within the period 2005-2015 the government estimates that two million students a year will be seeking tertiary education (Institute of International Education, 2005). As a consequence, to serve this growing number of students, the numbers of university libraries and their practitioners are increasing. Demands for up-to-date information services in the higher education sector are increasing. University libraries are now being recognised as an essential part of the country's development programme and university library practitioners are being recognised as information workers who will greatly contribute to the development of Vietnam. Therefore, to meet the information demands in higher education and to cope with changes in library and information activities, current practitioners need to expand and update their knowledge and skills.

In addition, due to the instructions from the government about the application of information technology (IT) in all activities, in particular "focusing on development of IT services in finance, banking, aviation, trade and public services including education, public health and libraries" (Communist Party of Vietnam, 2000, p. 4), public university libraries have taken a new direction, introducing innovations in such aspects as collections, infrastructures, services and staff training. Ten years ago, online resources as well as the internet were not provided in Vietnamese libraries, but now many libraries and information centres have begun automating their activities and introducing projects for establishing digital libraries (Hoang, 2003; Ministry of Culture and Information, 2005).

Many university libraries also have new facilities and are able to improve services and service quality as a result. For instance, with funding from Atlantic Philanthropies, the universities in Thai Nguyen, Hue, Da Nang and Can Tho have established learning resource centres and information services following Western models. With funding from the government, the libraries in Vietnam National universities in Ha Noi and Ho Chi Minh City also have new facilities, including buildings, computers and internet connectivity, and they also have begun providing their users with online resources and 
reference services. Accordingly, library practitioners are required to learn new competencies as well as to keep update with IT applications.

Along with these changes in facilities and practice, it remains the case that a large number of university library practitioners lack degree-level professional education (Denison \& Robinson, 2004; Nguyen, 2003c). In addition, the level and quality of LIM education remains a problem. As many authors have noted the curricula of most library schools are out-dated, both in structure and content (Tran \& Gorman, 1999), many have not made changes in the curricula for several years (Nguyen, 2001), and graduates have the ability to work only with traditional systems (Nguyen, 2003d). As a result, CE participation is a growing need in Vietnamese university libraries.

In fact, the opportunities for practitioners to participate in $\mathrm{CE}$ programmes are very limited. CE programmes are infrequent and unsystematic (Ngo, 2004; Nguyen, 2000b). They come from a range of providers including the National Centre for Scientific and Technological Information (NACESTI), the Federation of Southern Vietnam Academic Libraries $(\mathrm{FESAL})^{2}$, overseas organisations and separate libraries without any coordination. It appears that the providers have conducted programmes chiefly based on their available resources rather than on the needs of the practitioners, the needs of libraries or the government's strategic plans. The providers are also unaware of the factors affecting CE when designing and implementing CE programmes.

Therefore, the problem addressed in this study consists of two elements. First, there is a lack of understanding of the factors that enable or hinder the CE of university library practitioners in Vietnam. The second is that little is known about the actual CE needs of university library practitioners in Vietnam and which of those needs have the highest priorities. By understanding both elements of the problem, it will become possible for CE providers and university libraries to plan achievable learning programmes that will

\footnotetext{
${ }^{2}$ This organisation was reorganised and renamed the Vietnamese Library Association of Southern Academic Libraries (VILASAL) in August 2007. In this study, its former name FESAL is used.
} 
improve practitioners' performance in the areas of greatest need. By doing so, university libraries will directly support their universities in achieving their targets for contributing to Vietnam's national development.

\subsubsection{Research questions}

To understand the problem being addressed, this study answers the following research questions:

1. What are the contextual factors that affect $\mathrm{CE}$ for Vietnamese university library managers and operational staff (for example, with regard to the LIM profession, the relevant organisations, the environments and so forth)?

2. How do these factors affect $\mathrm{CE}$ for Vietnamese university library managers and operational staff?

3. What are the most important $\mathrm{CE}$ needs for Vietnamese university library managers and operational staff from the perspectives of managers, operational staff and organisations?

4. What are the main CE priorities for Vietnamese university library managers and operational staff?

\subsubsection{Research objectives}

This study has three objectives:

1. To develop a preliminary contextual model of factors that affect the $\mathrm{CE}$ and learning needs of Vietnamese university library managers and operational staff.

2. To assess the model by:

i) Identifying and understanding factors affecting the $\mathrm{CE}$ of Vietnamese university library managers and operational staff. 
ii) Identifying learning needs and establishing priorities of learning needs for Vietnamese university library managers and operational staff.

3. Based on the assessment, to provide a revised contextual model for use in planning CE programmes for Vietnamese university library managers and operational staff.

Hereafter, the term "university library practitioner" will be used to refer to both library university managers and operational staff.

\subsubsection{Significance of the research}

The goals of the study are to determine and understand factors affecting CE, to identify and prioritise learning needs for university library practitioners, and, based on these, to provide a contextual model for CE for Vietnamese university library practitioners. This study will contribute to the theory of $\mathrm{CE}$ and to the improvement of $\mathrm{CE}$ programmes for LIM in Vietnam. To date, no similar research has been conducted in Vietnam.

The findings of the study are of particular value to: (1) professional organisations, (2) university libraries, (3) CE providers or potential providers and (4) university library practitioners.

Understanding the factors affecting $\mathrm{CE}$ will enable professional organisations and university libraries to make policies to encourage their staff to participate in $\mathrm{CE}$ activities, and to offer opportunities and organise $\mathrm{CE}$ activities that meet the learning needs of staff and libraries. The study will particularly benefit CE providers, or potential providers, in designing and implementing well-planned and effective CE programmes. It will also be of value to university library practitioners in assisting them to be aware of enablers and barriers to their $\mathrm{CE}$, to engage in self-assessment of learning needs analysis and to select $\mathrm{CE}$ activities that will enhance their performance in their particular jobs, as well as in their professional careers. 


\subsubsection{Research methodology}

Desk research, individual interviews, focus group interviews and documentation have been employed in this study. An interpretative perspective has been adopted for this study, and the research has been undertaken in three phases.

The first phase was desk research to develop a preliminary contextual model for CE for university library practitioners in Vietnam. This model was developed by identifying and applying the factors affecting $\mathrm{CE}$ and modifying an existing model in the literature of adult education and $\mathrm{CE}$ in professions.

The second phase involved collecting data to determine the factors affecting CE and to identify the CE needs of university library practitioners in Vietnam. The data was collected using several processes, including individual interviews with library managers, focus group interviews with operational staff and the gathering of documentary evidence.

The third phase was analysis of the data gathered in the second phase with the aim of assessing the preliminary model from the first phase. The analysis involved: (1) identifying and understanding factors affecting the CE of Vietnamese university library practitioners, (2) identifying and prioritising the learning needs for CE of university library practitioners in Vietnam, and (3) based on the above, assessing and revising the contextual model as needed.

\subsubsection{Delimitations and limitations of the study}

The delimitation of this study is that it only looked at the factors affecting CE and the learning needs priorities for public university library practitioners in Vietnam. Only the library managers and operational staff in 10 selected public university libraries were studied. 
To assess the preliminary CE model this study is chiefly based on the perceptions of public university library practitioners. A limitation of this study is that the findings with respect to the learning needs cannot be generalised to the whole Vietnamese library system, though the revised model should have applicability across the system. In addition, nine of the ten participating managers were library directors; therefore, their perceived learning needs might not be accurate for lower managers. Another limitation of the study is the possible shortcomings in translating the results of the data analysis into English since the data was collected in Vietnamese. To limit these shortcomings several steps were taken, which are discussed in the section on methodology.

\subsubsection{Definitions of key terms}

The definitions provided below are based on the literature review that informed the study.

Continuing education (CE): All educational or training activities that provide opportunities to gain knowledge and skills in Library and Information Management (LIM) to those both with and without formal qualifications in LIM to help them to satisfy the requirements of and changes in their jobs.

Continuing education needs: All topics concerned with professional knowledge and skills that can be shown to be needed for adequate performance by practitioners. CE needs also include educational formats that are preferred by practitioners. In this study, the terms CE needs and learning needs are used interchangeably.

Library and Information Management (LIM): The profession that applies theory and technology to the creation, selection, organisation, management, preservation, dissemination and utilisation of collections of information in all formats.

University library manager: A practitioner who is responsible for running a library or a department of a university library, for example, the director of a library, deputy head of a library or head of a department in a library. 
University library operational staff: A practitioner who is not responsible for running a university library. University operational staff include group supervisors, senior staff and line staff.

University library practitioner: A person who works in Library and Information practice in a university library, regardless of his or her initial educational qualification and his or her position in the library. University library practitioners include library managers and operational staff.

\subsubsection{Organisation of the thesis}

This thesis is organised into eight chapters.

- Chapter 1 provides background to the study, including the introduction to the study and the background of the LIM profession in Vietnam.

- Chapter 2 reviews literature and develops a preliminary model for the study by adopting and modifying factors affecting $\mathrm{CE}$ in the literature of adult education and $\mathrm{CE}$ in professions.

- Chapter 3 addresses the methodology for this study.

- Chapter 4 provides information about the sample libraries and participants.

- Chapters 5 and 6 analyse the data to identify and understand factors affecting CE for university library practitioners.

- Chapter 7 conducts a triage to identify and prioritise learning needs for university library practitioners.

- Chapter 8 assesses and revises the preliminary model, and gives conclusions.

\subsection{Background on library and information development in Vietnam}

This section gives a brief introduction to Vietnam, including the country itself; the historical background of library development; the education and CE for LIM practitioners; and the library system. 


\subsubsection{About Vietnam}

The formal name of Vietnam is the Socialist Republic of Vietnam. The capital is Hanoi, and the biggest city is Ho Chi Minh City (HCMC). Geographically, Vietnam is located in Southeastern Asia, bordering the Gulf of Thailand, the Gulf of Tonkin, alongside China, Laos and Cambodia. The size of Vietnam is approximately 331,688 square kilometres. By mid-2006 the population of Vietnam was an estimated 84,402,966, and the birth rate was 16.86 births per 1,000 people. In terms of literacy, $90.3 \%$ of people aged 15 years or older can read and write (The World Factbook, 2006).

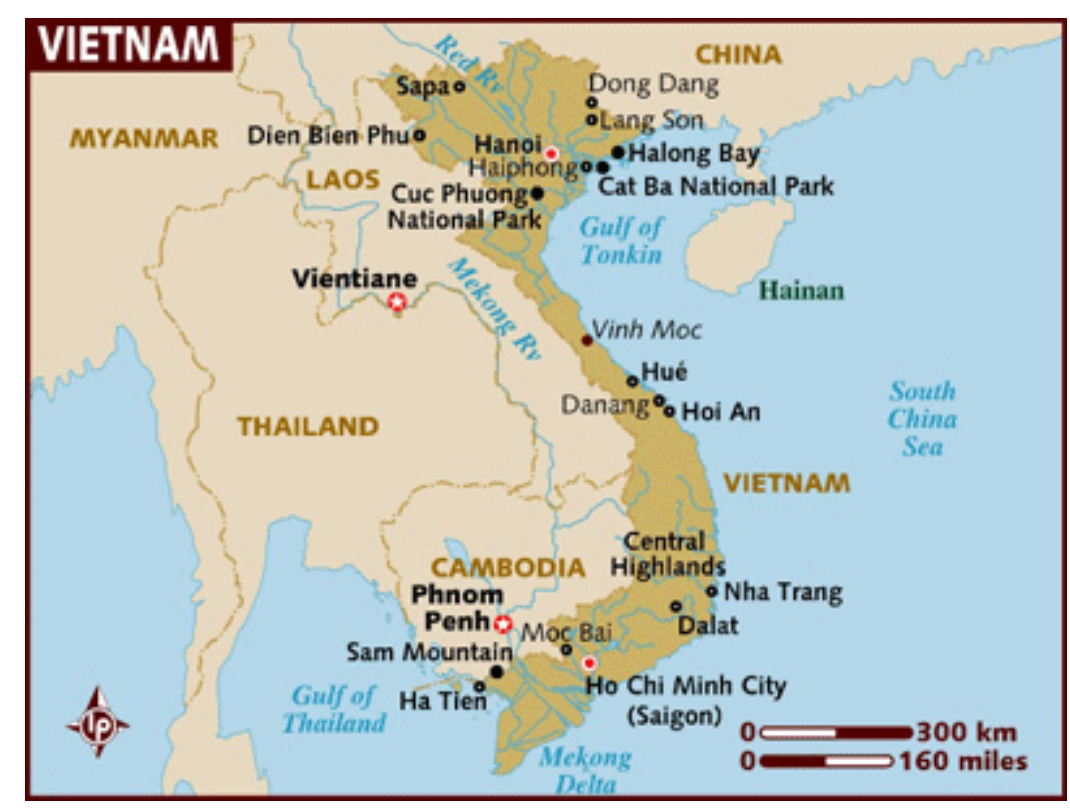

Figure 1.1: Map of Vietnam

Source: Lonely Planet (2007)

Buddhism is the main religion, but others include Christianity, Taoism, Confucianism, Hoa Hao, Cao Dai and Islam. In 2006, 27.12\% of the population lived in urban areas, while $72.88 \%$ lived in rural areas (General Statistics Office, 2006).

Vietnam is a one-party state governed by the Communist Party. The Politburo is constitutionally responsible to the National Assembly, which is elected for a five-year term. The government controls all areas, including education, in the country. When the 
Đổi Mới reform policies were launched in 1986, Vietnam started the process of integrating into international economics and education as well as socio-culture. Some private enterprises in commerce and education are now permitted. Information technologies are increasingly applied in many areas. New values, beliefs and expectations come from the process of industrialisation and modernisation. However, traditional rural customs and traditions still play a vital role in shaping the culture of Vietnam.

\subsubsection{Historical background of library development in Vietnam}

The oldest libraries were formed in the $11^{\text {th }}$ Century after Vietnam gained independence from China. Their main function was to store Buddhist canonical texts and prayer books. At that time, libraries served the ruling classes (Duong, 1999; Nguyen, 2000a).

In 1853 the French occupied Vietnam, commencing 10 decades of French dominance. During this time, some libraries, including public libraries, specialised libraries and provincial libraries, were established. Among them, the library of Viễn Đông Bắc Cổ University and the Central Library of Indochina (both in Hanoi) were well-known in Indochina. The Central Library of Indochina was renamed Library Pierre Pasquier in 1935, and is now the National Library of Vietnam (Duong, 1999).

On 2 September 1945 Vietnam unilaterally declared independence, but the French continued to rule until the Battle of Điện Biên Phủ in 1954. After the defeat of the French by the Communists in Điện Biên Phủ and under the Geneva Accord of 1954, Vietnam was divided into two parts. The North was the Democratic Republic of Vietnam, ruled by a socialist government and the Communist Party. The South was the Republic of Vietnam, dominated by a non-Communist government supported by the United States (US). Libraries in this period developed under two different political systems. In the North, library development was based on the theory of socialist libraries 
adopted from the Soviet Union. In the South, library development was supported by the US (Tran, 1999b). In 1975 the North and South of Vietnam were unified.

From 1976 all the libraries had the goal of building socialism throughout the country. However, after 30 years of full-scale war (1945-1975) Vietnam's economic performance was seriously hampered by the failures of foreign policy and economic management, and the impact of US-led trade and investment embargoes. As a result, Vietnam stood among the poorest countries in the world in standard of living (Tran-Nam \& Pham, 2003). Therefore, to foster global economic and technological development, and implement industrialisation and modernisation in the country, in 1986 the VI National Congress of the Communist Party of Vietnam launched its Đổi Mới reform policies for all sectors, including the economy, culture and education (Communist Party of Vietnam, 1996, 2001). Currently, education is one of the sectors that has received significant government investment in recent years: $17.1-18 \%$ of all state expenditure is devoted to education, and this percentage is expected to increase to $20 \%$ by 2010 (Ministry of Education and Training, 2003). As a consequence, the number of public universities increased from 52 in 2000 to 109 in 2007. In addition, 30 private universities were established during these years (Ministry of Education and Training, 2007). These universities, including their libraries, are recognised as an essential part of the development of the country.

At the same time, due to encouragement from the government to apply information technology in all activities (Communist Party of Vietnam, 1997, 2000), public university libraries in particular have taken a new direction, introducing innovations in such aspects as collections, infrastructures, services and staff training. Many libraries and information centres have started to automate their activities and projects for establishing digital libraries have been initiated (Hoang, 2003; Ministry of Culture and Information, 2005). In recent times, changes in activities and services within university libraries have become rapid, and university libraries are now considered the strongest group in the Vietnamese library system. 


\subsubsection{Vietnamese library system}

In Vietnam, most libraries are organised and administered by the government. The Ministry of Culture and Information is responsible for library development ${ }^{3}$. The Library Department of the Ministry administers the country's library system (Government of Vietnam, 2007). Its functions include drafting laws, ordinances and regulations relating to the library system; drawing up short-term, long-term and annual plans for library development throughout the country; seeking cooperation with overseas libraries; participating in projects, programmes and activities concerned with librarianship; organising professional activities at national and regional levels; establishing a national library network; and undertaking routine inspection work to check that laws and regulations are being complied with (Ministry of Culture and Information, 1995).

There are two fundamental categories: (1) public libraries and (2) specialised and multidisciplinary libraries. The public library category includes the National Library, provincial or city libraries, and district libraries. Specialised and multi-disciplinary libraries include research institute libraries, school libraries, university libraries, libraries of other educational institutions, governmental agency libraries, military libraries and the libraries of political organisations, social organisations, socio-professional organisations, economic units and public service organisations (Ministry of Culture and Information, 2004a). It should be noted that public libraries are also under the administration of Provincial or City People Committees, and specialised and multidisciplinary libraries are also under the administration of related functional ministries. Figure 1.2 summarises the Vietnamese library system.

\footnotetext{
${ }^{3}$ The ministry was restructured and renamed the Ministry of Culture, Sports and Tourism of Vietnam in December 2007. In this study, its former name, Ministry of Culture and Information is used.
} 


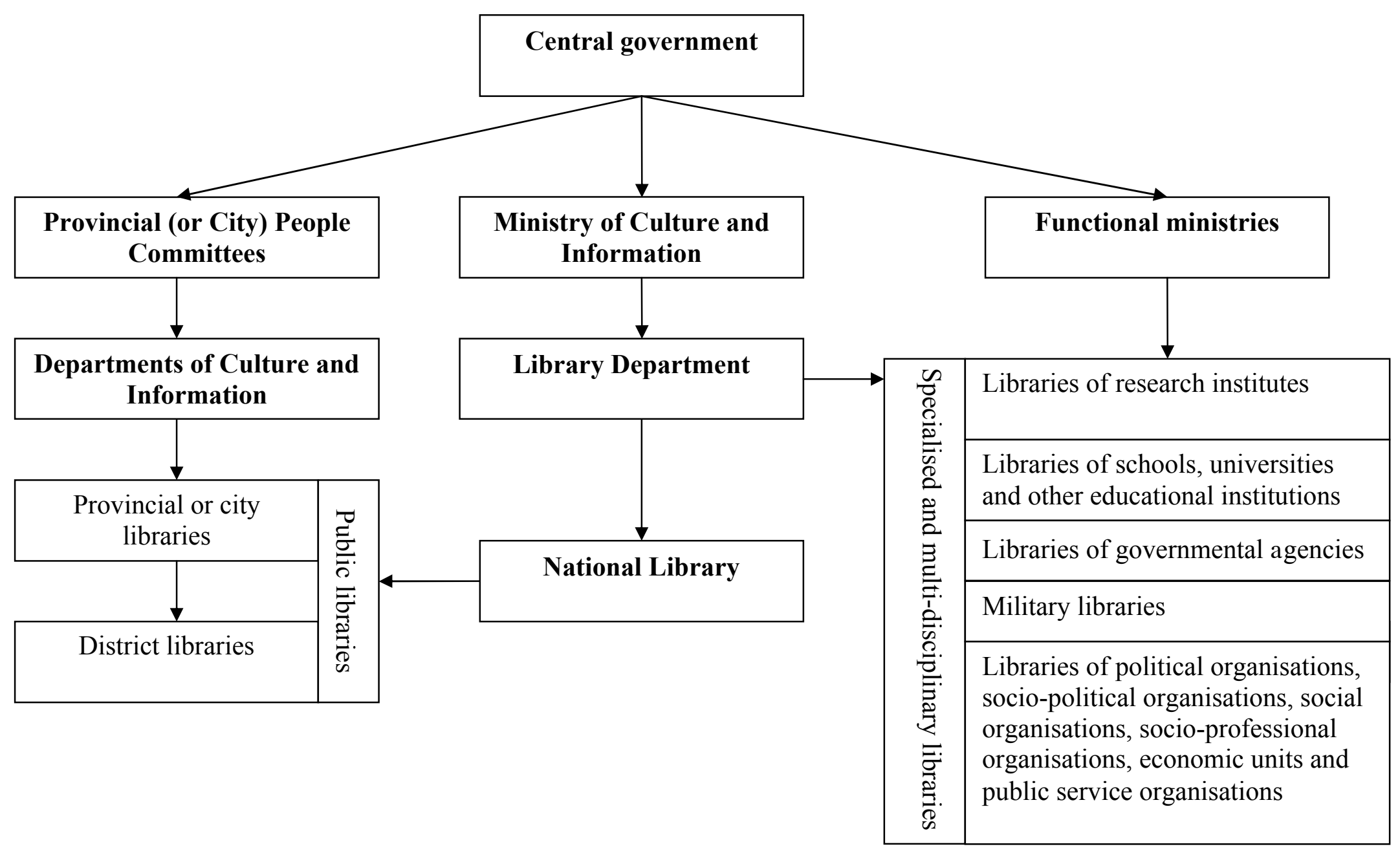

Figure 1.2: Vietnamese library system 
University libraries are part of the specialised and multi-disciplinary libraries category. In Vietnam there are both public and private university systems. This study focuses on libraries in the public universities. They are concentrated in four cities: Hanoi in the North of the country, Ho Chi Minh (HCMC) in the South, and Hue, and Da Nang in the central part of the country, and are divided into two types: specialised universities and multi-disciplinary universities.

Specialised universities focus on a single area of study, such as economics, engineering, fine arts, medicine or law - for example, Hanoi National Economics University or HCMC University of Medicine and Pharmacy. All these universities are under the administration of the Ministry of Education and Training (MOET), but some are also under the administration of another functional government ministry. For example, HCMC University of Education is administered only by MOET, while Hanoi Agriculture University is administered by both MOET and the Ministry of Agriculture.

The multi-disciplinary universities include Vietnam National University-Hanoi (VNUHN), Vietnam National University-Ho Chi Minh city (VNU-HCMC), Thai Nguyen University, Hue University and Da Nang University. These universities have their own member universities. For instance, VNU-HN includes the University of Natural Sciences, the University of Social Sciences and Humanities, and the University of Foreign Languages. The national and regional universities are under the administration of MOET. However, VNU-HN and VNU-HCMC have similar autonomy to an independent ministry.

Figure 1.3 illustrates the public university libraries in Vietnam, using examples to illustrate the disciplinary focus and organisational structure of universities. 


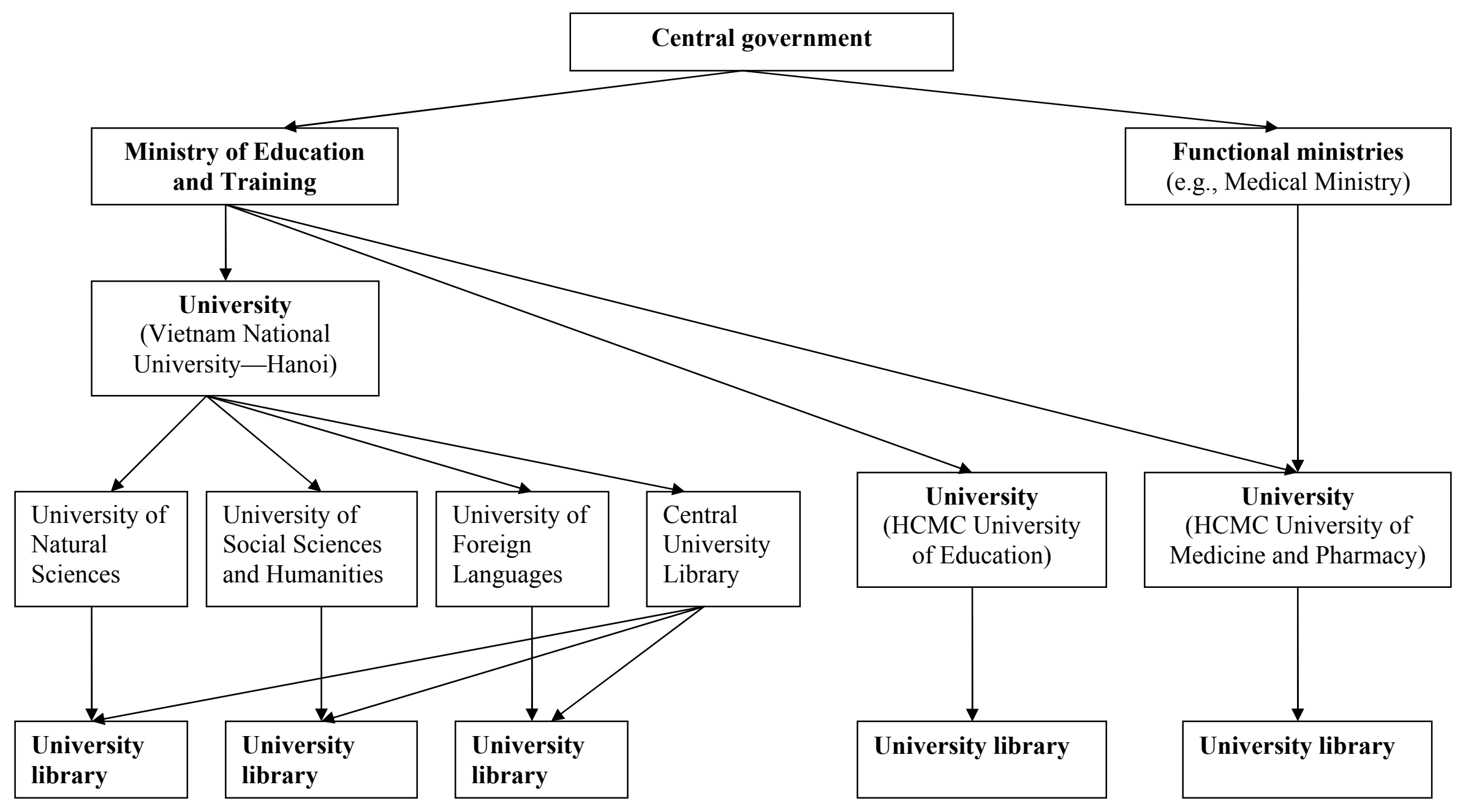

Figure 1.3: Organisational structure of public university libraries 
All public university libraries are funded by the government. However, a few libraries have also received funding from external organisations to establish infrastructure and upgrade the form and quality of information services, for example, the libraries of Can Tho University, Hue University and Thai Nguyen University. The investment from the government and different organisations promotes the application of technology to university library activities. Recently, online catalogues have become widespread, there are more databases and spacious modern facilities are provided in several university libraries, particularly in those that have received funding from external organisations.

However, there are many challenges facing university libraries. The government objectives in the current period (Ministry of Culture and Information, 2007) require university libraries to progress towards the establishment of digital libraries. The application of new bibliographic standards, the increasing application of IT in library activities and organising high-level reference services are challenges for university libraries, as library staff often do not have the skills and experience to work with developed library services (Denison \& Robinson, 2004).

A large number of university library practitioners have not received a LIM professional education. For instance, in the central library of Can Tho University, the biggest library in the Mekong Delta, only 33\% of the staff have qualifications in LIM (Central Library of Can Tho University, 2005), and in the central library of Hue University $25 \%$ of the staff have degrees in LIM. In addition, current LIM education programmes tend to be out-dated (Nguyen, 2001), LIM degree holders only have the ability to work with traditional card cataloguing systems (Nguyen, 2003d). Therefore, improving the professional knowledge and skills of practitioners is vital for all Vietnamese university libraries. 


\subsubsection{Library and information science education and CE activities in Vietnam}

In 1959, Hanoi Culture University started offering a Bachelor's programme in library professional education. During the 1980s and 1990s, the University of Social Sciences and Humanities in $\mathrm{HCMC}$, the Culture University of HCMC, the University of Social Sciences and Humanities in Hanoi and Dong Do University also began to offer similar programmes. In 2005, sponsored by the Atlantic Philanthropies, Can Tho University introduced a new undergraduate programme in library science.

Three universities offer Master's programmes in library science: Hanoi Culture University (from 1991), the University of Social Sciences and Humanities in HCMC (from 2003) and the University of Social Sciences and Humanities in Hanoi (from 2006).

Annually, 400 students graduate from the LIM undergraduate programmes of these universities (Nguyen, 2004), and the number of graduates is continually increasing. However, there is a big gap between library science education and the actual library and information environment (Bui, 2002; Tran \& Gorman, 1999). In particular, most graduates do not have sufficient knowledge of technology or the digital environment (Nguyen, 2003d). Accordingly, all practitioners, including graduates from professional schools and those who lack LIM education, need ongoing training and educational opportunities to gain or update their professional knowledge and practical skills.

Responding to this need, NACESTI, FESAL and some libraries have offered CE courses or activities (Ngo, 2004; Tran, 1999a). However, current CE for LIM practitioners tends to be conducted haphazardly and without coordination between institutions (Nguyen, 2000b). The CE activities implemented by these organisations are based on their available resources rather than on the needs of practitioners, libraries or the requirements of strategic plans. 
One of the basic reasons for inadequate $\mathrm{CE}$ activities is the lack of understanding of the factors that act as enablers and barriers in $\mathrm{CE}$ as well as how to identify and prioritise learning needs. Thus, research on CE in general and on the determining factors affecting $\mathrm{CE}$ in particular is necessary for LIM in Vietnam. 


\section{CHAPTER 2: LITERATURE REVIEW AND PRELIMINARY MODEL}

This chapter reviews the relevant literature to provide an understanding of continuing education $(\mathrm{CE})$ in the professions, in particular in Library and Information Management (LIM). This understanding facilitates the identification of significant CE issues in LIM, which is the focus of this study. The review also provides a theoretical framework for the study.

The literature review consists of five main parts:

- Discussion of the views on $\mathrm{CE}$ to identify a definition of CE for LIM practitioners in Vietnam.

- Discussion of the rationale for CE in LIM to confirm that CE is a topical issue in the profession, particularly in the Vietnamese context.

- Examination of previous research on CE within LIM, particularly research concerned with learning needs, to stress the necessity of developing a model that will help to identify and prioritise learning needs for the design of achievable CE programmes.

- Identification of factors affecting CE from the literature in adult education and $\mathrm{CE}$ in professions to establish a theoretical framework for the study.

- Presentation of a preliminary contextual model for this study based on the framework inferred from the literature.

It should be noted that, due to the limited amount of Vietnamese literature on CE, most of the literature in this review is from Western developed countries.

\subsection{Definition of CE}

Although CE in the professions is a relatively recent topic of research in Vietnam, it is not new in Western societies. In the early 1960s, Western countries began developing systems of CE. According to Cervero (1988), the first clear signal of this activity was the publication in 1962 of a conceptual scheme for the lifelong learning of physicians. 
In the 1970s, the concept of CE began to be understood as a basis for "recertification" (Cervero, 1988, p. 56). By the 1980s, organised and comprehensive programmes of CE had been developed in engineering, accounting, law, medicine, pharmacy, social work, librarianship, nursing, public school education and other professions (Cervero, 1988). During that decade, many professions also developed their own systems of accreditation for providers of CE (Kenney, 1985).

In the 1990s, factors such as the knowledge explosion, the introduction of new technologies and advances in society and economics have increased the prominence of CE for every profession. In different contexts, educationalists and organisations have diverse visions and have suggested a variety of definitions of $\mathrm{CE}$, some of which are examined here.

\subsubsection{Broad approach to CE}

CE can be conceptualised at both general and specific levels. Among those who have taken the broad view are Venables (1976), McIntosh (1979 as cited in Jarvis, 2004), and Jarvis (1995; 2004). According to Venables (1976) CE comprises:

...all learning opportunities which can be taken up after full-time compulsory schooling has ceased. They can be full time or part time and will include both vocational and non-vocational study. (p. 19)

Venables (1976) believed that CE is a learning process that starts immediately after compulsory schooling and lasts throughout a person's life, with no limits to content, formats or levels.

McIntosh and Jarvis agreed with Venables' broad approach. However they disagreed with him on the point at which CE starts. McIntosh (1979, as cited in Jarvis, 2004) suggested that $\mathrm{CE}$ refers to post-initial rather than post-compulsory education. Similarly, Jarvis did not believe that CE would be taken up after full-time compulsory schooling. 
He commented that initial education may continue for longer than compulsory education, so if CE followed compulsory education it would actually happen during this period of initial education for many people (Jarvis, 1995, 2004). He went on to state that

"continuing education is a term which refers specifically to post-initial education.... It refers to both vocational and non-vocational education" (Jarvis, 1995, p. 28); and "continuing education may be seen to be a continuation of the educational provision beyond initial education, especially in the vocational sphere" (p. 29). This view is also affirmed in many recent works of Jarvis. For example, in a recent book he wrote, "Continuing education: those learning opportunities which are taken up after the end of full-time initial education" (Jarvis, 2002, p. 36).

Although these authors may disagree about the point from which CE starts, all approach $\mathrm{CE}$ from the broad view. They agree that $\mathrm{CE}$ is a term that refers to all formats of training and education - to both vocational and non-vocational education, but especially the vocational sphere. However, as mentioned earlier, there are other more specific approaches that emphasise the continuing learning process of practitioners in a profession.

\subsubsection{Specific approach to $\mathrm{CE}$ focusing on professions}

Over thirty years ago, Houle (1967) presented CE as a process that includes:

(1) keeping up with new knowledge relating to one's profession; (2) establishing mastery of new conceptions of that profession; (3) continuing to study the basic principles which support one's profession; and (4) growing as a person as well as a professional. (pp. 263-264)

Houle (1967) shared the opinion of Jarvis and some others that CE occurs after initial education, but he narrowed the context of CE to professional knowledge and implied that the only participants in $\mathrm{CE}$ are practitioners. Houle's definition has provided the basis for many current definitions of $\mathrm{CE}$ for practitioners in professions. 
Many writers have taken a similar approach to Houle in focusing on CE content and formats that help practitioners to achieve good performance to satisfy the requirements of their professions ${ }^{1}$. For instance, Knox and McLeish (1989, p. 373) considered CE to refer to "all types of self-directed and externally provided activities which professionals use to enhance their proficiencies and enrich their careers." Brennan (1990), Eraut (1994) and Brennan and Dymock (1995) defined CE as a part of the professional education of those who are involved in those occupations accepted as being professions. Writers in several professions, including LIM (e.g., Brine, 2005; Wikle, 1998; Woolls, 2005) have identified a range of activities from reading journals to attending conferences and seminars, taking courses, giving presentations, publishing and workplace learning as formats that help professionals to update their knowledge and skills.

Hence, most authors believe that $\mathrm{CE}$ in a profession includes all activities and all formats of training and education where professional knowledge is the main content of those activities.

\subsubsection{Definitions of CE within the LIM profession}

Each of the authors concerned with CE issues in the LIM profession has a particular definition and explanation of CE. Generally, most of them agreed with Houle's view. Elizabeth Stone (1969), one of the pioneers of research on CE for librarians, provided the following definition of CE within the LIM profession:

...all activities and efforts by the individual to upgrade his knowledge, abilities, competencies, and understanding in his fields of work or specialization so that he can become a more effective professional and be able to handle responsibilities of greater scope and accountability. (p. 21)

Similar definitions can be found in current literature within LIM. Authors have emphasised CE as a tool to maintain professional competencies (Doney, 1998; Majid,

\footnotetext{
${ }^{1}$ Some authors have used different terms to describe the CE process for practitioners in a profession, such as "continuing professional education" and "continuing professional development".
} 
2004); update existing knowledge and skills (Feather \& Sturges, 2003; Prytherch \& Harrod, 2000; Weingand, 1999); and attain new or additional knowledge and skills for practitioners to keep abreast of changes in the profession (Keenan, 1996; Smith, 2001; Weingand, 1999). The following are some examples of CE definitions in LIM literature:

...a learning process which builds on and updates previously acquired knowledge, skills, and attitudes of the individuals. Continuing education comes after the preparatory education necessary for involvement in or with library media services. It is usually self-initiated learning in which individuals assume responsibility for their own development and for fulfilling their need to learn. (National Council on Quality Continuing Education for Library and Media Personnel, 1980, p. 1)

...education activities primarily designed to keep practising librarians and information professionals abreast of their particular domain in the library or information centre, and to provide them with training in new fields. (Pors \& Schreiber, 1997, p. 34)

...the systematic method of learning that leads to growth and improvement in professional abilities, enabling individuals to function successfully in a changing work environment... the purpose of continuing professional development activities is to fill-in the knowledge gaps between formal education and the needs of the professional practice. (Majid, 2004, p. 58)

In each of these definitions, $\mathrm{CE}$ is related to a high level of professional education and therefore is not applicable to para-professional or very junior staff.

\subsubsection{The definition of $\mathrm{CE}$ for this study}

As discussed above, Western scholars in LIM have reached a consensus on the specific approach of $\mathrm{CE}$ in terms of focusing on updating professional knowledge. However, the requirements and educational qualifications of Vietnamese LIM practitioners as well as the infrastructure of the country and the profession are different from others. 
In developed countries, the highly developed infrastructure gives librarians many opportunities to learn. In that case, it is reasonable for the content of CE in librarianship to focus on updating, improving and broadening professional knowledge and skills to keep staff abreast of changes and developments in the profession (Houle, 1967; Doney, 1998). In Vietnam, as mentioned in Section 1.2.3, not all LIM practitioners have obtained a basic education in LIM. Although many of them have a Bachelor's degree in LIM, a larger number have a qualification in another discipline. Practitioners who have a master's degree in LIM are few. Thus, as Vietnamese practitioners working in LIM areas, in general, and in university libraries, in particular, have different educational qualifications, they need CE at different levels, for different purposes and with different content.

When the purpose of CE for practitioners is solely regarded as to "upgrade knowledge, abilities, competence" (Stone, 1969, p. 21) or keep up with "new knowledge relating to one's profession" (Houle, 1967, p. 263), it will not create learning opportunities for practitioners whose initial education is not in LIM. Such people need the opportunity to acquire basic professional knowledge and skills. Therefore, it seems more reasonable that CE for Vietnamese library practitioners should be understood in the broad sense as Jarvis (2002) suggested: “...those learning opportunities which are taken up after the end of full-time initial education" (p. 36). In this sense CE should comprise learning opportunities for all library and information practitioners, including those with and without qualifications in LIM. However, the definition by Jarvis still does not clarify the content, purposes and scope of the learning process.

Ideally, CE for LIM practitioners should provide learning opportunities for all staff, regardless of their educational qualifications. CE should enable those with educational backgrounds in different disciplines to gain the basic professional knowledge and skills, while maintaining and updating the professional knowledge of those who already have initial education in LIM its content should cover a spectrum from the essential basic skills to mastery of new concepts to help practitioners meet requirements and adapt to 
changes in their jobs. It should include a mix of formal study and informal learning activities. The former category could include course work in credit or non-credit courses. The latter could include a wide range of activities such as attending conferences, workshops and professional meetings, reading professional materials, on the job training programmes and so on.

Thus, for this study, CE is regarded as all educational or training activities that provide opportunities to gain knowledge and skills in LIM for library staff both with and without formal qualifications in LIM to help them to satisfy the requirements of and cope with changes in their work.

\subsection{Rationale for CE in the LIM profession}

In general, it is crucial for every profession to maintain professional currency and keep pace with changing society and technology (Cervero \& Scanlan, 1985; Houle, 1980;

Weingand, 1991). This requires all practitioners to pursue CE. In particular, the literature review revealed overcoming the limitations of initial education, improving professional knowledge and skills, and surviving in competitive working environments as the prime rationale for the CE of LIM practitioners, including those who work in university libraries.

\subsubsection{Overcoming the limitations of initial education and improving professional knowledge and skills}

As many writers (e.g., Gorman, 2000; Newton, 2001; Stone, Patrick, \& Conroy, 1974) have discussed, LIM practitioners are required to have knowledge, skills and attitudes that help them to deal with issues confronting their own professional field, to resolve them in effective ways and to persevere in matters involving professional principles. However, no practitioners can work effectively with the basic knowledge that they gained in school prior to beginning their working lives (The Library Association, 1986). Any system of initial education has its own limitations. The limitations include content, 
short lifespan and the slowness with which the curriculum adjusts to changes. These views are shared by authors in a range of professions including LIM.

In his classic work published in 1961, Houle explained that a "pre-service curriculum cannot and should not include every subject of professional knowledge. In fact, there are many subjects that can be learned better later or can be acquired only by mature and experienced people" (Houle, 1961 as cited in Jarvis \& Griffin, 2003, pp. 196-197). Both he and Jarvis (1996, p. 240) believed that a curriculum of initial education cannot be revised quickly enough to cope with changes in professions. Houle argued that, even though faculty members keep up-to-date and have not been caught in "the eddies of a cultural lag", knowledge moves on so rapidly that what is taught to students may be obsolete or wrong by the time they graduate. Houle's opinion is supported by Dillon (1997):

Schools of library and information science are changing their curricula, but the impact of new graduates in the workforce is insufficient for the current challenge: their numbers are too few, their skills are too unpractised, and their ability to influence organizational change is too limited. All of these limitations, of course, are usually remedied by time, but time is of the essence. Drastically shortened technological life cycles do not allow libraries the luxury of time for a natural, generational renewal of professional skills as might be provided by traditionally matriculating students. New, dramatic, and innovative approaches to ongoing professional training and education are needed. (As cited in Guy, 2002, p.11)

Further, as Knowles (1976) insisted, it is impossible to think of professional education as being terminated at any point. Similarly, Houle (1981) argued that learning is a continuous process throughout life, in which early stages are, in part, determined by an awareness of what will happen in later stages. He stated:

Every profession must be concerned with the education which occurs during the total life-span of its members. Pre-service training is only the first of this process. (1981 as cited in Jarvis \& Griffin, 2003pp, 196-197) 
This view is also present in LIM professional literature (e.g., American Library Association, 1970; Chan, 2002; Doney, 1998; Elkin, 1997; Roberts \& Konn, 1989; Webb, 1995). As The Library Association (1986) stated:

For the professions as a whole, basic education is intended to develop the perception, the understanding and the ability to think and act which are essential to the launching of a professional career. It cannot provide all the knowledge and skills essential to the fulfilment of that career; these must come to a large extent from continuing education. (p. 28)

In terms of the limitations of initial education, Stone (1985b), Robert and Konn (1991), Freeman (1994) and Newton (2001) added that the lifespan of an academic qualification is short. The average life of a qualification (academic, vocational and technical) is estimated to be only five years, according to Rugaas (1993). It is even shorter according to Weingand (2001) - "academic degrees, in this time of rapid change, have a shelf life of approximately three years" (p. 266) - and cannot keep pace with changes in the profession.

Indeed, initial education is only the first step in helping practitioners to perform their jobs. There is no professional education that can provide practitioners with the full knowledge and skills necessary to face their daily tasks, to cope with changes and to shape their own careers. Thus, practitioners must accept their responsibility to undertake CE throughout their working lives.

\subsubsection{Keeping abreast of changes and surviving in a competitive workplace environment}

The professions, like society as whole, are in a constant state of change. Changes in social, economic and political conditions alter a society's and a profession's values, norms and expectations, while changes in management techniques influence work processes and practices (Chan, 2002). 
Rapid developments in technology have an impact on the role and function of the modern professions (Cervero \& Scanlan, 1985). For the professions as a whole, changes in technology compel them to change the delivery of their services and even to reconceptualise their mission (Houle, 1980). For an individual practitioner, such changes demand significant reform in the nature of one's practice or in the very way in which one views the field (Houle, 1980; Stone et al., 1974). In the LIM profession, to do things differently, practitioners have no choice but to continue learning (Guy, 2002; Smith, 2001).

As early as the 1970s, Knowles (1976) in his work published in a proceeding of continuing library education assembly, Conroy (1978) and some others warned library practitioners against obsolescence in the profession. They stressed the importance of CE as a means to support practitioners facing the arrival of new technology, to overcome obsolescence and survive in a changed environment, and to maintain the value of the profession to society. Knowles (1976) wrote:

...the era of stability of knowledge, of practice and everything else is over and an era of accelerated change is upon us... and so we are, by virtue of the fact of our civilization, bound to a heavy commitment to professional continuing education.... In my estimation, the greatest threat to our civilization in the next century is not going to be war, or pollution, or disease. It is going to be the impending obsolescence of man and in particular, in the professional segments of society. (pp. 84-85)

Conroy (1978) concurred:

...all categories of library personnel in all types of library have needs to learn.... The daily tasks and major issues that confront individuals require them to apply their knowledge and skill appropriately to each situation. The standards for personnel performance and institutional accountability are increasingly demanding, and without consistent and deliberate efforts, obsolescence is inevitable... technological and societal change are rapid and unavoidable, and inevitably affect libraries and their personnel. (p. xi) 
The 1990s saw a shift in the roles of LIM practitioners due to the rapid pace of technological change. Almost every area of LIM practice has been affected, from the access and provision of information, to academic subject knowledge, customer service and education, and collection management. New technologies have and still are reshaping the workplace, requiring new competencies for professional practice (Evans, Ward, \& Rugaas, 2000; Qureshi, 1990). Many authors, such as Smith (1993), Alemna (1995), Hill (1997), Bender (1998), Flagello (1998) and Forter (1999), emphasised that the LIM profession must meet these challenges. In discussing the importance of CE participation, Smith (1993) stated, "In order to survive and remain relevant, in order to be a viable and contributing part of our society, the profession must change" (p. 11). These authors highlighted the role of $\mathrm{CE}$ as a central means to help library and information practitioners survive and develop. Moreover, the requirement to keep abreast of changes is emphasised in the professional literature as a rationale for CE.

In recent years, the emphasis placed on information and knowledge by society and changes in technology has continued to greatly affect the LIM profession and increase the need to update the skills and knowledge of practitioners. As Woolls (2005) stated, "No one would question the introduction of new technologies as a catalyst for drawing librarians to CE” (p. 17). The current work environment of LIM practitioners involves a complex mix of information technology, including integrated library systems, digital materials, electronic reference services, the Internet, networks and imaging systems (Corrall, 2005).

The arrival of digital technology and development of digital information resources have especially increased the training needs in terms of technical aspects. As Dorner (2004) and Orick (2000) observed, libraries can no longer operate effectively with traditional organisational structures. The digital library requires practitioners not only to have traditional skills but also to know how to access the vast amount of information on computers throughout the world and guide users to this information. Practitioners need education about the different aspects of digitisation including managing projects, 
negotiating (with content providers and suppliers), developing digitisation policies and strategy documents, and administering copyright and other legal issues. An integrated CE programme would help practitioners to meet these needs (Dorner, Chawner, \& Searle, 2002).

Technological change and the social change it has engendered have made the LIM profession invaluable (Hurych, 2002) - in Moyo's words (2002), library and information workers have become "key players" in today's "information society" (p. 230). However, these changes also bring the profession into competition with other information professions for status (Bellanti, 2001; Danner, 1998). Moyo (2002) concluded:

The emerging information society, with information at its core has increased the pressure on librarians... to undertake continuing professional education to ensure that they have relevant skills and competencies to make them remain competitive in the information marketplace where there are many other players. (p. 230)

Indeed, the LIM profession now operates in an environment of information explosion, rapid developments in information technologies and increasing competition in the information market. To cope with the new developments, practitioners continually need to learn how to do their job, and how to do it better. In the other words, CE offers the means for LIM practitioners (including university library practitioners) to overcome any limitations of initial education, improve professional knowledge and skills, keep abreast of changes and survive in a competitive workplace environment. As a consequence, $\mathrm{CE}$ will help LIM practitioners to improve their performance, maintain and enhance their value to society and contribute to its development.

\subsubsection{Vietnamese context}

In the Vietnamese context, the literature review reveals that the limitations of LIM professional education and changes in LIM practice have pressed practitioners to pursue further learning to meet the responsibilities of the profession. 
Many writers have affirmed that there is a big gap between library science education and the actual library and information environment in Vietnam (Nguyen, 2003c; Nguyen, 2001; Tran \& Gorman, 1999). They have stressed that the curricula of most library schools are out-dated, both in structure and content (Tran \& Gorman, 1999), and many have not made any changes in the curricula for several years (Nguyen, 2001). Some writers also consider that the current professional abilities of library practitioners are insufficient. Examples of such observations include: library practitioners often have "inadequate skills in modern information handling, processing and dissemination, which means they are ill-prepared to meet the high demand for information services placed on them by users" (Tran, 1999b, p. 15); library graduates only have the ability to work with traditional card cataloguing systems (Nguyen, 2003d); and staff do not have experience with developed library services (Denison \& Robinson, 2004). Furthermore, as mentioned in Section 1.2.3, in Vietnam not all LIM practitioners have an educational background in the field. This situation is particularly prominent for university library practitioners. As a result, all practitioners need CE opportunities to overcome their inadequate initial education, and to update and improve their professional competencies.

As discussed in Chapter 1, in recent years Vietnam has implemented the Đổi Mói reform policies for all areas including the economy, culture and education (Communist Party of Vietnam, 1996). Đổi Mới, along with current national development plans (Communist Party of Vietnam, 2001, 2006) and the policies related to the application of technology in all activities (Communist Party of Vietnam, 2000), provides a particularly strong incentive for developments in higher education. The number of universities and university libraries is growing. The application of technology in higher education, especially in university library activities, is increasingly considered essential. Consequently, this has led to an increase in the number of university library practitioners and their need for up-to-date knowledge and skills is becoming more apparent.

Thus, in order to overcome possible limitations of professional education, improve professional knowledge and skills, keep abreast of changes and develop in a competitive 
workplace, all library practitioners must pursue CE. Due to the limitations of current professional education and rapid development in society in general, and higher education in particular, university library practitioners in Vietnam more than ever need to engage in $\mathrm{CE}$. Accordingly, it is conceivable that $\mathrm{CE}$ is, or should be, considered one of the top priorities in enabling university libraries to meet the demands of the higher education sector, as well as the socio-economic development of the country. As a result there is a great need for more research on $\mathrm{CE}$ for Vietnamese university library practitioners.

\subsection{Research on CE within LIM}

In this section, previous research concerning $\mathrm{CE}$ for LIM practitioners is reviewed to provide an understanding of $\mathrm{CE}$ in the LIM context. The review is divided into two parts: developed countries and Asian developing countries, including Vietnam. In each part, prominent research concerning $\mathrm{CE}$ is reviewed first, followed by particular research focusing on learning needs.

\subsubsection{Research in developed countries}

\subsubsection{Overview of prominent research}

Studies of CE for LIM practitioners have been conducted from the late $19^{\text {th }}$ Century and continue today. The works published by Dewey (1898) and Williamson (1923) called attention to the importance and necessity of CE, emphasising that library workers should seek continued professional growth and improvement. Dewey advocated a system of library institutes for the continuing improvement of librarians. Similarly, Williamson strongly expressed his belief in the value of correspondence courses. He declared that a system of certification for professional library and information staff should be developed. Their views have been accepted and some of their recommendations implemented since the early $20^{\text {th }}$ Century in Western countries (Stone, 1985a). 
The late 1960s and 1970s saw a growing interest in CE in LIM. Initially, writers in the field simply emphasised that more attention needed to be paid to CE. For example, Rothstein (1965, p. 2226) pointed out that the period of professional education in library school should be a "port of entry", not a "terminus". CE should be adopted in the profession as a duty. After this perspective gained acceptance, researchers began to study a variety of theoretical issues of $\mathrm{CE}$, including the value and scope of and responsibility for CE, and motivational factors. Examples of such early studies include Stone (1969), Stone, Patrick and Conroy (1974), Conroy (1976) and Stone (1979), who also started examining the development of CE programmes, identifying learning needs, and the planning, implementation and evaluation of $\mathrm{CE}$ in the profession.

Theoretical issues have been a popular topic of more recent works (e. g., Brine, 2005; Oldroyd, 1996; Roberts \& Konn, 1991; William, Mahmoodi, Miller, O'Donnell, \& Stone, 1985). These authors emphasised that CE has a large scope. It includes introducing new concepts and skills, updating basic professional foundations, refreshing aspects of professional training, providing professional competencies to make career advancement or change possible, and furnishing the individual with an overview of his or her profession as a changing and evolving discipline. They believe that $\mathrm{CE}$ is the shared responsibility of the individual, the employing institution, the state library agency or national library, library schools and professional associations.

In particular, there are a number of studies calling for the systematic development of CE programmes to meet the needs of library practitioners at all levels and in all types of libraries. The work of Williamson (1986), Lipow and Carver (1992), Avery, Dahlin, and Carver (2001), Brine (2005), Allan (2007) and Wood (2007) are examples. These authors contended that, for $\mathrm{CE}$ to be effective, planning, implementation and evaluation are essential. Of these processes, identifying learning needs is the crucial first step (Avery et al., 2001; Conroy, 1978; Jordan \& Lloyd, 2002; Massis, 2004). Studies relating to learning needs are discussed below in detail. 


\subsubsection{Research on learning needs}

Most research into learning needs for CE within LIM has focused on identifying the learning topics and determining the preferred delivery formats. The following are selected examples of previous studies on this issue.

Swanson (1988) identified the learning needs of library media specialists in Texan elementary and secondary public schools by using a questionnaire. The questionnaire was based on a review of the literature and learning resource specialist competencies. Learning areas identified in this study included:

- educational technology

- functions-curriculum development

- teaching techniques

- learning theory

- media resources production

- use of information technologies.

With a similar purpose and technique, Yang (2001) conducted a survey of government document librarians in the United States. The priority learning areas were found to be:

- administration and management of documents

- government statistical data sources

- census publications.

More recently, the findings in the field have become more specific and comprehensive. The results across studies, including Auster and Chan (2004), Fisher, Hallam, and Partridge (2005), Dakshinamurti and Braaksma (2005), and Larsen (2007), revealed that two domains - professional knowledge and personal/generic skills - are important learning needs for LIM practitioners. For example, in Canada, Auster and Chan's survey (2004) found the following priority topics for reference librarians in public libraries:

- internet applications

- electronic resources 
- $\quad$ search strategies

- office applications

- integrated system applications

- public service skills

- troubleshooting equipment

- teamwork

- problem solving

- communication

- instructional techniques

- $\quad$ supervisory or management skills

- occupational health and safety

- employee rights and benefits.

The first seven topics relate to professional skills and the remaining ones relate to personal capabilities and general knowledge.

In their work, Fisher et al. (2005) reviewed two research projects conducted in Australia and the United Kingdom (UK) that focused on identifying the skills and knowledge essential for information professionals in the $21^{\text {st }}$ Century. These research projects took different approaches, but had remarkably similar results (Fisher et al., 2005). In the UK the research project was conducted by analysing documentation and interviewing to identify the specific learning needs of employers. In Australia the research was conducted by establishing focus groups among employers, educators and the Australian Library and Information Association (ALIA) to identify essential knowledge and skills. Both projects found that the two domains of professional knowledge and personal/generic skills are essential for LIM professionals. The following is a combination of the results of these studies. 
Learning content concerning professional knowledge and skills:

- information and society

- ethics and legal responsibility

- management in LIM

- information organisation

- information services

- $\quad$ promotion and marketing

- collection management and development

- information resources and retrieval

- information management/knowledge management

- information systems for library and information professionals

- web content management

- career planning skills

- records management and archives

- research in library and information science (LIS).

Learning content concerning generic capabilities:

- information literacy

- lifelong learning ability

- teamwork

- communication

- ethics and social responsibility

- project management

- critical thinking

- problem solving

- business acumen

- self-management. 
Hence, this literature review shows that learning needs are changing and becoming more complex. There is consensus among authors in the field that modern practitioners need to strengthen their ability in both domains - professional and personal.

Research on learning needs assessment in LIM has also focused on preferred formats. This aspect was the focus of studies by Konn and Roberts (1984), Parson (1988), Black, Dunn, Miller and Skrzeszewski (2002), Chan and Auster (2003), and Hardesty and Sugarman (2007). Questionnaires were used for data collection in most of these studies. They showed that reading professional literature is the most preferred learning mode (Konn \& Roberts, 1984; Parson, 1988; Chan \& Auster, 2003; Hardesty \& Sugarman, 2007). Other preferred modes are professional meetings, conferences and conventions, seminars, discussion with colleagues, visiting other libraries, tutorials, non-credit and credit courses, and workshops offered by employers, educational institutions and professional associations (Konn \& Roberts, 1984; Parson, 1988; Black et al., 2002; Chan \& Auster, 2003).

It could be said that the studies on CE within LIM have attempted to provide an understanding of learning needs as a base for implementing effective CE activities. However, there are several shortcomings regarding research into this area.

First, the scarcity of studies is a shortcoming regarding needs analysis within LIM. Learning needs are dynamic, constantly shifting due to organisational, societal and technological changes (Monette, 1977; Puetz, 1987). The needs are influenced by current situations and issues, and activated by personal priorities and job changes (Monette, 1977). Therefore, the needs assessment process ought to be continual and regular.

Next, the scope of research into learning needs within LIM is narrow. According to literature in various fields, a needs assessment process should provide a focus for the content of the education programmes, for the programme design, for the method of 
delivery, and for determining the most convenient time of year or day, and session frequency and duration, as well as location preferences (Aherne, Lamble, \& Davis, 2001; Knowles, 1980; Queeney, 1995). This information would help CE providers conduct $\mathrm{CE}$ activities successfully. However, most research into CE learning needs within LIM has chiefly focused on identifying the priority topics. Only a few studies have focused on determining other elements useful for programme design and delivery.

In addition, there are various approaches to assessing learning needs, including the discrepancy approach, the self-perceived individual approach, the competency-based approach and so on (Grant, 2002; Gupta, 1999). Depending on the approach, there are various methods, including questionnaires, interviews, using existing data, employing observation techniques, and processes that involve community forums and groups to identify needs (Gillam \& Murray, 1996; Noe, 2002; Queeney, 1995; Witkin \& Altschuld, 1995). However, most studies within the LIM profession have focused primarily on the self-perceived needs of the practitioner approach.

Moreover, based on adult education and CE theory, there are complex factors that may affect the learning process in general as well as learning needs in particular (Cervero, 1988; Mott, 2000; Nowlen, 1988). The needs assessment can be widened and more comprehensive when factors impacting on CE are considered (Nowlen, 1988). These factors include the characteristics of the individual practitioners and given profession, together with the influence of the environment in which the practitioners live, as will be discussed in Section 2.4.1. However, when identifying and prioritising CE needs, most of the previous research within LIM has been based on participants' views. Very few studies have examined the complex set of factors that influence the needs of practitioners. The literature review only found one recent study by Chan (2002) and another by Buchanan (2005) that focused on factors affecting CE participation. Chan (2002) used a mail questionnaire to examine the effects of selected individual characteristics and organisational factors on participation in CE by reference librarians. Similarly, Buchanan (2005) also used a mail questionnaire and found that organisational 
support including release time and funding, and supervisor support were the most significant factors facilitating library practitioners' CE participation. However, to date, there are no theoretical frameworks or conceptual models demonstrating these factors in LIM literature.

It is noted that a range of studies examining the relationship between the characteristics of professionals and $\mathrm{CE}$, or identifying conditions which should be included in successful development programmes have been conducted in other professions (e.g., Jennings, 2007; Mathieu \& Martineau, 1997; Nowlen, 1988; Tracey, Hinkin, Tannenbaum, \& Mathieu, 2001). Such studies are particularly varied in higher education (e. g., Russett, 1991; Shuman, 2005; Zinn, 1997) and in the health professions (e. g., Ayres, 2005; Curran, Fleet, \& Kirby, 2006; Francke, Garssen, \& AbuSaad, 1995; Lonie, 2005; Walsh, 2003), enabling providers and educators to implement effective CE programmes.

Indeed, attempting to identify and prioritise learning needs without awareness of the contributing factors might lead CE providers and policy makers in libraries to have difficulty in understanding the needs of practitioners as well as of libraries. Accordingly, they might lack the necessary information for designing and implementing achievable learning programmes. Thus, to develop effective CE activities in LIM, analysis of the factors affecting practitioners' $\mathrm{CE}$ needs is necessary.

\subsubsection{Research in Asian developing countries}

As mentioned earlier, in Western developed countries CE for professions including LIM, has been studied since the 1960s. However, this issue is quite new in the professional literature of Asian developing countries, particularly in Vietnam. Works concerned with CE have only appeared recently, concentrated on countries such as China, Thailand and India. Many of them are articles in the professional literature; others are theses or dissertations. 


\subsubsection{Overview of prominent research}

Asian research on $\mathrm{CE}$ is mostly concerned with two themes. The first is $\mathrm{CE}$ as a principal means to overcome the low status of LIM practitioners and to satisfy job requirements in a new environment. The second is an understanding of learning needs and the factors influencing the participation of LIM practitioners in CE.

In most studies, Asian writers mentioned changing roles of LIM practitioners as the foremost rationale for implementing CE activities. For example, Anwar (1998), Dong (1993), Kanjilal (2002) and Saechan (2001) pointed out that, to provide effective services, a modern library practitioner needs to acquire some of the knowledge and skills of different professions, such as computer and software specialists, database managers, publishers, media specialists and so forth. They stressed that CE programmes are essential to develop the skills required by LIM practitioners.

There is a consensus among Chatterjee (1993), Majid (2004), Saechan (2001) and Song (2005) on the lack of Library and Information schools in Asian countries and the fact that the curricula of the schools have been slow in keeping pace with new developments. This fact has increased CE needs. However, the number of CE programmes has been insufficient and their quality quite low compared with the needs of practitioners (Kanjilal, 2001, 2002; Majid, 2004). As Kanjilal (2002) asserted:

Though there is a steady rise in the number of CE programmes in recent years, these are not yet able to cater satisfactorily to the needs of the LIS practitioners. Most of these programmes are of a short duration, informal and not very extensive in nature. Moreover, barring a few, most of these programmes lack the adequate infrastructure facilities required for hands on training and have been developed with meagre financial support. The CE system for LIS practitioners therefore urgently needs to be institutionalized in order to effectively cater to the growing demand for such programmes. (p. 189)

Asian authors have attempted to determine the specific topics and learning formats that meet the needs of practitioners. For example, Kanjila (2002) and Gupta and Ghos (2002) 
discussed modes of delivery, Dong (1993) and Yun-Chon (1991) examined different forms of CE, while Saechan (2001) and Ramaiah and Moorthy (2002) identified the desired topics, duration and formats of CE programmes.

Only a few writers have paid attention to the factors that influence participation in CE by practitioners. Majid (2004) and Siega (1985) focused on the abilities of CE providers as an influential factor, while Li (2001) studied the influence of the work environment and learning styles of librarians.

Asian researchers recognise the necessity of study of CE issues, but to date their works have been few and narrow in scope. Among existing studies, identifying learning needs emerges as the most prevalent topic. The following section examines the Asian literature on learning needs in $\mathrm{CE}$ in more detail.

\subsubsection{Research on CE needs}

The studies of learning needs have mostly been conducted in Thailand, Malaysia, China and India. In Thailand during the 1980s and 1990s various studies examined the learning needs of librarians working in public, scientific and technological, and academic libraries (e.g., Krailassuwan, 1988; Nonmali, 1987; Saechan, 2001; Tepaya, Rongsavat, \& Daeponkran, 1997). Thai researchers have tried to identify desirable CE topics, location, duration and delivery preferences, and incentives for participation.

Saechan (2001) used questionnaires to gather information in order to design effective CE programmes for academic librarians. The study identified five CE topics for academic librarians:

- an overview of the Internet

- OPACs

- automation in cataloguing

- automation in acquisition/fund management 
- teamwork in libraries.

The study also found that the preferred location for CE is a university or college during the summer and the preferred duration is two or three days (Saechan, 2001). According to Saechan (2001), the primary motivating factor for academic librarians is the opportunity for professional growth. Other incentives are being given release time and having expenses paid by the employing institution, opportunities for networking, certification of $\mathrm{CE}$ completion and consideration in promotion evaluation.

In Malaysia, Anwar (1998) conducted a study assessing the training needs of academic librarians. He concentrated on identifying constraints affecting participation, suitable periods and durations for $\mathrm{CE}$ activities and potential topics for $\mathrm{CE}$ programmes. $\mathrm{He}$ found four incentives affecting practitioners' participation in CE activities:

- expenses paid for participation

- efforts taken into consideration when staff apply for promotions

- certificates of participation

- paid time off and rises in salary.

The constraints affecting participation in $\mathrm{CE}$ were:

- lack of financial support from libraries

- lack of encouragement from library management

- personal financial constraints

- lack of time and shortage of staff to cover at work

- lack of personal interest

- lack of requirement for promotion.

Anwar (1998) pointed out four potential areas of focus for CE programmes:

- professional skills

- information and communications technology 
- management

- research skills.

He ranked 14 specific skills within the above areas that practitioners are most interested in. Among them, electronic information sources and reference services, design and conduct of user education programmes, and collection development were the most important (Anwar, 1998).

Such research has been also conducted in India. From a survey of 40 participants of a CE course, Ramaiah and Moorthy (2002) compiled a list of topics which library practitioners feel are needed:

- use of modern technologies in libraries

- computer applications

- library automation

- refresher knowledge in LIS

- networking

- library management

- internet

- latest library software

- database management

- multimedia

- distributed information services

- reference services.

In China, Xue (2003 as cited in Song, 2005) suggested basic knowledge that academic library practitioners need to master:

- basic knowledge covering library science, information science, informatics, taxonomy, cataloguing and computer science 
- basic knowledge of certain subjects or disciplines, including fundamentals of social science, natural science and liberal humanities, such as knowledge of sociology, psychology, pedagogy and so on that are also relevant to information services

- operations in academic libraries relying on modern information technology, such as digital technology, networking, multimedia and database management

- ability to read materials in a foreign language. (Song, 2005, p.23)

Reviewing the learning needs identified in the studies across Asian countries, CE on information technology in libraries is the highest priority. Professional knowledge is also important content for CE. However, in contrast to the findings of Western studies, personal capabilities do not seem to be a priority for the $\mathrm{CE}$ of Asian library practitioners.

Looking at the Asian literature, the majority of studies from Thailand are unpublished Master's theses and quite out of date, and there are only a few works from China and India. Similar to research from developed countries, those works have tried to create specific lists of learning needs by analysing the literature or observing practitioners, and have been based on the self-assessment of practitioners rather than an examination of the nature of or reasons for the learning needs. Although Anwar (1998) demonstrates awareness of the incentives and constraints relating to $\mathrm{CE}$, most studies concerned with learning needs have not examined the relationship between the $\mathrm{CE}$ needs of the practitioner and the social environment or the organisation's or individual's characteristics.

This review of the literature reveals that there have been initial efforts in determining the learning needs of practitioners in order to organise effective CE programmes in Asian developing countries. However, research in this area is still weak in terms of quantity and quality. The review also suggests that a theoretical framework for identifying learning needs is still absent. More research in this area is required. 


\subsubsection{Research in Vietnam}

As previously mentioned, $\mathrm{CE}$ is becoming more important for library practitioners in Vietnam. It is now emphasised in government documents that CE is the primary way to achieve the mission and goals of the Vietnamese library and information profession (Ministry of Culture and Information, 2004b, 2007). However, current CE programmes are few and conducted in isolation from each other (Ngo, 2004; Nguyen, 2000b).

The Tuan Nguyen (1979 as cited in Bui, 1997) and Lan Thanh Nguyen (1993) touch on the $\mathrm{CE}$ issue in their dissertations. The Tuan Nguyen observed and analysed CE activities in the Soviet Union and gave a list of suggestions for applying the findings to Vietnam. However, this research is quite dated.

Lan Thanh Nguyen (1993) analysed the weaknesses of in-service training and CE for library staff in Vietnam. She commented that $\mathrm{CE}$ activities have been carried out unsystematically and without planning. She emphasised that improving and upgrading professional qualifications for library staff are one of the main responsibilities of the professional organisations and that there should be a system for organising CE activities. She recommended that training activities be conducted regularly, depending on the educational levels of library staff and particular conditions of the organisation.

Recently, there have been many articles on CE (e.g., Ngo, 2004; Nguyen, 2003a; Nguyen, 2003b; Nguyen, 2000b; Tran, 1999a). Tran (1999a) described the CE activities conducted by the Vietnamese National Library. He recommended establishing a department that would be responsible for training activities, publishing professional materials, designing a curriculum for $\mathrm{CE}$ programmes and regularly organising training courses for practitioners who do not have a basic professional education.

More recently, Ngo (2004) stated that current CE activities do not meet the needs of LIM practitioners. Most CE activities are conducted in leading organisations, including NACESTI, the Vietnamese National Library or the General Sciences Library in HCMC. 
Practitioners from small libraries and provincial libraries do not have opportunities to attend such activities. Ngo recommended developing a strategy for CE activities, establishing a central organisation, diversifying modes of $\mathrm{CE}$, publishing professional materials and enhancing cooperation between institutions in the implementation of $\mathrm{CE}$ for library and information practitioners.

Although Vietnamese authors have acknowledged the importance of $\mathrm{CE}$ and made recommendations, their works have focused predominantly on reporting current $\mathrm{CE}$ activities in libraries rather than examining the nature of these activities. No author has conducted research into implementing their recommendations or suggested a framework for carrying out $\mathrm{CE}$ activities in practice. There is a lack of research on LIM practitioners' specific learning needs as well as the factors affecting their CE within a Vietnamese context.

In sum, the literature review shows that $\mathrm{CE}$ is not a new phenomenon but ongoing and always topical in the LIM profession. Much previous research on the subject has focused on the development of CE programmes to meet the actual needs of practitioners. Identifying and understanding learning needs is the foremost step in the development of such programmes. Understanding the factors affecting CE is fundamental to identifying, understanding and prioritising learning needs. However, existing research on these issues in the LIM profession in both developed and developing countries is meagre and not comprehensive. These issues are completely absent in the research on $\mathrm{CE}$ in Vietnam.

These shortcomings have given rise to the research problems that have inspired this study, which has two key aims: (1) to develop a model that will be used to understand the factors affecting the CE of university library practitioners, and (2) to identify and prioritise the CE needs of university library practitioners. The next sections are a review of relevant literature on factors that may affect $\mathrm{CE}$. The findings will be used as a theoretical framework for developing a preliminary model for this study. 


\subsection{Theoretical framework}

To develop a framework for a study, an understanding of the accepted factors and existing theories of the field in question, as well as related fields guides the researcher in how to conduct the study and provides audiences with an understanding of the relevant concepts and issues (Creswell, 2003; Powell \& Connaway, 2004).

Theories of $\mathrm{CE}$ in the professions are considered a subfield of educational practice (Cervero, 1988; Nasseh, 1996), similar to the adult education field (Brennan \& Dymock, 1995; Cookson, Knowles, Nadler, \& Nadler, 1998). To ensure the robustness of the theoretical framework for this study, the review includes literature on both adult education and $\mathrm{CE}$ in professions. It firstly focuses on factors affecting adult education and $\mathrm{CE}$ in professions and subsequently on some existing models.

\subsubsection{Factors affecting $\mathrm{CE}$}

According to the literature, the factors affecting $\mathrm{CE}$ can be grouped into the characteristics of a society, a profession and individual practitioners.

\section{The characteristics of a society}

A society is a complex system with components such as culture, economics and technology, which are unique, constantly changing and influencing all its members' experiences, including learning (Houle, 1972, 1980, 1996; Jarvis, 1995, 2004, 2006; Merriam, Caffarella, \& Baumgartner, 2007).

Culture refers to the sum total of knowledge, values and beliefs of a society (Jarvis, 1995, 2004; Nowlen, 1998; Boyd, Apps \& associate, 1980). Every individual has the culture of his or her society transmitted to him or her through interaction with other people - or as Jarvis (2004) termed it, "socialisation" - and education. Although the process of acquiring culture is perhaps most significant during childhood, both through socialisation and education, sociologists believe it is a lifelong process (Berger \& 
Luckman, 1991, as cited in Jarvis, 1995). Like other components of society, culture is also dynamic. Thus, the components of a cultural system, including the knowledge, beliefs and values of society, will support or diminish the development of an individual (Nowlen, 1988). They affect what an individual needs and wants to attain a level of skills that will help their self-esteem in their cultural environment.

Changes in economics and technology also have greatly influenced society's work practices in recent years, requiring different kinds of preparation and training (Jarvis, 2004, 2006; Merriam, Caffarella, \& Baumgartner, 2007). Since changes are occurring continually in society, everybody needs to confront new knowledge, values and practices. Changes in the characteristics of a society, in culture, economics and technology, become the content that individuals have to learn to keep up-to-date and effective in their society. Therefore, the characteristics of that society influence the learning agendas of practitioners in all its fields.

\section{The characteristics of a profession}

Developing CE for practitioners in a profession requires a full understanding of the

profession (Queeney, 1992; Robertson, Umble, \& Cervero, 2003). The characteristics of a profession and the concept of professionalisation provide a context for thinking about the goals and methods of CE within the profession (Houle, 1980; White, 2004).

The problem of defining professions or identifying the criteria of a profession has a long history. Sociologists have tried to differentiate between occupations that are professions and those that are not by attempting to define the traits of a profession. According to Wadding (1996), there is no single item accepted by every author. However, according to the literature review of Millerson (1964, as cited in Frost, 2001, p.6) the most frequently mentioned characteristics are:

- $\quad$ skills based in theoretical knowledge

- $\quad$ provision of training and education

- $\quad$ testing of competencies of members 
- $\quad$ organisation

- $\quad$ adherence to a professional code of conduct.

The approach of defining professions by descriptive sets of criteria remains problematic (Johnson, 1972, as cited in Jarvis, 1983), because characteristics may be added to or withdrawn from any existing list by any author without any theoretical rationale.

Moreover, this approach does not consider the professions in relation to the growth of professional work and the influence of economic, social and/or technological change (Roberts \& Konn, 1991). An implication for CE is that educators may not have a clear idea of the characteristics of professions, or which occupations are professions and which are not (Cervero, 1988). On account of these difficulties, Houle (1980) suggested the concept of "professionalisation". This concept refers to a dynamic process which assumes no clear-cut boundary separating professions from other occupations.

Professionalism needs to be seen as being constantly constructed and re-constructed through the relationship between practitioners and clients. Every profession or occupation is constantly facing changes in the nature, form and content of knowledge and expertise. As a result, it has to readjust its criteria to keep abreast of change (Houle, 1980).

This perception is important because, accordingly, CE can occur in all occupations regardless of whether they are professions (Cervero, 1988). The concept of "professionalisation" has been widely adopted in the field of CE for practitioners (Brennan, 1990; Cervero, 1988).

Houle (1980) described the process of professionalisation as occurring on two levels: the degree to which a particular occupational group has reached professional status and the means by which established professions seek to preserve and strengthen their 
professional status. He suggested 14 characteristics that can be associated with the dynamic process of professionalisation, arranged under three headings:

Conceptual characteristics

1. Clarification of the profession's functions

Performance characteristics

2. Mastery of theoretical knowledge

3. Capacity to solve problems

4. Use of practical knowledge

5. Self-enhancement

Collective identity characteristics

6. Formal training

7. Credentialing

8. Creation of a subculture

9. Legal reinforcement

10. Public acceptance

11. Ethical practice

12. Penalties

13. Relation to other vocations

14. Relation to users of the service

According to Houle (1980), the conceptual characteristics make practitioners aware of the mission and the changing sense of mission of the profession. To achieve the mission of the profession, practitioners, after gaining their initial vocational education, must expect to be constantly challenged by the "assertion of new fundamental orientations," continuing to learn throughout their working life (Houle, 1980, p. 39). This view is supported by Squires (2005), who maintained that the function of a profession reveals requirements for practitioners to have specific knowledge and skills to perform well in their practice. As a result, practitioners need to learn the content that helps them execute the mission of their profession. 
The performance characteristics require practitioners to become experts in their field. During their career, practitioners need to enhance the knowledge base of their profession, to be able to use theoretical bodies of knowledge to deal with specific problems, and even to seek new personal dimensions of knowledge and skills through the study of topics not directly related to their work (Houle, 1980). Thus, practitioners need to keep pace with the growth of and changes in the body of knowledge and competencies of their profession to cope with the practical requirements of their jobs. Dall'Alba (2004) and Squires (2005) echoed Houle's view, emphasising that some knowledge and skills are taught in professional schools, but many are learned through experience, practice and $\mathrm{CE}$ programmes.

The collective identity characteristics require practitioners to maintain their status as professionals. In other words, practitioners should have professional formal training. They should maintain relationships with other members of a professional community to nurture a distinctive subculture. They should seek special protection and privileges from legislative, judicial and administrative bodies. They should follow the code of ethics. Also, they should contribute to the further development of their particular body of knowledge and skills (Houle, 1980). This view was supported by others, such as Boyd et al. (1980), Davis and Davis (1998), and Stolee, Esbaugh, and Aylward (2005). Stolee et al. (2005) found that many studies concerned with CE in the health professions suggest that particular organisational system factors can facilitate or hinder knowledge transfer and the sustained impacts of $\mathrm{CE}$. Hence, distinctive characteristics of a profession, including the subculture, code of ethics and organisational structure, all affect the $\mathrm{CE}$ needs of practitioners.

Thus, the characteristics of a profession, including its mission (conceptual characteristics), body of knowledge and competencies (performance characteristics) and particular characteristics (collective identity characteristics) depend upon CE and influence the learning needs of practitioners. 


\section{The characteristics of individual practitioners}

Researchers in the adult education and CE fields share the opinion that all adults can learn but have their own way of learning, which differs from that of children or young people. Variables such as previous education, experience, social background, cultural background, personality, physical condition, and the roles and relationships of individuals contribute to adults' learning needs (Blank \& Russell, 2000; Boucouvalas \& Krupp, 1989; Cross, 1981). Many writers (e.g., Blank \& Russell, 2000; Cervero, 1988; Knowles, 1980) have concurred that learners are the centre of educational programmes. Therefore, for the development of effective CE programmes, a conceptual model should consider the characteristics of the practitioners involved (Stern \& Queeney, 1992; Umble \& Doole, 2004). The following is an analysis of the individual characteristics that should be taken into account when organising learning for practitioners.

Theorists in adult education (e.g., Anderson, Brown, \& Race, 1997; Jarvis, 1992; Knowles, Holton, \& Swanson, 1998a; Knowles, 1990) suggested that adult learners have their own personality, a self-concept of being responsible for their own decisions and for their own lives. If adults undertake to learn something of their own volition, they will invest energy in learning. In contrast, it is not easy to expect them to participate in educational activities unrelated to their daily lives unless they are forced by social or economic pressure to acquire a qualification (Cross, 1981).

Sharing these views but focusing more on learners in professions, Houle (1980) maintained that learners have personality or attitudinal traits that either foster or inhibit their participation in CE. He called such traits "zest for learning". He suggested that practitioners can be divided into five groups based on their attitudes toward practice: innovators, pacesetters, middle majority, laggards, and facilitators. Innovators are people who continually seek to improve their performance. They are learning oriented or independent learners. Pacesetters are those who want to be progressive in their practice, but are conservative about "avant-garde" practices. The middle majority is the largest group. Their attitudes range from those who look to pacesetters for new ideas to those 
who adopt new practices only after they have become widely accepted. Laggards learn only what they must to stay in practice. Those who bear titles that reflect the profession but share only part time or not at all in its central activities constitute a fifth group facilitators.

Adult learners have their own rich and complex experiences, which include backgrounds, motivations, needs, interests and goals. Such experiences will have both positive and negative effects on their CE activities (Knowles et al., 1998a; Muhamad \& Associates, 2001). They may be a rich basis for ongoing education, but adult learners may have difficulty approaching a new task with an open mind, or recognising that they have made a mistake (Rogers, 1989).

In addition, Houle (1980), Cervero (1988) and Queeney (1992) considered the effect of practice settings and career stages on CE participation. Practitioners may practise independently, in groups or classes, or as members of a community. The settings will influence the selection of delivery methods of CE activities (Queeney, 1992). Practitioners in a hospital, for example, who may only have a small amount of time for CE, may welcome a series of short self-study modules (Cervero, 1988).

Finally, although adult learners are mature and have their own needs, interests and purposes, they need particular support in learning pursuits to overcome their individual barriers, such as age or family difficulties. As Ross-Gordon (1998) observed, although the effect of age on intellectual capacities is not a significant hindrance, the quality of perception, attention, motivation and physical health does affect the learning process. In fact, studies on the effect of age on participation in learning activities reported contradictory results. Some studies found that older practitioners tend to participate in fewer formal educational activities than younger practitioners (Grotelueschen, 1985; Noe \& Colquitt, 2002). Cleveland and Shore (1992) also found that age is negatively correlated with participation in development activities. However, according to Tharenou (1997; 2001) age is not necessarily a predictor of participation in training and 
development activities. Moreover, the reviews of Cross (1981) and Maguire, Maguire, and Felstead (1993) showed that lack of financial support and child care, and home responsibilities may also affect the participation of adult learners. Accordingly, age and family conditions may influence adult learning.

The literature review demonstrated that the characteristics of learners are an important factor affecting their CE. This factor comprises several variables: personal traits; individual background, needs and goals; and individual conditions.

Societal, professional and individual characteristics are the three main factors affecting the learning process and the learning needs of practitioners. To design and implement effective CE programmes, it is important to understand the nature of these factors and their influences on learning needs. In developing a $\mathrm{CE}$ model for all professions, including the LIM profession, these three factors need to be considered. Figure 2.1 is a summary of these factors and their variables. 

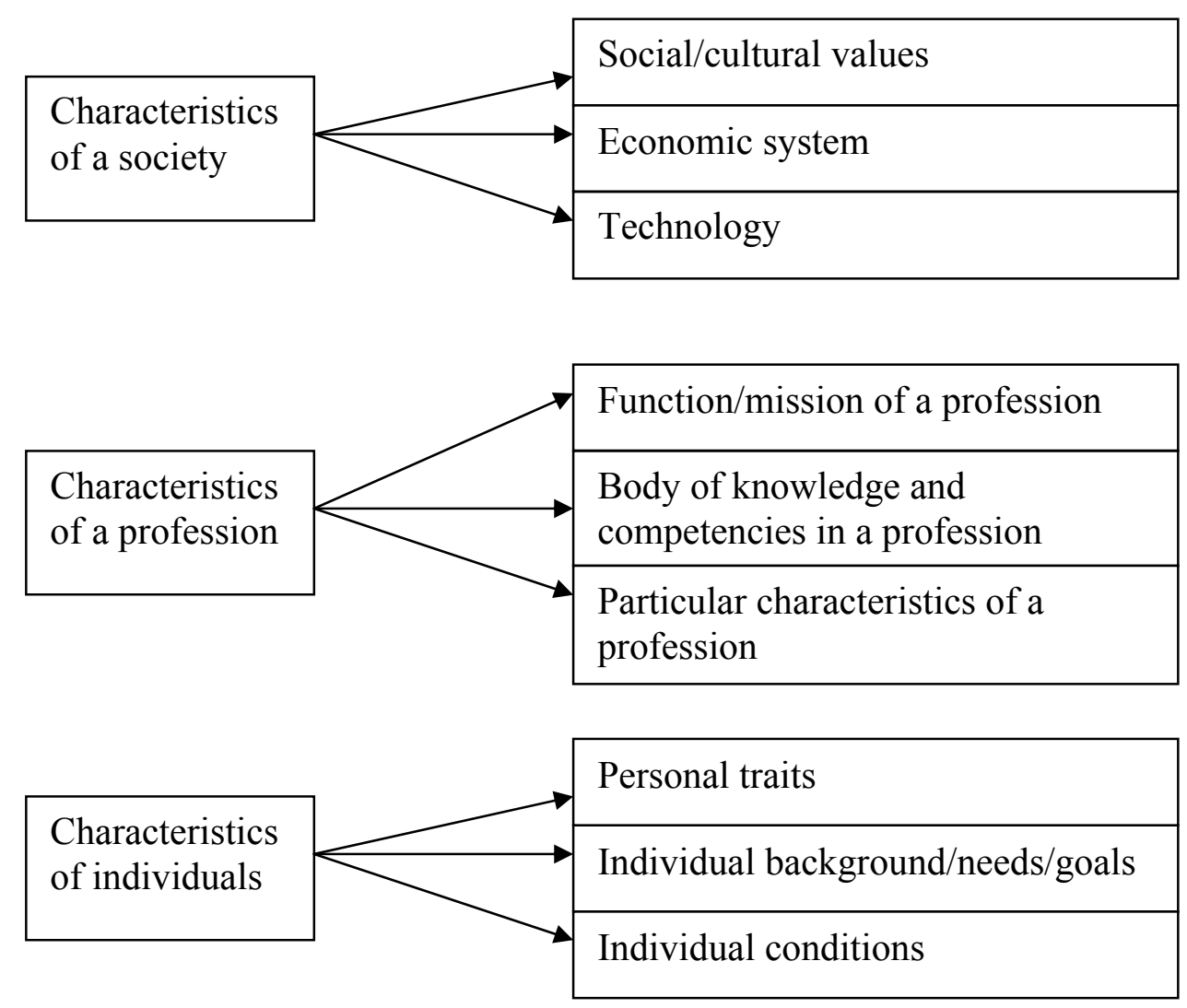

Figure 2.1: Factors affecting adult education and CE from the literature

\subsubsection{Overview of conceptual models of adult education and $\mathrm{CE}$ in the literature}

There are many models relating to adult education as well as to $\mathrm{CE}$ in the professions. All the models more or less include the factors affecting adult learning discussed above. Based on the literature reviewed here and the review of training models conducted by Ayres (2005, pp. 120-125), the following table demonstrates the main factors in some existing models. 


\begin{tabular}{|c|c|c|}
\hline Author & Personal characteristics & $\begin{array}{l}\text { Environmental } \\
\text { characteristics }\end{array}$ \\
\hline Ayres (2005) & $\begin{array}{l}\text { - Demographic characteristics } \\
\text { - Knowledge, skills, abilities, } \\
\text { experiences } \\
\text { - Initial education, additional education } \\
\text { - Degree of advancement in education } \\
\text { - Years of experience } \\
\text { - Previous CE experiences }\end{array}$ & $\begin{array}{l}\text { - Transfer climate } \\
\text { - Peer support } \\
\text { - Supervisor } \\
\text { - Situational } \\
\text { - Reason for attending learning } \\
\text { programmes (voluntary versus } \\
\text { mandatory) }\end{array}$ \\
\hline $\begin{array}{l}\text { Tracey, Hinkin, } \\
\text { Tannenbaum and } \\
\text { Mathieu (2001) }\end{array}$ & $\begin{array}{l}\text { - Job involvement } \\
\text { - Organisational commitment }\end{array}$ & • Work environment \\
\hline Machin (1999) & $\begin{array}{l}\text { - Education } \\
\text { - Ability } \\
\text { - Locus of control } \\
\text { - Self-efficacy } \\
\text { - Job involvement } \\
\text { - Career attitude } \\
\text { - Reaction to previous training } \\
\text { - Reaction to training }\end{array}$ & $\begin{array}{l}\text { - Climate influences pre-training } \\
\text { self-efficacy, which in turn } \\
\text { influences learning and post- } \\
\text { training self-efficacy }\end{array}$ \\
\hline $\begin{array}{l}\text { Mathieu and Martineau, } \\
\text { (1997) }\end{array}$ & $\begin{array}{l}\text { - Demographic characteristics } \\
\text { - Abilities (ability, education, experience, } \\
\text { self-efficacy) } \\
\text { - Personal needs } \\
\text { - Work related job involvement } \\
\text { - Job utility } \\
\text { - Career utility }\end{array}$ & $\begin{array}{l}\text { - Climate (peer and supervisor) } \\
\text { - Reasons for attending learning }\end{array}$ \\
\hline Poteet (1996) & $\begin{array}{l}\text { - Self-efficacy } \\
\text { - Career planning } \\
\text { - Knowledge }\end{array}$ & $\begin{array}{l}\text { - Peer/supervisor support } \\
\text { - Accountability }\end{array}$ \\
\hline $\begin{array}{l}\text { Facteau, Dobbins, } \\
\text { Russell, Ladd and } \\
\text { Kudisch (1995) }\end{array}$ & $\begin{array}{l}\text { - Career factors } \\
\text { - Organisational commitment } \\
\text { - Intrinsic and extrinsic incentives }\end{array}$ & $\begin{array}{l}\text { - Subordinate support } \\
\text { - Peer support } \\
\text { - Supervisor support } \\
\text { - Top management }\end{array}$ \\
\hline $\begin{array}{l}\text { Francke, Garssen and } \\
\text { AbuSaad (1995) }\end{array}$ & $\begin{array}{l}\text { - Background characteristics } \\
\text { - Knowledge, skills and attitudes }\end{array}$ & - Social system \\
\hline Quinones (1995) & $\begin{array}{l}\text { - Fairness perceptions } \\
\text { - Self-efficacy }\end{array}$ & $\begin{array}{l}\text { - Previous education leads to } \\
\text { motivation to learn }\end{array}$ \\
\hline Foxon (1994) & $\begin{array}{l}\text { - Motivation } \\
\text { - Ability } \\
\text { - Job utility } \\
\end{array}$ & - Organisational factors \\
\hline Noe (1986) & $\begin{array}{l}\text { - Locus of control } \\
\text { - Reaction to skill assessment } \\
\text { - Career and job attitudes } \\
\text { - Job involvement }\end{array}$ & $\begin{array}{l}\text { - Social } \\
\text { - Task }\end{array}$ \\
\hline Cervero (1985) & $\begin{array}{l}\text { - Laggards } \\
\text { - Middle majority } \\
\text { - Pace settees } \\
\text { - Innovators } \\
\end{array}$ & $\begin{array}{l}\text { - Proposed change } \\
\text { - Practice environment } \\
\text { - Social system }\end{array}$ \\
\hline
\end{tabular}

Note: This is an adaptation of the table in Ayres (2005, pp. 120-125)

Table 2.1: Main factors in models of CE 
Looking at Table 2.1, all the models focused on personal characteristics as significant factors affecting the learning process. Regarding environmental characteristics, the models focused either on the social environment or the working environment. Thus, the characteristics of the individual and society, organisation or profession are important factors for $\mathrm{CE}$ in these models. However, these models tended to focus on selected variables rather than examining a broader framework by including the comprehensive elements that together may influence CE.

The model of Merriam and Caffarella (1999), Houle's Fundamental System (Houle, 1972, 1996), the Three-Dimension model of Boyd and Apps (1980) and, particularly, the Performance Model of Nowlen (1988) have taken a broader approach. In these models, individual characteristics, work environment, socio-cultural characteristics and their interactions are all considered important in relation to CE. For example, in the Fundamental System, published in 1972 and revised in 1996, Houle showed that, together with an understanding of the characteristics of learners, it is also important to understand that the milieu in which a training or education activity occurs has its own particular set of limitations and possibilities. He explained that the characteristics of the environment, including its norms, values and prevailing traditions, constitute elements of a specific situation and exercise distinctive influences on adult education. Therefore, understanding the complexities of interacting elements, including the characteristics of the learners and the environments in which they live and practise, is necessary when organising CE.

Considering more specific factors that influence CE, Nowlen (1988) suggested a Performance Model of CE in professions. This model is a combination of two previous CE models (Nowlen, 1988) - the Update Model and the Competence Model broadened by including other variables that influence the performance of practitioners in professions. It covers factors - individual, professional and societal characteristics - that are included in most of the other models, as well as in theories of adult education and CE. However, it places emphasis on the influences of those factors on CE needs and the 
interactions between the $\mathrm{CE}$ needs of individuals and organisations. The Performance Model is quite comprehensive and will be modified to generate the preliminary model for this study. It is discussed in detail below.

\subsubsection{Review of the Performance Model in CE (Nowlen, 1988)}

Nowlen (1988) considered that the frame of CE activities should be wider than simply keeping practitioners up-to-date and teaching required competencies for their particular jobs. The frame of CE should be widened to include group as well as individual performance, because most practitioners experience professional performance as "an encounter among a client, an ensemble of interacting practitioners and others" (Nowlen, 1988 , p. xi). Therefore he suggested a "performance approach" to CE that accommodates variables from his updating and competence approaches as well as addressing those variables demonstrated to have a strong influence on the performance of both individual practitioners and their organisations.

Nowlen (1988) considered performance to be a combination of an individual's abilities and skills, their motivation to perform, opportunities to perform, and directions that guide the individual to perform in his or her day-to-day practice (p. 86). He believed that performance is "the result of interacting social and personal influences" therefore; it is "a function of both individuals and ensembles" (Nowlen, 1988, p. 86). He explained that the performance is determined by "two complex interactive strands" (Nowlen, 1988, p. 86). One is the cultural strand, which carries the cultural meanings, values, expectations and norms of the environment in which the individual lives. The other is the individual strand, which carries experience, growth, skills, values and attitudes. The pairing of these strands results in performance not only of the individuals, but also of the group or organisation in which they work. The combination of these two strands will help to explain professional performance and prioritise the individual's learning needs to achieve adequate performance (Nowlen, 1988, p. 73). 
Based on these considerations, Nowlen (1988, p. 87) developed the Performance Model with these variables: update needs, new roles preparation, applied human relations, critical skills of mind, individual/organisational learning skills, personal/organisational development balance, life skills and influences of environments and cultures of practice.

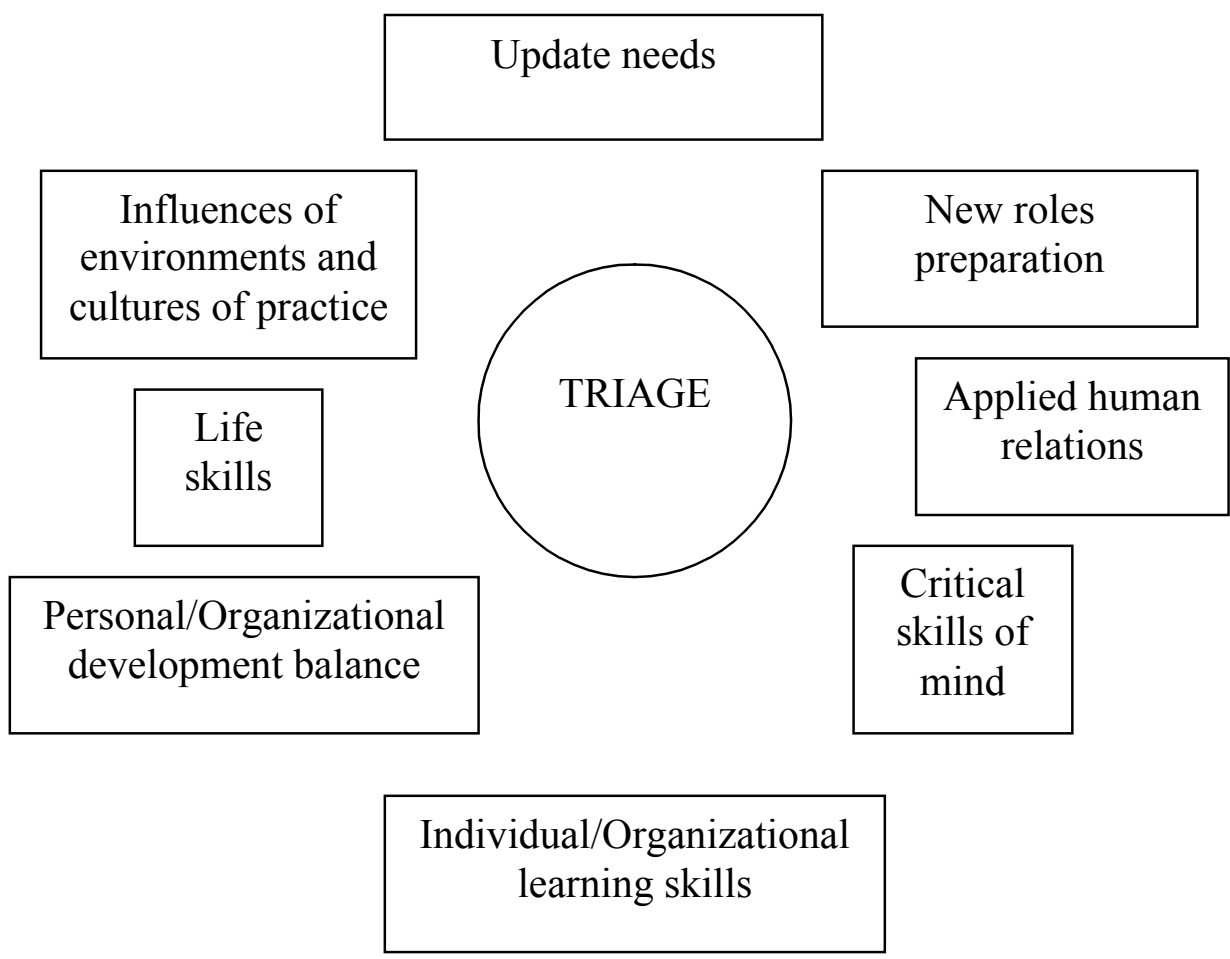

Figure 2.2: Performance Model

Source: Nowlen (1988, p. 87)

Nowlen (1988) suggested that these variables influence the performance of practitioners and organisations, and therefore should be included in conceptual frameworks and operations of needs analysis, educational design and evaluation of learning programmes.

The update needs variable is adopted from the Update Model, an earlier CE model developed by Nowlen (1988), in which the central aim of CE is keeping practitioners upto-date in their practice. The update needs variable implies that the profession's 
knowledge/skills base, new knowledge/skills and new technology are what practitioners should learn and update (Nowlen, 1988, p. 24).

The new roles preparation, applied human relations and critical skills of mind variables are adopted from the Competence Model, another of Nowlen's earlier CE models. This model focuses on analysis of the function of a job, role or task of an individual to identify sufficient or standard competencies that individual practitioners are required to possess. Nowlen (1988) explained that competency is generally defined as sufficient aptitude, skills, strength, judgment or knowledge without noticeable weakness or demerit (pp. 32-33). The competencies include new role preparation - a person's selfimage and his or her evaluation of the image, for example, as a professional. To be aware of his or her image and evaluation of that image, the practitioner is urged to set goals to achieve a new role in his or her career or cope with changing roles in his or her profession. The applied human relations competency relates to the practitioner's initiative in dealing with a particular problem in his or her job or task, and their ability to make decisions in a particular situation. Critical skills of the mind refers to the abilities or skills to demonstrate a set of behaviours related to a performance goal that a practitioner is required to possess, for instance, critical or logical thinking.

With the Performance Model, Nowlen added more variables. The life skills variable involves skills in coping with life's surprises. This variable reflects the personal characteristics of each individual. The influences of environments and cultures of practice variable reflects the characteristics of the society and organisations in which individuals live and work. He mentioned that cultural values, personnel, processes, policies and financial resources together influence the performance of individuals and organisations as well as their learning agendas. This variable is an extension of the cultural strand.

Significantly, Nowlen (1988) extended the individual and cultural strands by considering interactions between the performance of individuals and the organisations in which they 
practice and live, and the balance between the development of individuals and organisations. He considered that the individual is "both unique and composite" (p. 66). The performance of individuals creates the performance of the group. In its turn, the group affects the performance of individuals. Therefore, the relationship between individuals and organisations, the balance between their development, and their fit to one another are considered in the Performance Model.

The Performance Model consists of variables that have a strong influence on the performance of practitioners as well as organisations. Nowlen suggested that these variables have to be considered through triage. Triage is a process in which individual practitioners, organisations and CE providers assess learning and development agendas. The triage process will help CE providers to design CE programmes with appropriate content and formats to meet the needs of both practitioners and organisations (Nowlen, 1988, pp. 87-88).

The review of the Performance Model shows that this model has two significant features. First, the model not only emphasises the characteristics of individuals in a way similar to many other models in the field of adult education and CE, it also emphasises the interactions between individuals and their organisations. Nowlen suggested components of the practice setting that may affect the performance of practitioners and considering the relationships between those components in creating learning agendas for practitioners and organisations. This makes the Performance Model an effective approach to CE in the current context in which, as many other writers, such as Queeney, (2000), Robertson et al. (2002) and Brine (2005) observed, practitioners can no longer rely solely on their own capabilities, but must be able to function as a part of a complex mixture of environments.

More specifically, this approach widens the field of vision of needs assessment for CE. In the Performance Model, CE learning needs analysis includes the profession's knowledge and skills that need to be refreshed or updated, and new research, technology 
and societal developments that need to be brought instructively to a practitioner's attention (as in the Update Model). The field of vision also includes personal competencies and traits that are shown to be related to effective or outstanding individual performance in a job (as in the Competence Model). The field of vision of needs assessment may also encompass environmental variables that affect practitioners' lives and work, such as the economic system, social system or technology, as well as the structure and characteristics of the organisation in which the practitioners work. Significantly, the scope of the needs assessment takes into consideration the relationship between individuals and organisations. All these variables should be considered in developing CE activities for practitioners in the professions.

The other significant feature of this model is that both individuals and organisations are expected to engage in triage to identify and prioritise their learning needs. Moreover, triage for $\mathrm{CE}$ is considered in the light of keeping a developmental balance between individuals and organisations, and the fit of individuals and organisations to one and other.

Many other writers (e.g., Brine, 2005; Donaldson \& Kuhne, 1997; Knox, 1993, 2000; Parker, 1997; Queeney, 2000; Swanson \& Holton, 2001) share Nowlen's perspective that $\mathrm{CE}$ should be planned and implemented according to the understanding that professional performance is affected by a complex mixture of personal and environmental factors. Also, Knowles (1990) and Grisciti and Jacono (2006) concurred with Nowlen that different stakeholders, including individuals and organisations, should be involved in learning needs analysis.

Nowlen's model has been assessed as a comprehensive and useful CE model by writers such as Mann (1994), Mott (2000) and Nasseh (1996). Mott (2000) stated that the Performance Model addresses the three basic points of professional practice. First, practitioners are individuals influenced by their environments, self-image, roles and values. Second, professional practice is a complex network of interdependent systems. 
Third, performance cannot be affected significantly by only single form of intervention. These points are most helpful in understanding factors affecting the performance and needs of practitioners and the organisations.

In summary, Nowlen's (1988) Performance Model covers the main factors that are included in most other models as well as in the theories of adult education and CE. Further, it builds on components of those factors. As in most of the other models, the Performance Model recognises that individuals play a key role in identifying and prioritising their learning needs. However, it is significant in that it emphasises the interaction between individuals and organisations and the resulting performance of each, including both in the triage process. As a result, programmes based on the Performance Model have the potential to be far more varied, identifying and developing a range of programme resources identified or developed (Nasseh, 1996).

To facilitate comparison of the variables in the Performance Model with the factors affecting $\mathrm{CE}$ in the adult education and $\mathrm{CE}$ literature summarised in the Figure 2.1, the variables in the model and their contents are summarised in Figure 2.3. 


\subsection{The preliminary model for $\mathrm{CE}$ for university library practitioners in Vietnam}

The preliminary model is presented as a framework for conducting this study. It guides the process of data collection and analysis to enable understanding of factors that affect $\mathrm{CE}$ and to identify and prioritise learning needs for university library practitioners in Vietnam.

\subsubsection{Adaptation of factors affecting $\mathrm{CE}$ from literature}

Based on the literature review and the Performance Model (Nowlen, 1988), the characteristics of the profession and individual practitioners and the influences of the environments in which practitioners live and practise are incorporated into the preliminary model as factors affecting CE. In addition, based on the Performance Model, interaction between practitioners and organisations is also considered as a key factor, as is the triage concept. Figure 2.4 illustrates the adaptation of factors and variables in the preliminary model. 
Factors affecting adult education and $C E$ from the literature

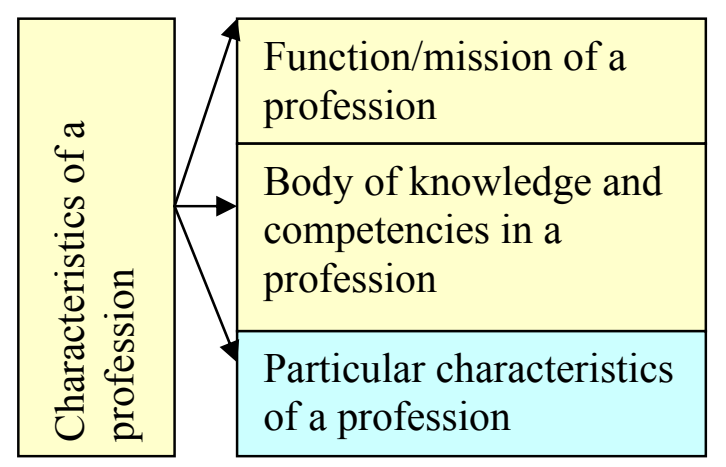
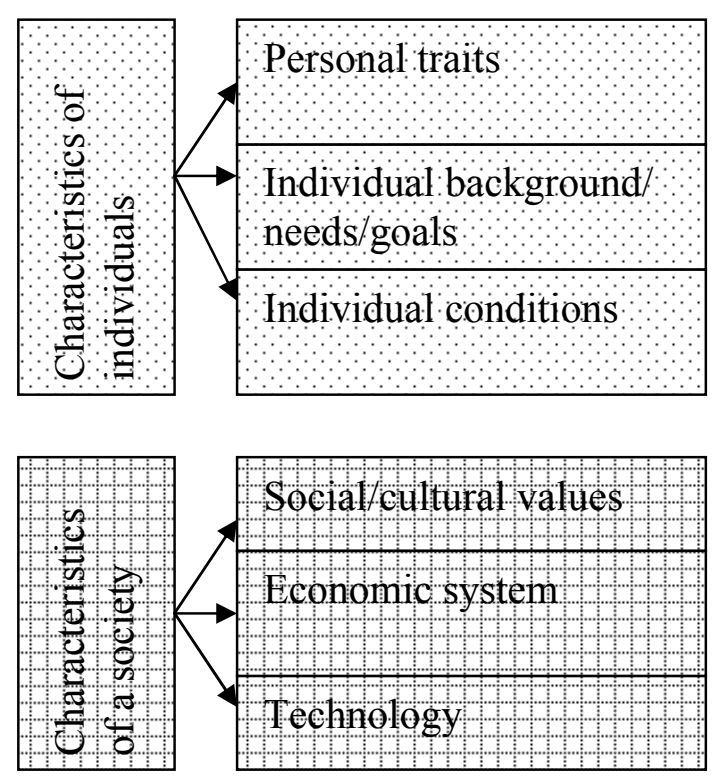

Variables in the Performance Model of Nowlen (1988)
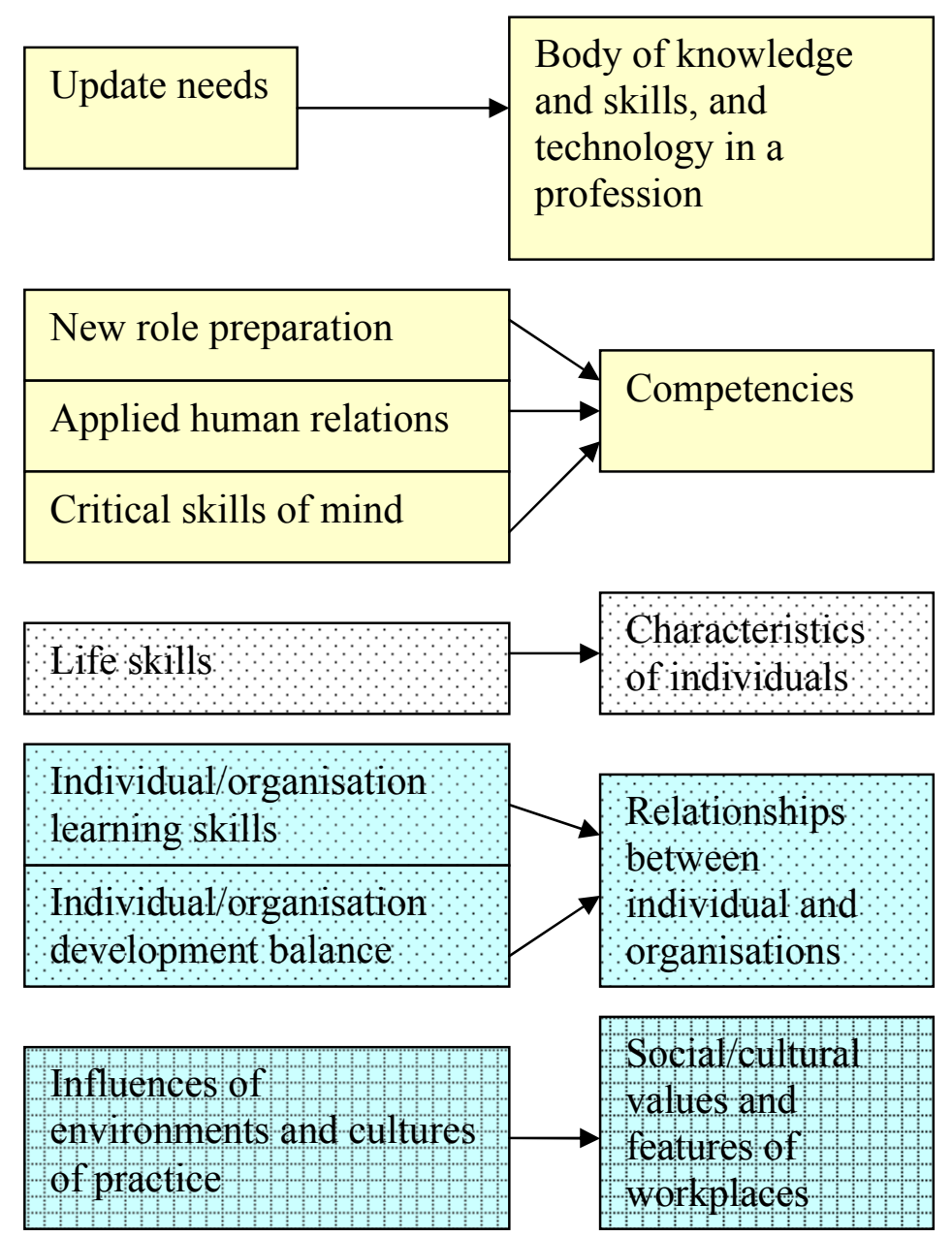

Adapted variables in the preliminary model for this study

\begin{tabular}{l}
\hline LIM profession \\
- Knowledge and skill base \\
- Competencies \\
- IT systems
\end{tabular}

\begin{tabular}{|l|}
\hline Organisations \\
- Central government \\
- Ministries \\
- Universities \\
- Libraries \\
\hline
\end{tabular}

\begin{tabular}{|c|}
\hline 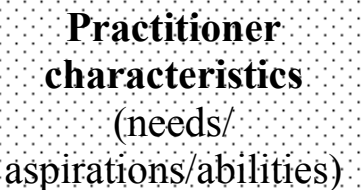 \\
\hline
\end{tabular}

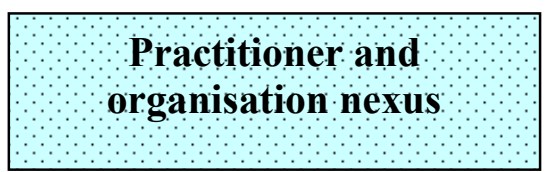

Social environment (Social/cultural values)

Figure 2.4: The adaptation of variables to the preliminary model for this study 
The variables adapted in developing the preliminary model for this study are grouped into five sets. They form the first part of the model.

- Library and Information Management (LIM) profession - professional knowledge and skill base, competencies, and information technology (IT) systems.

- Organisations - central government, ministries, universities and libraries.

- Practitioner characteristics (needs/aspirations/abilities).

- Practitioner and organisation nexus.

- Social environment (social/cultural values).

The second part of the model is triage of CE. Using the triage concept from the Performance Model (Nowlen, 1988) discussed in Section 2.4.3, in the context of this study triage is a process to identify and prioritise the learning needs for university library practitioners based on theirs and their organisations' needs. The results of triage can be used as the basis for creating learning programmes. This process is affected by the sets of variables indicated above. Through triage, CE providers should be able to identify priority content and delivery formats to enable the design and implementation of effective CE programmes that will meet the needs of individual practitioners and organisations.

The model is illustrated in Figure 2.5. Each suggested set of variables is discussed in the next section. 


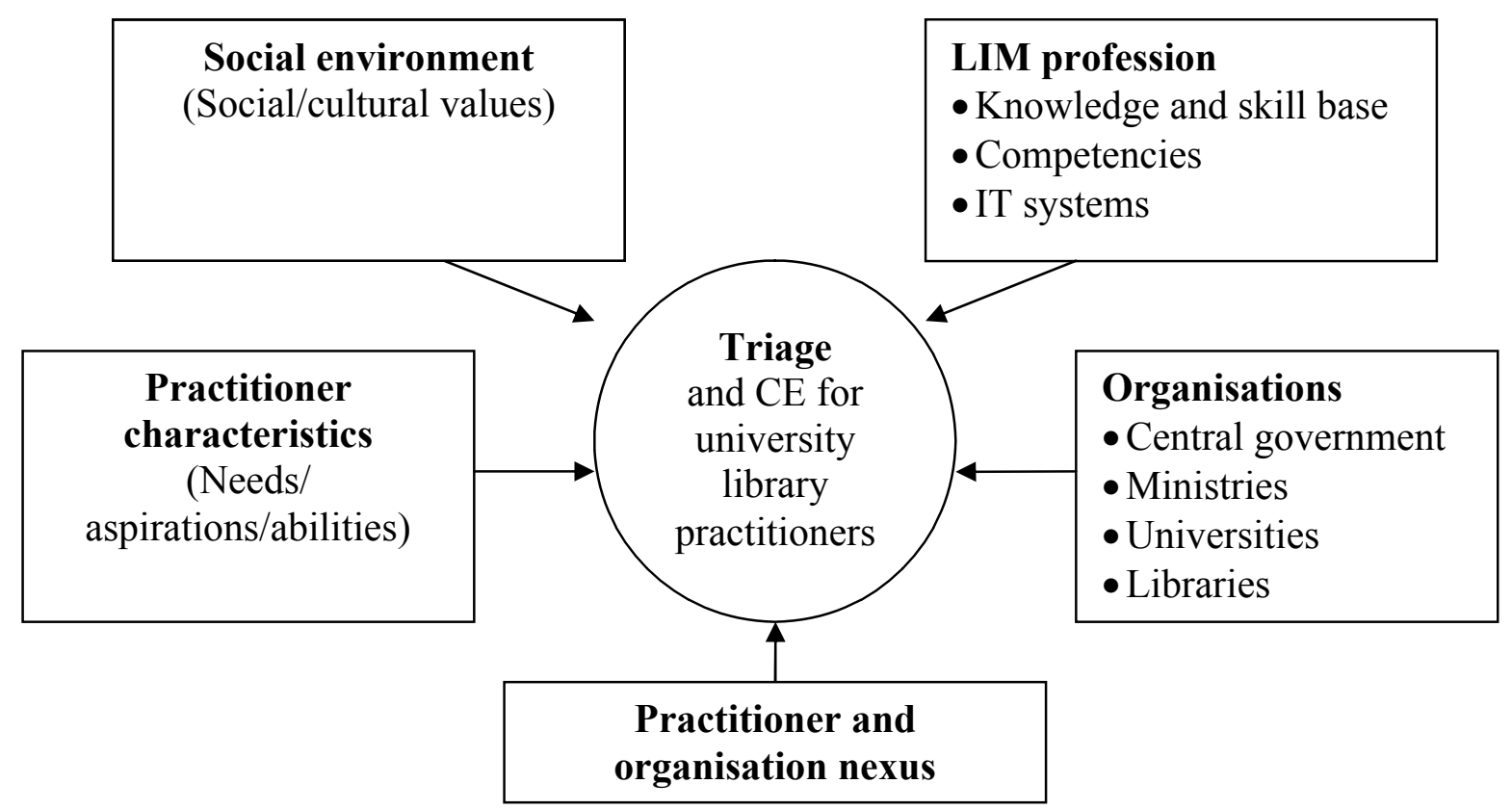

Figure 2.5: The preliminary model for $\mathrm{CE}$ for university library practitioners in Vietnam

\subsubsection{Suggested sets of variables}

\section{LIM profession: Knowledge and skill base, competencies and IT systems}

As discussed in Section 2.4.1, mastering the body of professional knowledge and skills, updating new knowledge and skills, and creating, enhancing and maintaining competencies all require practitioners to participate in CE (Cervero, 1988; Houle, 1980). Based on these requirements, the goals, content and modes of $\mathrm{CE}$ activities can be developed. In the Performance Model, the update needs, new role preparation, applied human relations and critical skills of mind variables reflect $\mathrm{CE}$ issues related to the body of knowledge and competencies. These variables have a strong influence on triage for CE. Accordingly, they are included in the preliminary model for this study.

In the Vietnamese context, as mentioned in Section 1.2.3, a number of practitioners have not undertaken professional education in LIM. They need opportunities to gain the LIM knowledge base, which includes the theoretical foundation and practical skills that 
practitioners must acquire for current and future professional practice. Hence, the requirement to master the knowledge and skills of the profession is likely to motivate practitioners to participate in $\mathrm{CE}$ and comprises their learning needs. In addition, university library practitioners must have competence to deal with their daily tasks in the changing context of LIM practice. The required competencies, therefore, also affect the learning needs of practitioners.

Furthermore, as mentioned in Section 1.2.2, information technology is being increasingly implemented in LIM services in Vietnam. Technology is also used in teaching, learning and research in higher education. Therefore, knowledge and skills related to IT are important in ensuring that university library practitioners can provide high quality services to their patrons. This component requires practitioners to gain IT knowledge through participation in CE activities. Accordingly, developments in IT may push practitioners to learn, thereby affecting their learning needs.

Therefore, knowledge and skill bases, competencies and IT within the LIM profession are identified as potential factors affecting the participation and learning needs of Vietnamese university library practitioners.

\section{Organisations: Central government, ministries, universities and libraries}

As discussed in Section 2.4.1, according to writers in the adult education and CE fields, such as Boyd et al. (1980), Houle (1980) and Stolee et al. (2005), the features of a profession, including subculture, code of ethics and structure, affect the CE of its practitioners. Similarly, through extending the cultural strand, Nowlen (1988) suggested that the characteristics of the environments in which individuals practise is a variable that has a strong influence on triage and therefore on CE.

In the Vietnamese context, as mentioned in Section 1.2.3, all public universities and their libraries are under the administration of the central government and functional ministries. The universities directly control all LIM activities, including CE, and provide 
funding. The libraries' missions have to follow those of their parent universities which are to support the teaching, learning and research activities of the university by providing information services to students, lecturers, researchers and staff within the university (Education University of HCMC, 2005; Library and Information Center VNU - Hanoi, 2005; Natural Sciences Library - VNU - HCMC, 2005).

At the same time, the central government is the highest lead organisation for public universities, their libraries and their staff. As mentioned in Section 1.2.1 the government controls all areas of the political and economic system in Vietnam, including education. Based on government policies and strategies, functional ministries have their own policies and strategies which then filter down to the public universities' policies and strategies and further down again to those set by their libraries. Consequently, the needs of the central government, ministries and universities, their requirements for practitioners, their policies relating to salaries and promotion, and their support, or lack of it, for the activities of libraries are all likely to affect participation in CE as well as the learning needs of the library practitioners. Accordingly, the central government, ministries, universities and libraries must all be included in the preliminary model to reflect the influences of organisational features and the political and economic system on the $\mathrm{CE}$ of university library practitioners in the Vietnamese context.

\section{Practitioner characteristics (needs/aspirations/abilities)}

As discussed in Section 2.4.1, learners are at the centre of CE activities (Blank \& Russell, 2000; Cervero, 1988; Knowles, 1980). Learners' personal characteristics affect their selection of the purpose, content, and format of learning activities. Similarly, the Performance Model places emphasis on the "individual strand" (Nowlen, 1988), which carries the individual's experience, growth, skills, values and attitudes into the triage for their CE.

Vietnamese university library practitioners, as adult learners, have their own characteristics in terms of goals, needs, abilities, learning skills, enablers and barriers 
when participating in learning activities. Intrinsic needs, such as becoming better at their jobs, growing as a person, being able to change career or achieve better positions, are also likely to motivate practitioners to participate in CE activities. Therefore, practitioners' needs, aspirations and abilities may facilitate or pose barriers, and must be considered in developing CE programmes.

\section{Practitioner and organisation nexus}

As discussed earlier, the relationship between individuals and organisations, the balance between their development and their fit to one another are considered in the Performance Model of Nowlen (1988). Other writers such as Queeney (2000) and Brine (2005) also pointed out that such interactions can affect the performance of both the individual and the organisation.

This perspective suggests that the needs, aspirations and abilities of the individual library practitioners and those of the organisations may influence each other. In other words, the requirements of the organisation are likely to impact on the learning needs of practitioners, while the performance of an individual may impact on the performance of a library as a whole. Accordingly, library policies relating to promotion, human development or financial support for training will affect practitioners' CE triage and activities. In addition, as Nowlen (1988) indicates, individuals exist in relation to groups therefore relationships among the various practitioners in a library might also affect their CE. So, this nexus may strongly influence CE and triage for university library practitioners.

\section{Social environment (social/cultural values)}

In the literature and the Performance Model, the characteristics of a society - involving a complex set of variables including social/cultural values, economic, technological systems and so forth - influence participation in CE and the learning needs of individuals. 
As mentioned in Section 1.2, the social/cultural values, economic system and infrastructures of Vietnam are rapidly changing. The resulting new values, knowledge and technology and change in all areas are, theoretically, strong motivators for practitioners to update through CE. In particular, increasing opportunities to achieve higher education, the growing importance of information services in the process of moving from central planning to a market economy and more jobs in the labour market may motivate the learning pursuits of practitioners. However, traditional social/cultural values continue to influence every member of society. The principles of central planning economics still exist. Each of these factors is likely to impact on the performance and learning needs of university library practitioners.

Thus, environmental influences can act as enablers or barriers to the CE of Vietnamese university library practitioners. The impact of developing technologies, and the political and economic system have already been addressed in the sets of variables for the "LIM profession" and for "Organisations". The influences of social/cultural values are included in the set of variables labelled "Social environment".

In sum, this preliminary model seeks to address the influence of individual and environmental factors on $\mathrm{CE}$ for university library practitioners in general and on prioritising their $\mathrm{CE}$ needs in particular. The preliminary model suggests that the identification of factors affecting $\mathrm{CE}$, and understanding the effects of each factor, are crucial for implementing achievable and effective CE programmes in terms of both content and programme design. It also suggests that understanding the relationship between the $\mathrm{CE}$ needs of individuals and their organisations is very important for identifying and prioritising CE needs. The model will be assessed and revised based on findings from the data of this study. The revised model will be valuable for assisting CE providers and the LIM profession to find ways to integrate CE into the ongoing careers of individual practitioners which in turn will accelerate the development of the profession. 


\section{CHAPTER 3: RESEARCH METHODOLOGY}

This chapter describes the methodology used to conduct the research for this study. It includes the methodological approach and research design as well as addressing the validity, reliability, language and ethical issues of the research.

\subsection{Philosophical perspectives}

Positivism and interpretivism are the two main approaches to research in the social sciences (Bryman, 2004). The positivist perspective is founded on an ontology in which an objective physical and social world is believed to exist independently of humans' knowledge of it. Positivism seeks to explain and predict what happens in the social world by searching for regularities and causal relationships between its constituent elements (Orlikowski \& Baroudi, 1991). Positivist research is concerned with testing a theory or gathering facts to provide the basis for a theory. Researchers who adopt this paradigm try to discover the general principles or laws which govern the natural and social world (Bryman, 2004). Research is assumed to be value free, so that the researcher remains detached, neutral and objective. The positivist perspective underlies what are called quantitative methods (Guba \& Lincoln, 1994).

In contrast, an interpretivist perspective is based on an ontology in which reality is regarded as subjective. Reality is a social product constructed and interpreted by humans according to their beliefs and value systems. Interpretivist research attempts to understand phenomena through accessing the meanings that participants, in their own words and images, assign to the phenomena, and focuses on their cultural and historical context (Darke, Shanks, \& Broadbent, 1998). Interpretivist researchers attempt to gain a deep understanding of the phenomena being investigated, and acknowledge their own subjectivity as a part of this process. The value of an explanation is judged by the extent to which it allows others to understand the phenomena and makes sense to those being studied (Walsham, 1995). The interpretivist researcher is not simply laying bare how participants interpret the world around them, he or she will almost certainly be aiming to 
place these interpretations into a theoretical frame (Bryman, 2004). The interpretivist perspective underlies what are called qualitative methods (Guba \& Lincoln, 1994).

This study involves examining the perceptions of human beings - university library practitioners - about factors affecting their $\mathrm{CE}$ and their $\mathrm{CE}$ needs. Interpreting the perceptions, thoughts and explanations of university library practitioners allows for an understanding of factors affecting their CE and learning needs. In addition, document analysis provides additional evidence to contribute to the understanding of the issues. For these reasons, an interpretivist approach has been adopted in this study.

\subsection{Methodological approaches}

The methodological approach should be appropriate to what researchers are trying to discover (Murray \& Overton, 2005). When the nature of the issues being studied requires exploration because little literature exists, then qualitative approaches are best (Creswell, 2003; Rubin \& Rubin, 2005). They are also useful when the researcher needs to focus on the social or organisational context of an issue. These qualitative approaches include observation, interviewing, focus groups, and the collection and qualitative analysis of texts and documents, or historical studies (Bryman, 2004; Gorman \& Clayton, 2005).

Since the purpose of this study was to explore factors affecting the CE of Vietnamese university library practitioners and only a small amount of literature appeared to exist on the relevant issues, the perceptions of practitioners and documentary evidence from relevant organisations were gathered and examined. The qualitative methods of individual interviews, focus groups and qualitative analysis of documents were employed.

\subsection{Research design}

In this section, the research process, research samples, data collection and data analysis procedures are discussed. 


\subsubsection{Research process}

As mentioned, multiple methods were employed to achieve the purpose of this study. In addition, notes were taken as supplementary data. Using different methods concurrently helped to generate comprehensive, diverse and insightful data. The research was undertaken in three phases:

Phase One: Desk research - Review of literature and creation a preliminary contextual model

Phase Two: Data collection

$$
\begin{array}{ll}
\text { 2.A } & \text { Individual interviews } \\
\text { 2.B } & \text { Focus group interviews } \\
\text { 2.C } & \text { Documentary evidence }
\end{array}
$$

Phase Three: Data analysis

$$
\begin{aligned}
& \text { 3.A Analysis of factors affecting CE } \\
& \text { 3.B Identification and prioritisation of learning needs (by conducting a } \\
& \text { triage) } \\
& \text { 3.C Assessment and revision of the preliminary contextual model }
\end{aligned}
$$

Figure 3.1 illustrates the research process. The methods used in the study are discussed in detail in Section 3.3.3 on data collection procedures. 


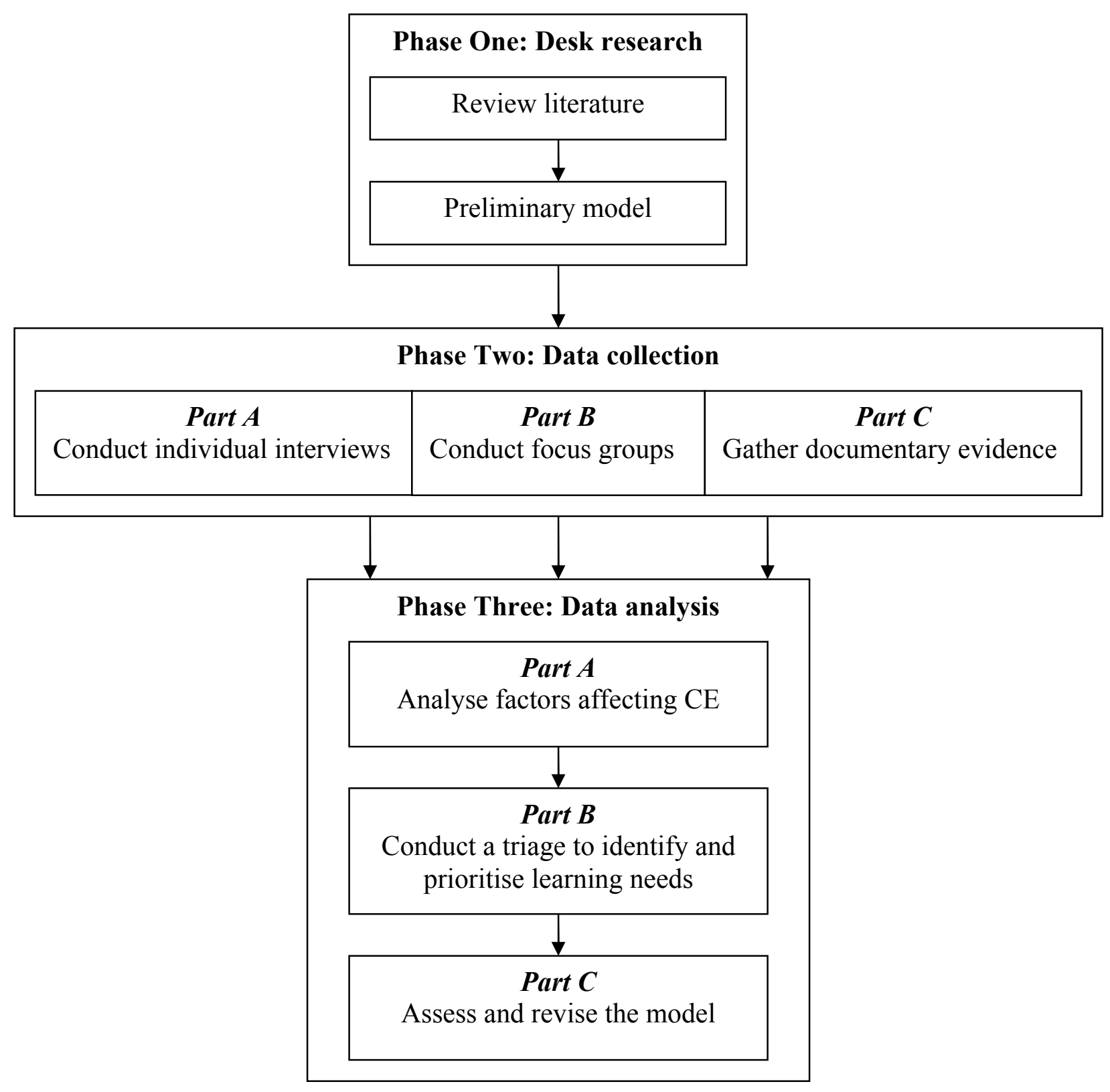

Figure 3.1: The research process

\subsubsection{The research samples}

As explained in Section 1.2.3, all public university libraries in Vietnam are funded and administered by the government. However, they differ in attributes such as the disciplinary focus of the university, location and number of staff. To ensure that the 
selection of sample sites in this study took into consideration all these attributes and that the population of individual interview subjects and focus groups was representative, purposive sampling was required. Purposive sampling is a sampling method in which subjects are selected because their characteristics are important for the research (Sproull, 1995).

To provide a rational explanation of sample selection, as required when using the purposive sampling method (Leedy \& Ormrod, 2001), two sample frameworks were created. The first was a sample site framework listing the main attributes of university libraries. The second was a sample population framework listing the main characteristics of university library practitioners. Based on these frameworks, the sample sites and the sample population were selected in such a way that the total number of samples included all categories of university libraries and all categories of practitioners. Strictly following the frameworks not only helped in ensuring that the samples were representative, but also helped in avoiding the biases of personal sample selection (Alreck \& Settle, 2004).

\subsubsection{Research sites}

Research sites framework:

- Geographical location (university libraries are in different parts of the country):

- North

- Central

- South.

- Type of university (university disciplinary focus):

- specialised university

- multi-disciplinary university.

- Numbers of library staff:

- large number of staff (more than 40)

- medium number of staff (from 25 to 40)

- small number of staff (less than 25). 
Following the sample site framework, libraries from 11 universities in locations from throughout the country were selected as potential research sites: four from the North, two from the central region and five from the South. Among these, five were in specialised universities and six in multi-disciplinary universities. There were three libraries with a large number of staff, four with a medium number and four with a small number. Of the 11 libraries, one was used to pilot the manager interview and focus group interview questions, so was excluded from the data collection and analysis procedures. Following the pilot interviews, this left 10 libraries available for data collection. Information about these 10 sample sites is presented in more detail in Chapter 4 together with demographic information about the participating libraries. Table 3.1 outlines the sample sites. The identities of the 10 university libraries participating in the study have been protected by using the pseudonyms listed in the table.

\begin{tabular}{|c|c|c|c|c|c|c|}
\hline \multirow[t]{2}{*}{ University library } & \multicolumn{3}{|c|}{$\begin{array}{c}\text { Geographical } \\
\text { location }\end{array}$} & \multicolumn{2}{|c|}{ University type } & \multirow[t]{2}{*}{ Number of staff } \\
\hline & 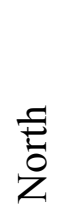 & $\frac{\bar{\pi}}{\stackrel{\widetilde{J}}{0}}$ & $\begin{array}{l}\text { 吾 } \\
\text { ठ }\end{array}$ & 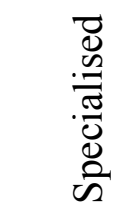 & 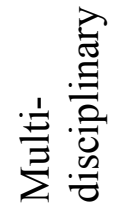 & \\
\hline Hoan Kiem & $\mathrm{x}$ & & & $\mathrm{x}$ & & Medium \\
\hline Hong Ha & $\mathrm{x}$ & & & & $\mathrm{x}$ & Large \\
\hline Ho Tay & $\mathrm{X}$ & & & $\mathrm{x}$ & & Small \\
\hline Ho Guom & $\mathrm{x}$ & & & $\mathrm{x}$ & & Small \\
\hline Hoa Sua & & $\mathrm{x}$ & & & $\mathrm{X}$ & Large \\
\hline Hai Van & & $\mathrm{x}$ & & & $\mathrm{x}$ & Large \\
\hline Ben Thanh & & & $\mathrm{x}$ & & $\mathrm{X}$ & Medium \\
\hline Thanh Da & & & $\mathrm{x}$ & & $\mathrm{X}$ & Small \\
\hline Tan Binh & & & $\mathrm{x}$ & $\mathrm{x}$ & & Medium \\
\hline Dam Sen & & & $\mathrm{X}$ & & $\mathrm{x}$ & Medium \\
\hline
\end{tabular}

Note: Large $=$ more than 40 staff. Medium $=$ from 25 to 40 staff. Small = less than 25 staff

Table 3.1: Participating university libraries 


\subsubsection{Sample population}

Sample interview population framework:

- Practitioners who work in one of the following areas of LIM practice:

- cataloguing

- collection development

- circulation

- reference

- information technology.

- Practitioners whose educational qualifications are in:

- LIM

- other disciplines.

- Library managers who have responsibility for or are interested in CE.

Following the framework of the sample population and using the lists of practitioners in the 10 selected libraries, from each library one manager, who was in charge of CE, was selected as an individual interviewee, five senior staff and supervisors were selected as interviewees for a focus group, and five line staff were selected as interviewees for another focus group. To divide participants in such a way created a more comfortable and safe focus group environment for them. This is one of the requirements of focus group interviews (Morgan, 1997). However, in libraries with a small number of staff, only one focus group, consisting of both supervisors/senior staff and line staff, was conducted. Hence, 10 individual interviews and 17 focus groups were conducted in this study.

Usually, as stated in the sample population framework, there are five main practice areas in Vietnamese university libraries. Therefore, selecting one staff member and one supervisor/senior staff member from each area within a library would have been ideal. However, this was impractical because library staff commonly worked in two or more areas of practice. It also should be noted that nine of the managers who had 
responsibility for CE happened to be library directors. The Table 3.2 introduces the same population with illustrations of their positions, qualifications and areas of work.

\begin{tabular}{|c|c|c|c|c|c|c|c|c|c|c|}
\hline \multirow[t]{3}{*}{ Position } & \multirow{3}{*}{ 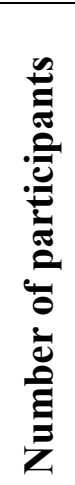 } & \multicolumn{6}{|c|}{$\begin{array}{c}\text { Highest educational } \\
\text { qualification }\end{array}$} & \multicolumn{3}{|c|}{ Area of work } \\
\hline & & \multirow[b]{2}{*}{\begin{tabular}{l}
0 \\
\multirow{0}{0}{} \\
0 \\
0 \\
0
\end{tabular}} & \multirow[b]{2}{*}{ 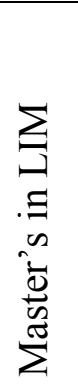 } & \multirow{2}{*}{ 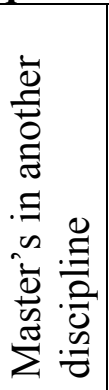 } & \multirow{2}{*}{ 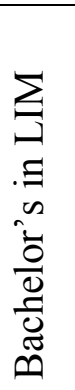 } & \multirow{2}{*}{ 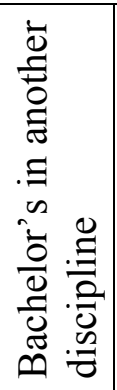 } & \multirow[b]{2}{*}{ Ũ } & \multicolumn{2}{|c|}{$\begin{array}{c}\text { Technical } \\
\text { services }\end{array}$} & \multirow[t]{2}{*}{$\begin{array}{c}\text { Information } \\
\text { services }\end{array}$} \\
\hline & & & & & & & & $\sqsubseteq$ & 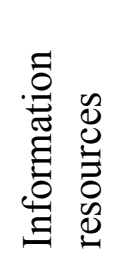 & \\
\hline Managers & 10 & 3 & 3 & 2 & 0 & 2 & 0 & \multicolumn{3}{|c|}{$\begin{array}{ll}- & \text { Overall responsibility } \\
- & \text { Development strategies } \\
- & \text { Finance issues } \\
- & \text { Human resources } \\
- & \text { Professional issues }\end{array}$} \\
\hline $\begin{array}{l}\text { Supervisors/ } \\
\text { Senior staff }\end{array}$ & 39 & 0 & 9 & 3 & 15 & 12 & 0 & 10 & 17 & 12 \\
\hline Line staff & 43 & 0 & 0 & 1 & 17 & 23 & 2 & 8 & 14 & 21 \\
\hline
\end{tabular}

\section{Table 3.2: Participants}

\subsubsection{Participant recruitment}

After approaching the library directors (including the director from the pilot library) to invite them informally to participate in the study, the researcher requested that they provide lists of the names, positions and tasks of their staff. This process took several months to complete because the researcher was not located in Vietnam and had no opportunity to approach them directly. All contacts were by email at that stage and in some cases directors did not regularly check their email or did not reply promptly. With persistence, the researcher finally gained permission to conduct interviews in all 11 libraries. In accordance with the requirements of the Human Ethics Committee of Victoria University of Wellington (VUW), which granted approval for this research to 
be undertaken, an information sheet and consent form were then sent to each library director officially asking for their agreement to participate (see Appendix A).

Initially, participants were selected from the staff lists provided, based on the population sample framework as described earlier, and then the lists of participants were submitted to the directors for their recommendations and approval. Next, information sheets and consent forms were sent to each participant to obtain their agreement before commencing the interviewing (see Appendices B and C).

\subsubsection{Data collection procedures}

The methods of data collection for the study included gathering documentation and conducting qualitative individual and focus group interviews.

\subsubsection{Phase One: Desk research}

To develop a preliminary model of factors affecting CE, initially, an extensive search for literature in the fields of adult education, $\mathrm{CE}$ in professions and specifically CE in LIM was conducted. This review identified the main factors affecting adult education and CE. Subsequently, the researcher focused on models relating to adult education and CE to find one that could be modified to become a preliminary model for this study. Nowlen's (1988) Performance Model for CE in professions was selected. Finally, the preliminary model was created by modifying Nowlen's model to encompass factors from the literature review. This phase was discussed in Section 2.4.

To identify relevant materials the researcher used the databases provided by the VUW Library, such as ERIC, Emerald and ProQuest, the VUW Library collections and interloan service, and the National Library of New Zealand collection. 


\subsubsection{Phase Two: Data collection}

To assess and revise the preliminary model and identify the learning needs of Vietnamese university library practitioners, the data were collected from different sources - focus groups and interviews with university library practitioners, and documentation from the libraries and universities in which the practitioners work, and from central government and relevant ministries. In addition, notes were taken during each part as supplementary data.

Using the preliminary model as a framework, the researcher examined the perceptions of the practitioners (as recorded in the interviews and focus groups) and analysed the documentary sources to explore the factors affecting their $\mathrm{CE}$ and their learning needs. All the data obtained in this phase were analysed in Phase Three.

The field trip through Vietnam for data collection lasted about three months. However, collecting documentary evidence and keeping in touch with participants to clarify the data as needed continued until the data analysis was completed. The following section discusses the data collection processes further including the rationale for choosing the methods.

\section{Part A: Individual interviews}

Qualitative interviews are especially useful when researchers are interested in understanding people's perceptions, describing their experiences, and clarifying and elaborating their own perspectives on issues in their lived world (Brockington \& Sullivan, 2005; Klave, 1996). Interviewing gives insight into how and why people believe, feel, interpret events and behave in the ways they do (Gorman \& Clayton, 2005; Mason, 2002). In particular, semi-structured interviews can provide a more valid explication of informant's perceptions of reality (Minichiello, Aroni, Timewell, \& Alexander, 1995). According to Minichiello et al. (1995), the semi-structured method entails researchers using broad topics to guide interviews. An interview guide is developed around a list of topics without fixed wording or fixed ordering of questions. 
In this way, semi-structured interviews can invoke an in-depth examination of people's perceptions of topics without losing focus.

Accordingly, face-to-face semi-structured interviews were conducted with the managers in charge of $\mathrm{CE}$ in their libraries. These managers were able to understand enablers for, and barriers to $\mathrm{CE}$, as well as the learning needs of library managers. Furthermore, they were able to understand the missions, strategies, policies, requirements and needs of their libraries and universities that may affect the $\mathrm{CE}$ of library practitioners. As a result, they were able to provide an understanding of what and why their staff might need to update or gain particular knowledge or skills. Therefore, their perceptions of learning needs for their staff are considered representative of the learning needs of their institutions.

Individual interviews lasting about one hour were necessary in order for managers to explain issues comprehensively and insightfully. An audio digital recorder was used during the interview sessions. To guide the interviews, a protocol was created as a research instrument, based on concepts drawn from Yin (2003). The protocol contained: (1) field information to ensure the researcher was fully prepared for the interviews, (2) the interview schedule and (3) the procedure for conducting an interview (see Appendix D).

In addition, themes were drawn from the preliminary model and sample interview questions were created as a prompt to ensure the interviews would obtain the required data (see Appendix E). A preliminary list of CE needs was developed also, based on a review of previous $\mathrm{CE}$ programmes of information and library associations in some developed countries. This list (see Appendix F) was used to assist the researcher to discover the learning needs of Vietnamese university library practitioners through interviews. 
One university library was used to pilot the interview questions so could not be included in the data collection phase. The manager in this library answered sample questions and his responses were recorded. The researcher listened to the recording and conducted a trial of data transcription and analysis. The transcription was shared with her supervisors to get their feedback. As a result of this pilot interview, the researcher reworded questions prior to commencing the actual data collection.

Following the pilot interview, 10 individual interviews of managers were conducted at the interviewees' workplaces. As part of the interviewing process, an explanation of the processes and relevant terms was provided by the researcher. Each interview lasted approximately one hour and was completed when the saturation point was reached. The saturation point indicates that the interviewee has no new information to offer about the topic (Sarantakos, 1998), in this case when the manager had related all he or she could on their perceptions of the factors affecting CE and learning needs.

The questions covered the themes and issues that the researcher sought to explore but were not in the same order in all interviews. After introducing the researcher and the purposes of the study, all interviews began with warm-up questions such as "Please tell me about yourself" or "Please share with me your learning experiences." Further questions were based on the initial responses from each interviewee, and focused on determining and understanding the factors affecting the informant's own CE and then their staff's CE, their own learning needs and then their staff's needs. Checking the themes listed in the protocol, the researcher then asked the interviewees for their perceptions about any themes not yet covered. Similarly, after referring to the preliminary list of CE needs, the researcher asked the interviewees for their perceptions about learning needs they had not yet mentioned.

The participating managers were often busy or away on work business. Therefore to conduct an hour-long interview, the researcher had to make an appointment with them one or even two months in advance and regularly check with them to make sure that 
their work schedule would not change. However, all kindly helped and were willing to discuss the issues. In addition, they readily arranged time for their staff to participate in the study.

To contribute further insights into the data collection procedures, notes were taken during the interviews (Denscombe, 2007; Glesne, 2006). Following the recommendations of Bryman (2004) the researcher: (1) wrote the notes as quickly as possible upon hearing or observing something interesting during interviewing (jotted notes); (2) wrote notes with many more details at the end of the day (mental notes and full field notes); and (3) wrote plainly and clearly. Notes helped the researcher to formulate new questions as the interviews moved along, to check something said earlier and to make sure that the interviews were still focusing on the issues. It is never possible to understand another person well without observations, therefore notes related to how easy it was to elicit the perceptions from participants and how easy it was for them to express their opinions. The notes also included initial ideas about the participants' interpretations, impressions and feelings. All these facilitated data analysis later on, including locating important quotations from the recordings.

\section{Part B: Focus group interviews}

Focus group interviewing can be used to explore the range of perspectives around a particular issue and to obtain detailed qualitative data from the exchange of ideas and opinions in a predetermined group of people (Krueger \& Casey, 2000; Schensul, 1999b). It is useful for exploratory research (Frey \& Fontana, 1993), which involves investigating an area about which the issues are unknown or unclear. For example, focus group interviewing may provide baseline information for developing specific programmes, including those related to $\mathrm{CE}$.

According to Berg (2007), Morgan (1997) and Stewart and Shamdasani (1990), one of the key characteristics of a focus group is that it creates an environment which enables participants to share their views comfortably without fear of censure or judgement. It 
encourages a range of responses which provide insights into and diversity in the attitudes, perceptions or opinions of participants about a particular area. However, these authors also mentioned that there are disadvantages of this method - the results obtained in a focus group interview may be biased by a very dominant or opinionated member, and the quality of the data collected greatly depends on the skills and motivation of the facilitator.

Due to the features and advantages of focus group interviewing, it was appropriate to adopt this method to obtain a wide range of information and insights into factors affecting $\mathrm{CE}$ and $\mathrm{CE}$ needs of university library staff in different areas of professional practice. This method enabled the participants to provide considered responses after discussion among the group.

To create an environment that encouraged participants to feel comfortable sharing their opinions, the participants in each library were separated in two groups as already discussed in Section 3.3.2.2. To limit potential biases caused by dominant or opinionated members, as well as to make sure that groups would run smoothly, the researcher followed the guidelines suggested by Schensul (1999b) and Vaughn, Schumm, and Sinagub (1996) (see Appendix H). Similar to the individual interviews, the researcher created a focus group interview protocol (see Appendix G), using the list of themes and sample of interview questions (see Appendix E) and the preliminary list of CE needs (see Appendix F) as research instruments.

As with the individual interviews, a pilot focus group was conducted to test the questions and the protocol. After the pilot study, 17 focus groups were conducted using the procedures in the focus group interview protocol. It should be noted that the predetermined interview questions were continuously revised after every focus group. However, to ensure the reliability of the study, the themes did not change, thereby maintaining as much consistency as possible throughout the series of focus groups. 
Focus group interviews were conducted at the participants' workplaces. Each interview lasted approximately 1.5 hours and was completed when the participants' perceptions concerning the given issues reached saturation point. An audio digital recorder was used during the interview sessions.

Because the library directors had approved the list of participants and allowed the interviews to be conducted during work hours, there was no difficulty for the researcher in recruiting participants. However, most of them were not familiar with the research interview process and some seemed hesitant initially because they were worried that they could not help. Therefore, although the information sheets had been sent in advance, the researcher needed to spend considerable time explaining the interview purposes to overcome their hesitation.

As a Vietnamese university lecturer in LIM, the researcher has a good understanding of Vietnamese culture and people. To create an open atmosphere that encouraged the participants to discuss freely, the researcher shared some personal information about herself and let the participants share similar information about themselves. This is a good way to become acquainted with interviewees because Vietnamese consider that asking about family status, age or living place is not only acceptable, it is a way to express one's concern for people. Moreover, Vietnamese have a complex system of personal pronouns depending on age and gender, on whether the situation is formal or informal, and even on speakers' habits, so it is important to address people properly. Furthermore, the personal pronouns used in business conversation may differ from those in casual conversation. When the researcher used personal pronouns properly and flexibly switched them as needed, a friendly atmosphere was created, encouraging people to talk more openly.

As with the individual interviews, notes were taken. It should be observed that, in some cases, when the researcher turned off the recorder, some participants became more active speakers. They repeated their views in more direct ways or gave more precise 
examples to illustrate their views. Therefore the researcher kept taking notes even after the interview seemed to have ended.

\section{Part C: Documentary evidence}

As mentioned in Section 2.5.2 which discussed sets of variables in the preliminary model, characteristics of organisations, including policies, requirements and needs may influence $\mathrm{CE}$ and $\mathrm{CE}$ needs of practitioners. Also, the preliminary model recognises that not only the needs of individuals but the needs of organisations need to be considered in triage. Therefore, to understand barriers to and enablers for CE, as well as CE needs from the organisational perspective, along with the perceptions of interviewees, the researcher gathered and examined documents relating to $\mathrm{CE}$ from organisations, including the central government, related ministries, universities and libraries.

The document gathering occurred concurrently with the interviewing. It was conducted using the following steps:

- Searching for published and unpublished documents through the main libraries in Vietnam, such as the National Library and NACESTI (the organisation that most frequently conducts CE programmes in Vietnam).

- Looking at relevant websites, such as the website of the Communist Party of Vietnam or the website of MOET.

- Searching for published and unpublished documents in the collections of university libraries that are the sample sites of the study.

- Asking library managers and university officers for access to documents from their organisations that may be relevant to the study but cannot be found in the above sources.

Documents gathered included:

- criteria for civil servants in librarianship

- government strategies, policies and objectives for the development of university libraries 
- strategies, policies and development plans of sample libraries

- staff competencies, promotion policies and CE for staff of sample libraries

- meeting and annual reports, seminar documents and training reports of sample libraries.

The unpublished documents of libraries provided the researcher with some evidence about library policies, CE activities and learning needs. However, it was very difficult to gather documents from sample libraries. Only five library managers provided such documents and these only with the proviso that the researcher not cite or quote from them in this thesis.

Two published government documents were found to be relevant to identify required learning needs of organisations for library practitioners. They are (1) Decision No 428/TCCP-VC on Professional Criteria for Civil Servant Ranks in Culture and Information Fields (Committee of Governmental Organisation and Personnel, 1993), (2) Decision No 10/2007/QD-BVHTT on Approval of Vietnam's Master Library Development Plan Until 2010 and Vision to 2020 (Ministry of Culture and Information, 2007).

Although the first document was issued 14 years ago and is not exclusively for university library practitioners, it is the most recent government document identifying the required knowledge for all ranks of civil servants working in the library field. This document guides the contents of civil servant examinations in librarianship. As the university libraries examined in this study all are government institutions, so practitioners must pass a civil servant examination to become official civil servants. Therefore, this document is relevant for the purpose of this study in regard to identifying the learning needs of library managers and operational staff from the organisational perspective. 
The second document is the government's development plan for all Vietnamese libraries. It states objectives for each kind of library, including university libraries. This plan has been discussed and disseminated among Vietnamese libraries since 2004 (Ministry of Culture and Information, 2004b) and was only formally promulgated in 2007. Although it does not directly states the required knowledge and skills for library practitioners, the expected elements can be drawn from each objective. For the purpose of this study, through its specific objectives for university libraries, the document provides evidence of the most current required knowledge and skills for university library practitioners from the organisational perspective.

Therefore, examining these two documents together provided a comprehensive understanding of the $\mathrm{CE}$ needs for practitioners from an organisational perspective.

\subsubsection{Phase Three: Data analysis}

In this study Phase One was based on the literature review and completed at the same time as the preparation of the proposal for this research. Phase Two involved the data collection. All data obtained in Phase Two were analysed in Phase Three. The following section discusses the analysis procedures for all data obtained in this study.

\subsubsection{Data analysis procedures}

Before conducting the data analysis, the researcher followed the suggestions of Bryman (2004) in transcribing the interviews, and organising and becoming familiar with the data. The recordings of the individual and focus group interviews were transcribed as soon as possible after the interviews. After gathering and reviewing, the relevant documents were selected for analysis. Subsequently, pseudonyms were created for the libraries and codes for the interviewees. Identifiable material was removed from the transcripts. The next step was the process of familiarisation, which involved the researcher listening to the recording, reading and re-reading the data and making memos before formal analysis could start. 
The data analysis procedure largely followed Miles and Huberman's (1994) interactive model. This was used because of its clear process which includes three linked subprocesses: data reduction, data display and conclusion drawing/verification. Each component of the framework was adapted in this study as follows.

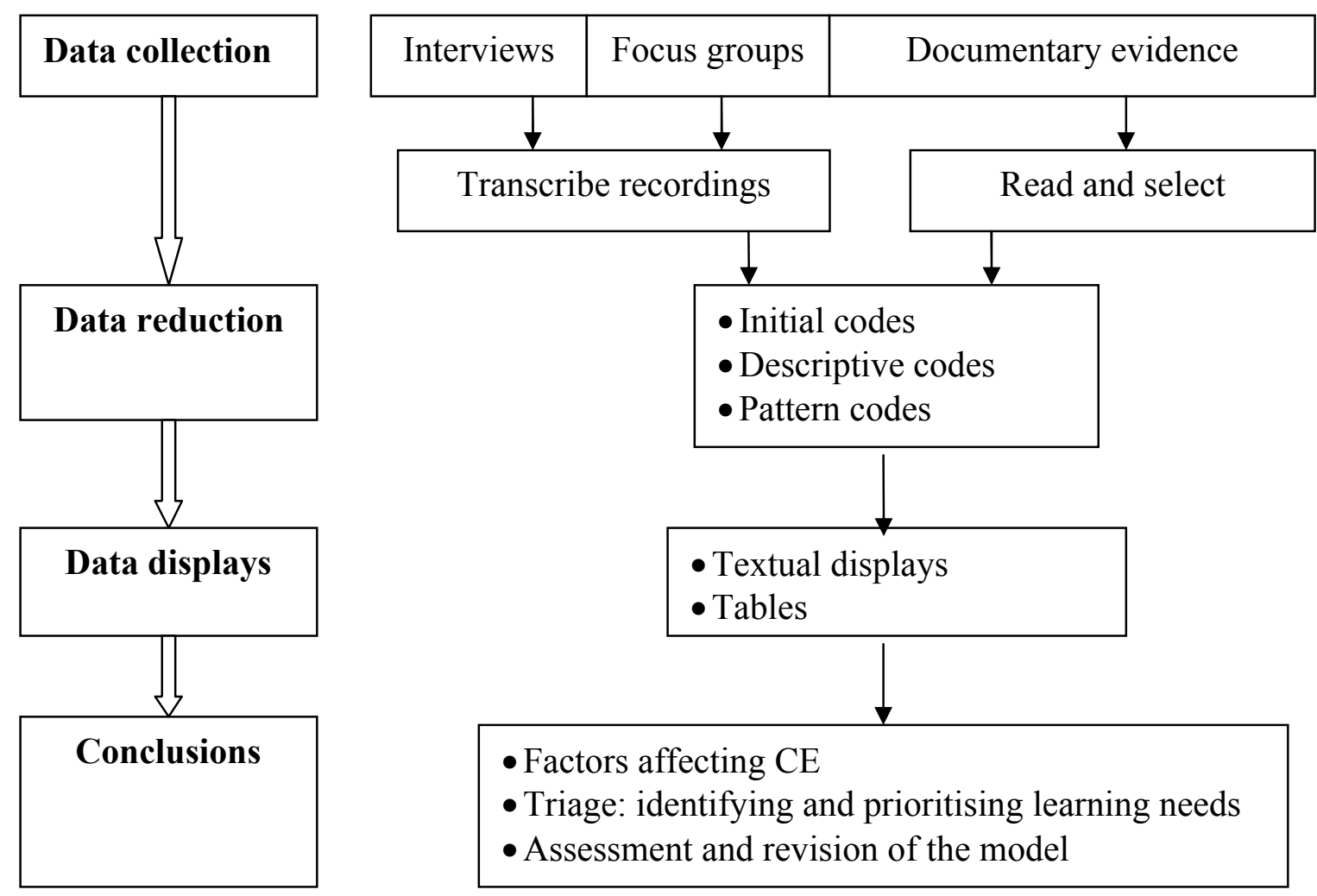

Figure 3.2: Data analysis procedures of the study

\subsubsection{Data reduction}

\section{Interview data}

Following the model of Miles and Huberman (1994), together with recommendations from Auerbach and Silverstein (2003), the researcher created a framework for data reduction. The framework consisted of six steps that are discussed below and summarised in Table 3.3. There are software packages available that specialise in data 
analysis; however, such software is not available in the Vietnamese language. The researcher of this study only used Microsoft Word to assist the process of data reduction.

\section{Step 1: List explicit research concerns}

To guide the selection of relevant data and create codes, the researcher reviewed the research questions and the preliminary model to create a list of research concerns (initial codes). They included the suggested factors affecting $\mathrm{CE}$ and their specific components (see Figure 2.5). In addition, the learning areas of library practitioners also were research concerns.

Step 2: Select relevant text to formulate ideas

To cut down the mass of raw text from the transcripts into a manageable proportion, the researcher followed this process:

- Reading each transcript.

- Highlighting text that expresses a distinct idea related to research concerns, using the highlight feature of Microsoft Word, with specific colours to highlight text related to different research concerns. For example, blue was used to highlight all ideas related to changes in cataloguing tasks.

- Generalising the relevant text into short phrases to formulate ideas (descriptive codes). For example, the phase "changes in cataloguing" was used as the descriptive code for any text concerning changes or new applications in classification and descriptive cataloguing.

During this step, the researcher took notes to record why a particular selected text was important, and capture thoughts or ideas stimulated by the text. The notes mainly focused on the relationships between the interviewees and their ideas. More specifically, to understand the factors affecting $\mathrm{CE}$, the researcher made notes on the respondents' gender, educational background, position, areas of work and their library infrastructure. To understand their learning needs, the researcher made notes about the respondents' responsibilities and tasks at work, their university type and library infrastructure. By 
doing so, the researcher could gain an integrated understanding of the effects of a particular factor on the $\mathrm{CE}$ of practitioners in their context. Similarly, the researcher could understand the importance of a particular learning area to practitioners in relation to their situations.

Step 3: Group ideas into coherent categories

Within each transcript, the researcher collated ideas that expressed a common theme into categories (pattern codes). Similar to the previous step, to name the categories the researcher used short phrases to capture the essence of the group of ideas. For example, "changes in the profession" was used as the pattern code for all ideas expressing changes or new applications in library work including information formats, storage and retrieval of information, clients' demands, and IT application and so on. The result of this step was a list of categories.

It should be noted that during this step, some ideas were merged or divided. When an idea was too broad, it was broken up. When too narrow, it was merged with another. When an idea was solitary, it was discarded or the data reviewed again to find additional supporting text, or it was noted that only one person had that particular idea.

Step 4: Organise categories into more theoretical concepts

This step moved the analysis from description to a theoretical level. The researcher combined categories and ideas from all transcripts, and then grouped related categories to formulate concepts. Correlating categories with the factors suggested in the preliminary model and related literature helped the researcher to create theoretical concepts. For example, all categories concerning the characteristics of the LIM profession in the Vietnamese context that affect $\mathrm{CE}$ and the learning needs of library practitioners were grouped together. These categories included job requirements, changes in the profession, and features of current professional education and professional leadership. The grouping of these categories allowed the researcher to 
formulate the theoretical concept that professional factors have a significant impact on the $\mathrm{CE}$ and learning needs of university library practitioners in Vietnam.

The researcher also took notes on relationships between categories and the factors suggested in the preliminary model. By doing so, the researcher was able to identify similarities and differences between the findings in the data and the suggestions in the preliminary model. Combining ideas from all the transcripts also helped the researcher recognise the similarities and differences between the learning needs of practitioners across the sample libraries as well as those of operational staff and managers.

Step 5: Summarise ideas, categories and concepts

To summarise all the ideas, categories and theoretical concepts revealed from the data, the researcher reviewed all codes from analysed transcripts and revised as necessary. In this step, the researcher initially selected the "best" quotes for the data interpretation process. These were relevant texts which represented the perceptions of interviewees on particular ideas or which revealed important or interesting ideas.

Step 6: Create data mines

To store and enable retrieval of data for the interpretation process, two data mines were created: one from the manager interviews and another from the staff interviews. All relevant quotes from all transcripts were gathered and organised by ideas and categories. It should be noted that the quotes included supportive ideas as well as solitary ideas that may not endorse the findings. 


\begin{tabular}{|c|c|c|c|c|}
\hline Steps & Why & How & Results & Simultaneous work \\
\hline $\begin{array}{l}\text { 1. List } \\
\text { explicit } \\
\text { research } \\
\text { concerns }\end{array}$ & $\begin{array}{l}\text { To guide } \\
\text { selection of } \\
\text { relevant data and } \\
\text { create codes }\end{array}$ & $\begin{array}{l}\text { Review the research questions and preliminary } \\
\text { model to create a list of research concerns }\end{array}$ & $\begin{array}{l}\text { A list of } \\
\text { research } \\
\text { concerns } \\
\text { (initial codes) }\end{array}$ & \\
\hline $\begin{array}{l}\text { 2. Select } \\
\text { relevant text } \\
\text { to formulate } \\
\text { ideas }\end{array}$ & $\begin{array}{l}\text { To cut down the } \\
\text { mass of raw text } \\
\text { to a manageable } \\
\text { proportion }\end{array}$ & $\begin{array}{l}\text { - Read the transcript } \\
\text { - Highlight text that expresses a distinct idea } \\
\text { related to research concerns } \\
\text { - Generalise the relevant text in short phases to } \\
\text { formulate ideas }\end{array}$ & $\begin{array}{l}\text { A list of ideas } \\
\text { (descriptive } \\
\text { codes) }\end{array}$ & $\begin{array}{l}\text { - Take memos to record why particular } \\
\text { selected text is important, and thoughts } \\
\text { or ideas stimulate by the text } \\
\text { - Take notes on the relationships between } \\
\text { selected text, interviewees and research } \\
\text { concerns }\end{array}$ \\
\hline $\begin{array}{l}\text { 3. Group } \\
\text { ideas into } \\
\text { coherent } \\
\text { categories }\end{array}$ & $\begin{array}{l}\text { To formulate } \\
\text { categories }\end{array}$ & $\begin{array}{l}\text { - Within each transcript, group ideas that } \\
\text { express a common theme into categories } \\
\text { - Name categories using a short phrase that } \\
\text { capture the essence of the group of ideas }\end{array}$ & $\begin{array}{l}\text { A list of } \\
\text { categories } \\
\text { (pattern codes) }\end{array}$ & $\begin{array}{l}\text { - Take notes on relationships between } \\
\text { ideas, categories and factors in the } \\
\text { preliminary model } \\
\text { - Revise and change ideas if needed } \\
\text { Idea too broad: break up } \\
\text { Idea too narrow: merge with other } \\
\text { Solitary idea: discard or try to find text that } \\
\text { confirms solitary idea }\end{array}$ \\
\hline $\begin{array}{l}\text { 4. Organise } \\
\text { categories } \\
\text { into the } \\
\text { concepts }\end{array}$ & $\begin{array}{l}\text { To move the } \\
\text { analysis from } \\
\text { description to a } \\
\text { theoretical level }\end{array}$ & $\begin{array}{l}\text { - Combine categories and their ideas from all } \\
\text { transcripts } \\
\text { - Group related categories to formulate } \\
\text { theoretical concepts }\end{array}$ & $\begin{array}{l}\text { Theoretical } \\
\text { concepts }\end{array}$ & $\begin{array}{l}\text { Correlate categories with factors } \\
\text { suggested in the preliminary model }\end{array}$ \\
\hline $\begin{array}{l}\text { 5. Summarise } \\
\text { ideas, } \\
\text { categories } \\
\text { and concepts }\end{array}$ & $\begin{array}{l}\text { To summarise } \\
\text { ideas, categories } \\
\text { and abstract } \\
\text { concepts }\end{array}$ & $\begin{array}{l}\text { - Review and revise all codes } \\
\text { - Create two checklist matrixes on ideas and } \\
\text { categories from transcripts: one from manager } \\
\text { interviews and another from staff interviews }\end{array}$ & Two checklists & $\begin{array}{l}\text { - Identify similarities and differences } \\
\text { between manager and staff perspectives } \\
\text { - Selecting "best" quotes for the } \\
\text { interpretation process }\end{array}$ \\
\hline $\begin{array}{l}\text { 6. Create } \\
\text { data mines }\end{array}$ & $\begin{array}{l}\text { To store and } \\
\text { enable retrieval } \\
\text { of data for } \\
\text { interpretation } \\
\text { process }\end{array}$ & $\begin{array}{l}\text { - Create two data mines from transcripts: one of } \\
\text { manager interviews and another of staff } \\
\text { interviews }\end{array}$ & $\begin{array}{l}\text { Two data } \\
\text { mines }\end{array}$ & $\begin{array}{l}\text { - Gather all relevant quotes including } \\
\text { quotes used as evidence to support the } \\
\text { findings as well as solitary quotes that } \\
\text { may not support the findings. Organise } \\
\text { by idea and category. }\end{array}$ \\
\hline
\end{tabular}

Table 3.3: Framework of data reduction 


\section{Documentary evidence}

As shown in Part C of Section 3.3.3.3 which discussed the collection of documentary evidence, two government documents were selected to analyse the learning needs for library practitioners from the organisational perspective. Three steps for documentary reduction are discussed here; however, steps to conduct the triage are discussed simultaneously with the triage process in Chapter 7.

Step 1: Read the documents

The researcher read the documents carefully in their original language (Vietnamese) to understand the professional criteria for librarians stated in the first document and the current and future development objectives for university libraries stated in the second document.

Step 2: Identify learning needs

Based on each criterion in the first document and each objective in the second document, the researcher identified the learning areas needed for practitioners to achieve these goals.

Step 3: Translate the results into English

Following the translation strategies discussed in Section 3.4.3, the researcher translated the professional criteria and objectives and the learning needs identified from these criteria and objectives into English.

\subsubsection{Data display}

There are many methods to organise, compress and assemble information, including text, charts, diagrams and graphics to help the researcher to draw conclusions. Effective data display can help the researcher avoid the extended text that can result from large amounts of data during the analysis stages.

For this study, a textual display method was employed to analyse and interpret the ways and reasons that different factors affect CE for university library practitioners in Vietnam. In addition, tables also were used when needed. 


\subsubsection{Conclusion drawing and verification}

The reasons for reducing and displaying data are to assist the researcher in making conclusions. The process seems to be sequential but in fact these processes occur concurrently (Miles \& Huberman, 1994). Following the recommendations of Miles and Huberman (1994), the researcher displayed the data in the order of perceived factors affecting $\mathrm{CE}$ rather than by kinds of participant, that is managers and then staff. This assisted the researcher to focus on each factor, thereby directly achieving the research objectives of identifying and understanding the factors affecting CE.

Conclusions can be noted at the early stages of analysis but they may be vague and incomplete (Punch, 2005). Therefore, the researcher kept an open mind until the conclusions became explicit and were verified. To determine and understand factors affecting $\mathrm{CE}$, the researcher not only based interpretation on the interview data related to factors affecting $\mathrm{CE}$ but also on results of the triage process.

In verifying the findings, this study followed the strategies suggested by Creswell (2003), which are discussed in the next section.

\subsection{Issues related to the research}

\subsubsection{Validity}

Validity is one of the basic principles of social research (Sarantakos, 1998). Validity means the ability to produce findings that are in agreement with theoretical or conceptual values - in other words, to produce accurate results and measure what is supposed to be measured. There are different aspects, including measurement validity, internal validity, external validity and ecological validity (Bryman, 2004). However, validity is usually taken to refer only to measurement validity, also known as construct validity, which deals with whether a measure used in a study really reflects the concept that is supposed to be represented (Bryman, 2004; Sarantakos, 1998). There are several strategies to tackle the issues of validity including triangulation, member checking and clarification of bias (Creswell, 2003). In this study triangulation was used. 
Triangulation strengthens a study by using different data sources of information to build a coherent justification for themes (Creswell, 2003). In this study, the data were collected through individual interviews and focus group interviews with a range of participants in a variety of university libraries. The interviewees included managers, supervisors, senior staff and line staff in different areas of professional practice. In addition, data were collected from the documents of different organisations and different organisational levels (libraries, universities, ministries and the central government). The different data sources led to an enrichment of understanding, by offering several perspectives on the same issue. At the same time, they allowed the researcher to check the reliability and consistency of perceptions among interviewees. The researcher found that the individual interviewees and discussions from different focus groups were generally consistent with each other.

\subsubsection{Reliability}

Reliability is concerned with whether the findings of the study are replicable (Bryman, 2004). A method is reliable if it produces the same results whenever it is repeated, even by other researchers. Reliability is also characterised by precision and objectivity (Babbie, 2001; Sarantakos, 1998).

To increase reliability, the researcher of this study followed the research sample frameworks to ensure the sample was representative. The researcher used protocols to enhance the consistency and compatibility of procedures and targets in each interview. Replication of the study is expected to be achievable in all public university libraries in Vietnam.

\subsubsection{Language}

Since the data were collected in Vietnamese but the study is presented in English, it led to the issue of meaning equivalence in the translation process. Translation is the transfer of meaning from a source language to a target language. The translator is an interpreter who processes the vocabulary and grammatical structure of the words 
while considering the individual situation and the overall cultural context (Esposito, 2001; Lim \& Firkola, 2000).

According to Rossman and Raills (2003) and Robinson-Pant (2005), students whose first language is the source language of their studies are the best translators of their data into English. Based on the experiences of several authors, Esposito (2001) recommends the following procedure to minimise errors: developing an original transcript, translating it into the target language, checking the translated version for grammatical errors and whether it can be understood by monolingual native speakers, and back-translating this version to the original.

Based on the recommendations of the above authors, the researcher in this study applied the following translation strategy. Firstly, the researcher analysed the data in Vietnamese to elicit information. After identifying the common and main issues, and developing ideas and categories, the researcher translated these results into English to enable consultation with her English-speaking supervisors. The parts of the transcriptions and the documentary evidence that needed to be quoted in the writing process were completely translated into English. To further confirm the meaning of the translations, the researcher used the services of a professional bilingual translator. The researcher worked with the translator to check the English translation version with respect to vocabulary, idioms, grammar and syntax.

\subsubsection{Ethics}

The study met the strict criteria of the VUW Human Ethics Committee, whose approval must be sought before any University research involving human participants can be carried out. Criteria included an information sheet that had to be provided to interviewees and a consent form which was signed by participants before they engaged in the research. It should be noted that, in the focus group situation, an agreement of confidentiality among group members was stated in the consent form that every participant signed. The privacy and confidentiality of participants have been maintained in the final publication of the study and will be maintained in any subsequent publications or conference presentations. 


\section{CHAPTER 4: DEMOGRAPHIC INFORMATION}

Before interpreting participants' perceptions of the learning needs and factors affecting the $\mathrm{CE}$ of Vietnamese university library practitioners, it is necessary to provide information about the participants and the environment in which they live and work. This information will set the stage for understanding how the participants perceive the issues.

The first part of this chapter introduces the organisations in which the participants work - the participating university libraries - in terms of background, organisational structure and staff. Since information about the society in which the practitioners live is introduced in Section 1.2, it is not repeated here. The second part describes the participants - the library managers, senior staff, supervisors and line staff.

The information presented in this chapter comes from the various documents of the participating libraries, the interviews and focus groups, and the notes taken during the data collection. Because of the need to maintain the confidentiality, specific data for each participating library cannot be given. Instead, broad information is provided to help set the context without allowing the identification of individual libraries.

\subsection{The participating university libraries}

As discussed in Section 3.3.2 which focused on the research samples, 10 Vietnamese university libraries participated in this study. Their pseudonyms and brief information about their geographical location, university disciplinary focus and number of staff have been already introduced in Table 3.1. These following sections provide some more information about the sample libraries.

\subsubsection{Background and infrastructure}

Eight of the libraries were established at the same time as their universities and began providing services around 40 years ago. Initially, many of them were a subordinate part of a university department, such as the Research Affairs Department or Office of Academic Studies. Their main function was to lend text books to 
students. From the early 1990s, all these libraries became separate units in their universities and initiated upgrading projects. The remaining two libraries were established around seven years ago.

Generally, all 10 libraries had a similar mission, to serve the study, teaching and research needs of their universities; and to meet the needs of their clients, who include undergraduate and graduate students, academic faculties and all staff of their universities. In addition, the libraries also served the outside scholarly community in some circumstances.

In terms of infrastructure, three libraries had new buildings with modern facilities. According to the participants who were library directors, the space and facilities of these libraries, such as security gates, reading spaces, computers, internet terminals and integrated library systems, are good enough to meet the needs of their clients. For example, one of these libraries had a fashionable new building with a total area of around $7,000 \mathrm{~m}^{2}$ (very large by Vietnamese standards) for about 20,000 fulltime and 20,000 part-time students.

Three other libraries had dedicated buildings with adequate facilities, when compared with other Vietnamese university libraries. One was large at $1,400 \mathrm{~m}^{2}$ with 500 seats and 135 computers for 30,000 students. However, the buildings of two of these libraries had become outdated.

The remaining four libraries had inadequate infrastructure in terms of both space and facilities. There were not enough places for their students, reading rooms were old and some rooms did not have sufficient lights. The work rooms for staff were narrow and distant from each other. As a result staff in these libraries had to spend more time on physical work. For example, to process books they had to carry the books from the acquisitions room to the cataloguing room and then to the store or reading rooms. However, two of these libraries had development projects in progress. In the next two years they will each have a new building and modern facilities. 
Nine libraries had OPAC, LAN and internet access. However, internet availability and speed were limited in most libraries. For example, according to participants from Hong Ha, each staff member could only gain free access to the internet for 15 hours per month for their non-work needs, including research and learning. One library did not have internet access at all.

LIBOL was the integrated library system used in four libraries and VeBrary was used in two others. Three libraries used other systems and one library had no management system.

In discussing organisational factors, participants emphasised the features of background and infrastructure as an influence on the $\mathrm{CE}$ and learning needs of practitioners. These will be discussed in Section 6.3.2.

\subsubsection{Staff}

Of the 10 participating libraries, three had a small number of staff (less than 25), four had a medium sized staff (from 25 to 40 ) and the remaining three had a large number (more than 40).

Brief demographic information on the staff of the participating libraries was included in the lists of staff provided by the library directors. This provided a statistical overview of the academic qualifications of staff in these libraries, which revealed that practitioners holding a doctoral degree were very rare - just three; and only about $6 \%$ had a Master's degree. However, the majority of staff (about $68 \%$ ) had a bachelor's degree.

It should be noted that the educational background of practitioners differed across libraries. In some, such as Ben Thanh and Hoan Kiem, most staff had academic education in LIM while in others, such as Thanh Da, Hoa Sua and Hai Van, the majority of staff only had academic degrees in other disciplines. 


\subsubsection{Library organisational structure}

As discussed in Section 1.2.3, all Vietnamese universities are governed by MOET. However, some universities are under the administration of two governing organisations - MOET and another functional ministry, or VNU-HN or VNUHCMC. Of the 10 participating universities, four libraries had two governing organisations. Therefore, in some circumstances these libraries were funded and administered by both organisations. Figure 4.1 is an illustration of university library organisational structure.

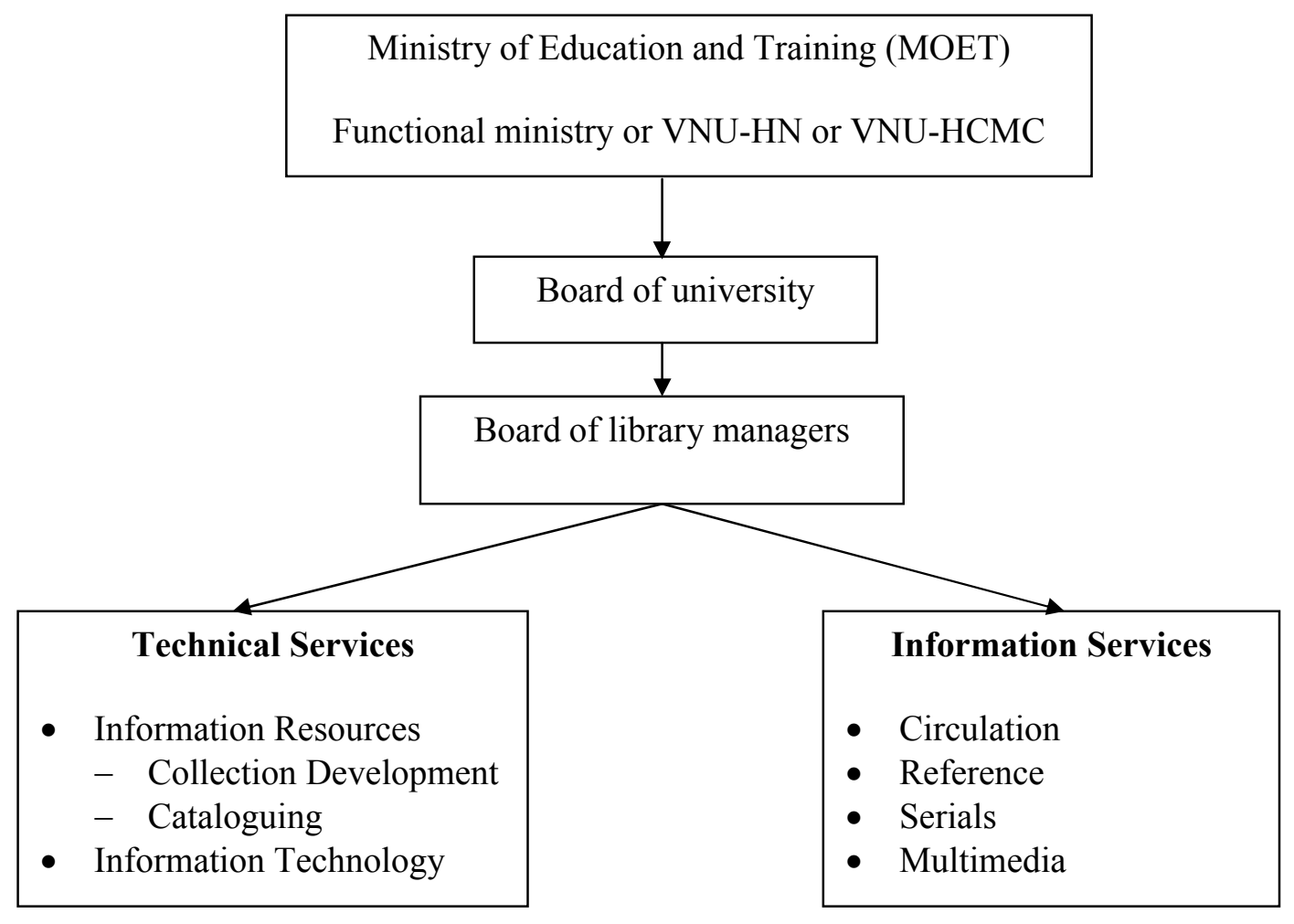

Figure 4.1: Organisational structure of participating libraries

The direct governing organisation of a library is the university. This means the universities control the finances of libraries and make decisions concerning the facilities or infrastructure of the libraries. Virtually all library activities need approval from the governing university. These include hiring, promoting and paying staff, and in some circumstances staff education. However, three of the libraries were 
relatively independent units in their universities. The directors of these libraries had authority for funding and staff policies.

Library development strategies and annual activities are based on those of the parent university and functional ministries. Consequently, as participating library managers recognised, all governing organisations affect the $\mathrm{CE}$ and learning needs of their practitioners. Since the available funding and funding priorities differed among the universities, the infrastructure of the libraries varied. This may cause differences in the learning needs of practitioners across libraries.

Most libraries had the following operational sections: Collection Development, Cataloguing, Information Technology (IT), Circulation, Reference, Serials and Multimedia. These were usually grouped into two main departments - Technical Services and Information Services. Staff in the Technical Services department were responsible for collection development, cataloguing materials and operating the automatic systems of the libraries. However, in Hoa Sua, Hai Van and Hoan Kiem, IT was a separate department. These libraries also had a separate administration department. Some libraries, such as Ho Guom and Tan Binh, did not have a separate reference unit. Six of the libraries had a main library and one or more branches (usually just one).

In terms of the organisational structure of the libraries, there were two prominent features that should be noted in regard to CE. First, the libraries had to follow the administration of their parent universities as well as MOET. Therefore, the policies relating to staff education and training, as well as the appointment and promotion of staff in these institutions, influence the learning pursuits of the library practitioners. Second, in all libraries, the Board of Managers set the library activities. All members were required to follow the decisions of the Board. According to Nguyen (2005), this is the centralisation attribute of the organisational structure of Vietnamese university libraries. Change rarely happens in this centralised system; however, it helps stabilise library processes. Accordingly, the role of managers, especially library directors, is extremely important in all library activities. In discussing the effects of 
organisational characteristics on $\mathrm{CE}$ and learning needs, participants emphasised the significance of the role of managers. These points will be discussed in Section 6.4.

\subsection{Participants}

To understand the data, demographic information about the participants is important. In total, 92 university library practitioners participated in this study. Ten individual interviews were conducted with library managers, seven focus group interviews with supervisors and senior staff, seven focus group interviews with line staff and three focus group interviews with a mix of staff (supervisors, senior and line staff). Each focus group interview involved five staff, except three groups that had only four participants because the fifth was unable to attend at the last minute. On average, each focus group had one male participant. Half of the managers were male. Brief information about participants has been already introduced in Table 3.2, and the following sections provide more details.

\subsubsection{Library managers}

Nine of the participating managers were directors of their libraries and one was a vice director. These managers were responsible for all library activities. In particular they were in charge of development strategies for the libraries, financial issues, human resources and education for staff. In terms of professional issues, such as the adjustment or application of professional knowledge in the libraries, most of these managers played an important role as chairperson of their library's academic committee.

These managers played a significant part in the study. Without their permission, none of the interviews could have taken place. Fortunately, they were all supportive in letting their staff join the study and they themselves gave considerable time for the interviews. All of them were quite comfortable expressing their opinions on factors affecting their own and their staff's CE. 
Most of them were in their late forties or early fifties and had about 15 years' experience in LIM, except two of the directors. These two had many years of experience in management positions, but had only started in the library area some six to eight years ago. It should be noted that, of the interviewed managers, seven also participated in teaching as university lecturers or guest lecturers.

Three managers held a doctorate. Five directors had a Master's degree, three of them in LIM. The remaining two managers held Bachelor's degrees in a field unrelated to LIM. All were senior civil servants - a formal rank for employees in government organisations in Vietnam. Ranks of civil servants are discussed in detail in Section 6.1.1 and 7.1.1.

\subsubsection{Supervisors and senior staff}

Thirty-nine supervisors and senior staff members participated in this study. The supervisors were in charge of professional issues and responsible for instructing and assessing the line staff in their sections. The senior staff members were key persons with many years of experience in the job. Of all the supervisors and senior staff, 10 were in charge of IT, seven in charge of cataloguing, 12 in charge of information services, and 10 in charge of both collection development and cataloguing.

Of the supervisors and senior staff, nine held a Master's degree in LIM and three held a Master's degree in another discipline. Fifteen held a Bachelor's in LIM and 12 in another subject. In terms of age and years of experience, most participants from Hong Ha, Ho Guom, Dam Sen and Tan Binh were in middle aged (late forties) and had about 15 years' experience in libraries. In Hoan Kiem, Ho Tay and Ben Thanh most participants were young (in their thirties) and had from 6 to 10 years in library services. In Hoa Sua and Hai Van half of the participants were young and the other half were middle aged. In most of the libraries, the supervisors and senior staff were officially civil servants - another formal rank for employees in government organisations. Only in Hong Ha were the supervisors senior civil servants. 


\subsubsection{Line staff}

Forty-two line staff took part in the focus group interviews. With the exception of two, all held a Bachelor's degree and one a Master's degree. Of the 39 Bachelor's degrees, 17 were in LIM. None of line staff was a senior civil servant, some were civil servants, but many had not taken the civil servant examinations.

As per the sample framework presented in Section 3.3.2, line staff were practitioners working in different areas of LIM. Most of them were in their late twenties or early thirties and had from three to six years experience working in libraries, except for six who were in their forties and had about 10 years' experience. Eight line staff had tasks relating to IT, 14 worked in cataloguing and the rest worked at circulation desks or in reading rooms.

The preceding information summarised in Table 3.2 shows that a large number of participants lacked professional qualifications in LIM. Managers holding a doctoral degree were very rare (and only one has a doctorate in library science). Only a few practitioners among supervisors, senior and line staff had a Master's degree. The lack of professional degrees impacts on the learning needs of practitioners as well as their desire to attain a higher education qualification. This point is examined in the next chapter.

Official demographic statistics on practitioners in Vietnamese university libraries in general are not available. However, based on the observations of the researcher and the demographic information provided by the lists of staff of participating libraries, the groups of participants seem representative.

Together with the background information on library and information development in Vietnam presented in Section 1.2, the demographic information provided here places the study into context and will assist in understanding the data. The next three chapters are devoted to the interpretation of the perceptions of participants about the factors affecting their $\mathrm{CE}$ and their learning needs, as well as examining the relevant documents. 


\section{CHAPTER 5: SOCIAL, PROFESSIONAL AND INDIVIDUAL PRACTITIONER FACTORS}

The aim of this study is to develop a contextual model for planning continuing education (CE) programmes for university library practitioners in Vietnam. To accomplish this aim, one of the objectives is to determine and understand the contextual factors affecting the $\mathrm{CE}$ of these practitioners, based on the perceptions of the participants together with analysis of documentary evidence. This chapter and the next one achieve this objective. Based on the interview data, they address the first two research questions and provide a base for assessing and revising the preliminary model.

RQ1. What are the contextual factors that affect CE for Vietnamese university library managers and operational staff?

RQ2. How do these factors affect CE for Vietnamese university library managers and operational staff?

Five main factors affecting the $\mathrm{CE}$ of library practitioners were identified from the data:

- social factors

- professional factors

- individual practitioner factors

- organisational factors

- practitioner and organisation nexus.

Because of the large amount of data, the first three factors are examined in this chapter and the remaining factors in Chapter 6. Steps for data analysis were already discussed in Section 3.3.4. For each factor, the managers' perceptions are examined first, followed by the perceptions of operational staff. In some cases, these perceptions are analysed simultaneously. To maintain the confidentiality of participants, pseudonyms were created for the libraries (see Table 3.1) and a code was also assigned to each interviewee. Each code includes two parts separated by a 
hyphen. The first part is the initials of an interviewee's library pseudonym. The second part is the job position of an interviewee - "staff" stands for a line staff member, "super" for a supervisor or senior staff member, and "manager" for a library manager. For focus group participants, a number follows the job position to differentiate between practitioners, for example, "HH-staff2" is the code of the second of participating line staff members in Hong Ha.

\subsection{Social factors}

Consistent with the opinions of many writers in adult education and CE (e.g., Houle, 1980, 1996; Jarvis, 2006; Merriam et al., 2007), analysis of the data in this study reveals that features of the social environment are factors affecting the $\mathrm{CE}$ of individuals. The participants mentioned different aspects and used different examples to illustrate the social influence on the $\mathrm{CE}$ of university library practitioners in Vietnam. Their opinions mostly focused on the effects of society's perceptions of women's roles in society, library work and learning.

\subsubsection{Society's perceptions of women's role}

The majority of participants, including managers and operational staff, perceived that, in Vietnamese society, women's primary obligation is to take care of their family and household. The value of women is measured by how well they handle their family life. As a result, $\mathrm{CE}$ is not considered a priority for female practitioners. As a male manager noted:

The majority of our staff are women. After working hours they have to hurry back home to take care of their husbands and children.... They are not persistent in updating because they have more important things to do. This is serving their husbands and children. (HH-manager)

Both male and female managers appeared to empathise with female staff who have to give up or delay their learning because of family obligations. This empathy reflects the respect with which the traditional role of women is held. In particular, the female managers cited that it is impossible to request that female staff keep learning when they are breastfeeding and bringing up young babies. The manager's comment below 
is typical. It not only reflects her empathy for the heavy responsibilities of women, but also her belief in Vietnamese society's traditional perceptions of women. She said:

Women have to take responsibility for caring for the family, giving birth and bringing up children. Therefore, it is understandable that their first choice is family instead of a professional career. (BT-manager)

Another manager was even tolerant of female staff when they seemed distracted at work and seemed to neglect CE. She also thought that the most important thing for women is family. She reported:

My staff never join CE courses that are held on weekends or evenings. They only want to give that time to their families. You know, sometimes during work hours they ask me to let them go to pick their children up from school. I can't say no because I understand they have to do it. (TBmanager)

The female managers also admitted that such perceptions had an effect on their own CE. They noted that, being women, they could never ignore their family obligations, even though they held important positions in their institutions and were busy with their jobs. Some of them said that they would rather miss opportunities to get a higher academic degree than neglect their family commitments. As one manager said:

...two years for a Master's programme and then three years for a $\mathrm{PhD}$ programme. As a woman, I couldn't neglect family duties and spend such a huge amount of time studying. After completing my Master's programme, my university offered me a doctoral scholarship, but at that time I couldn't arrange my family duties. (HS-manager)

As revealed in the discussions above, society's preconceptions of women's role are a constraint on the CE female practitioners. The managers in Hoa Sua and Tan Binh used the terms "obstacle" and "hinder" to express this constraint.

The effects of society's perceptions of women's role were discussed more in the focus group interviews with operational staff. Regardless of gender, age and position, 
most staff mentioned that society's expectations determine the self-perceptions of female practitioners and shape their needs and wants. Most of the married female participants shared this idea: "This is our social constraint. However, as women, we are happy to accept these duties" (HV-staff3). One female supervisor emphasised:

We are talking about men and women as equal, but actually, it shouldn't be that everything can be equal. Women have to care for children, men never do this job. (TB-super1)

Most of the female middle-aged married staff across the libraries mentioned that, in their families, the husbands took responsibility for family finances and they, as wives, took responsibility for caring for the children and housework. As a senior staff member commented:

Half of the women staff at our age [late forties] work here because we just need a job to do. Our husbands take care of the family finances. They let us do this job because library work used to be simple and light, therefore we could have time to take care of housework. (DS-super4)

Similar to female managers, female staff would rather miss CE opportunities or give up their learning pursuits than neglect family obligations. One staff member said:

I had a scholarship from RMIT [Royal Melbourne Institute of Technology] for an advanced English programme in Hanoi two years ago. However, I could not leave my family at that time. I really regretted losing this chance, but I had no choice. (TB-staff3)

Similar ideas were echoed by many of the younger staff: "I am happy to become a mother" (HV-staff3); "I need my family more than anything else" (BT-super4) and "The happiness of a woman is in the family" (DS-staff4).

The preceding data show that female staff recognised family obligations as a disadvantage in engaging in $\mathrm{CE}$ and succeeding in their professional careers. But for the most part they seemed happy with their obligations and wanted to hold on to them. They seemed to accept this disadvantage as natural and believed that it is an acceptable reason for them not to pursue learning. Accordingly, it could be seen that 
Vietnamese society's perceptions of women discourage female practitioners from CE desires.

However, analysis of the data also reveals that participants recognised changes in societal perceptions of women caused by the process of rapid development in Vietnam. Participants had different views on the changes. Some considered that society currently encourages women to pursue higher education and higher positions, but that the influences of the traditional constraints on women still prevail in Vietnamese society. As a result, women tend to obtain a certain level of education to ensure a stable job, but pursuing $\mathrm{CE}$ to strengthen or further their professional careers is not their priority. For example, one staff member noted:

I remember that about 10 years ago when I had just entered university, my relatives thought, "Why does a girl need higher education?" Now people accept the fact that more and more girls enter university to get a degree to help with getting a job. However, becoming successful in a career is still not what society expects from a woman. (BT-staff2)

Others had a different opinion. They considered the development process offers motivation for women to demonstrate ability, not only in the family, but also in their institutions and society. Female practitioners retain their domestic duties, but also try to take opportunities to be successful in their careers. As a younger supervisor said:

Everyone has her own family obligations, but we should somehow overcome our problems. Otherwise we never get a chance to study and therefore will fall behind. (BT-super3)

Analysis of the data suggests that society's perceptions of women affect the meanings that women assign to their lives. For most of them, family is the first priority before success in professional careers. However, new values, beliefs and expectations are arising due to the development process in the country. There seems to be a gradual acceptance in society of the new role of women - as an individual in the community. Hence, the development process can become an enabler for female practitioners' CE. 
The participants' perceptions of the effects of gender and family commitments on CE will be discussed further in Section 5.3 where individual practitioner factors are examined.

\subsubsection{Society's views of library work}

Society's views of library jobs emerged as another social influence on CE. Many participants emphasised the public's low regard for librarianship has a negative effect on their $\mathrm{CE}$. On the other hand, some considered this a catalyst for their learning. Some also referred to current changes of LIM status and their responsibility to contribute to these changes, which in turn motivates their CE.

As mentioned in Section 1.2.2, university library activities have significantly improved in recent years and libraries have become an important part of universities in assisting teaching and learning. However, the data revealed that a wide range of people continue to have a low regard for library work and library practitioners.

In the view of some manager participants, the low quality of "staff inputs" is evidence of the low regard for librarianship. By "staff inputs" they meant the quality of students admitted to LIM educational programmes and the staff recruited. The managers in several libraries remarked that no outstanding students had ever chosen a LIM major so far. They gave evidence that the marks from the university entrance examinations of students admitted to LIM programmes were low in comparison with many other programmes. This comment was typical:

Students are fighting to enter schools of business administration or international studies, but library school is the last option when they have no other choice.... They don't understand that libraries will greatly help the development of our society.... LIM students don't even like to work in libraries after graduation. (TD-manager)

The managers in some libraries also remarked that universities lack a staff recruitment strategy for their libraries. They did not consider LIM professional degrees or LIM competencies as requirements for candidates. This lack of concern 
about library practitioner quality reflects the low regard for library work. As a manager said:

The government doesn't set a rule that requires library staff to have a LIM qualification. This fact itself reflects the indifference of our society to library work. (HK-manager)

Similarly, to illustrate the low expectations when employing staff in university libraries, another manager stated, "Most people working in libraries aren't brilliant." He continued:

People who have a degree in another discipline and now work in libraries do that just because they need a job in the city. Actually, those people are usually not proficient in their original background. (HH-manager)

Operational staff saw the low image of librarianship among their friends, people in their institutions and society as a whole as evidence of the low status of library work. Among operational staff, senior staff across the sample libraries appeared to be the most discontented with the public's view of their profession. Their long library service meant they had experience from the days when libraries had an even lower image. Many senior staff members described a historical context when a library was considered a place for those who were "incompetent", had "weak ability" or had "no other choice". For a long period people thought that librarians did not need to have professional training and special competencies or to update their knowledge. A senior supervisor with about 20 years in the profession said:

People considered our library a university dust bin where there were all types of rubbish of society. The library was a shelter for people who were reduced to a lower rank as a punishment, for people who just needed a job in the city or for people who didn't have any professional degree. Some people still think it is not necessary to have professional library training. Working there is just about reading books for free. (HV-super1)

Although university libraries are no longer considered "a university dust bin" and being a librarian as a form of punishment no longer reflects current practice, the low regard for library work and library practitioners remains. The younger practitioners 
recognised a low image of the LIM profession among their friends: "My friends who were studying other majors looked at me with disgusted eyes" (BT-staff3) or "My friends told me that 'in the next coming years, you will be an old and strict lady with thick glasses yelling at students all the time"” (HK-staff5).

The participants also considered library practitioners were held in low regard by academics and by universities as a whole. A staff member reported:

Right in this university, lecturers look down on library practitioners. They ask me where I am working, and I say, "At the library." They then say, "What the hell are you doing there? There is nothing to do there." They have no respect for our jobs. (HK-staff1)

As another example, supervisors and senior staff members in Tan Binh agreed with this comment:

The library role is neglected in our university.... If the university leaders and faculty members can recognise the importance of the library... if they can set specific rules that require us to reach certain standards and fulfil our responsibilities, we will find our role in the university and strive for improvement. The current situation now doesn't give us an opportunity to be assessed so we are in such a gloomy position. (TB-super4)

The old image of a library with librarians who do not need any special competencies still remains in the public mind and even among academics. As one participant commented, this image is "an ingrained view of our profession" (HK-staff5). As a result, this view has demoralised library practitioners and discouraged them from CE. However, this view has also become a catalyst for some practitioners to pursue learning. The two different effects on CE of society's views of library work are discussed below.

Regarding the negative effect, the low opinion of library work makes it difficult for practitioners themselves to recognise the true value of their profession. As one manager commented, "How can librarians have enthusiasm to improve themselves when people don't recognise their value?" (TD-manager). Another manager observed, "Because of the public's low estimation of library work, some staff think 
that it is useless to further their study" (HK-manager). Their comments reflect that the low regard for library work has diminished the enthusiasm for learning among some practitioners.

Further, some managers thought that the low status of library work has caused practitioners to worry about the future of the LIM profession. Although this perception has not destroyed interest in learning, it has lessened the enthusiasm of staff. As one manager said:

The low estimation of the library profession causes a negative effect on us. It is not so much that staff don't want to learn anything, but they feel discouraged.... They keep learning but it doesn't foster the idea to learn in order to make something change. (DS-manager)

Operational staff seemed to place stronger emphasis on the low status of LIM as a negative effect on CE. Some felt that LIM was not appreciated in comparison with other professions. As a line staff member stated, "People in the university make us think that we are not on the same street as them" (BT-staff2). Some even had a sense of inferiority about their occupation. A senior supervisor reported:

To introduce their job, some staff just mentioned that they are working "in a university" instead of "in a university library". They do not have pride in the profession because society doesn't understand what the library profession is. Society just imagines that we are keepers of books and anyone, even someone who is unqualified, can do the job. (HH-super1)

Some staff members conceded that the lack of public appreciation for LIM had caused them to become dispirited and to have a negative attitude towards their profession. Consequently, they had lost interest in CE. They did not believe that their learning efforts would be useful for their future. As one staff member said:

Society's opinion of the library profession still hasn't changed much and therefore I ask myself, do I need to learn more? I can handle my tasks now. It is not necessary to learn because, even if I learn more, things stay the same. Our society doesn't appreciate this profession. (TD-staff1) 
The preceding data demonstrate that many participants considered the public's low regard for library work as a barrier to the CE of library practitioners. However, there were participants who indicated that they did not regard this as an excuse to neglect their learning. Instead, this perception stimulated them to assert themselves and became a catalyst for them to pursue learning. Discussions from participants in several libraries revealed this point.

The participants in Dam Sen, Hong Ha and Hoa Sua mentioned that they felt bitter about the low status of LIM, but they appeared to be aware of the reasons for this prejudice and recognised their responsibility to deal with it. They thought that, in order to change society's poor view of library work, they must first of all be competent and perform better themselves. For example, in a focus group of senior staff and supervisors, one person said:

Whether people look at us with a negative or positive view depends on library activities. Some years ago, librarians were just keepers of books. Therefore, people obviously didn't estimate us highly. (DS-super4)

The participants in this focus group emphasised that society's views of LIM will change if library practitioners demonstrate their proficiency and usefulness. One said:

Now people change their minds when they come and use some library information centres. For example, I know some who completely changed their views on library jobs after visiting Da Lat and Can Tho university libraries. They are impressed by the library activities and library practitioners there. (DS-super5)

This opinion was echoed by senior staff in three other libraries. They recognised that engaging in $\mathrm{CE}$ helped them to be knowledgeable and competent so that they could do the job better and meet society's demands. This is a positive way to change public prejudice towards library work. Moreover, some participants claimed that the low regard for their profession had acted as a catalyst to arouse their pride in the profession and therefore motivated them to update their skills and knowledge in 
order to assert their ability and their jobs' worth in the community. A senior staff member with approximately 15 years' library experience said enthusiastically:

For many people, including those in this university, the library is a place nobody knows or pays attention to. However, we have our self-esteem and pride in our profession. We give our minds to work and give our minds to study so that we can answer all the questions relating to our duties well. Then people will have a different way of thinking about us and our jobs. We would like to study because of our self-esteem and pride in our profession.... In the old time, libraries were considered a gloomy corner. Therefore, now we need to study more and higher so that we can show people our capabilities and let them know that we also can catch up with development in society. I hope we can make them appreciate us. (HHsuper4)

Some younger participants also expressed their determination. This is an example:

Of course the public perceptions affect us, but I think that as we are the new generation, we ought to have a new view of the LIM profession. People curled their lips in scorn when they found out that I'm working in the library, but this motivates me to learn. We need to assert ourselves and give them a new view of our jobs. We are educated. We have opportunities to read, to look at overseas websites about libraries and to visit some modern libraries so that we are aware of the important and useful role of the library. We believe the public will highly appreciate our job one day. (HV-staff2)

In fact, public perceptions of LIM appear to be gradually changing. Some participants highlighted these changes and saw them as incentives to pursue CE. One supervisor said:

In the last 10 years, there have been many changes in libraries. Public and press have started paying attention to the development of libraries. Many universities have projects to develop their libraries. Perhaps, the change is still superficial - we only have new buildings but the way we serve clients isn't changing much. Perhaps, the old people manage the new buildings in the same way therefore the change isn't deep and the public still doesn't highly appreciate library jobs. However, generally the library job is changing and step-by-step is improving... each of us needs to continually strive for mastery. (TD-super4) 
The data above suggest that the public's low regard of library work impacts on practitioners' attitudes towards their jobs as well as ambitions. Since society in general, and friends and university co-workers in particular, underestimate the value of libraries, practitioners sometimes feel inferior and have doubts about their professional career development. Consequently, they have no motivation to pursue learning. However, some try to overcome this negative view, making it a driving force for their CE. Analysis of the data shows that public perceptions of LIM are one of the factors affecting practitioners' CE, with differing effects.

\subsubsection{Society's perceptions concerning learning}

Societal perceptions of learning and age, and traditional methods of teaching and learning are other elements affecting the CE of Vietnamese university library practitioners.

Regarding the relationship between learning and age, participants across the sample libraries commented that learning is a duty as well as a privilege for youth, but that people should stop learning when they reach a certain age and reserve the learning opportunities for younger people. They seemed to believe that this notion is traditional Vietnamese preconception of learning and seems to have diminished the learning desire of some older practitioners. As a staff member commented:

In our society, people think that older people shouldn't keep learning instead of giving chances to the younger people. Elders will retire soon so why should they need to learn? (HS-staff5)

Analysis of the data also reveals that getting a high degree is important in Vietnamese culture. It implies having power, knowledge and respect from society. However, this traditional view of the value of education may cause a "diploma disease" rather than stimulate a desire for knowledge. As one manager observed, people might pursue a higher qualification simply in order to have a higher position rather than to improve their professional performance. This "degree hunger" might cause a "harmful effect" on the learning pursuits of practitioners, such as dishonesty 
in learning or inflating credentials or seeking the trappings of academic success. As a consequence, this view might potentially decrease the value of learning. He said:

Yes, a higher degree is great... but in my university many people go to Master's and even Doctoral programmes but they never have the capabilities to apply their obtained knowledge. You know, someone works in a technical field but goes to a Master's programme in a commerce subject... what they learn doesn't help to improve their professional performance, but only helps to gain a higher ranking position. (HKmanager)

Several staff shared this view. They indicated that they felt disillusioned with learning when they saw people learning just for the degree and using it as a tool to gain power or increase their reputation. This comment represented the thinking of many staff members:

It is quite funny when some people even can't handle their daily tasks but try to pursue higher academic degrees... some people go to learn, but in fact they try to "buy" a degree in order to keep their seats or to reach higher positions. (TD-staff1)

However, for younger people, these very perceptions fostered a sense of obligation as one of their motivations to pursue learning. For instance, one participant said, "I myself understand that I have to improve my education level because firstly I am young" (DS-staff5). Another participant echoed this opinion, "It is unacceptable when young people, like us, don't learn” (HK-staff2).

The social perception of learning as a privilege reserved for young people has led institutions to give more learning opportunities to younger over older staff. For example, a manager insisted: "I only want to send younger staff to CE programmes" (BT-manager). Also, this perception has led families, particularly parents, to give financial and emotional support to their children to encourage them in keeping learning (in Vietnam, most young people stay with their parents until they marry). Many younger participants mentioned family expectations as their learning motivation. This comment was typical: 
All parents want children to be able to pursue learning and have a good job. Our parents' expectations become our motivations to learn. Sometimes I find it difficult to pursue my goals. My parents encourage me and I again try my best. (TD-staff3)

It is recognised that society's perceptions of learning have different effects on the CE of practitioners. These perceptions encourage the young to pursue learning but tend to discourage those who are older. They motivate people to obtain higher education, but may lead people to value certification above quality, which might lower the worth of CE in the eyes of others.

Another effect of the social environment is that the traditional methods of teaching and learning are still evident in Vietnamese universities. According to some operational staff, although there had been changes in the teaching and learning methods in their universities, many lecturers kept the old teacher-centred teaching style. Students only needed to follow course books, repeat what the teachers said and do what the teachers demonstrated. In-depth independent learning was not encouraged nor did teachers urge students to seek assistance from librarians to find information for their assignments. As a result, the role of librarians was not being promoted as an important part of universities' academic support systems. This discouraged library staff from strengthening their competencies. One participant commented:

In such education, the role of libraries is never improved. All a student needs is to attend classes, repeat what teachers say, read the course books that teachers provide. Therefore, why should they have to take time to go to the library? (HS-super4)

Another participant gave a conclusion: "nothing changes in teaching and learning methods in universities - library staff don't see a reason to upgrade themselves" (HSsuper3).

The data discussed in these sections show that both managers and operational staff across the sample libraries identified characteristics of the social environment as factors impacting on the $\mathrm{CE}$ of university library practitioners. This finding is in 
agreement with other research discussed in the literature review (e.g., Boyd et al., 1980; Jarvis, 2006; Nowlen, 1988). However, specific factors determined in this study may only have significance for the CE of library practitioners in Vietnam. The particular attitudes towards learning and teaching, the low regard for library work that still persists in Vietnam, and the fact that most library practitioners are female and therefore subject to traditional preconceptions of women's role in society are three specific social factors that have a strong influence on the CE of Vietnamese university library practitioners.

\subsection{Professional factors}

As discussed in the literature review, authors in adult education and $\mathrm{CE}$, such as Houle (1980), Cervero (1988) and Brennan (1990) as well as Nowlen (1988) in his Performance Model, have suggested that the CE of professionals is influenced by the characteristics of their profession, including:

- body of knowledge, the skills base and technology

- competencies that individuals are required to possess

- organisational features.

In this study, participants also determined the characteristics of the LIM profession in Vietnam as being factors that affected their CE. They particularly emphasised the nature of LIM employment, the features of LIM professional education and professional leadership.

\subsubsection{Nature of employment}

According to most participants, the nature of the employment, including the professional knowledge requirements, job requirements and abilities to keep abreast of the changes in technology and professional standards, is a driving force in their learning pursuits. 


\subsubsection{Job requirements}

Regardless of their tasks and positions, all participants agreed that they mostly needed to learn because of the requirements of their daily tasks. Eight of the ten managers emphasised that they had to pursue learning in order to solve problems in their professional practice and management role. As one manager said:

I need to have knowledge that helps me to carry out my tasks. It is true that the requirements of the work require me to learn. When dealing with any professional issue, such as setting up a new job in library processes, I need to understand the nature of the job, to imagine what the job is and even to know who can take on the job. That means I need to be able to assess the job and the staff. As a manager, I have to be able to do these things and, if I don't learn, I can't perform well. (HT-manager)

Some managers mentioned that their jobs required them to be able to deal with diverse issues, even some unrelated to their daily tasks or their own specific fields. As a manager noted:

In professional meetings, people expect me to know everything regardless of my daily responsibilities and my education background, for example, archive issues... therefore I have to ask other experts. I can't say, "I don't know." You know, in Vietnam people expect that a leader has to know everything. (HH-manager)

Similarly, the primary CE driver for operational staff is the need to perform their tasks. Many staff understood that their daily work required them to learn and upgrade continually, regardless of which section they worked in, tasks they dealt with and positions they held. As a senior staff member noted: "To do the job, I need to learn" (BT-super4). A line staff member stated: "I learn, first of all, because of the requirements of the work" (DS-staff3). A supervisor reported: "The need to improve the quality of our services forces us to have various competencies, so without learning and updating, we can't handle the work" (HH-super4).

Indeed, each job in a library requires particular knowledge and skills. Working in technical services seems routine, but practitioners are required not only to master cataloguing knowledge and skills, but also to have diverse subject knowledge 
relating to their university's programmes. These requirements prompt practitioners to participate in learning and stipulate the content of their learning. As a staff member who worked in the cataloguing section explained:

As you may know, doing cataloguing requires me to possess both knowledge of cataloguing and knowledge of several fields relating to our university education programmes. Besides, we have to be able to read in a foreign language. Thus, we have to learn and keep learning. (DS-super1)

Working in information services requires operational staff to be able to deal with people. As many participants explained, they had to know how to listen, understand and satisfy clients. They felt their performance was an indicator of the quality of the library service. As one participant remarked, "This section is the face of the library" (TD-super4). Moreover, their clients are faculty members and students, who are relatively sophisticated users, so library staff have to be proficient. A staff member from information services section said:

Some students keep asking for help to do a simple thing, such as how to make a photocopy, but many of them are very skilful in using technology facilities and searching on the web. When they ask for assistance to search for materials within a specific topic they expect that we can search better than they do. Therefore, we have to learn, because the more we know, the better we are able to satisfy their needs. (TB-staff3)

Analysis of the data also shows that the requirements of employment affect the learning of participants, regardless of their age and length of time in library services. At each stage of their professional career, staff may have different tasks; over time they may accumulate work experience and improve their academic degrees, but work requirements continually prompt them to engage in learning. A young staff member noted, "I have worked here for three years but I'm still new in some tasks. I need to keep learning" (HK-staff3). A senior staff member with about 15 years of experience said:

The requirements of work force me to learn. I was trained to become a librarian, but when I was doing cataloguing I had to learn English.... When I moved into the information services section, I was responsible for 
the library bulletin so I had to learn how to get news, how to write news, how to take a photo and so on. (HH-super1)

As seen in the discussion above, job requirements have a significant impact on the $\mathrm{CE}$ of practitioners. Managers and staff need to take part in $\mathrm{CE}$ activities to acquire relevant knowledge and skills, and remain up-to-date. Job requirements also influence the scope and content of CE. Practitioners have to gain knowledge and skills not only in the LIM field, but also in related fields.

\subsubsection{Changes in the profession}

The nature of the work in the LIM profession has changed dramatically since the information explosion and rapid development of IT. As a result, professional standards, particularly bibliographic standards, have changed in Vietnam. In all interviews these changes were mentioned as an important element affecting library practitioners' engagement in CE.

Many managers viewed changes in the profession as an obvious process. They affirmed that to cope with change, managers need to learn. As one noted, "A manager is the first person who needs to learn about changes" (BT-manager). In particular, the managers recognised that moving from traditional to electronic library services has caused big changes in operating a library. As a result, library managers need to keep learning not only in the LIM professional field, but also in management areas. This was typical of the comments from managers: "Management knowledge and skills are changing very much in the current period. To manage our library I have to update" (TD-manager).

Operational staff who have encountered professional changes directly in their daily tasks discussed in more detail the impact of changes on their CE. They stated the range of changes that LIM practitioners have faced and confirmed that the need to respond to changes has required LIM practitioners to update and learn continually.

First, the changes in information formats were considered an impetus to learn among staff. As several staff members emphasised, some years ago, the majority of 
information in libraries comprised printed materials; but now it includes digital materials. Therefore, library practitioners need to learn how to use diverse information formats. As a senior staff said, "Now, our collections include not only books and journals but CD ROMs, databases, software and so on. We need to know all about these new material formats" (HH-staff3).

Next, changes in the storage and retrieval of information and bibliographic standards in Vietnam were indicated as big challenges that propelled library practitioners into the learning process. A senior staff member illustrated:

The information explosion has led to changes in information storage and retrieval. We have to study bibliographic standards and try to apply proper standards in our libraries. We start talking about a unique bibliographic standard and a library network. Everything is new to us. Besides, we have to change information services. Now, materials in libraries include printed and electronic formats. We need to master searching and using resources appropriately before we can assist clients to use them. You can see a lot of changes that we have to face. How we can handle those if we don't continue learning? (HK-super3)

The increase in the demand for information was pointed out as another challenge for library practitioners. As discussed in the previous section, participants cited that their clients, including students and faculty members, were becoming more knowledgeable and had more complicated information demands. Therefore, as a senior staff member concluded, "Library practitioners are required to upgrade not only professional skills, but also general knowledge, social knowledge, critical thinking ability and foreign language proficiency" (HV-super5).

Application of IT in libraries was particularly emphasised as having an impact on CE pursuits in general and learning content in particular. Staff noted that using an integrated library system changed all the library activities. The automated system caused changes in cataloguing processes, information search tools and user services. Consequently, practitioners have been required to learn, otherwise they would not be able to do the work. One supervisor said, "Now we have to learn computer skills and 
IT, because IT is applied in many library activities. We want to move to a digital library system" (DS-super2). Another senior staff member said:

Obviously, if we don't learn, we soon become out of date and can't handle the job. At certain points in time, each job has its own requirement for change. For example, last year we learned DDC21, but this year people are talking about DDC22. We have to continue learning. (DS-super3)

Finally, the growth of the internet was a learning driver for practitioners. The following comments are indicative of the discussions in most of the focus groups: "The internet is more and more available in university libraries. We have to practise using it in order to assist with the information needs of our clients" (TD-super4) or "We need to master internet searching skills to provide relevant information to users" (HK-staff2).

Currently, providing wider internet access, creating websites, and creating and sharing online databases are all being attempted in Vietnamese university libraries. The development plan for university libraries emphasises these targets (Ministry of Culture and Information, 2007). In fact, developing digital collections was one of current projects of some participating libraries, such as Ben Thanh, Dam Sen and Thanh Da. In these libraries, staff acknowledged that they were new to such tasks and understood that the applications of new tools in their work would force them to look for opportunities to learn. One member in Dam Sen said:

We are going to create electronic curricula on the web for lecturers and students. At the very least we need to learn essential skills concerning the Web, HTML, PowerPoint or Photoshop. If not, how we can handle the job? (DS-super3)

As discussed in the literature review, according to Houle's (1980) concept of "professionalisation", every profession faces changes in the nature, form and content of knowledge and expertise. Change is constant. It happens in every profession and at any time. As a result, practitioners have to update existing and gain new knowledge and skills to meet the evolving requirements of their profession. Vietnamese LIM appears to be undergoing the "professionalisation" process that 
requires all members to engage in learning commitments. The nature of and changes in library work are learning drivers, requiring practitioners to participate in CE.

\subsubsection{Professional education}

The features of current LIM professional education in Vietnam emerged as another professional factor affecting CE. The limitations of current education programmes and the lack of LIM education among large numbers of practitioners in Vietnam have affected their CE needs and particularly the content they need to learn.

As discussed in the literature review, the limitations of professional education are considered a key rationale for CE (Houle, 2003; Jarvis, 1996; Weingand, 2001). Similarly, all participants in this study, regardless of their initial professional education, academic degrees or when they graduated from university, cited that what they learned in school was not adequate for them to handle their current jobs - they would need to keep learning.

In general, participants, including managers and staff, understood that, because change is constant, the LIM education programme could not cover all knowledge and skills essential to their professional career. They understood that a curriculum could not be revised quickly enough to cope with changes in the profession. Further, they recognised that there are many skills that they could only learn in particular circumstances. Therefore, to cope with practical issues and changes in the profession, all practitioners need to keep learning. As a senior staff member noted:

When I was a student at university, our society was different from our current society. The professional knowledge that we gained from university was not as much as what people know and what people need now. Actually, a university cannot change its curriculum immediately. Therefore, now I have to update and study more in order to continue working in the profession. (BT-super2)

A younger staff member also commented: 
My major is IT and IT changes very quickly. Some technologies I was taught in school were obsolete by the time I'd just graduated. Nobody can do anything to avoid this fact. Therefore, we have to keep learning. (TDstaff2)

At the same time, however, participants pointed out that the content of current LIM curricula seemed quite dated which caused all of them to look for CE opportunities. A common view among operational staff who graduated from different library schools in Vietnam and the managers of those staff was that current Vietnamese LIM programmes do not meet the demands of professional practice. Some participants even used the terms "backward" or "obsolete" to refer to the quality of LIM programmes. This assessment was typical:

What has been taught in library schools is not relevant for current practice... these curricula are outdated. Therefore library practitioners need to be re-educated and to keep learning. (BT-manager)

Some managers contended that current undergraduate LIM programmes keep focusing on knowledge and skills for a traditional library rather than on providing what is essential for a library in the current environment. As one manager commented:

Even the curriculum of the most long-standing library school doesn't meet the needs of actual practice. Graduates are able to work only in a traditional library. Primarily, they were taught to become keepers of books. All the things they know are how to keep the books firmly on the shelves! They don't know how to deliver books and help people to use books properly. The current curriculum doesn't include many essential skills, such as working with clients and working in a team.

Another manager was very critical in saying: "The things students learn now are rubbish" (HV-manager). Most managers shared the observation that practitioners with a Bachelor's degree in LIM are not ready to handle tasks after graduation. Accordingly they need $\mathrm{CE}$ as soon as they start their professional career. As a manager noted, "Graduates can't handle the job when they start working in the library. They all need some more training" (HS-manager). 
The younger staff members who had recently graduated from library schools emphasised the weaknesses of the professional education curricula they had received. According to several, even as students they had recognised the inappropriateness of the education programmes. Some members shared the reflection made in this comment:

When participating in the internship [for senior students], I already recognised the gap between what we were taught and actual practice. I was very confused. (HK-staff5)

When they entered the profession, some recognised even more the inappropriateness of what they had been taught. A younger supervisor said:

Right after I got the job, I recognised a big gap between what I had learned in school and what I had to do. In school, I was taught to create catalogue cards but here people have done this stuff on computers for some years. You know, even after completing the course on bibliography, I still didn't understand what the course was about. Therefore, I need to learn on the job and re-learn many things. (DS-super5)

Many participants who had done or were pursuing LIM Master's programmes seemed to be disappointed at the quality of these curricula. They cited that the current programmes mostly provided basic professional knowledge and not the advanced or current knowledge that they really needed. This was a typical comment:

The Master's programme only provides us with basic professional knowledge, as a kind of general theory. Although they mention some specific issues, we haven't gained much of what we need to solve our practical issues. (BT-super5)

Some managers were also worried about the capability of Master's degree holders. As the manager in Hoan Kiem observed:

Current postgraduate programmes are just formal and superficial education programmes. I don't know what and how they are studying. In the end, everybody gets a successful [grade] but in fact they are unable to do anything better. 
The preceding data reveal that the lack of currency of LIM professional education programmes in Vietnam causes young graduates to look for CE opportunities right from the start of their professional career. Postgraduates must also keep looking for opportunities to upgrade their knowledge to deal with actual professional practice. This factor affects both the need to attend CE and the content that practitioners need to learn.

The lack of LIM education is another factor having effects on the CE of library practitioners in Vietnam. As presented in Section 4.2, a large number of participants, including managers and staff, did not have a degree in LIM. As a result, CE is the main vehicle for many practitioners to acquire a professional knowledge base. The managers in Hoa Sua and Hai Van, where the majority of staff lacked a LIM qualification, reported that it was obligatory for staff to attend training programmes to acquire basic library skills and that those programmes were important projects of the libraries.

In Ho Tay and Tan Binh, the managers reported that their libraries were not able to conduct in-house CE activities, but staff were encouraged or even required to take a part-time professional education programme to gain a degree in LIM.

Many operational staff in Hoa Sua, Hai Van and Tan Binh noted that CE was the primary means for them to acquire professional skills. As one said, "My background wasn't librarianship. I mostly learn professional skills on the job and by attending CE courses" (HS-staff4).

The focus of professional education is to provide students with a foundation of professional knowledge; and educational curricula cannot be expected to cover every aspect of the work, particularly with the rapid rate of change. Practitioners upgrade their knowledge and skills by continuing to learn. However, in the current Vietnamese situation, the gap between professional education and the demands from practice is quite big. In addition, the lack of LIM professional education among practitioners is widespread. This situation represents a real problem as, without 
appropriate professional education, library staff may lack the perception, understanding and ability to think and act in ways that are essential to their professional career in LIM. The lack of update knowledge and skills in LIM makes it difficult for practitioners to practise effectively in the current library environment. Thus, the limitations of current LIM education and the lack of professional degree for a number of practitioners in Vietnam affect participation in CE as well as the learning content of practitioners.

\subsubsection{Professional leadership}

As introduced in Section 1.2.3, the Library Department of the Ministry of Culture and Information is assigned as the lead organisation for the Vietnamese library system. However, in reality, as all the interviewed managers asserted, the Library Department does not direct university library activities, particularly with regard to CE. Many managers mentioned the Federation of Southern Vietnam Academic Libraries (FESAL) and the Northern Academic Library Association as the main CE providers. However, the managers also noted that, although these associations occasionally conducted CE programmes based on their resources, they did not have the ability to set the professional competency for university libraries. As a result, the lack of professional leadership was a disadvantage to those seeking $\mathrm{CE}$ activities in the library field. This was a common statement:

At the moment there is no professional organisation which leads university libraries. This is a disadvantage because no official organisation takes care of CE for university library staff. (TB-manager)

Operational staff, particularly supervisors and senior staff, also remarked on this disadvantage. First, because of the lack of professional leadership, CE activities lack official guidance. Therefore, participants wondered what proper knowledge or standards should be applied in their practice and who is authorised to issue standards and provide them with essential up-to-date knowledge and skills. As a supervisor commented: 
Our library system is underdeveloped and really needs to upgrade. We need to learn new knowledge.... Nobody orientates us. How can we know which way is the appropriate one? We should learn on our own. Okay, we learn and we will learn, but who will let us know what is suitable and what is not? (HK-super1)

Next, because of the lack of professional leadership, the required competencies and criteria for the official civil servant ranks for library practitioners are not up-to-date or consistent. According to the managers and supervisors in some libraries, university library practitioners can enter the civil servant ranks in either librarianship or bureaucracy, depending which is more convenient for them to take civil servant examinations in. Staff members in Hoa Sua, Hai Van and Ho Tay seemed unclear about the criteria for civil servant ranks and some senior staff members in Ben Thanh and Hong Ha commented that the content for civil servant examinations is not up-todate. These points are discussed further in Section 6.1.1.

Finally, because of the lack of professional leadership, current CE programmes have been conducted without governing strategic plans. Many managers complained that, in many cases, they received information about $\mathrm{CE}$ programmes by accident. Therefore they missed those programmes or dispatched staff to programmes in an ad hoc way. As one manager said:

One of the difficulties is that providers don't send us information about CE programmes in advance. We can hardly arrange time for staff to join such programmes. (DS-manager)

Moreover, the quality of these programmes is not evaluated by an authorised professional organisation. In many cases, practitioners found attending such courses was of limited value. As a supervisor complained:

I need to learn to do my job more effectively. You know, online databases are very expensive. It is a waste of our money when we can't effectively use them. We need CE courses for learning how to best use the databases, not for listening to advertisements about databases. But in many courses, people just introduced and then compared databases and nobody assesses the quality of such courses. (HK-super5) 
The lack of a lead organisation has resulted in a lack of authorised CE providers who could offer frequent, high quality and well-planned CE programmes. This has also resulted in difficulties for practitioners in identifying appropriate learning resources, strategies and even content to progress their professional careers.

It is evident that the characteristics of the profession affect participation in and the content of $\mathrm{CE}$ for all library practitioners. The requirements of daily tasks are a significant driving force for practitioners to look for CE opportunities. This finding is consistent with some previous studies (e.g., Li, 2001; Russett, 1991). However, given the distinctive features of current LIM education and professional leadership in Vietnam, the findings in this study regarding their effects seem unique. Analysis of the data suggests that all these factors should be taken into account in the design of relevant and effective CE programmes for university library practitioners in Vietnam.

\subsection{Individual practitioner factors}

Similar to the findings of theorists in adult education and CE, such as Cross (1981), Houle (1980) and Knowles et al. (1998b), the data in this study demonstrated the considerable influence of the individual characteristics of practitioners on their CE. The perceptions of participants on this issue are grouped into personal traits, personal demographics, individual goals and attitude towards the job, and family conditions.

\subsubsection{Personal traits}

Most participants felt that personal traits affected their pursuit of learning. As a senior staff member stated:

Actually, personal traits are very important. Whether people learn depends much on their traits. You see, some people have very good conditions for learning; however, they have no desire to learn. (TB-super5)

The participants referred to self-confidence, self-esteem and learning orientation as personal traits which foster the pursuit of learning. Likewise, they considered that individuals without these traits tend to be less engaged in leaning activities. 
Regarding self-confidence as a trait to foster learning pursuits, participants in this study perceived that self-confident people are likely to be innovators, as Houle (1980) identified when he discussed "zest for learning". Self-confident individuals feel free to express their desire for learning. They believe in their learning ability, work proficiency, and capacity to manage their own lives. They seek to apply their learning in practice. These attributes encourage them to take full advantage of learning opportunities.

Examples of the effects of different aspects of self-confidence were given by managers, senior staff and line staff. However, younger staff emphasised this trait the most. They highlighted personal capability as essential for a person to become successful. They cited that the personal capacity to manage work and life facilitates CE. This opinion is an example:

I think it is very important for our CE if we can arrange our work flexibly and live in a way that we can handle family duties and work requirements. Everybody has difficulties in terms of family responsibilities. I also have a young baby, but I can arrange my family duties so I always keep learning. (BT-super3)

Younger interviewees who appeared confident in their learning ability and personal capacity seemed to find it easier to engage in learning. For instance, although members in one focus group considered that learning resources were rare for librarians, one member who seemed very confident had a different opinion:

My background isn't in LIM. However, I am sure that when I really need and want to know more about LIM, I can find materials to read and places to acquire needed LIM skills. They are there. (TD-staff1)

Some younger staff members thought that people who like to take the initiative and are keen to apply new knowledge in practice engage more actively in learning. One commented: 
I am sure that personal characteristics impact on our CE. An individual with a strong personality and who can take risks will be willing to learn something new, for example about IT. People who always feel fear of new things don't dare to do anything... they won't learn. (BT-staff2)

In addition, staff members in some libraries noted that confident individuals can express themselves well and, therefore, usually have more CE opportunities, while those who lack confidence may have poor expression and, therefore, often lose their opportunities. One participant concluded, "If we don't try overcoming this weakness, it becomes a hindrance for us in doing CE" (HH-staff1). Accordingly, lack of selfconfidence is a barrier to CE.

Self-esteem is another trait that fosters learning pursuits. According to participants, for Vietnamese people, self-esteem of individuals was derived not only from their own views of their worth but primarily from the views of the community around them. Consequently, many participants considered that affirming their abilities, and receiving recognition and appreciation from others are significant motivators for them to keep learning. Among the participants, managers emphasised this trait the most. The respect from their staff and higher managers motivated them to learn. As one manager said, "I have to keep face" (HH-manager). Another manager cited:

I want to be respected... to be knowledgeable and competent I have to learn. By being knowledgeable and competent, I can handle my tasks perfectly so that nobody can disregard me.... I think whoever I am and whatever my position is, I need my leaders and my staff to perceive me as a knowledgeable person. (HT-manager)

Similarly, self-esteem was also a learning motivator for operational staff. As one manager observed, "Nobody wants to be disregarded. The staff keep learning because of their self-esteem. They want to assert themselves, at least in front of their peers" (DS-manager).

In many focus groups, operational staff affirmed this opinion. For example, one said, "I feel very ashamed when I can't do the job as well as others" (DS-staff2). A senior staff member said, "I should affirm myself... It is unacceptable when I have this and 
that degree, but in fact I don't know anything" (BT-super4). Being equal to others also encourages staff to learn - as another young staff member said, "I have to learn, I have to move on; if not, I will be behind others. This means I lower myself" (HHstaff1).

In addition, staff in Dam Sen, Hoa Sua and Hoan Kiem highlighted professional selfesteem as their learning driver. They shared this opinion of a senior staff member:

We have our professional self-esteem. We try to work hard and learn hard.... Users will regard us highly when we can proficiently respond to their requests. We learn in order to strengthen our professional selfesteem. (DS-super3)

Finally, being learning-orientated was also indicated as a trait to foster learning. Participants described a learning-oriented person similar to the description by Houle (1961; 1980). Learning-oriented people pursue learning for its own sake. They seem to possess a fundamental desire to be knowledgeable. They seek challenges and new opportunities for growth through learning. Their activities are constant and lifelong.

Most managers stressed that their being learning-orientated inspired them to pursue education. For them, learning was a pleasure. As one manager said, "For me, I can never learn enough. There is no period in my life in which I stop my learning. I always learn" (DS-manager). Similarly, another manager said, "I feel like my daily tasks still aren't completed if I don't read something new in a journal" (HSmanager).

Discussion among operational staff also revealed that learning orientation is a trait which facilitates their learning. A typical idea voiced was the desire to discover. One staff member said:

You know, some staff in my section think that our job is simple so we don't need to learn anymore. Day after day we just do the same things. That's it. But some of us have a different view... like me. I want to learn more. I really want to learn. When I have a chance, I make the best of it.... We now know that there are a lot of new things around us. If we just 
superficially know them and never try to understand them in depth we aren't knowledgeable. (HS-staff2)

Another typical idea was that opportunities to grow stimulate the learning of learning-oriented people. As a senior staff member said:

I learn partly because of the requirements of the job but foremost, learning is useful for me to grow as an individual. I like to understand the nature of my daily life, society and life in general. I learn. (TB-super1)

A younger staff member felt that the desire to become knowledgeable motivated him to learn more than any organisational requirements. He cited:

For me, organisational enforcement isn't an important driver for learning. When I find it useful for me to grow and become knowledgeable, I will learn. I don't need to be forced. (HK-staff2)

In a view shared by some managers, staff members considered the desire to learn as motivation in itself. One senior supervisor said:

I like to learn. When I like I will learn at all cost.... Many years ago, people didn't learn English because we never had a chance to go abroad, but I like to learn, therefore I learned. I worked overtime and took a parttime job to earn money to pay the fees. I arranged my housework to have time to learn. (HV-super1)

Analysis of the data also suggests that individuals who are not learning-orientated seem to neglect CE. Here are examples of participants' observations:

Self-consciousness about learning is important. There is no value when people are given a chance to attend a CE course, but they don't like learning. (HH-staff3)

Most say that we like to learn. However, some don't really like to. They just learn when it is convenient for them. That's all. But they aren't really willing. (HS-super1) 
The preceding data show that personal traits affected the learning pursuits of individuals. Being self-confident, having good self-esteem and being learningoriented motivate individuals to become more active in learning.

\subsubsection{Personal demographics}

Personal demographics, including age, gender and educational background also emerged as elements affecting the $\mathrm{CE}$ of practitioners.

\subsubsection{Age}

As mentioned in the literature review, the effect of age on CE is a topic discussed in several studies. The previous studies showed contradictory effects of age and, as Cervero (1988) commented, it is not easy to use information about the age of practitioners in designing CE programmes. In this study, participants did not emphasise the effects of age per se but its effects in relation to other elements.

Only one staff member in Hoa Sua and one senior staff member in Hong $\mathrm{Ha}$ considered that older people want to maintain a stable status, so they do not have a desire to learn much. One staff member in Thanh Da suggested that memory declines with age, which makes it difficult for older people to learn. However, other members in her group did not support this view. In fact, they suggested the opposite. One supervisor noted that older people have advantages when learning. She explained:

Sure there is a general slowing down and a decline of memory as people grow older, but older people have rich experience. You can understand that experience is an advantage in learning. We can learn insightfully, not like a parrot learns. (TD-super4)

The idea that "learning is a lifelong task, no matter how old we are" (HV-super5) was echoed in several focus groups. Some managers also affirmed this view. For instance, one manager reported: 
I pursued my Master's degree when I was rather old, but I was determined to learn my best. Many people, even my wife, thought that it was too difficult for me to learn, but finally I got it. (HT-manager)

However, participants indicated that age might be a factor affecting $\mathrm{CE}$ in another way. Several managers observed that learning opportunities do not attract staff who are in their late forties because they are close to retirement: "Why should people learn when they are old and will retire very soon" (TB-manager). Similarly, in focus groups, operational staff pointed out that the government retirement policy may be a reason for the reduced participation in CE by older staff. A supervisor said:

Staff who are 50 years old don't want to learn anymore because they are getting ready to retire. In just five more years they have to retire and the government is now even considering a new policy that would set the age of retirement for women at 50. Therefore, most of them don't want to do anything more. (TD-super4)

One manager noted that a few of her older staff members seemed to have lost the will to learn because of the government civil servant policy. She said:

They don't attempt to learn because they are already official civil servants. When civil servants have worked a long time in services and haven't made a serious mistake, they aren't fired. They clearly understand this policy; therefore when they find it difficult, they just ignore rather than learn. (BT-manager)

Line staff members in Hoa Sua pointed out the age issue in the government personnel policy as a disincentive to participating in CE. They all agreed with this comment:

Our government policies also limit the age for learning. If they are over 35 years old, staff don't attend Master's programmes; over 45 years old, staff don't attend $\mathrm{PhD}$ programmes; and over 50 years old, staff don't need to learn anything more. (HS-staff5)

At the same time, as discussed in Section 5.1.3, the societal perceptions of learning being for the young may make age a barrier to CE. In addition, the data analysis reveals that older staff seemed particularly unwilling to learn about IT. For example, 
the manager in Hoan Kiem remarked that age did not actually lessen the CE engagement of his older staff but older people did seem to be afraid of IT topics. He said:

They all participate in [CE activities]. Actually, they don't want to get left behind; they don't want the young to overtake them... they only seem to avoid participating when topics concern IT.

Another idea raised in the discussion among staff in Ho Guom revealed the effect of age in relation to another element - working conditions. These participants first supposed that aging brought about neglect of learning. One member said, "Staff at our age [late forties] don't want changes. Only the young can make changes and try to learn to keep pace with changes." However, later on, this member made the comment below, with which the rest of the group agreed. She said:

If we have better working conditions, we will learn. We will read books. We will go to learn even in the evenings. If not, young people will quickly overtake us. (HG-super4)

This comment seems to indicate that age in combination with working conditions affected their CE, not age per se.

In considering all the comments of participants about the effects of age on participation in CE activities, it appears that age is not a significant element on its own. Rather, it needs to be understood in the Vietnamese context. First, Vietnam's mandatory retirement age is 55 for women and 60 for men. Since most library practitioners are female, there is little reason for them to seek CE opportunities as they draw close to retirement age. Second, government policy regarding job security means that many civil servants are not motivated to engage in $\mathrm{CE}$, while government policy regarding learning age for civil servants lessens learning opportunities for older staff. Third, society's preconception of learning being for the young discourages older staff from pursuing learning. In addition, it seems that the CE topic when combined with age also affects the desire to participate - older staff may be somewhat technology averse. 
Hence, analysis of the data suggests that age per se does not significantly affect CE. However, through its association with other elements, age may lessen the learning engagement and opportunities of practitioners. It should be noted that the data again revealed the effects of characteristics of society on $\mathrm{CE}$. Government policies were also indicated as a factor affecting CE. This factor will be discussed further in Section 6.1.

\subsubsection{Gender}

Gender is another demographic element that has an effect on the CE of participants. Its effects are caused by Vietnamese society's perceptions of women as discussed in Section 5.1.1 and in the family conditions of practitioners as discussed in Section 5.3.4. Therefore, it is not necessary to repeat them here. However, it should be reiterated that family commitments and social constraints are barriers to the $\mathrm{CE}$ of female practitioners. Male practitioners in Vietnam do not have the same constraints and so have more advantages in relation to learning than female practitioners.

\subsubsection{Educational background}

As mentioned in Section 4.1.2, the practitioners in these 10 libraries had a variety of educational backgrounds. Regardless of their initial education, they must acquire and improve their LIM knowledge and skills through CE in order to do their jobs. They had different opinions about the influence of their educational background on their CE. They mentioned both advantages and disadvantages to holding or not holding a LIM degree in regard to learning participation and outcomes.

Regarding the effects of holding a LIM qualification, there was an opinion that LIM degree holders tend to be more engaged in CE. A staff member with about 15 years experience observed: "Staff with LIM degrees tend to pursue a career in librarianship. They try to learn in order to get a better position here" (HH-staff1). Sharing this opinion, one manager generalised that the more education in the profession practitioners have, the more education they desire, and the more they participate in learning activities. She explained: 
Practitioners who have higher degrees in LIM come to desire more CE. When practitioners don't have education in LIM, they can't be aware of the importance of the profession. Formerly, I didn't like my library job. I didn't understand the job very much. But after gaining a Master's degree in LIM I understood it more systematically, understood its value, and now I love it. I want to learn more. (HS-manager)

Nevertheless, some LIM degree holders in several libraries mentioned the disadvantages of upgrading their competencies. They found it difficult to learn IT or specific subjects. They seemed to believe that practitioners with degrees in the sciences can absorb IT skills more readily and practitioners with a specific subject background, such as history, economics or biology, are better equipped to acquire specialist subject analysis and indexing skills than LIM graduates. The following explanation was typical:

My background is in LIM. However, as you know, skills for working in a modern library and IT are not provided much in library schools. Now IT knowledge and skills are necessary. Working with online databases or doing cataloguing all require us to have IT skills.... I see that I learn IT more slowly than those who have an IT or English background. (HHstaff5)

So, a LIM background might be an advantage for CE in some ways, but not in others. It might affect whether staff members pursue library career and accordingly enhance learning commitments. However, LIM degree holders have to face challenges in absorbing some subject areas.

Regarding the effects of not holding a LIM qualification, the data showed two opposing views on the effects on CE. The first was that there was no difference between people with different initial education in terms of $\mathrm{CE}$ participation and outcomes. The second was that those without a LIM qualification were at a disadvantage in regards to $\mathrm{CE}$. Agreeing with the first view, one manager spoke from his experience:

I don't have a LIM degree, however, I used to spend all day in libraries when I was a student, so I can understand what people need when they 
come to libraries. In addition, I learn about LIM knowledge in different ways. I don't find it difficult. (HV-manager)

The staff in Tan Binh who did not have a LIM qualification also thought that it did not hinder their CE.

We all hold Bachelor's degrees. We have certain abilities and can understand new things quickly. Further, this profession doesn't have much challenge for us; therefore, it isn't necessary to gain a degree in LIM. (TBstaff1)

The younger staff members in Hai Van were very confident in their view that holding a degree in a field other than LIM, such as English or IT, actually supported them more in learning new LIM knowledge and skills through CE activities. One member explained:

In our library, the majority of staff have degrees in English, not in LIM. This is an advantage because when learning something new, we don't confuse new knowledge with out-of-date knowledge. (HV-staff4)

As revealed in the discussion above, the educational background of practitioners does not appear to significantly affect CE participation and the ability to learn or update LIM knowledge and skills.

However, many other participants expressed a rather different opinion. As an example in Hoa Sua where the majority staff lacked a LIM degree, operational staff recognised that it was difficult for them to deal with theoretical issues in the profession because they were unfamiliar with LIM professional concepts. One staff member said:

I don't have a background in LIM so I don't really understand the terminologies when reading professional materials. In CE courses, if trainers don't explain in detail, I can't absorb anything. (HS-staff2)

Some managers and operational staff noted that, to enrol in any graduate programme in Vietnam, government regulations require students to have an undergraduate 
degree in the same discipline. As the desire to achieve a higher degree is a motivation for $\mathrm{CE}$ (this point is discussed in Section 5.3.3), this regulation prevents staff without a background in LIM from pursuing CE. As a supervisor noted:

Some staff in the cataloguing section don't have an opportunity to get a master's degree in LIM because they only hold degrees in English. In fact they don't need a master's degree in English; therefore it seems that achieving higher education isn't their learning motivation. The lack of a LIM background becomes their disadvantage. (TD-super4)

Other managers added that many practitioners whose educational background was not in LIM preferred to improve their abilities and qualifications in their initial fields of study. This observation of a manager was typical:

Those people only want to learn more about their initial fields study. For example, someone who has a degree in linguistics will pursue linguistics. They always seem more interested in their initial background. (HHmanager)

Some staff members confirmed the above observation. For example, an IT staff member in Hai Van appeared a confident and learning-oriented person; however, he openly admitted that he was not keen to join CE activities that focus on LIM. He stated:

No, I don't want to spend much of my time and money learning many things about the LIM field. A couple years ago I had a chance to get an overseas scholarship for a Master of library and information science programme, however I would learn if it was a programme in IT, not in information management.... I only want to upgrade my IT background. For me, working in a library just is a case study for my IT background. The library job isn't my lifelong job. Perhaps, it is my limitation in terms of CE for a librarian. (HV-staff1)

So, in the views of many participants, educational background might affect career plans and, therefore, CE choices. The lack of an educational background in LIM is a disadvantage for learning and updating LIM knowledge, in that it does not motivate practitioners to develop and improve their LIM competencies. 
Analysis of the data shows that individuals' educational background affects their $\mathrm{CE}$ participation as well as the learning content. Practitioners with a LIM qualification might have advantages in updating some areas of LIM theories but not in other areas. Practitioners with IT or specific subject backgrounds were perceived to have more advantages in learning some topics, but these practitioners must also be provided with even the basic library skills. Educational background has also influenced the purpose of practitioners' CE.

\subsubsection{Individual goals and attitudes}

Individual goals and attitudes towards the job emerged as other significant factors affecting the $\mathrm{CE}$ of the participants.

\subsubsection{Individual goals}

Operational staff shared these ideas: "Learning pursuits are connected to personal goals" (HH-super2) or "Whether people learn primarily depends on their will and their aspiration to improve" (HK-staff2). Similarly, a manager observed, "People learn well when they have a clear aim... When they don't see a specific target, they are not persistent and quit very soon" (HV-manager).

The data showed that participants had various personal goals and desires that motivated them to keep learning. A few of them mentioned being a good example to their children as a goal that motivated them to learn. For example, a supervisor said:

Beside the requirements of work, I learn because I want to be a good example to my kids. They can see that I'm older but I keep learning, therefore there are no reasons for them to be poor at learning. Moreover, by keeping up-to-date, I can help my kids when they have difficulties with their study. (TD-super4)

The majority of participants indicated the desire to achieve higher education degrees and the prospect of promotion as factors that affected their learning. Their perceptions are examined below. 
Regarding the desire for higher degrees, as discussed in Section 5.1.3, Vietnamese traditionally have a high regard for academic qualifications that infuses a goal in individuals, particularly young people, to achieve higher degrees. Currently, more library schools in Vietnam are offering Master's programmes in LIM. Opportunities to gain higher degrees or attend professional internships overseas are increasing. Having these opportunities encourages practitioners to accumulate knowledge and, in particular, to learn English. As one manager observed:

We now have many opportunities to get scholarships to study overseas. Some years ago the library sent staff to TOEFL or IELT courses - they stayed a month and then quit. But now they learn with greater determination. They try to gain the chance to study abroad. Now everybody wants to learn English. (HS-manager)

Among participants, younger staff appeared to be particularly keen when discussing how the desire to attain higher education degrees or to obtain an overseas scholarship encouraged them to learn. As a staff member said, "There are many reasons to learn.

Getting a higher degree is one" (BT-super3). One member in another library noted:

Maybe, in our library, nobody speaks out but everybody learns because we want to accumulate knowledge in order to catch opportunities to get a higher education overseas. (HV-staff2)

On a more personal level, a supervisor said:

After graduating from university I found that it is not easy to gain a scholarship for higher study overseas. I started working here. I understand that while working here I have to accumulate experiences, update knowledge and improve skills, and then I may get a scholarship. Actually, I'll never have thousands of dollars for overseas study. The university also never pays such huge amounts of money for staff learning. Therefore I have to look for an overseas scholarship. As you know, they only give such scholarships to outstanding people. To gain a scholarship has become my learning motivation. It may be a huge goal and I may never get it, however, it motivates me to learn. (HK-super5)

However, for managers and middle-aged staff, this element was not mentioned as a major factor in their own learning motivation. As presented in Section 4.2.1, three of 
the ten managers had a $\mathrm{PhD}$ degree, five managers had a Master's degree and two held a Bachelor's degree. They all appeared to understand that achieving a higher education degree is an indispensable requirement for managers at this time. However, currently no university in Vietnam offers a $\mathrm{PhD}$ programme in LIM. Therefore, except for one, the managers without a $\mathrm{PhD}$ degree found that they did not have the opportunity to obtain higher education. As the manager in Tan Binh said, "I don't have any chance to upgrade my degree, so I don't think about it." Only one manager, who gained her Master's degree at an overseas university, expressed a desire to pursue a doctoral degree overseas, which encouraged her to keep learning.

As seen in the discussion above, engaging in higher education particularly inspires younger practitioners. This inspiration affects their enthusiasm for learning and learning content; for instance, they become keen to learn English. However, the lack of opportunity for $\mathrm{PhD}$ study and the government policies and social perceptions concerning age discussed earlier discourage older practitioners from pursuing higher education degrees.

Together with achieving higher degrees, progressing in their jobs and reaching a higher position motivated the participants to engage in learning. Many managers mentioned that staff pursue learning because of hopes of promotion. One manager observed, "I know that some staff learn with a plan to achieve a certain position" (TB-manager). Another manager commented:

CE now is not just a duty or obligation. Staff learn because of their desire for promotion. They understand that to succeed in their career, they have to study. As an example, only by engaging in learning they can satisfy the criteria of the different civil servant ranks that the government requires. (HH-manager)

These observations were supported in the group discussions. Many younger staff directly mentioned that getting a promotion was a key objective that greatly inspired them to learn. For example, the participants in Dam Sen and Hai Van mentioned that all people have an aspiration or a plan for the future that motivates them to work and 
learn. This fundamental need encourages them to learn at any cost. One younger staff member said:

I think that everybody wants to be successful; everybody has a certain aspiration. Each person has ways to reach their aims - me too. I often think about how I can progress. I know everything has its price but we should move on. (DS-staff3)

More openly, a staff member emphasised ambition as a strong motivator for her to learn. She said:

Honestly speaking, I study because of my own future, because of succeeding in my career. I don't want to stay in the same place.... This need strongly encourages me to continue learning. (BT-super3)

The preceding data show that achieving higher education and the prospect of promotion are considerable motivators for the participation of practitioners in CE. It is possible that this motivation is a consequence of the expectations of society and families for young people, as discussed in Section 5.1.3. The younger practitioners seem to be aware that they are expected to and have the privilege of furthering their education. As a result, being successful becomes the goal that encourages their CE.

\subsubsection{Attitude towards the job}

Together with the need to be successful, disposition of individuals towards their jobs also affected their learning pursuits. Dedication to the job and a belief in the future of library work motivated practitioners to learn. Likewise, a lack of dedication caused disinterest in CE.

"There is no motivation to keep learning, if a person doesn't love her job" (DSmanager) was a comment representing the view of many participants. For managers, belief in the value of library work encouraged them to devote themselves to the task. As a result, they learned in order to handle their jobs more effectively. For example, one manager said: 
Being aware of the value of the profession, I like the library job more... I understand that our profession has significant value. Furthermore, we know that LIM is a science; the library is a teacher of teachers... I mean, loving the job and understanding its value strongly motivate us to keep learning. (HS-manager)

This opinion was emphasised more by operational staff. Many staff used phrases like "passion for the job" or "interest in the job" to describe their motivation to engage in CE. Here are some of their opinions:

My passion for the job is the main motivator for my CE. If I don't have such passion, nothing encourages me to learn. When I don't like my job, I can't learn about it. (HT-super1)

I learn primarily because I like my job... you know, some years ago I had a chance to get another job, but I like this job so I stayed with it. (DSsuper2)

I think when we love our jobs, we will learn at any cost. Discouraging words from outside can't have any impact on me. I like the job so I learn in order to understand it more and handle it better. (TB-staff4)

Some others seemed to place more emphasis on the potential for a better position in their work as their learning driver. As an example, the supervisors and senior staff in Hoan Kiem shared this view:

Yes, we work for a low salary but when we can see a promising future, when we believe that we will have a better position, we will stay with the job... when we can see the potential to develop our careers, we will learn. (HK-super1)

Further, because of a love of and belief in their jobs, some participants felt compelled to assert the value of librarians to the public by becoming competent professionals. For example, to convince those close to her of the value of library work, a young staff member engaged in learning. She said:

I like library work... they [relatives] questioned me about the meaning of LIM.... When I had just started working here, I could only answer: "It is quite an interesting job."... I learned about the web and OPACs (Online 
Public Access Catalogue) and then I could explain to them how wonderful it is when a librarian can guide people to access to proper information from different sources. (BT-staff2)

The supervisors and senior staff in some libraries mentioned that love of their work informed their professional ethics. They explained that dedication to the job compelled them to work with "responsibility and conscience" (DS-super2) - they cared about the needs of clients, and wanted to provide professional services to clients, therefore they learned in order to perform better. One supervisor said:

Yes, we love the job so we have professional ethics. Actually, when people don't like their job, they do their job in order to just do the job; they don't need to learn much. But we love our job. We want to carefully and effectively deal with the job. Therefore we have to learn. (HH-super4)

These data revealed that love of the job engenders a professional ethic which in turn motivates practitioners to improve their competencies. More evidence in support of this point can be found in Section 5.1.2. The participants thought that their improved proficiencies have brought about change in the social perceptions of library work, which in turn gives LIM a better future. It should be noted that the participants who felt dedicated to the job were also those who had a positive attitude in response to the public views of librarianship. Dedication gave them enthusiasm for learning and commitment to pursuing a library career, despite being aware of the low status and low income of library practitioners.

Likewise, the data provided diverse evidence from staff comments to illustrate the negative effects on $\mathrm{CE}$ of a lack of dedication to the job. In some focus groups participants considered that, when library staff perceive their job as "tedious work and with no bright future" (HS-super1), they forget about learning. For example, senior staff members in Hoan Kiem mentioned that they sometime felt bored with their job, which diminished their enthusiasm for learning. One said, "Yes, everyday our work is book processing. Books, books and books all the time - nothing is new. It's so boring" (HK-super2). Senior staff members in Hoa Sua admitted that, because they could not see a bright future for library work, they sometimes became stagnated and ignored learning. One member said: 
When people don't feel secure about the future of the job, they don't think about career ambitions. The young might strive, but people like me just wait for the day to retire. Nothing encourages me to learn. (HS-super3)

A young IT staff member in Hai Van also stated that doubts about the future of LIM was a reason for him to think about changing jobs. He cited:

I wonder whether we can keep pace with changes in our society. I think I won't work here when I see that my ability doesn't fit with this job... actually, for handling the job I don't need to learn more. I can say that I'm overqualified for my current job here. Already three years have passed with no change in the IT system. (HV-staff1)

Supervisors in Hong Ha provided observations about the lack of dedication among young staff in their library. As key persons in charge of instructing and assessing the staff in their sections, these supervisors appeared to understand the feelings of staff. One observed, "Actually, library work isn't an interesting job for many people, so there is no desire for them to learn" (HH-super1). Another added:

The work is quite boring for the young. They are now very realistic. They want chances to earn big money. They like more challenges. In doing this work, basically we do the same things day after day. It doesn't excite the young staff. Therefore, some of them don't invest much energy in this work, don't like this work and don't want to stay with it for long. (HHsuper2)

Some supervisors observed that younger staff may ignore the need to improve their LIM competencies but instead focus on learning skills to improve employment opportunities outside libraries. As one supervisor noted:

Actually, they also keep learning but they learn Law or Education management. That means they learn so they can acquire other degrees in order to find other jobs. (HH-super3)

The preceding data demonstrate that a lack of dedication to the job discourages practitioners from improving their competencies. It could be argued that the public's low image of library work, as discussed on Section 5.1.2, and the lack of professional leadership, as discussed in 5.2.3, might also cause the lack of adequate attention to 
the development of the LIM profession. Accordingly, some practitioners cannot see a future in the profession and, therefore, view $\mathrm{CE}$ as pointless.

It is evident that the goals and attitudes of individuals have an important effect on CE. An understanding of the aspirations of individual practitioners would assist in encouraging them to engage in learning. Analysis of the data suggests that dedication to the job has a significant impact on the pursuit of learning, therefore, enhancing staff's sense of job commitment is important for their CE.

\subsubsection{Family conditions}

Finally, regarding individual factors, analysis of the data shows that each individual has distinctive family commitments and/or support that can be enablers or barriers to his or her CE.

It should be noted that family commitments were already discussed as a barrier to female practitioners $\mathrm{CE}$ in Section 5.1.1, however individual female practitioners have different family conditions and so the degree to which commitments affect their $\mathrm{CE}$ is different. Male practitioners also have their own family commitments. To examine the influences of individual factors on CE comprehensively, the effects of family commitments are further discussed here.

Female managers felt they had the ability to manage their time well, but they did not find it easy to arrange their housework to allow time for study. For example, one manager said:

I know that I have to keep up-to-date and in fact learning is a pleasure to me. However, as a woman I have to handle my housekeeping, cooking, shopping and many other things. This is a really big problem for me. (HSmanager)

Female operational staff provided more evidence of the effects of family commitments on their CE. Many of them agreed that family duties limit their learning opportunities. In some focus groups, the discussions about the differences 
between women with families and those without showed that female staff with families had more barriers to learning. Here is an example of comments made:

We can see the difference between a married and a single woman. A person like X [a single woman in the focus group], who hasn't a family yet, can freely go to study while Y [a married woman in the focus group], who already has a family, has to consider whether she should go. I know that, even if Y has a scholarship, she still has to think what will happen when she leaves her family behind. (HK-super5)

In particular, staff with young babies noted that it was hard for them to pursue learning even if they really wanted to. This comment was typical:

You know, getting out of the office to go back home, I immediately forget all my work - my motherhood occupies my mind. It is very difficult for me to handle all my duties. My baby is still quite young. I can't do anything better. (HS-staff1)

For female staff who are single mothers or who do not have financial support from their husbands, the learning opportunities are even fewer. As the manager in Tan Binh observed:

A few staff have very difficult family conditions, for example, a single mother with two children. They can never go to CE courses in the evenings or do something like self-learning. They can only participate in $\mathrm{CE}$ activities during office hours.

As seen in the preceding data, family commitments are barriers for the CE of female practitioners. However, for male practitioners, analysis of the data reveals that, although family commitments may lessen the CE pursuits in some cases, they are not a significant barrier. Some staff claimed that, because library practitioners' incomes are low, male staff often have a supplementary job and so do not have much time or energy for CE. As a supervisor noted, "Since men usually have a second job in the evenings, it is hard for us to attend CE activities that aren't held in office time" (TBsuper2) and a younger staff member said, "Everybody needs money to support a family. I always have to think about how to earn money" (HS-staff3). 
However, no male managers indicated difficulties in supporting their families financially. Perhaps, this is because they were successful men who were all in their fifties, who had been working for many years and whose children had grown up; therefore, they did not have a heavy family financial load.

In fact, the data revealed that family was a great support for the learning of many male participants, younger staff members and some female practitioners. Most of male participants felt that the families were their motivation. Of the 16 male staff interviewed, 12 mentioned that their families supported them in attitude and 4 said that their families supported them both attitudinally and financially to attend learning. For example, one reported:

My wife always encourages me to learn. I still remember I was pursuing a part-time undergraduate programme when my family was in very poor circumstances. My wife took full responsibility for taking care of the family. For me, family is a big source of support. (TB-super3)

Many younger staff who recently graduated from university emphasised support from their parents. This point was already discussed in Section 5.1.3, but one more example is presented here: "My parents give me great support. They willingly pay for my learning. They don't care how much or for how long they will pay." (BTstaff2)

Finally, some married women commented that financial support from their husbands allowed them to stay in their library jobs and keep learning. On behalf of all members in her focus group, one supervisor in Hong Ha said,

Our incomes are low. If our husbands can't support us, we could never stay in this profession. If they can't support us, we can't think about learning. (HH-super4)

A few female participants acknowledged the encouragement of their husbands as a factor. As one manager cited, "My husband is a military officer. He always encourages me to pursue my professional career. For me, family is a source of encouragement" (TB-manager). 
As shown in the preceding data, in most cases, family commitments create a barrier for the $\mathrm{CE}$ of female practitioners. Such commitments limit time and energy for pursuit of learning. In some cases, family commitments also are a barrier to the $\mathrm{CE}$ of male practitioners. Their responsibilities as bread-winners do not allow them to spend much time and energy on CE. At the same time, however, family is considered a great support by many younger staff and male practitioners. Therefore, the family conditions of each individual can be barriers to or enablers for his or her CE.

It should be noted that these data also reflected the effect of gender on CE. It is suggested that female practitioners have greater disadvantages than their male counterparts in relation to CE opportunities.

The perceptions of participants, including managers and operational staff, reflected that each practitioner is unique and each aspires to his or her goals, both personal and professional. Personality, educational background, age, gender, ambitions, attitude towards the job and family conditions together contribute to individuals' needs for CE participation and learning content. In particular, the data revealed that individuals with self-confidence, self-esteem and learning orientation tended to be more active in learning pursuits; participants with an educational background in LIM tended to pursue library careers more than those without LIM education; younger practitioners with LIM qualifications were more likely to pursue higher degrees; practitioners who were dedicated to the job seemed keen to engage in learning; and female practitioners had more limitations on their CE than their male counterparts. All these factors must be considered in planning effective $\mathrm{CE}$ for practitioners.

It also should be noted that although the sample sites included university libraries from different parts of the country, the data were not collected in a manner that permitted examination of the possible effects of differences in the interviewees' individual backgrounds, i.e. people from small or large cities, or people from rural or urban areas. Further, data were not collected in a manner to permit examination of perceptions of women's role in society based on interviewees' backgrounds. Further research is required in both areas. 
In summary, this chapter examined the effects of social, professional and individual factors on the $\mathrm{CE}$ of university library managers and operational staff in Vietnam. Together with the findings discussed in the next chapter, this provides an understanding of factors affecting $\mathrm{CE}$ for university library practitioners. These findings address the first two research questions and are used to assess and revise the preliminary model. A summary and further discussion of these findings are presented in Chapter 8 when the model is assessed. 


\section{CHAPTER 6: ORGANISATIONAL FACTORS AND PRACTITIONER AND ORGANISATION NEXUS}

This chapter continues to examine factors affecting CE for university library practitioners in Vietnam. It focuses on organisational factors and the nexus between individual practitioners and organisations. Together with the previous chapter, this chapter addresses the first two research questions ${ }^{5}$ and contributes to the base for assessing and revising the preliminary model.

The findings from data in this study are consistent with Nowlen (1988) and other authors in adult education and CE (e.g., Houle, 1996; Jarvis, 2004) about the effects of the characteristics of the working environment in which individuals practise. Participants across the sample libraries pointed out the influence of the policies of organisations, including central government, universities and libraries. They highlighted the effects of working climates and relationships between staff members in the institutions. In particular, most participants emphasised the influence of managers. Finally, the features of current $\mathrm{CE}$ activities were also identified as a significant factor affecting the $\mathrm{CE}$ of practitioners.

While participants were discussing the effects of various organisational factors, the nexus between individual practitioners' needs and those of the organisations also emerged as one of the key factors affecting CE.

\subsection{Government policies}

The data revealed significant effects of the government policies on the $\mathrm{CE}$ of practitioners. These include policies on civil servant standardisation, salaries, retirement and personnel. As the effects of the latter two policies have already been discussed in Section 5.3.2.1, only the civil servant standardisation policy and the salary policy are examined here.

\footnotetext{
${ }^{5}$ RQ1: What are the contextual factors that affect CE for Vietnamese university library managers and operational staff?

RQ2: How do these factors affect CE for Vietnamese university library managers and operational staff?
} 


\subsubsection{The civil servant standardisation policy}

Becoming an official civil servant in Vietnam ensures a secure and lifelong job with benefits that include health care, social insurance and a retirement pension. According to the Ordinance of Civil Servants issued in 1998 and revised in 2003 (Standing Committee of National Assembly, 2003), Government Decree No. 116/2003/ND-CP on the Recruitment, Employment and Management of Civil Servants (Government of Vietnam, 2003) and Circular No. 10/2004/TT-BNV on the Recruitment, Employment and Management of Civil Servants (Ministry of the Interior, 2004), employees must pass an examination in order to become civil servants. All professions and institutions in Vietnam are governed by these regulations. The compulsory segment of the examinations consists of general and professional knowledge. General knowledge includes foreign language proficiency, computer skills, knowledge of civil laws and the current documents and resolutions of the Communist Party Congress. Professional knowledge depends on the particular requirements of each field.

Currently, university library practitioners must become civil servants, but can apply for either the librarianship or the bureaucracy ranks. The Ministry of Culture and Information sets the examinations for the librarianship ranks. The frequency of examinations varies, depending on the plans of the Ministry. The content of the examinations covers the compulsory general knowledge mentioned above, and the LIM knowledge and skills stated in Decision No. 428/TCCP-VC on Professional Criteria for Civil Servant Ranks in Culture and Information Fields (Committee of Governmental Organisation and Personnel, 1993).

University library practitioners can also enter into the bureaucracy ranks as officials who assist with the teaching and learning in universities. MOET or VNU-HN or VNU-HCMC set the examinations for employees under their administration who are in the bureaucracy ranks. The frequency of examinations varies, depending on the needs of the universities. Currently, they are organised annually or biennially. In addition to the compulsory general knowledge mentioned above, the examinations 
cover knowledge of education law and the regulations of the administrative system in government organisations.

According to many participants, although the standardisation policy for civil servants has been promulgated since 1998, the implementation of the policy has lacked uniformity and consistency across university libraries. The participants mentioned two main inconsistencies. First, not all university libraries arrange for staff to take part in civil servant examinations frequently. Second, not all university library practitioners apply for civil servant ranks in librarianship. These differences coloured participants' perceptions about the influence of the policy on their CE.

Regarding the first inconsistency, as discussed in Section 5.1.2, many universities lack a staff recruitment strategy for libraries and do not have specific recruitment criteria for library staff. When the Ordinance of Civil Servants was introduced, in several libraries such as Hong Ha, Ben Thanh and Dam Sen, the long service practitioners gradually took examinations to make their civil servant rankings official, and junior staff were required to pass the entry examination. Therefore, the practitioners in these libraries had plans to reach a certain rank, such as librarian or senior librarians. As a result, the prerequisites for taking civil servant examinations and the content of the examinations influenced their learning needs. As the manager in Dam Sen said:

To enter a civil servant rank or to get higher rank, we should pay attention to the required criteria and try to learn in order to reach those criteria. We want to be ready to pass the examinations. For example, a couple of years ago, doing research was ignored. We never cared about this thing. However, now doing research is a requirement for Senior Civil Servants. We now care about it and have started doing research tasks.

The staff in these libraries also agreed that the need to pass the examinations required them to learn. As one supervisor said:

Yes, the standardisation policy impacts on us very much. We just took a foreign language test as a requirement to attend the civil servant examination and recognised that our proficiency does not meet the 
requirements. Thus, we have to learn more seriously now. We are hurrying to learn now. (DS-super3)

However, in Hoa Sua and Ho Tay, practitioners seemed unaware of the examination criteria and procedures. They did not think that the civil servant policy directly affected their learning. As one participant reported:

We were informed about the examination 10 days before it was to be organised. The library hastily reviewed staff to find who satisfied the prerequisites for the examinations. So far, information on examinations is unclear and the examinations are not held frequently. Therefore, they don't impact on our learning. (HT-staff3)

In Tan Binh and Hai Van, line staff were not even given information relating to the policy. Line staff in Tan Binh shared this comment:

We are not informed about civil servant examinations and information concerning them... many staff who have been working here for many years don't even know the frequency of such examinations. I don't think the policy has any influence on us. (TB-staff5)

Since the implementation of the policy has been inconsistent across the sample libraries, the data revealed different views on the effects of the policy. It seems to have no effect on the $\mathrm{CE}$ of practitioners in cases where they are uninformed about the procedures of the examinations. However, it significantly affects learning needs if civil servant examinations are organised regularly and planned towards.

Regarding the second inconsistency, some managers explained that, since the Ordinance of Civil Servants allows practitioners to transfer their civil servant ranks when needed, university library practitioners can take examinations in either the bureaucracy sector or the librarianship sector. As a result, practitioners across the libraries had accumulated different prerequisites and learned different content for the examinations. They discussed their views about civil servant examinations.

Staff who had taken bureaucracy examinations explained that they had to learn specific content because they needed to pass the examinations, not because the 
content was useful for their daily tasks. They viewed the current civil servant examinations as a means to "officialise" rather than to "standardise" their civil servant ranks. Therefore, in their opinion, learning in order to pass the examinations was merely a reaction to the policy rather than a motivator to improve their competency. This comment was typical:

To pass the exam I had to learn how to draw up a text file, the government structure, the rights and responsibilities of the president and so on.... These things are just general knowledge. I learned them only because I needed to pass the exam. You know, I don't remember any of those things now. Actually, we can gain such knowledge by reading newspapers or watching TV, but we don't apply such knowledge in our daily jobs. We are librarians - we need to master other knowledge and skills. (BT-super5)

Staff who had taken the examination in librarianship reported that the actual content of the examinations did not really reflect the knowledge and skills required for their jobs. As one member said: "Actually, it was hard to study all of the prescribed content for the exam, but in the end the exam only focused on general knowledge" (HH-staff1).

At the same time, however, some participants pointed out that the civil servant examinations were at present a formality, but in the near future their quality would be improved and this change would affect what the examinees would have to learn. As a supervisor explained:

Currently civil servant exams are just a way to "officialise" the title of Librarian. For the moment, we have to accept this situation because, for a long time, librarians hadn't many opportunities to update. In small or remote libraries, most librarians are in their late working years and their learning opportunities are limited. They would never reach a high professional standard. However, the examinations will be more demanding very soon and staff will have to study seriously to pass such exams. (HHsuper2)

In addition, some managers, supervisors and senior staff members affirmed that in the near future all library practitioners would have to enter the librarianship ranks through the civil servant examinations and the civil servant policy would affect 
staff's learning needs considerably. As one member asserted, "I am sure the standardisation policy for librarians will be applied consistently soon and will affect the CE of practitioners" (HH-super1).

Again, because the civil servant standardisation policy has been implemented inconsistently across libraries, it has had different effects on practitioners' CE. However, some participants were of the view that the policy will soon be implemented in a consistent manner and, when it is, it will become a motivator for $\mathrm{CE}$ and, particularly, compel practitioners to pursue learning in the prescribed areas.

\subsubsection{The salary policy}

Most participants considered their low salaries as a significant barrier to learning. Currently, government salaries for civil servants in every profession are based on their academic degrees, civil servant ranks and positions. However, as participants in several libraries commented, the basic government salary is very low compared with living costs, and libraries cannot provide opportunities for supplementary income. Participants also mentioned that the current rapid development in Vietnam is causing great differences between the income of employees in government and private organisations, between academic and commerce fields, and between local and international organisations. In many government organisations in commerce fields, the organisations can improve the salaries of employees by offering supplementary work. But in government organisations in academic fields, particularly libraries, such opportunities are rare. Without supplementary income, it is very hard for library practitioners to live. As one manager commented:

It is very difficult to keep learning when one has to work hard for a low salary. We only have a basic salary... this really is a discouragement for us to learn. You know, we say that a woman working in library is fed by her husband and a man working in library is fed by his wife. Therefore, to encourage staff to stay in the job is hard enough; to encourage them to keep learning is even harder. (HG-manager)

Sharing this opinion, five other managers observed that the low salary not only discourages $\mathrm{CE}$ among staff, but also makes it difficult to retain proficient 
practitioners. In particular, the low income might diminish the enthusiasm for learning of junior and talented staff and could lead them to change jobs. The comment of the manager in Thanh Da was representative:

The biggest barrier is salary. We can't require much of staff because the salary is so low. You know, many of our staff, when they become proficient, find other jobs or go to other organisations offering higher income.

Staff also emphasised the negative effects of the low income. As a supervisor said, "Our salaries are small, so taking away part of it for learning fees is extremely difficult for us" (HK-super2). Similar ideas appeared in many focus group interviews. In particular, some male practitioners who were the main income earners in their families emphasised that they did not have much time for learning because they had to take a supplementary job to improve their family finances. For example, a male senior staff member said, "The salary is low but we have to live. I have to find a way to earn more money. This always occupies my mind" (HS-super5). A younger male staff member explained that, because his salary was low, his learning priorities focused on getting paid more, not improving in his daily library job. He said:

Generally, I learn because of the requirements of the job. However, I usually prioritise my learning needs. I will firstly learn what helps me to get paid more. Because of the living costs, we need money. (HV-staff1)

The preceding data demonstrate that practitioners tend to supplement their low primary incomes with additional employment, thus limiting the time and energy available for $\mathrm{CE}$ as well as for their library jobs. The low salary also is a reason for staff to look for other jobs, thus discouraging them from enhancing their LIM proficiencies. The low salary also means staff are less able or less inclined to participate in CE programmes when they have to pay the costs themselves.

It is recognised that the effects of government policies are part of the effects of the political and economic system. In other words, in this study, the effects reflect the 
effects of the lead organisation at the highest level, as well as the political and economic systems, on the CE for practitioners in Vietnam.

\subsection{University and library policies}

As mentioned earlier, nine of the participating managers were library directors - they were the key persons involved in setting library policies and in charge of proposing annual development plans and projects for their libraries. These managers appeared to understand clearly the administrative regulations and policies relating to staff development, evaluation, promotion and bonuses within their institutions, and the influence of those policies on the CE of library practitioners.

The level of understanding by operational staff of the various policies, however, differed across libraries. In Ben Thanh, Thanh Da, Dam Sen, Hai Van, Hoa Sua and Hong $\mathrm{Ha}$, staff appeared to understand their institutional policies and could indicate the influence of the specific requirements or expectations of their institutions. In the remaining libraries, staff did not seem to be very clear about these issues. Nevertheless, regardless of how well they understood their institutional policies, they all agreed that the policies had effects on their CE.

\subsubsection{Library development plans}

As mentioned in Section 4.1.3, the administrative features, finances and development strategies of the whole administrative system including the individual libraries, universities, and functional ministries, influence library activities. Library development plans or projects and policies have to be based on those of the parent university and higher institutions. As one manager said, "Our annual development plan has to fit with development strategies of the university.... To identify priority activities, we need to base it on their plan" (DS-manager). Analysis of the data shows that such plans and policies were both motivation and enforcement for the $\mathrm{CE}$ of practitioners. 
In libraries which have particular development projects, such as Ben Thanh, Hoa Sua and Hai Van, the effects of these projects seemed significant. The managers in these libraries noted that both managers and staff tended to learn new competencies in the belief that the projects would accelerate the development of the libraries and create better working conditions. They tended to set learning goals and select learning content based on the current and future requirements of their libraries. As one manager said:

When I explain to staff the goals and objectives of our development project, they look for learning opportunities more actively. We all want to be competent and ready to take over the tasks in the new working conditions. We don't want to be puzzled in the modern working environment. For example, I explained to staff that in the next five years we will buy a self-issue machine, so staff who now do issuing understand that, if they don't want to face redundancy, they need to enhance their searching and reference skills to be ready to take over new tasks. (BTmanager)

Staff also confirmed the effects of their institutions' strategies, plans and requirements on their CE. "Generally, we learn in order to do the job here. Therefore, what we learn depends on the requirements of the library" (HK-super1) or "The development process of the library drives us to acquire particular knowledge and skills" (BT-staff1) were ideas voiced in the focus groups. In more detail, a supervisor pointed out how the library project determined her learning needs:

I didn't used to be interested in writing abstracts for materials. We didn't do this thing. However, in the last two years the library has launched a project to create bibliographies for particular subjects. We recognised that we weren't skilful in this job so we started learning. Next time, we will have a project to digitise special collections. We know for sure that we will need to learn skills relating to digitising collections, so we are starting to learn. (DS-super1)

In addition, discussion among operational staff in some libraries also revealed that positive staff attitudes towards the requirements of library projects and eagerness to achieve the projects' goals created a positive learning atmosphere in their libraries. This atmosphere in turn inspired all members to put efforts into their learning. This comment represented the view of staff in these libraries: 
You know, we all want to contribute to the success of our library.... We feel happy when we can accomplish a library project, so we learn what helps us to deal with the goals of the library projects. (DS-staff2)

In contrast, in the libraries which did not have specific development projects, participants seemed to lack specific learning goals. Participants in Ho Guom, for example, commented that because of "no investment" and "no particular development project" they had little motivation to learn. They did not recognise any specific learning needs and seemed to have little or no inclination to look for $\mathrm{CE}$ opportunities. One member said, "I think I am already skilful in my daily tasks" (HG-super1). Another noted:

If we have money for a specific development project, staff will learn to apply something new in our library. But now, as you can see, the library is poor and there is nothing new to do, so how could we take an interest in learning? (HG-super4)

As the preceding data show, specific library development objectives determine learning needs and the enthusiasm for learning of practitioners. The data also revealed that individual practitioners create their learning agendas based on library requirements and at the same time attitudes towards their libraries' requirements affect their enthusiasm for learning. These points reflect a nexus between the learning needs of libraries and individual practitioners, which emerged as another factor affecting $\mathrm{CE}$.

\subsubsection{Bonus and promotion policies}

Bonus and promotion policies also emerged as an element affecting the learning of practitioners. Participants emphasised that appropriate staff evaluation and bonus policies were an incentive for them to pursue learning. For example, in Hoan Kiem, the manager and staff pointed out the effect of their "Superior Belt" bonus policy. As the manager explained, the library awarded this to practitioners, including managers, supervisors and line staff, who had the highest level of expertise in specific types of jobs. Each award holder received a certain amount of bonus money every month. The award holders would lose their "belt" if they were unable to meet the requirements of 
new tasks that arose in the workplace. The participants in this library agreed that this policy encouraged them to keep learning. The manager said: "This is a good policy because it not only offers staff more money but also, and this is more important, it is an honour for staff to be recognised as an expert."

In contrast, in libraries where bonus policies were mere formalities, participants commented that the bonus did not provide much motivation for learning. For example, line staff in Hai Van agreed with this comment, "The annual bonus in our library isn't much, just a certificate. It isn't a consideration for us" (HV-staff2). In some cases, practitioners even considered the bonus policy in their university to be unfair. A senior staff member said:

When I was in a training course [overseas], the university cut all my bonuses. You see, I went to the training course to improve my professional skills so I could do the work and serve clients better, but my bonuses were cut. (BT-super1)

The policy on supplementary income was also mentioned as having an effect on CE. To improve the salary for practitioners, some libraries have offered extra paid working hours or permitted staff to take secondary jobs. Four of the ten sample libraries offered supplementary work or had particular projects which allowed them to provide staff with extra paid work. According to the managers of these libraries, practitioners attempted to acquire the required skills in order to take advantage of the additional work. As one of them noted:

The library offers different kinds of overtime jobs. If staff want to take a job with good pay, they have to have relevant competencies. If not, they can only handle physical jobs with lower pay, such as book deliveries. Therefore, they learn in order to have the well paid jobs. (HH-manager)

Staff also emphasised the positive effects of this type of policy. For example, a senior staff member said:

The university has some projects and services in which we can be paid to participate. The prospect of extra income motivates us to learn in order to have the ability to get these jobs. (DS-super4) 
In addition, analysis of the data reveals an unwritten promotion convention that affected the learning pursuits of practitioners. As a common rule in Vietnamese institutions, libraries are inclined to promote their own staff rather than to recruit outsiders to be managers. This convention provides motivation for staff to pursue learning. For example, one manager explained that being aware of promotion opportunities motivated her staff to upgrade their abilities. She said:

Here, staff understand that people like me can't stay here forever as leaders. We will retire someday therefore we need to prepare future managers to be in charge of the library. So, we encourage them to learn and they themselves are aware of this. (HS-manager)

This point was also reflected in the views of staff. A senior staff member said:

In our administrative system, management isn't a job, but power. Working in an institution for a certain time and achieving a high degree of professionalism, a person will have a chance to become a manager. Therefore to become a manager, first of all a person has to have good professional performance. (HS-super3)

The data discussed above demonstrate that extrinsic rewards have a considerable impact on improving practitioners' performance. It is an enabler for the $\mathrm{CE}$ of practitioners when libraries link learning with improved income and promotion policies.

\subsubsection{Policies for CE activities}

Finally, several institutional policies emerged as having significant effects on staff CE. Policies for staff selection, for providing time and financial support for CE, and some other specific policies emerged as having significant effects.

Regarding staff selection for CE programmes, many libraries had a similar policy to manage the limitations of finance, time and available places in CE programmes. In addition to ensuring a match between the course content and a staff member's job requirements, library managers often selected staff for $\mathrm{CE}$ programmes based on their ability to transfer the knowledge to other staff. Some managers felt that this 
policy was the fairest and best suited to their situation. One manager illustrated this point:

The staff we send [to CE programmes] must have the ability to train others.... The staff have to report what they have learned to colleagues. They have to share the updated knowledge they get from the courses. This is our responsibility to peers who don't have the chance to attend the courses... This is a very good way for us. (BT-manager)

Staff generally agreed with their managers regarding the advantages of this policy. However, they also indicated that there were some disadvantages. For example, in comparison to higher level staff, line staff had very few chances to take part in CE programmes. As one participant noted:

Why do supervisors get to go to CE programmes more often than other staff do? In fact, we all need and want to learn. Obviously, the library favours the supervisors over other staff. (DS-super5)

Another disadvantage was that there were very few chances for staff who felt uncomfortable about promoting themselves to their managers. As a staff member observed:

Each person has their own characteristics. Some like to show off and they impress managers more than those who have ability but are reticent.... Therefore, it is very common that the show-off ones have chances and the reticent ones miss chances. (HH-staff1)

Another disadvantage was that there were unequal CE opportunities for staff from different sections. Participants in a focus group in Hoa Sua agreed with this statement made by one of the interviewees:

We work in the information resources section. We actually need to understand databases, how to use them, how to create them. But in our library, the information services section takes charge of everything concerned with databases, therefore the staff in that section have priority to attend courses about databases, even though we all need such knowledge. (HS-super4) 
Many younger staff argued that one does not work in the same job forever, so every staff member needs an equal chance to diversify their skills and knowledge. They further argued that library jobs are interrelated; therefore, all staff need the opportunity to learn all essential professional skills. In addition, operational staff in Tan Binh and Hong Ha noted that, in fact, on returning from CE programmes, staff might share information person to person, but they rarely get the opportunity to conduct presentations for all colleagues. The lack of time and training experience among staff were reasons for this situation.

The policy of sending only a selected few to CE programmes may be cost effective for libraries and encourage knowledge-sharing among staff, but it can be a barrier to the CE of many staff, and may be seen as unfair by others.

Similar to the findings of previous studies (e.g., Anwar, 1998; Chan, 2002), the data suggest that organisational policies for providing staff with time and financial support for $\mathrm{CE}$ are important elements that significantly affect the $\mathrm{CE}$ of practitioners. Three of the ten participating libraries allowed staff to engage in $\mathrm{CE}$ activities during working hours. The managers in these libraries concurred with this view: "Not many staff can take time [outside of working hours] for improving their competencies - the library must provide them with time for their learning" (HVmanager). These managers seemed to be content with their time support policy and the staff seemed to appreciate the policy. They all viewed it as an enabler for CE. As one manager said:

The library supports staff CE very much. When staff need to participate in a CE course, the library lets them use working hours to study. Staff don't have to work overtime. You see, this is an enabler for CE. (HS-manager)

A senior staff member also noted, "I have gained a degree in English because the library let me go to learn in work time" (HH-super4).

Each of the remaining libraries had a policy of flexible working hours to accommodate CE. While staff were not allowed to use working hours, they were 
nonetheless able to attend CE programmes by swapping their shifts among themselves or making up the time, or managers shifted the work around in particular cases. In these libraries, many operational staff considered the non-provision of work time as a deterrent to their CE. For example, a member in Hoan Kiem said:

At this time, many of us need to take an English course. The course is held in the morning, so to attend it we have to complete our routine tasks in our own time. If we didn't have to work overtime, we all would be willing to learn... lack of time support is a barrier. (HK-super3)

In terms of financial support for $\mathrm{CE}$ there was a variety of different policies among the sample libraries. As mentioned in Section 4.1.3, three of them had external financial support, which they were able to use for internal CE courses and training projects to address the primary learning needs of staff. However, they were still very limited in what they could spend on other CE activities, including sending staff to external CE programmes, professional conferences, workshops or visiting other libraries. As one manager said:

Currently, we have funds for a training project. However, in cases where we need to send staff to $\mathrm{CE}$ activities outside the library, we have to consider carefully whether staff really need to do such activities. We will pay if the activities are really useful. However, the funding available for such $\mathrm{CE}$ activities is very small. (HS-manager)

Staff in these libraries seemed to rely heavily on financial support from the library to pay for CE activities. As one manager observed, "I have never known any staff to have paid CE fees themselves" (HV-manager).

The other libraries were completely dependent on their parent universities for funds for supporting CE. The data, including both the interviews and documentary evidence (e.g., university regulations for internal finance and annual reports), showed that four universities had similar policies for providing financial support. At these universities, there were three different ways of providing financial support for CE: (1) conditional reimbursement, (2) half-payment, and (3) full-payment. Conditional reimbursement meant that practitioners had to pay their learning fees in full. When 
they successfully completed the learning activities and presented evidence, such as a certificate or diploma, the universities reimbursed the practitioners either $70 \%$ or $100 \%$ of the learning fees. Half-payment meant the universities paid half the CE fees for each practitioner without any conditions attached and the practitioner paid the other half. The full-payment method meant that the universities paid the full cost of the CE directly to the providers. The method chosen depended on the universities' assessments of the learning needs for their staff and the content and quality of the specific CE programme or activity.

The managers in these four libraries believed that this type of policy, though not ideal, was adequate for their staff. As one manager claimed, "The university can't satisfy all our needs, but it does provide relatively good support for staff to learn" (TD-manager). From the perspective of the operational staff, this type of policy was reasonable and provided support for their CE, though some staff members complained that the half-payment method was still a barrier to CE. For example, senior staff from Ben Thanh shared this comment:

Usually, to attend courses organised by our university, we have to pay half the course fee. It would be great if the university didn't ask us to pay - it would be an encouragement because not all staff can readily afford even half the fee. (BT-super2)

In the remaining three libraries, the participants said that their libraries did not have specific funding policies for CE. In general, practitioners in these libraries undertook $\mathrm{CE}$ activities that did not require payment or they themselves paid in full. Since library staff salaries were low, the lack of financial support from their libraries was a big barrier to their learning. As a supervisor said, "It is a big difficulty if I have to take one-third of my salary to pay learning fees" (HK-super4).

Participants across the sample libraries emphasised that sufficient time and financial support made CE more possible for them. Though it was highly unlikely that any of the libraries had sufficient financial resources to satisfy all the CE needs of all practitioners, the data suggested that when the libraries considered it their responsibility to improve staff competencies and to arrange time and financial 
support for staff to participate in $\mathrm{CE}$ activities, these actions acted as major enablers for the staff to participate in CE.

Finally, the data revealed two examples of unique policies that were specific to institutions and that affected the CE of the staff in those institutions. These policies were the "job rotation policy" in Hoan Kiem and the "learning commitment plan policy" in Dam Sen.

In Hoan Kiem, under the job rotation policy new staff are required to work for about six months in each section of the library before they are allowed to settle into one job. This requirement is an opportunity as well as a challenge for staff to learn essential professional LIM skills. All participants in this library agreed on the usefulness of the policy.

The second example was in Dam Sen. Every year each practitioner in Dam Sen must submit a learning commitment plan that he or she promises to follow. In this plan the practitioner is required to describe new learning content needed for his or her job and the ways that he or she can achieve the goal of learning this content. At the same time, based on information from the plans of all staff, the managers establish a CE plan for the library and submit it to the Board of the university for approval and financial support. The degree to which staff members have achieved their annual learning commitment plans is then used as a criterion in their annual performance appraisals. All participants in this library recognised that this policy stimulated them to participate in CE. As one participant commented, "We became more engaged in CE when this policy was implemented in the library" (DS-staff5).

However, some libraries did not appear to have specific CE policies. As an example, a line staff member in Tan Binh said that "the managers often encourage us to learn but the library doesn't have a particular policy about CE" (TB-staff2)". Staff in several libraries suggested that, without targeted policies or methods that committed them learning, they were less likely to engage in CE. As one staff member said: 
When we have no requirement to learn... I wonder how many staff here have a strong will to pursue learning? I myself understand that I need to improve both professional skills and English proficiency, but nothing pushes me so I delay my learning. I really don't know how long I will delay it for. (HH-staff5)

Analysis of the data suggests that targeted policies or enforcement from organisations may motivate practitioners to engage more in learning. It is an enabler for practitioners' CE when the library requires their self-commitment to learning and assists them in meeting their commitment.

The data discussed in this section show that university and library policies have direct effects on the $\mathrm{CE}$ of their employees. Policies on $\mathrm{CE}$ reflect the concern of an organisation for the development of its human resources. When a library requires its staff to commit to learning and assists them in meeting their commitment, these measures act as enablers for practitioners to participate in CE. Although the policies may not meet all the needs of all practitioners, where they exist they make it more possible for practitioners to engage in learning activities. A lack of policy on $\mathrm{CE}$ discourages staff from learning.

\subsection{Working climate}

Working climate is another important organisational factor that participants emphasised as affecting their CE. This factor consists of workload, infrastructure, working environment and relationships between colleagues.

\subsubsection{Workload}

Workload emerged as the main barrier to CE both for managers and staff in this study. Although the barriers for managers' CE were many, it seems that workload and lack of time were their most significant ones. Being in charge of not only managerial but also professional tasks, being involved in teaching as a secondary job in the case of seven managers, and being responsible wives and mothers in the case of the female managers, left very little time for learning. They were fully aware that 
keeping up-to-date is crucial for a manager; but a heavy workload and lack of time made it hard for them to participate in CE activities. This comment was typical:

Yes, lack of time - it is the most difficult for me and then workload. It is hard to focus on studying when work always occupies my mind. I always have a lot of tasks to deal with. (HT-manager)

The managers also recognised that workload and lack of time were barriers to the CE of their staff. It was difficult for managers to arrange time or swap shifts for staff to join in CE activities, particularly for the staff in information services. In this section, staff could not reschedule their tasks as they had to be available to serve clients at any time. As one manager emphatically stated, "Working at full stretch takes all of our time... no time for learning" (HG-manager). Another manager explained:

We all have to face a heavy workload. Staff have to serve clients from morning to evening, deal with professional issues... and participate in library projects.... Therefore, it is very hard for them to manage time for work, family and learning.... It is quite bad... when staff have a chance to study, we can't arrange for them to go. (DS-manager)

The workload and lack of time were also discussed in focus group discussions. This comment was echoed by many staff:

A barrier to CE is the pressure of work. The number of students is huge if just one staff member is absent for a week, the others can hardly cover all the work. (HH-super1)

Many staff who worked in technical services said that they could arrange time for CE activities when needed, but they had to complete their routine jobs in the evenings or at weekends to compensate. Therefore, as emphasised by operational staff, the "overwhelming volume of work" (DS-staff4) and "no time for relaxing" (BT-super3) were barriers for them. Even in the libraries which allowed staff to use working hours for CE activities, for example in Hoa Sua and Hai Van, the workload and lack of time were still barriers. As the staff explained, they did not have to work overtime but, because staff members had specific tasks which nobody else could take over, they had to complete their tasks anyway after returning from $\mathrm{CE}$ activities. 
It is recognised that, in all libraries, the managers indicated workload as their primary barriers to CE. A heavy workload and lack of time also were significant barriers to CE for operational staff.

\subsubsection{Infrastructure}

In terms of working climate, participants considered that infrastructure, including facilities, work spaces and opportunities to apply what is learned to the workplace, influenced their CE. In libraries with a less developed infrastructure in terms of work space and facilities (for example, the lack of a security system, or an old building not designed for library functions, or the lack of an integrated library system), managers and staff noted that "poor working conditions" (HG-super1) impeded their learning because they had few opportunities to apply what they learned to the workplace. As one member said, "It is hard to apply new things here" (HT-super1). Another stated: "We could not do anything better in such inadequate working conditions" (HGsuper3). Operational staff in Ho Guom and Tan Binh seemed very puzzled when asked to specify their learning needs - some said that they were qualified enough or even over-qualified to perform their tasks. As a senior staff member said, "We don't have an automated system, we do everything manually, so I don't think we need to learn anything more" (HG-super2).

In contrast, in libraries such as Hoa Sua and Hai Van that had a good infrastructure with modern facilities, high internet capacity and large spaces, the practitioners seemed to be eager for learning. They expressed pride in their work place and were happy to work there; therefore, they learned in order to keep their jobs. In addition, they recognised that the modern infrastructure allowed them to apply what they had learned and this motivated them to learn. In turn, the modern infrastructure required them to learn more in order to work productively within it. As the manager in Hai Van observed:

Compared to other libraries, our library has very good working conditions. We all are proud that we work here. We have facilities to assist us with working and learning... therefore, staff want to improve their proficiencies in order to retain their jobs here. 
Similarly, one staff member from Hoa Sua said:

Working in such modern conditions, everything is new, everything is fashionable. We need to learn how to work with such equipment and have the chance to apply new techniques. I recognise that library jobs now require us to be knowledgeable and skilful. I myself now really want to learn in order to be confident to work here. (HS-staff4)

In Hoan Kiem and Hai Van, staff members even went on to explain the use of multimedia equipment, the internet and professional software as learning tools. For example, the manager and staff in Hoan Kiem described how their intranet facilitated their learning. This intranet assisted them to be free and comfortable to discuss all issues in their daily work, to share information and experiences among staff and to get feedback from managers. They thought that this tool particularly helped them to learn from each other. The manager explained:

We have special software assisting us to communicate in daily tasks. We post reports, experiences, information and news on this intranet. By doing so, we can share experiences and learn from each other.

Analysis of the data reveals that working conditions can stimulate practitioners to learn. Practitioners are keen to learn when working conditions foster pride in the workplace, require staff to possess particular skills to work, allow them to apply their learning, and encourage them to take initiative. In contrast, where there are inadequate working conditions and a lack of workplace pride, practitioners find little use in learning and, therefore, neglect to learn.

\subsubsection{Working environment}

As Nowlen (1988) suggested, "An individual is never just an individual” (p.65). He explained that an individual is affected by the environment in which he or she lives and works. In particular, the performance of people around him or her has an influence upon the individual's performance. In this study, it was not surprising then that participants perceived that the university and the library environment affected their learning pursuits. 
Regarding the effects of the university environment, both managers and staff recognised that working in an academic environment like a university was a pressure as well as an opportunity for their CE. They explained that universities increasingly required all staff to achieve higher education degrees. In reality, the majority of academic staff and faculty members have gradually attained Master's or $\mathrm{PhD}$ degrees. Library practitioners are also university staff, therefore, they face the same educational requirement as staff in other departments. This requirement and, at the same time, the learning efforts of people in their universities motivate the $\mathrm{CE}$ of library practitioners. As one manager noted:

Staff in other departments gradually become Masters or Doctors. Looking at them, we understand that we have to have an equal qualification. I start to strongly encourage my staff to go to Master's programmes. (TBmanager)

A senior practitioner who went to a LIM Master's programme told about her experience:

I am not sure whether I would join a Master's programme if I worked in a library which was not a university library. Maybe, I wouldn't. No, definitely I wouldn't. I don't think I'd need a master's degree if I worked somewhere outside a university. I have many family and financial problems. They are hard enough for me to struggle with. However, working in a university, most people around me have a master's degree. This environment is good for studying; I can't stay at the same level, so I have to keep learning. (BT-super1)

In addition, working in an academic campus gave library practitioners learning advantages. They could attend classes as long as the subject was relevant to their job, as the supervisors in Tan Binh and Ben Thanh mentioned. They could easily access information about Master's programmes, English or computing courses and only needed to pay half the learning fees if such programmes were held in their universities, according to the participants in Ben Thanh and Thanh Da. These advantages are $\mathrm{CE}$ enablers specific to university library practitioners. 
Regarding the effects of the library environment on CE, participants considered that changing demands from their work environment drove them to keep learning. It was a pressure but at the same time it was a motivation to learn. As a supervisor noted:

Everyday we get demands or suggestions to do something new from the Board of Managers; therefore we have to move on. The demands force us to become more proactive and to recognise specific learning needs. (HKsuper5)

Many participants mentioned that a challenging environment can be a catalyst for CE. For instance, in Hoa Sua, staff in information services had to go to each university department to introduce people to their services, guide them to use library databases and get feedback from them. These tasks challenged them but strongly compelled them to learn.

Conversely, interviewees noted that mundane tasks made them neglect to learn. As an example, the participants in a library shared this view: "We just do the same thing forever - why do we need to learn?" (HG-super3). A supervisor in another library observed:

Staff don't need to learn more because their day-to-day tasks are checking student IDs, watching students and keeping the books tidy on the shelves. (HT-super1)

In addition, the attitudes, performance and efforts of others in their libraries affected staff members' motivation to learn. A line staff member commented:

Environments and people around us contribute to our stagnation. Working in a place where people are slow and work indifferently makes us eventually become the same as they are. (HS-staff5)

The preceding data show that working environment has a strong influence on CE. The expected levels of education in an academic environment and required competencies in a demanding environment motivate practitioners to learn. Likewise, working in an environment with no pressure of competition, or no reinforcement or incentive to perform tends to discourage learning. Analysis of the data also shows 
that the performance and learning efforts of colleagues influence practitioners' engagement in $\mathrm{CE}$. This point reveals that the nexus between individual practitioners and their organisations affects the learning pursuits of each. This issue is more apparent when examining the participants' perceptions of their workplace relationships.

\subsubsection{Relationships with colleagues}

Most managers agreed that sharing ideas with other managers or senior staff and asking for their advice or information are a way to up-date their knowledge. In particular, the managers in Hai Van, Hoan Kiem and Tan Binh who did not hold a degree in LIM conceded that they consult with senior staff on professional issues they learned from their colleagues. Moreover, according to the managers in Hong Ha and Hai Van, the assistance and sharing of managerial responsibilities among peers were a support for managers when they were on leave for professional activities, including CE activities.

The managers also recognised that relationships with colleagues affected the $\mathrm{CE}$ of their staff. They mentioned that the relationships between staff are very complex and can impact either positively or negatively on practitioners' attitudes to and outcomes from CE.

In terms of positive effects, some managers stated that staff sharing information after attending CE programmes was a strength in their libraries. They viewed this collaboration as stimulation for everybody to be involved in learning activities and as a contribution to positive learning outcomes. As one manager said, "It is quite nice when on returning from $\mathrm{CE}$ courses one passes on new information to peers with pleasure" (BT-manager).

Some managers observed that the learning attempts and progress of colleagues were good examples to staff. The following statement made by the manager in Hoa Sua typified this point: 
After a few of our staff gained Master's degrees from overseas universities, many staff made efforts to improve their English. They hope they will find a similar opportunity to get higher education. (HS-manager)

These positive influences were also mentioned in focus group interviews. Most staff agreed that discussing and exchanging ideas were not only helpful for their daily tasks but also stimulated their enthusiasm for learning and desire for excellence. They even highlighted learning from peers as an effective learning format. The Vietnamese idiom: "We learn not at school but in life and from friends," and the idea that there is no quicker way to learn than from peers, were repeated in many focus groups. Encouraging and shouldering the duties of each other were also seen as valuable support. As one supervisor said:

We have three staff in our cataloguing group. When I go to my class in the Master's programme, the other two take over my tasks. In my turn I do the same thing when they are away on CE courses. If everybody helps each other like that, all will have chances to learn. You know, they even remind me to focus more on studying when my exams are coming up. (BTsuper1)

Lack of such collegial support was a disincentive to CE for some practitioners, as another supervisor noted, "In my case nobody can help. My workload remains until I come back from learning courses and deal with it. This makes me tired and frustrated" (BT-super2).

The attitude towards learning and ambition of colleagues also influence practitioners. The participants in several focus groups expressed similar views to the one below:

When everybody feels free to express their ambitions and share their own ideas - with no inferiority complex, no envy, and no jealousy - learning becomes the norm in organisations. In this environment, the success of one motivates others, everybody will engage in learning and attempt to achieve a certain standard. (TB-super1)

In libraries where colleagues believe in each other and feel comfortable expressing their ideas, attitudes and aspirations, practitioners are more likely to engage in CE. The discussion of line staff in Dam Sen reflected this point: 
Young staff like us freely express our desires. We follow our peers' examples to be better. Oh yes, the older staff also keenly engage in learning. They have more difficulties than we have, but they still keep learning. (DS-staff4)

Conversely, envy and poor relationships between colleagues make collaborative learning less likely. The manager in Tan Binh observed that staff who had friendly relationships tended to help each other and shared their experiences, while those who did not have such relationships were more wary of each other and were more likely to do things on their own. A senior staff member in this library also mentioned difficulties when staff lacked similar perspectives about their jobs and learning.

We became library practitioners under different circumstances. Not all of us expected to be librarians. After entering the profession some have a positive attitude to the job, while some work but never like the job. Their negative attitude is a bad influence on others. They sometimes make unpleasant and even spiteful comments about others' attempts [to do well]. (TB-super4)

Different attitudes towards change among staff can also discourage learning. Younger staff in Hoan Kiem noted that they found it hard to apply new processes in their routine work because this challenged the "traditional experiences" of their older colleagues. A culture of avoiding change diminishes the desire of practitioners to learn.

As seen in the discussion above, relationships between practitioners can have a significant effect on their CE. Specifically, the learning activities, attitude and progress of colleagues can influence those of other practitioners. At the same time, each individual practitioner contributes to the learning atmosphere and the norm of the whole organisation. In its turn, the organisation, including its atmosphere and culture, affects the $\mathrm{CE}$ of individual practitioners. These mutual effects show a nexus between practitioners and their organisation that has a significant effect on the $\mathrm{CE}$ of university library practitioners. 
The data also revealed that the relationship between managers and staff strongly impacts on $\mathrm{CE}$ of practitioners. These effects are examined separately as the data showed they are a prominent factor.

\subsection{Managers' influences}

As mentioned in Section 4.1.3, university libraries in Vietnam are centralised. In the libraries participating in this study, the Boards of Managers governed all library activities, including human resources and issues concerning CE. The data revealed that managers, particularly directors, influence their staff's CE strongly and in many ways. To examine the influence of managers, the following sections will focus on their management approach and their opinions towards CE.

Based on the descriptions of Evans, Ward and Rugaas (2000), the management approaches of the managers interviewed are categorised here as either directive, decisive or formalistic. The managers' approach was reflected in the ways they operated their libraries and assessed staff as well as in the ways they coordinated CE activities. The attitudes of the managers towards $\mathrm{CE}$ affected the way they dealt with $\mathrm{CE}$ activities in their libraries. The influence of each management approach on CE is analysed separately. For each approach, the perceptions of managers are examined first, followed by the perceptions of their staff.

\subsubsection{Influence of directive managers}

According to Evans, Ward and Rugaas (2000, pp. 29-30) adherents of the directive approach believe that most people both want and need close supervision, to be told what to do and how to do it. This approach emphasises the rights, powers and authority of management, and contends that only the people on the top know what is good and what will work. Among the managers interviewed, those from Ben Thanh, Dam Sen and Hoa Sua appeared to be typical directive managers and the managers in Hoan Kiem and Thanh Da semed to rely primarily on this approach. 
In the view of the directive managers, their assertiveness and strictness prompted staff to learn. They described themselves as demanding and strict on their staff. They used strong verbs to express their actions, such as "I force", "I highly demand", or "I am strict". In managing their libraries, they appeared to be very assertive and liked to attend to every activity themselves. They assigned tasks to staff directly rather than through a middle person. They often kept track of staff and gave feedback immediately. They believed that their directives and feedback generated a serious attitude among staff towards their work. For example, one manager described the way she managed her staff:

In a library, it isn't really busy if staff just complete routine tasks that are the same day after day. But in this library, I force staff not only into handle the daily tasks well but also into conducting research and participating in particular projects. I make staff keep their minds on their work. (DS-manager)

The directive managers observed that, to meet the demands of managers, the staff were more focused on their tasks and made more effort to do them well. Consequently, staff kept learning in different ways in order to do the work better. As the manager in Ben Thanh said:

Managers, particularly the director, strongly affect CE for staff. The high demands of managers force staff to learn. I am sure that when managers force staff to join CE activities, staff will join.

She concluded, "The role and attitude of managers are very important" and repeated several times, "My requirements force staff to do their best."

The directive approach was also reflected in the ways the managers assessed staff. Since the directive managers were closely involved in all library activities, they believed that they knew the abilities of every staff member. In consequence, they assumed that they could allocate specific jobs, tasks and responsibilities to appropriate staff. They assumed that this involvement facilitated staff CE. As the manager in Hoa Sua noted: 
I usually consider the ability and the background of staff when assigning tasks for them. For staff in the reference section, I assign each staff member responsibility for a subject based on their backgrounds. Therefore, they can focus on particular tasks and gradually become experts in their particular subjects. You know, they find their jobs interesting so they learn and update frequently.

With regard to the ways in which managers coordinated CE activities, the directive managers tended to assess the context, then select among the staff and arrange for them to do CE activities. Managers seemed to believe that they were the right people to select the appropriate staff for the relevant $\mathrm{CE}$ activities, and that they could best understand the learning needs of their staff. As one manager argued:

Everyone wants to learn but the manager will have the vision to identify staff who have ability to learn effectively in particular courses.... I completely understand what the staff need and what they lack. (BTmanager)

Another manager made the following point: "I do trace out their learning. I don't let them learn just what they want. I require them to learn specific things which we need" (TD-manager).

Furthermore, the directive managers gave explicit orders to staff to participate in CE and then kept track of them. For instance, the manager in Hoa Sua said that she criticised staff who were absent from $\mathrm{CE}$ activities at staff meetings and she considered CE participation as a criterion for renewing staff contracts. She stated, "I need to do this. It is necessary to be assertive and to be rigorous."

Analysis of the data also reveals that, although these managers shared a management style, they had different attitudes towards CE for their staff which guided them in establishing library policies concerning $\mathrm{CE}$, in selecting $\mathrm{CE}$ activities for their staff and/or selecting staff for CE. Three different approaches to CE among the directive managers emerged: equal CE opportunities for all staff, different opportunities for different staff, and CE primarily as learning on the job. 
The manager in Dam Sen felt that all staff should have equal opportunities for CE. She was active in searching for information on $\mathrm{CE}$ activities and in finding financial assistance for staff. In addition, she considered that conducting research was a way for staff to strengthen their professional knowledge and to keep up-to-date as well as to reach a higher civil servant rank. She said:

You know, doing research almost never happened in the library. However, when it became a criterion for the rank of senior civil servant, I require, even force, and help staff to participate in research tasks. This helps them to reach the prerequisite to upgrade their rank.

As a directive manager, she insisted that she was the best person to identify the learning needs of her staff. However, she also was aware that the staff could recognise their weaknesses and that they themselves often tried to overcome them. Though she understood that it was necessary to select among staff for CE programmes due to insufficient financial resources, she nonetheless expressed concern about this. She said, "I feel very uneasy when I have to select one staff member over another to send to CE courses.... If I can, I will let them all go.” This manager developed a "learning commitment plan" policy, as discussed in Section 6.2.3, to involve the library and staff together in finding CE opportunities for everybody.

Conversely, the managers in Ben Thanh and Hoa Sua seemed to believe that not all staff have an equal ability to learn; therefore, the managers should determine the $\mathrm{CE}$ activities for each staff. As the manager in Ben Thanh explained:

I have to consider many points when appointing staff to go to learn, such as the staff should be young, and have the ability to absorb new knowledge and to impart knowledge to peers. The staff member with weak capacity can't impart knowledge to others or apply the learning. Therefore, it is a waste to let such a person go to learn.

Having this perspective together with the directive style, these managers tended to arrange the $\mathrm{CE}$ activities and require staff to follow their arrangements. In this sense they appeared somewhat autocratic but at the same time, the data revealed that they 
were actively searching for or initiating staff $\mathrm{CE}$ opportunities. As an example, the manager in Ben Thanh developed an exchange programme with overseas libraries to give her staff opportunities for overseas internships. She also appeared to be very conscientious in arranging for appropriate staff to participate in CE courses. She said:

When I get information about CE courses, I select the relevant staff for such courses, ask for financial support from the university, and arrange other staff to take over the daily tasks of those who will go to the courses.

Finally, the managers in Thanh Da and Hoan Kiem both believed that the primary purpose of $\mathrm{CE}$ is for staff to become competent in their daily tasks. These managers tended to encourage staff to learn on the job and through their colleagues, rather than to undertake formal courses or higher education programmes. They encouraged staff to focus on content which directly related to routine jobs and appeared to neglect other learning needs, such as personal skills or getting higher degrees. The manager in Hoan Kiem argued:

The issue is not that staff learn in order to achieve academic targets; the issue is they need to learn in order to do their daily jobs... the issue is not which degrees the staff hold but how well they perform their jobs.

He continued:

In theory, getting higher education is good, but in my opinion, before going to a graduate education programme, staff have to make the best of knowledge they gained in undergraduate programmes. If not, they don't need to learn something at a higher level.

The manager in Thanh Da was critical of a staff member who simply wanted a certificate from a $\mathrm{CE}$ programme when it was possible to receive in-house training to learn the needed competencies:

She [a staff member] asked me to let her attend a formal course on computer skills. I replied, "Why do you need to go there? If you need a certificate for an annual award or you need to accumulate certificates for promotion, okay just go. But I think you'd do better to learn computer skills here, at this library, through peers.... Why don't we teach each other 
here to do the job perfectly instead of going somewhere for this?"... So we set up a policy of teaching each other.

The preceding data demonstrate that the managers with the directive style seemed to consider that, by being assertive and strict with their staff, and active in relation to staff $\mathrm{CE}$, they were encouraging their staff to learn and were fostering a serious attitude towards CE within the library. However, some aspects of their approach to $\mathrm{CE}$ differed and, accordingly, their policies and influence on staff $\mathrm{CE}$ differed. The perceptions of their staff about their influence on CE are discussed below.

In general, staff appreciated the efforts of their managers. However, on some points, they interpreted the impacts of the managers differently. Most staff in Ben Thanh, Dam Sen and Hoan Kiem agreed that their managers' assertiveness both put pressure on and motivated them to be involved in learning. Line staff in Dam Sen agreed with the following perspective:

The managers require us to keep learning.... The requirements put pressure on us, but actually it is a positive pressure. It has a positive impact on us. (DS-staff2)

They also agreed with the managers' observations that learning needs arise when practitioners need to accomplish tasks. Senior staff and supervisors in Hoan Kiem concurred that the demands of managers compelled them to search for ways to solve problems. In addition, as line staff in Dam Sen and Hoan Kiem observed, by watching their performance and giving them feedback, the managers required them to keep their minds on the tasks, which at the same time helped them to understand the specific goals of the tasks. Operational staff thought that the more managers direct staff, the more staff are involved in the work. As a result, they could identify their actual needs and became eager to learn. As one supervisor in Hoan Kiem explained:

If the chief does not control us we may not be able to work effectively.... When the chief sets specific goals for us, we clearly understand our tasks. We understand that we have to take responsibility for the completion of tasks. To complete the tasks, obviously we have to update and learn. 
Sometimes, I have to spend hours searching and reading to find the way to handle a task. After that I become more skilful. (HK-super5)

Staff particularly appreciated their managers' attempts to find CE opportunities or run internal CE activities for staff. As an example, line staff members in Dam Sen noted, "It is very good that managers search for relevant courses and send us on those" (DS-staff4). The operational staff particularly remarked that the managers expressed high expectations of staff, but that their belief in staff abilities helped them to gain achievements that they would never have expected. Thus, the assertiveness of their managers fostered their progress. One member said:

You know, for a long time we didn't believe we could be involved in a research project. We thought only academics with a high education level could conduct research. But the Board of Managers requires us to participate in research tasks. We have to try and we realise that we can do it.... You know, doing research helps me to become more knowledgeable. (DS-staff2)

Hence, the operational staff confirmed the directive approach of their managers as a positive influence on their learning. The dynamic style of these managers inspired them to greater efforts.

However, staff also pointed out the negative influence of the directive management approach. As discussed in Section 6.2.3, the participants in Ben Thanh and Hoa Sua commented that, as staff selection for CE was mainly based on the assessment of managers, the dominance of directive managers was unfair for some staff. In Hoa Sua some staff remarked that directive management meant that they were dependent on their managers. A few staff thought that, in some cases, they were not able to learn what they considered necessary because of the managers' interference. As a supervisor commented:

In fact, the content of CE courses is mostly based on the assessment of managers, not of us, the learners.... We know that whatever we say, everything will end up as what the managers say. (HS-super4) 
In Ben Thanh the discussion of line staff revealed that the differences in access to CE opportunities and the dominance of managers in regard to staff $\mathrm{CE}$ hold back the development of some staff members. The following statement demonstrates this point.

Well, of course the managers have their vision. They may be reasonable to favour one over others in selecting staff for CE programmes. But if they don't look at two sides, some staff members never have the chance to grow. (BT-staff1)

In Hoan Kiem supervisors appeared to be disappointed with their manager's perspective on the pointlessness of higher education for library staff. They considered that they needed broader chances to learn. One member reported:

I have worked for several years here. It is time I enhanced my level of knowledge. However, it is very difficult to get permission to go to a graduate programme. (KH-super2)

In the views of operational staff, the assertiveness and activeness of managers motivate staff to concentrate on work and to learn. The efforts of directive managers to find $\mathrm{CE}$ opportunities and time and financial support are enablers for staff CE. In addition, high demands and high expectations together with confidence in staff ability motivate staff learning considerably. However, the domination of managers can be a negative influence when the managers do not consider the individual needs of staff.

\subsubsection{The influence of decisive managers}

According to Evans, Ward and Rugaas (2000, p. 25), the decisive approach focuses attention on logic and the rational process of analysing situations and problems to make decisions. The managers in Hai Van and Hong Ha appeared to apply this approach to the management of their libraries.

The decisive managers tended to let their subordinates manage daily tasks; however they required the subordinates to provide regular reports about their sections in order 
to coordinate the overall operation of their libraries. The manager in Hai Van described his approach, "I play a coordinator role to coordinate the work among sections but not control specific tasks."

To meet their staff's CE needs these managers focused on finding training projects rather than personally becoming involved in training or directly keeping track of staff $\mathrm{CE}$ attendance. They tried to use their networks to look for more learning opportunities for staff. For example, the manager in Hong Ha had close relationships with overseas experts who often came to Vietnam to coordinate CE activities, so, whenever they conducted CE courses, he sought extra places for his staff.

Regarding staff assessment, these managers placed great emphasis on the need for relevant rewards for staff. They had policies to retain proficient staff. Aware of the difficulties of low salary and lack of promotion for staff, these managers tried to offer proficient staff the best working conditions the libraries could offer. For example, one manager explained that staff in the technical services section of his library had more opportunities to learn than staff in other sections, so, when he recognised potential in staff members, he transferred them into technical services to give them more opportunities to learn and, thus, to be more successful. He also commented that "[the library] has never had an official policy on staff promotion but I try to promote a staff member when I see that a person has abilities" (HHmanager). Similarly, the other manager recognised that his IT staff had low salaries compared to IT staff in other institutions. Therefore, he helped staff to learn what would assist them not only to deal with their daily tasks but also with their secondary jobs, such as teaching. He said:

In fact, IT staff can find other jobs with higher salaries. The library can't pay such a high salary therefore we need to give them other opportunities. For example, the opportunity for further education, the opportunity to be instructors on IT courses conducted by the library. (HV-manager)

Unlike the directive managers, these managers appeared not to operate CE activities directly but their attention to individual circumstances and their strategies appeared to be enablers for staff CE. 
The staff seemed to be highly appreciative of this management style. Many of them noted that the ability of managers to recognise staff potential, to assign relevant tasks and to assess staff properly encouraged them to work and learn. As one supervisor commented:

The managers are very important people. They can recognise the ability of staff and assign relevant tasks to staff.... When they promote us based on our ability we will try our best. (HV-super2)

The confidence that managers showed in their staff particularly inspired them to work and learn. As a younger staff member in Hong Ha observed, the managers usually assigned important tasks and offered more CE opportunities to those who were outstanding. Therefore, staff felt proud when being assigned important tasks because this justified the managers' confidence on them. They strived harder to please their managers as well as to show their ability. She said:

Once I handle the tasks better than others, I recognise that my chief trusts me more and seems to encourage me more. In her eyes, I seem to be more prominent than my peers. I know that I have opportunities to make progress and to have a better position... I know I have to learn more. If not, I will lose the confidence of my chief. This becomes my learning motivation. For me, the confidence of the manager in me is very important. (HH-staff1)

The middle-aged staff in this library remarked on the impact on their outlook towards the confidence of managers. They believed that the trust managers placed in staff signified an appreciation of and respect for staff. One said, "The confidence of the manager puts me in good spirits, which makes me work more enthusiastically" (HHsuper1). Another noted, "I trust in my manager and the manager relies on me. This creates a relationship that motivates me to work devotedly" (HH-staff4).

As shown in the preceding data, although the decisive managers did not directly conduct $\mathrm{CE}$ activities or force staff to pursue learning, they had strategies to facilitate staff CE. These strategies included finding training programmes, setting policies to retain talented staff and establishing mutual trust and confidence between managers and staff. These strategies reflected the managers' understanding of the current 
circumstances and intrinsic needs of their staff, for example, the need for recognition. As a result the decisive managers inspired staff to improve their skills and work more enthusiastically. Unlike the findings from the directive and formalistic management approaches, the data did not indicate any negative influences of the decisive approach on $\mathrm{CE}$.

\subsubsection{Influence of formalistic managers}

According to Evans, Ward and Rugaas (2000, pp. 27-28) the formalistic approach assumes that it is important that staff have clearly defined and structured jobs and duties. It creates organisational stability despite radical changes in the environment. However, organisations with formalistic managers can become rigid, because staff initiative and creativity tend to diminish. The management approach of the managers in Ho Guom, Ho Tay and Tan Binh were similar to the formalistic approach in varying degrees.

The managers with a formalistic style tended to adhere to the traditional functions of a university library. They continued to focus on the provision of text books for students as the library's main mission rather than to offer new information services. These managers regarded innovations cautiously. Change in these libraries was slow, particularly in applying IT. For example, one library among them did not take responsibility for managing the databases of the university and another library still did not have an integrated library system. One manager even said, "It is good enough if I can encourage staff to keep doing the routine jobs" (HG-manager).

These managers did not seem to be proactive in implementing policies targeted at CE. As the manager in Ho Tay said, "We encourage staff to learn, but it's hard to set up a policy because it's bad when you set something up and then can't carry it out." These managers also seemed to ignore external CE opportunities for staff. They felt they could not force staff to learn when the salary of library practitioners is so low, the workload is heavy and most library staff are women who have family commitments. As the manager in Ho Guom said: 
There are many difficulties for staff to keep learning. Dealing with the workload already takes up all their time. In addition, the majority of staff are women. After work they have to hurry back home to take care their families... no time to do anything more.... The workload is heavy but the salary is very little, they can't keep learning.

They avoided making CE compulsory. As the manager in Tan Binh said, "Usually, I ask staff whether they can arrange to participate [in CE courses]. I let them make the decision. If they refuse, I will ask another.”

Hence, in the views of formalistic managers, they supported staff by being sympathetic to their personal circumstances, letting them learn at their own pace and avoiding putting pressure on them.

Operational staff in Tay Binh, Ho Guom and Ho Tay shared a common comment when they mentioned the role of their managers in CE: "The managers encourage us to learn in attitude but in fact CE opportunities are very rare for us" (HT-super1). These staff seemed to expect more than encouragement from the attitude of their managers. They remarked that the managers did not put any pressure on staff or set particular policies for $\mathrm{CE}$ in their libraries. As a result, the staff engaged in learning casually or on impulse. "No, we don't have such requirements; I myself learn when I want to be up-to-date in some issues" (HT-staff3) and "We acted on our own when we have to deal with practical problems" (TB-staff2) were typical comments among operational staff in these libraries.

Furthermore, some staff considered that their learning or initiatives could not be applied in their libraries because their managers tended to avoid innovation. A supervisor noted:

We update, we learn and then can't do anything with the new things. Nobody recognises our attempts. I see that here the managers don't acknowledge the need to encourage staff to undertake initiatives for improvement. (HT-super1) 
The staff in these libraries did not recognise the effects of staff assessment. As a staff member said, "Actually, I think that I have to complete my tasks. That's it. I don't have any ideas about assessment or rewards or anything like that" (HT-staff2).

In addition, the operational staff mentioned that they did not have much information about $\mathrm{CE}$ activities in their regions and that it was impossible for staff to seek financial support from the university on their own.

The formalistic managers appeared to avoid putting pressure on staff and to let staff learn at their own pace, principles recommended by adult education theorists such as Rogers (2001) and Ross-Gordon (1998). However, analysis of the data suggests that the failure of managers to search for learning resources for their staff, provide information or find financial support discouraged staff CE. As a result, CE activities in these libraries were rare and staff seemed to lack learning commitment.

With regard to the managers' influence on $\mathrm{CE}$, analysis of the data shows that staff CE significantly depends on the attitudes and actions of their managers. The ways managers operate libraries and deal with CE impact on the learning pursuits of staff. They shape the learning climate in libraries. Directive managers have a considerable contribution in creating learning opportunities for staff. Finding information and financial assistance, setting policies and conducting in-house CE activities, selecting learning topics and even forcing staff to participate in CE activities are enablers for staff CE. The support and trust given by decisive managers inspires staff to improve themselves. However, on its own the encouragement of formalistic managers seems insufficient to motivate staff to learn. The data revealed that staff need specific kinds of support from their managers. The data also demonstrated that the more managers are involved in establishing the learning environment, the more staff increase their efforts.

The discussions above also reveal the effects on CE of the nexus between staff and their managers. Managers who shape a positive learning climate, make learning opportunities available in the organisation and are perceived as active in support of 
their staff impact positively on the learning pursuits of individual practitioners. Mutual trust and support between staff and managers increase the enthusiasm of practitioners for learning. Hence, the data again showed that the nexus between individual practitioners and organisation is a factor affecting CE for library practitioners.

\subsection{Current CE conditions}

Finally, the current CE conditions emerged as a factor affecting practitioners' learning pursuits. The participants described CE conditions as the availability and quality of learning resources. These included reading materials, and internal and external $\mathrm{CE}$ activities.

\subsubsection{Reading materials}

Many participants, particularly managers, considered reading professional materials, including books, journals and online materials, as a useful way to keep up-to-date as well as to learn professional knowledge. The comment "reading is the learning method I like most" (HT-manager) was echoed by both managers and staff:

I learn from the internet... I can find useful skills and apply them in my work... mostly I learn by this method.... I learn from other people through the internet... join forums on the internet and share information with others. When I can't understand some information I read and I ask others by chatting with them. (TB-super2)

However, at the same time, many participants pointed out the shortcomings of LIM reading materials in Vietnamese as a barrier to their learning. As a staff member noted:

Professional reading materials in Vietnamese are mostly out of date. Upto-date materials can be found on the internet but they are in English. Our English is not good enough to read them. (HK-staff1)

Limited internet access was also mentioned as a barrier to CE. Practitioners at one library pointed out that their library lacked internet access, which was a great 
hindrance to their learning. At another library, the practitioners said that their learning was restricted by time limits on internet use while at a third library the practitioners complained that their $\mathrm{CE}$ was hindered due to unstable internet access.

Only one manager and one line staff member had different views. As that manager said, "I think that as we work in an information centre, there is no difficulty for us to access any kind of information" (HV-manager). However, this view had no support among others. The data analysis has shown that, though reading is a highly popular way of keeping up-to-date or gaining new knowledge, there are, nonetheless, serious access issues related to reading materials, which hinders the learning of library practitioners.

\subsubsection{External CE activities}

The features of CE programmes and professional activities, including conferences, workshops and seminars, emerged as another component affecting the $\mathrm{CE}$ of practitioners. The data revealed that $\mathrm{CE}$ activities are only useful when conducted effectively.

Currently, there are only a few CE providers in Vietnam: NACESTI, FESAL in cooperation with the Library of the Natural Sciences University-HCMC, the Central Library of VNU-HN and several overseas organisations. In addition, as discussed in Section 5.2.3, there is no lead professional organisation that directs, coordinates or supports CE providers. Most participants in this study appeared to know of only one or two CE providers. For example, the managers in Hong Ha noted, "CE courses in the LIM field are few. Only NACESTI and the Central Library of VNU-HN provide some courses." Staff members in Dam Sen agreed, "CE courses are very rare, only FESAL provides [such courses]" (DS-staff1).

In terms of the effectiveness of current formal CE programmes, some participants mentioned that to some degree these courses helped them to keep track of new issues in LIM, to update and gain new skills relating to their work. As one manager said, "CE courses are good. If it is possible I let all my staff participate" (DS-manager). 
Some operational staff acknowledged that occasionally they can gain insightful knowledge from such courses. For example, a staff member commented, "Knowledge becomes out of date so quickly.... Such courses [as those conducted by FESAL] keep us up-to-date" (DS-staff1). Another noted, "We implemented many changes in our cataloguing process after coming back from [a recent CE] course" (DS-staff3).

However, the data also provided abundant evidence of the weaknesses of current $\mathrm{CE}$ programmes. The first weakness was the superficial content of CE courses. Many participants used a Vietnamese idiom "enjoy flowers on a galloping horse" to express their thoughts. They implied that instructors rushed over content or only superficially imparted new content to learners. As a result, learners did not really acquire new knowledge or skills. These were typical comments:

They occasionally offer courses on search skills, but they hastily tutor us... just like we enjoy flowers on a galloping horse. (BT-staff1)

They conducted a one-week course but provided a huge amount of information. Everything was in a blur, like we enjoy flowers on a galloping horse. I don't see any benefit from such courses. (HS-staff3)

The second weakness was the irrelevant content of CE courses. For example, the operational staff in Ho Guom shared this comment:

We actually like to do CE courses but we found that in many cases they provide irrelevant content for us. Like they talk about using modern equipment for book preservation.... We don't have such equipment. (HGsuper4)

The participants also emphasised weaknesses regarding the organisation and design of courses. As mentioned in Section 5.2.3, the managers commented that they usually received information about $\mathrm{CE}$ courses at the last minute or accidentally. This made it difficult for them to arrange leave for staff to study. As one manager stated, "This is a barrier for us" (TB-manager). 
Many staff focused on the lack of needs analysis, proper teaching and evaluation methods in current $\mathrm{CE}$ courses. This comment is an example:

Recently, I attended a course in web design... it lasted two weeks - how boring a class it was. The provider was aware of our need so they provided that course, but the way they trained was inappropriate for librarians.... I saw that some people already knew what was being taught therefore they were bored sitting there, but some others didn't know anything and it was hard for them to catch up.... The provider should have understood the learners better. (BT-staff2)

One staff member gave a very negative comment and implied some CE courses are not worth attending. She said, "For me, it is nonsense to participate in such short courses" (HH-staff3).

The data revealed that the current CE programmes provide some opportunities to learn for practitioners, however, many programmes are not sufficient in terms of content, instructional methods, design and organisation. As a result, it is very difficult for practitioners to find reliable $\mathrm{CE}$ resources to enable them to acquire the knowledge to assist them with new issues in their practice. The often poor attitude of staff towards $\mathrm{CE}$ programmes may come from past experiences; therefore, $\mathrm{CE}$ programmes of low-quality may cause practitioners to lose faith in the value of $\mathrm{CE}$ activities.

Professional activities including conferences, workshops and seminars were also mentioned as current external CE activities for library practitioners. Again, participants noted that such activities were few. As one manager said, "It is very rare to receive an invitation to a professional conference" (TB-manager). Operational staff in many focus groups made this point. For example, line staff in Hai Van emphasised that chances for them to attend professional activities were very limited:

Some weeks ago a workshop about ICT was held, everybody wanted to join in, but only one or two staff in each section had the chance. This workshop was about standards in libraries. It would have been really useful for all of us. (HV-staff5) 
Opportunities to attend international professional activities were even rarer. For example, one manager reported:

It also isn't easy for me. I only have chances when the university has projects relating to other countries and because I am head of a department in the university. (HT-manager)

In some group interviews, operational staff focused on the weaknesses of current LIM workshops and conferences in Vietnam. They pointed out that the incompetence of organisers and the lack of contribution by attendees affected the quality of professional activities. As a result, practitioners became less interested in such activities. The following extracts from the discussion of supervisors and senior staff members in Ben Thanh illustrates these points:

The activities [workshops and conferences] would be useful if we conducted them seriously.... I attended some workshops and conferences and did not see their value. I don't think they were useful at all. In those workshops and conferences people just gave speeches, somebody read something like reports on their achievements and there wasn't any feedback from the attendees. (BT-super1)

I think there are two reasons [for the lack of effectiveness]. First, the organisers do not arrange them well. Second, the participants ourselves don't pay attention to the issues discussed there. We lack a serious attitude when attending conferences or seminars. We just sit there, listen and say nothing. I think even if I had something to say I wouldn't say it because nobody would listen. (BT-super5)

I think there is another reason, and that is who was sent to the workshops. It is important that libraries send relevant staff to relevant workshops. For example, the library should send cataloguers to the workshops about classification. (BT-super3)

Overall, the data showed that current formal CE programmes and $\mathrm{CE}$ activities for library practitioners in Vietnam are limited in regard to both quality and quantity. The lack of a professional organisation responsible for $\mathrm{CE}$, the small number of providers and the lack of high-quality activities are barriers to practitioners' CE. However, to some degree current providers and their activities are enablers for practitioners' CE in that they provide some up-to-date information. 


\subsubsection{Internal CE activities}

On reviewing the data, including the interviews and recent annual reports of the participating libraries, two libraries held in-house workshops or presentations, two offered more structured $\mathrm{CE}$ courses for their staff and staff from neighbouring university libraries, and two had staff training programmes sponsored by overseas organisations. These internal $\mathrm{CE}$ activities have a significant effect on learning of practitioners as discussed below.

In-house workshops, seminars and presentations were learning activities conducted in Hoan Kiem and Hoa Sua. In both libraries, they organised presentations where staff took turns to present topics relating to their work. The managers noted that to undertake such activities regularly was a big task for library managers in terms of organising, arranging time and encouraging staff to join in. For example, one manager said that they conducted such activities on weekends and provided free lunch for staff; another manager mentioned that the Board of Managers attended the presentations to give feedback and help staff to improve relevant skills. Despite the difficulties, these managers judged these activities were worthwhile in that practitioners learned when they prepared and gave a presentation and when they listened to other staff members' presentations. As the manager in Hoan Kiem said, "To make presentations staff have to prepare very carefully. They read and learn a lot in doing these." He mentioned that they intended to expand the internal CE activities and try to make them more effective.

In the future I would like to expand such presentation activities. I will also ask students [clients] to attend such presentations to let them understand library activities and get feedback from them to strengthen our skills. (HKmanager)

In Hoa Sua, they regularly conducted workshops in which managers or supervisors tutored staff on specific skills to deal with new issues in their practice. They also organised collaborative learning seminars in which staff from one section presented the key knowledge and skills relating to their tasks to staff from other sections. Such activities gave staff the chance to share their experiences. As the manager described: 
Staff in each section introduce professional skills to others. We regularly have meetings to exchange experiences or review and discuss collaboration among the sections, and what issues we should focus on more. We also conduct professional workshops. For example, I am in charge of reference tasks - in such workshops I have to impart reference skills and features of reference services to staff who haven't been trained in this area. We do these activities on a regular schedule. (HS-manager)

In general, staff acknowledged that these activities made them more involved in learning. As a line staff member in Hoan Kiem said, "These activities are challenges and opportunities for us to read more, to play with PowerPoint and to practise speaking in public" (HK-staff5). However, some participants conceded that not many activities attracted them and in some cases they found these activities were of limited value. For example, a staff member said, "The workshops in our library are not helpful. I don't think I have learned much from such workshops.” (HS-staff1)

Taking these comments together, it emerged that not all internal workshops, seminars and presentations are effective, but generally they do help practitioners to keep up-todate. Furthermore, these activities were efforts by the libraries to create a positive learning climate. They led practitioners to think about their CE commitments as well as to improve their competency.

Internal $\mathrm{CE}$ formats included the more structured in-house $\mathrm{CE}$ courses which were conducted in Thanh Da and Hong Ha. Annually, these libraries organised training courses for new staff and those who did not hold a degree in LIM. Occasionally, they conducted training courses for all staff, based on instructors' availability, with consideration of the needs of their libraries. A supervisor noted:

Usually, all sections send their learning needs to the Board of Managers. The Board tries to conduct short courses of about a week to train staff in particular skills which they consider necessary. Annually, we organise courses for staff who lack a LIM background. Generally, we organise CE courses for staff depending on their particular needs. (HH-super1)

Line staff in these libraries acknowledged the in-house courses as efforts by the libraries to enable their CE. 
Every year, the library organises courses for new staff and staff who lack LIM training. Sometimes the library also conducts courses to provide us with new skills. (HH-staff2)

However, there were different views on the effectiveness of such courses. In one library, the manager and supervisors reported that in-house courses were essential for their practitioners - the staff participated keenly and acquired up-to-date information and learned new knowledge and skills. The staff at this library shared this point of view:

These courses are very practical. They are relevant to the daily tasks of practitioners. Staff, on the whole, acquire the necessary knowledge and skills to handle their tasks. (HH-super3)

Conversely, some line staff considered that many courses were conducted without careful consideration of location and learners' needs. As a result, such CE courses were of limited value to them and seemed a waste of time. One staff member said:

Actually, the library has conducted CE courses for us, for example, an English course for all staff which I had attended. But, you know, our library has many branches, it was inconvenient for all staff to come here [to the main branch] to learn. Secondly, our English proficiency was at different levels, therefore, not everyone readily learned. Some were very busy with their household so they were in hurry to leave the class before it had really finished.... I went at first but soon quit.... The library also organises CE courses in LIM skills. However, those courses are of limited value for staff because the staff have different backgrounds. Our learning needs are different. (HH-staff1)

In the second library, the manager and staff shared the view that internal CE courses are an excellent opportunity to enhance knowledge and professional skills. They explained that staff who were expert in a particular subject could become instructors for relevant courses. This motivated them to update and improve their own professional knowledge and skills. A supervisor said about her experience:

You know, formerly I did not learn anything about reference work. In 1999 our library started some reference activities. First, I did not know what I had to do. I read books and journals, attended some courses and tried. After that I was assigned to teach this subject, and of course I had to 
learn more to design a curriculum and select examples for classes. Because of that task, I have become more knowledgeable about reference work. It is a very good opportunity for my CE. (TD-super4)

Although not all in-house CE courses are effective, they are attempts by the libraries to offer staff learning opportunities and to improve staff competency. In comparison with other libraries, these libraries are pioneers in their use of available resources to conduct structured $\mathrm{CE}$ activities for staff. The in-house courses are enablers for staff $\mathrm{CE}$ in these libraries.

Finally, the participants from two of the sample libraries discussed the effects of training programmes on $\mathrm{CE}$. These libraries received overseas support for their staff training. The support allowed them to organise a series of CE courses systematically and in consultation with overseas educators. Both managers and staff acknowledged the usefulness of these courses. They showed their excitement when talking about the projects and emphasised their keenness to join these courses. A manager noted:

The courses under the training project are very attractive and useful for staff. Specific topics are systematically presented. I think we will try to keep conducting such courses even after the project has been completed. (HV-manager)

Similarly, a staff member commented:

These courses are very helpful. They teach us to deal with issues or problems we meet in daily work. I can bring my questions to ask or discuss in the classes. I learn many things to apply in my work when I attend these courses. (HS-staff1)

The training programmes in these libraries were excellent opportunities for their staff to engage in CE. Relevant content and the expertise of trainers considerably attracted practitioners to attend.

The data showed that current $\mathrm{CE}$ opportunities for library practitioners are limited in Vietnam. The shortcomings of reading materials, formal courses, professional activities and providers are barriers to practitioners' CE. Both informal and formal 
CE courses have limitations regarding the organisation, design and abilities of instructors. Only a few libraries have in-house CE activities and not all activities are effective. However, the efforts of the libraries to conduct formal courses and inhouse activities do provide practitioners with some opportunities to keep up-to-date and they stimulate a learning climate in the libraries. High quality training programmes sponsored by overseas organisations are very effective. These CE activities are to varying degrees all enablers for CE.

In summary, in this chapter two main factors that have significant effects on the $\mathrm{CE}$ of university library managers and operational staff in Vietnam were discussed: organisational factors, and the nexus between practitioners and organisations. More specifically, the findings provide an understanding of the effects on CE of policy at different levels of organisation in the Vietnamese library system, the infrastructure and learning climate within organisations, and the relationships between staff members within organisations. The findings also provide an understanding of the influences on $\mathrm{CE}$ of the nexus between colleagues, between staff and managers as well as between individual practitioners and the whole organisation.

From the findings discussed in this chapter and the preceding chapter, five sets of factors have been identified that affect the $\mathrm{CE}$ of university library practitioners in Vietnam. These are (1) social factors, (2) professional factors, (3) individual practitioner factors, (4) organisational factors and (5) the nexus between practitioner and organisation. The findings also provide insight into the ways these factors affect the $\mathrm{CE}$ of practitioners. Together they address the first two research questions. A summary and further discussion of these findings are presented in Chapter 8 when the model is assessed. The assessment of the preliminary model also is based on the process of identifying and prioritising the most important learning needs of library managers and operational staff. This process is the focus of the next chapter. 


\section{CHAPTER 7: TRIAGE}

The purpose of this chapter is to conduct a triage to identify and prioritise learning needs, including content and formats, of library managers and operational staff in university libraries in Vietnam. This chapter addresses the third and fourth research questions and contributes to the assessment and revision of the preliminary model.

RQ3: What are the most important CE needs for Vietnamese university library managers and operational staff from the perspectives of organisations, managers and operational staff?

RQ4: What are the main CE priorities for Vietnamese university library managers and operational staff?

Using the triage concept from Nowlen (1988), as discussed in Section 2.5.1, the triage in this study is a process to identify and prioritise learning needs for university library practitioners based on their needs and their organisations' needs. This process must take into account factors affecting the CE of practitioners. The results of the triage can be used as the basis for creating CE programmes.

To conduct a triage, Nowlen (1988, pp. 86-88) stated that many approaches could be used. He proposed that it is useful for CE providers to use tools such as "competence framework, self-assessment instruments, and national profiles against which individuals can compare themselves" (p.87) to set the base lines for learning and development agendas by undergoing competence assessment. By identifying "competency areas that fall below the norm", it becomes possible to establish performance concerns. He concluded: “When the person's or organisation's performance profile has been compared with appropriate profiles of successful performance and key contributing factors have been identified and analysed, learning agendas begin to emerge" (p. 88).

In the context of this study, Vietnam's professional associations have not yet established a professional competence framework for practitioners in all kinds of libraries (see Section 5.2.3 - the effects of professional leadership). LIM education 
curricula have been slow in keeping pace with changes in the profession (see Section 5.2.2 - the effects of professional education). Therefore, there is no official competence framework to act as a norm for identifying learning needs.

However, as stated in Section 3.3.3.2 on data collection, two relevant government documents were found that bear direct relevance to the learning needs of Vietnamese library practitioners. The first document called Decision No. 428/TCCP-VC on Professional Criteria for Civil Servant Ranks in Culture and Information Fields provides evidence of the required learning content for practitioners in librarianship at a general level. The second document called Decision No. 10/2007/QD-BVHTT on Approval of Vietnam's Master Library Development Plan until 2010 and Vision to 2020 provides evidence of the expected learning content that university library practitioners should master. In other words, these documents provide evidence to identify required knowledge and skills for practitioners from the organisational perspective.

At the same time, the interview data revealed that participating managers and operational staff compared themselves with their own perceptions of what is required to operate their daily tasks, keep pace with changes in their workplaces, and achieve the goals of their libraries. They also were aware of the requirements of the profession's development plan in Vietnam.

Therefore, the approach taken for conducting triage in this study is examining and assessing the learning needs for practitioners, based on the perceptions of individuals and on the requirements of their organisations. The triage consists of three steps:

1. Identifying the perceived learning needs for practitioners from the organisational perspective and individual practitioner perspective, including manager and operational staff.

2. Identifying priority learning needs by collating and combining the perceived needs from the organisational and individual practitioner perspectives. 
3. Assessing priorities for learning needs based on the factors affecting $\mathrm{CE}$ identified by the participating managers and operational staff, on their perceptions of CE needs, and on the organisational requirements.

Following this process, the triage ensures that CE programmes consider the needs of individuals and organisations, and assists in prioritising learning content and determining the most feasible education formats. As a result, the triage helps to facilitate the design of effective and achievable CE programmes that satisfy the goals of both individuals and organisations.

\subsection{Identifying perceived learning content}

To identify perceived learning needs for library practitioners from the organisational perspective, relevant documents from government agencies were examined. To identify perceived learning needs for practitioners from the individual perspective, the perceptions of interviewees regarding their most important needs were analysed. In addition, interviewed managers were able to understand the needs of their universities and libraries. Their perceptions of the learning needs for operational staff are considered to convey the learning needs of their institutions.

It is relevant here to point out that the three steps for analysing the documentary evidence were discussed in Section 3.3.4.1. Based on each criterion stated in the first document and each objective stated in the second document, the researcher identified learning areas needed for practitioners to achieve each criterion and objective. Also, the six steps for analysing the interview data were already discussed in that section. To identify the most important learning needs, the researcher followed similar steps in examining the effects of various factors on CE. From each interview transcript, the researcher selected ideas concerning needs for a learning content area and its indicative topics, and grouped similar ideas into categories to understand all the reasons for the needs. Subsequently, the researcher combined categories and their ideas from all transcripts, and then grouped related categories to examine the common and distinctive needs of participants across the sample libraries. Also, the 
research examined similarities and differences of the learning needs of managers and operational staff.

As discussed in Section 3.3.4.1 during these steps the researcher made notes about the respondents' responsibilities and tasks at work, their university type and the infrastructure of their libraries. In order to reflect the similarities as well as differences of learning needs of practitioners across the sample libraries and to understand the distinctive learning needs of practitioners in particular situations, relevant notes are incorporated into the discussions in Sections 7.1.2 and 7.1.3, which concern identifying perceived learning content.

Learning content for operational staff and managers identified in the documentary evidence is examined first. Next, learning content for operational staff identified from the perceptions of interviewed managers and staff respectively is examined. Finally, learning content for managers identified from the perceptions of interviewed managers is examined.

\subsubsection{Learning content identified in the documentary evidence}

As stated in Section 3.3.3.2 and repeated in the beginning of this chapter, two government documents were selected to examine the organisations' learning needs for library practitioners. Hereafter, the first document is referred to as the 1993 Professional Criteria and the second document as the 2007 Library Development Plan.

\section{Learning content identified in the 1993 Professional Criteria}

As mentioned in Section 3.3.3.2, this document identifies the criteria for all ranks of civil servants in librarianship: (1) junior librarian, (2) librarian, (3) senior librarian and (4) executive librarian. The criteria for the two lower ranks (junior librarians and librarians) emphasise requirements for operational tasks. The requirements for these two ranks are similar (they differ mainly in prerequisite certification); therefore, they are examined together. The criteria for the two upper ranks (senior and executive librarians) emphasise requirements for managerial tasks; however, only the criteria 
for senior librarian rank are examined here. The criteria for the executive rank are not examined because, as the document states, this rank is only for practitioners in libraries at regional or national level, which excludes university libraries.

A summary of criteria for the various ranks as expressed in the 1993 Professional Criteria and the required learning content drawn from each of these criteria are presented in Tables 7.1 (for junior librarians and librarians) and 7.2 (for senior librarians). 


\begin{tabular}{|c|c|c|}
\hline \multicolumn{2}{|r|}{ Criteria for junior librarians and librarians } & Required learning content \\
\hline$\frac{\sqrt[n]{v}}{\frac{\pi}{E}}$ & $\begin{array}{l}\text { - Develop collections: policy creation and } \\
\text { acquisitions } \\
\text { - Store and preserve materials } \\
\text { - Catalogue materials: description and } \\
\text { classification } \\
\text { - Establish and maintain catalogue systems } \\
\text { - Design and deliver reference services } \\
\text { - Foster the joy of reading } \\
\text { - Prepare statistic and report library } \\
\text { activities to higher authorities } \\
\text { - Participate in planning for library } \\
\text { development } \\
\text { - Maintain library resources and facilities } \\
\text { - Assess the effectiveness of library } \\
\text { activities } \\
\text { - Apply emerging methods in library work } \\
\text { processes }\end{array}$ & $\begin{array}{l}\text { - Collection development } \\
\text { - Book storage and } \\
\text { preservation } \\
\text { - Cataloguing standards, } \\
\text { skills and systems } \\
\\
\text { - Information services: } \\
\text { reference services, nature } \\
\text { of client base and } \\
\text { information need analysis } \\
\text { - Reporting and statistical } \\
\text { skills } \\
\text { - Management knowledge } \\
\text { and skills: planning } \\
\text { process, resource } \\
\text { management, assessment } \\
\text { services developments }\end{array}$ \\
\hline 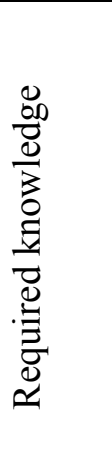 & $\begin{array}{l}\text { - Understand Government and Party } \\
\text { policies, regulations and laws concerning } \\
\text { economics, sciences, culture and } \\
\text { librarianship } \\
\text { - Possess LIM core knowledge and skills } \\
\text { - Understand current research in LIM and } \\
\text { when to apply it } \\
\text { - Understand safety and security } \\
\text { procedures } \\
\text { - Possess typing and computer skills }\end{array}$ & $\begin{array}{l}\text { - Government and Party } \\
\text { policies } \\
\text { - LIM knowledge and skills } \\
\text { - Research knowledge and } \\
\text { applications } \\
\text { - Workplace safety and } \\
\text { security procedures } \\
\text { - Computer skills }\end{array}$ \\
\hline 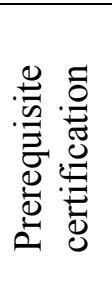 & $\begin{array}{l}\text { - Certificate in LIM (for junior librarians) } \\
\text { - Bachelor's degree in LIM (for librarians) } \\
\text { - "A" level (beginning) certification in a } \\
\text { foreign language (for junior librarians) } \\
\text { - "B" level (intermediate) certification in a } \\
\text { foreign language (for librarians) }\end{array}$ & $\begin{array}{l}\text { - LIM knowledge and skills } \\
\text { - Foreign language } \\
\text { proficiency }\end{array}$ \\
\hline
\end{tabular}

Table 7.1: Required learning content for operational staff identified in the 1993 Professional Criteria 


\begin{tabular}{|c|c|c|}
\hline & Criteria for senior librarians & Required learning content \\
\hline$\frac{\sqrt[n]{n}}{\stackrel{E}{E}}$ & $\begin{array}{l}\text { - Establish, organise and implement } \\
\text { professional tasks in library: cataloguing, } \\
\text { reference, collection library materials } \\
\text { - Establish and manage library work } \\
\text { processes } \\
\text { - Implement reference services and } \\
\text { instruction in reference skills for clients } \\
\text { - Train staff from lower ranks in } \\
\text { professional skills } \\
\text { - Participate in compiling professional } \\
\text { materials for CE and in academic } \\
\text { research } \\
\text { - Participate in the organisation of } \\
\text { professional activities, such as } \\
\text { conferences or seminars } \\
\text { - Manage the application of professional } \\
\text { research to improve library work } \\
\text { processes }\end{array}$ & $\begin{array}{l}\text { - Cataloguing management } \\
\text { - Collection management } \\
\text { - Information services } \\
\text { management } \\
\text { - Management knowledge } \\
\text { and skills } \\
\text { - Information services } \\
\text { knowledge and skills } \\
\text { - Training skills } \\
\text { - Research knowledge and } \\
\text { skills } \\
\text { - Management skills } \\
\text { - Management of emerging } \\
\text { professional practices }\end{array}$ \\
\hline 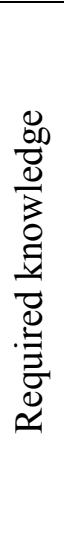 & $\begin{array}{l}\text { - Thorough understand Government and } \\
\text { Party policies, regulations and laws } \\
\text { concerning economics, sciences, culture } \\
\text { and librarianship } \\
\text { - Master LIM core knowledge and skills } \\
\text { - Understand current research in LIM and } \\
\text { understand how to apply in practice } \\
\text { - Understand safety and security } \\
\text { procedures } \\
\text { - Possess principles of library material } \\
\text { preservation } \\
\text { - Possess advanced computer skills }\end{array}$ & $\begin{array}{l}\text { - Government and Party } \\
\text { policies } \\
\text { - LIM knowledge and skills } \\
\text { - Research knowledge and } \\
\text { applications } \\
\text { - Workplace safety and } \\
\text { security procedures } \\
\text { - Preservation of library } \\
\text { materials } \\
\text { - Computer skills }\end{array}$ \\
\hline 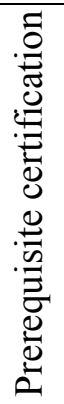 & $\begin{array}{l}\text { - Bachelor's degree in LIM } \\
\text { - Nine years' experience working in library } \\
\text { services } \\
\text { - "C" level (advanced) certification in a } \\
\text { foreign language } \\
\text { - Completion of academic research in the } \\
\text { library field (approved by the academic } \\
\text { committee of the library) }\end{array}$ & $\begin{array}{l}\text { - Foreign language } \\
\text { proficiency } \\
\text { - Research knowledge and } \\
\text { skills }\end{array}$ \\
\hline
\end{tabular}

Table 7.2: Required learning content for managers identified in the 1993 Professional Criteria 
As Tables 7.1 and 7.2 indicate, the focus of the 1993 Professional Criteria is on knowledge and skills in a more traditional library context. Such knowledge and skills would only equip practitioners for the traditional role of keepers of books rather than as proactive information practitioners in the digital environment. With regard to professional knowledge, the required learning areas for operational staff and managers are similar. For example, cataloguing, information services and management knowledge and skills are all required learning areas for both operational staff and managers. However, a higher level of knowledge and skills and management abilities are emphasised in the required learning content for managers. The management aspects in cataloguing, collections and information services are emphasised for managers while not an emphasis for operational staff.

It should be repeated that, as discussed in Section 3.3.3.2, the 1993 Professional Criteria states the professional criteria for all practitioners in librarianship (i.e., not exclusively practitioners in university libraries). Therefore, it does not provide distinctive criteria for practitioners working in the libraries of different types of university. In addition, it was issued 14 years ago; therefore, to ensure a comprehensive understanding of the learning needs for university library practitioners as set by the government, the second document (which is much more recent) also needs to be examined.

\section{Learning content identified in the 2007 Library Development Plan}

As mentioned in Section 3.3.3.2, this document includes the government's objectives for all kinds of libraries in Vietnam; however, for the purpose of this study only the objectives for university libraries are examined. A summary of the objectives as expressed in the document and the expected learning content drawn from these objectives are presented in Table 7.3. 


\begin{tabular}{|c|c|}
\hline Objectives & Expected learning content \\
\hline $\begin{array}{l}\text { - Improve sources of foreign materials and } \\
\text { combine and exchange materials among } \\
\text { colleges and universities and among } \\
\text { libraries }\end{array}$ & $\begin{array}{l}\text { - Collection management } \\
\text { - Interloan standards and skills } \\
\text { - Foreign language proficiency } \\
\text { - Collaboration/communication skills }\end{array}$ \\
\hline $\begin{array}{l}\text { - Increase exchanges between Vietnamese } \\
\text { and foreign libraries }\end{array}$ & $\begin{array}{l}\text { - Collaboration/communication skills } \\
\text { - Foreign language proficiency }\end{array}$ \\
\hline $\begin{array}{l}\text { Train and retrain library personnel, } \\
\text { especially in information technology, } \\
\text { marketing, information services and } \\
\text { foreign languages }\end{array}$ & $\begin{array}{l}\text { - IT knowledge and skills } \\
\text { - Information services } \\
\text { - Marketing library services } \\
\text { - Foreign language proficiency }\end{array}$ \\
\hline $\begin{array}{l}\text { - Develop information technology as a step } \\
\text { towards modernising the library system }\end{array}$ & - IT application in libraries \\
\hline $\begin{array}{l}\text { Establish standards in areas such as data } \\
\text { structures, classification and thesauri... } \\
\text { to ensure consistency and improved } \\
\text { access to materials and exchanges of } \\
\text { information }\end{array}$ & $\begin{array}{l}\text { - Bibliographic control: cataloguing } \\
\text { standards, indexing and data } \\
\text { structures }\end{array}$ \\
\hline $\begin{array}{l}\text { Based on the available computer systems, } \\
\text { to improve library services; to automate } \\
\text { libraries; to develop an accelerated data } \\
\text { system for all library operations }\end{array}$ & $\begin{array}{l}\text { - IT knowledge and skills } \\
\text { - Digital libraries: developing } \\
\text { databases } \\
\text { - Information services in an online } \\
\text { environment }\end{array}$ \\
\hline $\begin{array}{l}\text { - Apply the latest information } \\
\text { technologies, especially internet services } \\
\text { to improve current resources and } \\
\text { information services in order to reach a } \\
\text { wider range of readers }\end{array}$ & $\begin{array}{l}\text { - IT application in libraries } \\
\text { - Internet services } \\
\text { - Information services }\end{array}$ \\
\hline $\begin{array}{l}\text { - Develop a strong college and university } \\
\text { library system which provides digital and } \\
\text { electronic services, and enables timely } \\
\text { and easy information provision }\end{array}$ & $\begin{array}{l}\text { - Information services in a digital } \\
\text { environment } \\
\text { - Collaboration skills }\end{array}$ \\
\hline $\begin{array}{l}\text { - Digitise graduate and post-graduate } \\
\text { course books which can be uploaded } \\
\text { online }\end{array}$ & $\begin{array}{l}\text { - Digital libraries: developing digital } \\
\text { collections, intellectual property and } \\
\text { copyright }\end{array}$ \\
\hline
\end{tabular}

Table 7.3: Expected learning content identified in the 2007 Library Development Plan

In contrast to the learning needs identified in the first document, those identified from the objectives in the 2007 Library Development Plan are more development driven and proactive in relation to information professionals in the current 
environment. They focus on knowledge of and skill in IT application in all library activities and cooperation among libraries in national areas. Furthermore, knowledge and skills to create international cooperation are addressed. Along with professional knowledge and skills, generic skills (e.g., communication skills) are also identified as important learning content for practitioners.

It should be repeated that, as discussed in Section 3.3.3.2, this document makes no distinction between expected the learning content for managers and for operational staff; therefore, to ensure a comprehensive understanding of the learning needs for university library managers and operational staff as set by the government, the learning content identified from both documents is combined.

Before being combined to show the most important learning needs, the learning content drawn from the two documents is reviewed concurrently in Table 7.4. At this stage, the learning need priorities have not been identified; therefore, in the interests of neutrality, the identified learning needs are arranged in alphabetical order. At the same time, however, the learning needs that belong to a content area are presented together. 


\begin{tabular}{|c|c|}
\hline $\begin{array}{l}\text { Required learning content identified in } \\
\text { the } 1993 \text { Professional Criteria }\end{array}$ & $\begin{array}{c}\text { Expected learning content } \\
\text { identified in the } \\
2007 \text { Library Development Plan }\end{array}$ \\
\hline $\begin{array}{l}\text { - Foreign language proficiency } \\
\text { - Government and Party policies } \\
\text { - Information services: reference services, } \\
\text { nature of client base and information need } \\
\text { analysis } \\
\text { - Management knowledge and skills: } \\
\text { planning process, resource management, } \\
\text { assessment services development } \\
\text { - Research knowledge and applications } \\
\text { - Reporting and statistical skills } \\
\text { - Workplace safety and security procedures }\end{array}$ & $\begin{array}{l}\text { - Collection management, Interloan } \\
\text { standards and skills } \\
\text { - Bibliographic control: cataloguing } \\
\text { standards, indexing library } \\
\text { materials and data structures } \\
\text { - Collaboration/communication skills } \\
\text { - Digital libraries: developing digital } \\
\text { collections and databases, } \\
\text { intellectual property and copyright } \\
\text { - IT knowledge, skills and } \\
\text { application } \\
\text { - Foreign language proficiency } \\
\text { - Information services } \\
\text { - Internet services }\end{array}$ \\
\hline
\end{tabular}

\section{Table 7.4: Review of learning content for operational staff} in the documentary evidence

From the two columns in the table above, Table 7.5 combines the learning content to show the most important learning needs for operational staff identified in the government documents. Since book storage and preservation, collection development (in the first column), and interloan standards and skills (in the second column) are contents relating to collection management, they are grouped together in Table 7.5. Similarly, cataloguing standards, skills and systems (in the first column) and bibliographic control (in the second column) are grouped together because they all relate to knowledge organisation and retrieval in libraries, as are computer skills (in the first column) and IT knowledge and skills (in the second column). 


\begin{tabular}{|l|}
\hline \multicolumn{1}{|c|}{$\begin{array}{c}\text { The most important learning content for } \\
\text { operational staff in the documentary evidence }\end{array}$} \\
\hline $\begin{array}{c}\text { - Bibliographic control: indexing library materials, data structures, } \\
\text { and cataloguing standards, skills and systems }\end{array}$ \\
\hline - Collaboration/communication skills \\
\hline $\begin{array}{l}\text { - Collection management: collection development, book storage } \\
\text { and preservation, interloan standards and skills }\end{array}$ \\
\hline - Digital libraries: developing digital collections and databases, \\
intellectual property and copyright \\
\hline - Foreign language proficiency \\
\hline - Government and Party policies \\
\hline - Information services: reference services, nature of client base and \\
information need analysis \\
\hline - Internet services \\
\hline - IT knowledge, skills and application/computer skills \\
\hline - Management knowledge and skills \\
\hline - Marketing library services \\
\hline - Research knowledge and applications \\
\hline - Reporting and statistical skills \\
\hline - Workplace safety and security procedures \\
\hline
\end{tabular}

\section{Table 7.5: The most important learning content for operational staff} in the documentary evidence

Similar to the tables displaying learning content for staff, Tables 7.6 reviews the learning needs for managers drawn from the two documents and Table 7.7 is the combination of these needs. Similar to the combination of learning needs for operational staff, where the needs identified from each document belong to a content area, they are clustered together in Table 7.7. 


\begin{tabular}{|c|c|}
\hline $\begin{array}{l}\text { Required learning content identified in } \\
\text { the } 1993 \text { Professional Criteria }\end{array}$ & $\begin{array}{l}\text { Expected learning content identified } \\
\text { in the } 2007 \text { Library Development Plan }\end{array}$ \\
\hline $\begin{array}{l}\text { - Computer skills } \\
\text { - Foreign language proficiency } \\
\text { - Government and Party policies } \\
\text { - Information services knowledge, skills and } \\
\text { management } \\
\text { - Management knowledge and skills } \\
\text { - Management of emerging professional } \\
\text { practices } \\
\text { - Research knowledge and skills and application } \\
\text { - Training skills } \\
\text { - Workplace safety and security procedures }\end{array}$ & $\begin{array}{l}\text { - Bibliographic control: cataloguing } \\
\text { standards, indexing library materials } \\
\text { and data structure } \\
\text { - Collection management, Interloan } \\
\text { standards and skills } \\
\text { - Collaboration/communication skills } \\
\text { - Digital libraries: developing digital } \\
\text { collections and databases, } \\
\text { intellectual property and copyright } \\
\text { - IT knowledge, skills and application } \\
\text { - Foreign language proficiency } \\
\text { - Information services } \\
\text { - Internet services }\end{array}$ \\
\hline
\end{tabular}

Table 7.6: Review of learning needs for managers in the documentary evidence

\begin{tabular}{|l|}
\hline \multicolumn{1}{c|}{$\begin{array}{c}\text { The most important learning content areas for } \\
\text { managers in the documentary evidence }\end{array}$} \\
\hline $\begin{array}{c}\text { - Bibliographic control: cataloguing standards, indexing, data } \\
\text { structures/cataloguing management }\end{array}$ \\
\hline - Collaboration/communication skills \\
\hline $\begin{array}{c}\text { - Collection management: collection development, interloan standards } \\
\text { and skills, and preservation of library materials }\end{array}$ \\
\hline - Digital libraries: developing digital collections and databases, \\
intellectual property and copyright \\
\hline - Foreign language proficiency \\
\hline - Government and Party policies \\
\hline - Information services knowledge, skills and management \\
\hline - Internet services \\
\hline - IT knowledge, skills and application/computer skills \\
\hline - Management knowledge and skills \\
\hline - Management of emerging professional practices \\
\hline - Marketing library services \\
\hline - Research knowledge, skills and applications \\
\hline - Training skills \\
\hline - Workplace safety and security procedures \\
\hline
\end{tabular}

Table 7.7: The most important learning content for managers in the documentary evidence 
Combining the learning areas identified in the two government documents provides full lists of learning needs from the organisational perspective, shown in Table 7.5 for operational staff and Table 7.7 for managers. These learning needs include foundation, traditional and updated LIM professional knowledge and skills, as well as generic skills. A higher level of knowledge and skills and management abilities has greater emphasis in the required learning content for managers than for staff.

\subsubsection{Learning content identified for operational staff from interviews}

As discussed in Section 3.3.3.2 on data collection, the perceptions of library managers regarding learning needs for their staff are considered in this study as part of the organisational perspective and the perceptions of operational staff of their own needs are considered to be the individual perspective. The following sections examine learning needs for operational staff from perceptions of managers and individual staff.

7.1.2.1 Manager's perceptions of learning content for operational staff

From the interviews with managers across the sample libraries, common perceptions of learning needs for operational staff emerged. All managers began the discussions by emphasising LIM professional knowledge and skills as the most important content for their staff. Further, many managers discussed content to enhance the generic capabilities of staff, such as communication skills and teamwork. The managers from specialised universities added subject knowledge. Table 7.8 presents the learning content for staff based on the perceptions of managers drawn from the interviews. 


\begin{tabular}{|c|c|}
\hline Main areas & Specific topics \\
\hline $\begin{array}{l}\text { Cataloguing and subject } \\
\text { analysis }\end{array}$ & $\begin{array}{l}\text { - Classification skills } \\
\text { - Indexing and abstracting skills } \\
\text { - Subject heading assigning }\end{array}$ \\
\hline Information services & $\begin{array}{l}\text { - Search strategies and skills } \\
\text { - Information need analysis }\end{array}$ \\
\hline $\begin{array}{l}\text { IT knowledge and } \\
\text { computer skills }\end{array}$ & $\begin{array}{l}\text { - Advanced computer skills } \\
\text { - Working with integrated library systems }\end{array}$ \\
\hline Websites & - Website creation and maintenance \\
\hline Digital libraries & $\begin{array}{l}\text { - Digital library creation } \\
\text { - Digital collection developing }\end{array}$ \\
\hline Communication skills & $\begin{array}{l}\text { - General communication skills } \\
\text { - Presentation skills } \\
\text { - Knowledge transfer skills }\end{array}$ \\
\hline Corroboration/Teamwork skills & - Teamwork skills \\
\hline English proficiency & - English proficiency \\
\hline Subject knowledge & $\begin{array}{l}\text { - Subject focus of a university } \\
\text { (for specialised university libraries only) }\end{array}$ \\
\hline
\end{tabular}

Table 7.8: Learning content for operational staff based on managers' perceptions

\section{Cataloguing, subject analysis and information services}

Most managers felt that current core LIM knowledge and skills, particularly cataloguing, subject analysis and reference knowledge and skills, were the foremost important learning needs for their staff.

The managers in Hoa Sua and Hai Van, where the majority of staff did not have a LIM degree, stated that, because of lack of staff with professional degrees, their current training priority was basic knowledge and skills in technical services (including bibliographic description, classification and subject heading analysis) and information services (including analysis of clients' information needs and provision of different reference services). As one said:

In our library, most staff have backgrounds in non-LIM subjects. They have to participate in training courses in bibliographic description, classification, subject heading analysis and the main skills of information 
services. In fact, I think these topics are always some of the most important learning areas for all library practitioners. (HS-manager)

The managers in Ben Thanh and Hoan Kiem, where many staff had a LIM degree, also agreed that these areas are always important topics for CE programmes because all staff need to update continually and apply such learning to their daily tasks. Further, as discussed in Section 5.2.2 which focused on LIM education, many managers shared the observation that, currently, the content of LIM education programmes does not meet the demands of professional practice, thus requiring staff to pursue $\mathrm{CE}$ to learn and update core professional knowledge and skills.

More specifically, some managers cited that classification has been used for many years; however, subject headings, indexing and abstracting are relatively new in libraries in Vietnam. These managers thought that their staff needed to start learning assigning subject headings, indexing and abstracting skills at a basic level. They also mentioned that, to do the job better, their staff needed to strengthen their classification skills to reach an advanced level. For example, one manager noted:

My staff are familiar with classification tasks but they still need to reach an advanced level of classification skills. For subject analysis, indexing and abstracting library materials, they are quite new. They need to start to learn basic skills. (TB-manager)

Another cited:

We are talking about sharing bibliographic records so we all need to follow relevant and unique standards.... Now our library also uses the DDC. However, we have only started creating key words and abstracting for library materials. Staff need to learn more in these tasks. (DS-manager)

The managers also emphasised information services as their staff's learning needs. They explained that the staff faced a variety of information demands in their daily tasks, and in addition the staff were not sufficiently equipped with such content in their university studies. Client information needs analysis and search skills were among the topics that the managers emphasised most. This comment by a manager in a multidisciplinary university was typical: 
Currently our staff aren't able to deal well with searching and analysis of information needs. Actually, library schools don't provide adequate knowledge and skills to deal with these tasks. (BT-manager)

One manager from a specialised university also said, "Staff should satisfy the different kinds of demands from lecturers and students here.... They have to learn more in information analysis needs" (HT-manager).

As the preceding data suggest, the managers across the libraries were aware of the necessity to strengthen core LIM knowledge and skills in order for their staff to handle routine tasks. The lack of LIM initial education of a number of staff, weaknesses in staff's information services knowledge and skills, particularly reference knowledge and skills, together with changes in cataloguing standards and the increase in indexing tasks in libraries, required operational staff to focus on core LIM knowledge and particular skills.

\section{$\underline{\text { Basic IT knowledge, computer skills, websites and digital libraries }}$}

Regardless of the IT application levels in their libraries, the interviewed managers agreed that computer skills and IT knowledge are important learning areas for their staff. In Table 7.8 three content areas (IT knowledge/computer skills, websites and digital libraries) are IT-intensive. The managers explained that increasing IT application in libraries have meant that IT knowledge and skills have become a core part of the LIM body of knowledge. These observations were typical: "without such skills staff could not work in the current conditions" (BT-manager) and "Many staff are not competent in computer skills. Their skills are just enough to handle only simple tasks" (HT-manager). In some cases, managers specified IT topics that their staff specifically needed. For example, one manager indicated: "Our library is going to upgrade its LIBOL software to Version 6.5, so staff now need to be trained in this" (HT-manager). These data suggest that improving computer skills and using specific software in libraries are necessary for staff to handle their work.

In Ben Thanh, Thanh Da and Hai Van, where they had their own websites, the managers indicated that website creation and maintenance were important skills for 
library IT staff. As one manager emphasised, "Our staff really need to know how to design and create a library website" (TD-manager).

In addition, most managers mentioned that, because developing digital libraries is a goal for universities in Vietnam, staff need to learn about this area. In Thanh Da and Ben Thanh, which had projects to establish digital collections, learning to develop a digital collection was a crucial need for staff. As one stated:

To establish a digital library, it is critical to send staff to professional IT programmes to learn how to change the formats of materials, how to organise and retrieve digital materials and so on... briefly, how to create a digital collection. (BT-manager)

In Ho Guom and Tan Binh, which lacked a digital library development plan, the managers also mentioned digital libraries as a learning area; as one said: "Yes, we need to prepare for changes so staff also need to learn about digital libraries" (HGmanager).

The preceding evidence shows that, as a part of the current LIM body of knowledge, knowledge and skills in IT were regarded by managers across the libraries as significant learning content for their staff. It is recognised that managers took into account particular projects and the current infrastructure of their libraries when specifying indicative topics for their staff's CE.

\section{Communication and teamwork skills}

According to several managers, library practitioners in general, and operational staff in particular, need to possess essential generic skills. Further, they mentioned that their staff had not learned adequate communication skills. This comment represented the managers' view:

Skills to communicate with clients are very important. LIM students are not provided with such skills. My staff really need to learn them. No matter how hard we work, if we are not able to connect well with clients and make them feel happy, they never appreciate our work. (DS-manager) 
The managers specified presentation skills and the ability to transfer knowledge as crucial for all library staff. For example, the managers in Thanh Da and in Tan Binh emphasised that, to deal with reference or user training tasks, staff should know how to convey information to clients. The managers in Ben Thanh and in Hoan Kiem and Ho Tay judged that their staff lacked the ability to collaborate and teamwork skills. This is one of their comments:

LIM students are not provided with this set of skills. In fact, staff need the ability to work together. We also need to know how to share our resources among libraries. (HK-manager)

Again, regardless of the types of university, the managers were aware that the generic skills, including skills in communication, presentation and teamwork, are essential for all library staff. In their views, generic skills assist the staff to do their jobs and are among the most important learning needs for operational staff.

\section{English proficiency}

All managers agreed that foreign language proficiency, particularly English proficiency, is one of the most important learning needs for all practitioners. As some managers explained, the current international integration process in Vietnam affects all aspects of library work and requires staff to possess good knowledge of English. English also helps staff to gain opportunities for further education overseas. This comment was typical:

I believe that currently, without English proficiency, it is hard for staff to be successful. Now a large number of materials in the library collection are in English so they need to be able to read in English. They want to go abroad for further study or attending a professional internship or activity; they need to be able to speak English.... Foreign language proficiency also is a requirement to become civil servants. (BT-manager)

Further data on the need of improving English proficiency can be found in Section 5.3.3.1, which discussed the desire for higher education. 


\section{$\underline{\text { Subject knowledge }}$}

Three managers in the specialised universities indicated that dealing with cataloguing tasks and assisting clients to access information required staff in their libraries to have subject knowledge relevant to their universities. Two of them emphasised that their staff needed to learn relevant subject knowledge through CE. One of them cited that specific subject knowledge was essential for library staff, so the library preferred to recruit those with initial degrees in their university's area of expertise. For example, one manager said:

This is X [area of expertise] university so my staff need a background in $X$. This is a big issue to us. It is very hard to send staff to a full time professional education programme to learn about X. We don't have money and time. Staff need to learn through CE. (HT-manager)

However, the managers from the libraries in multi-disciplinary universities did not raise subject knowledge as a learning requirement for their staff.

Regarding learning needs for operational staff, the data showed that managers across the sample libraries shared the emphasis on learning needs for staff in areas of LIM professional knowledge and skills, including cataloguing, subject analysis, information services and IT. There also was consensus about the needs for improving generic skills, including communication skills and English proficiency for their staff. However, the data only provided evidence of the need for subject knowledge in specialised university libraries.

\subsubsection{Operational staff's perceptions of their learning content}

Analysis of the data shows a clear pattern of opinions from operational staff when they discussed their views of required learning content. In all focus groups, participants began the discussions by emphasising areas of LIM knowledge and skills directly related to their daily tasks, and then areas of IT knowledge and skills. They emphasised these knowledge areas and specific skills as essential for all library practitioners. Further, they highlighted the need to become proficient in a foreign language, particularly English. They also discussed the need to improve 
communication skills. The respondents regarded communication skills and English proficiency as generic skills that not only helped them to perform better in their jobs but also helped them to grow as successful individuals. In addition, some participants mentioned relevant subject knowledge as one of their learning needs. Table 7.9 illustrates the learning areas drawn from the focus group interviews with operational staff, which are discussed below.

\begin{tabular}{|c|c|}
\hline Main areas & Specific topics \\
\hline $\begin{array}{l}\text { Cataloguing and } \\
\text { subject analysis }\end{array}$ & $\begin{array}{l}\text { - Using AACR2 } \\
\text { - Classification skills } \\
\text { - Using DDC } \\
\text { - Catalogue creation and maintenance } \\
\text { - Cataloguing digital collections } \\
\text { - Using MARC21 } \\
\text { - Indexing and abstracting skills } \\
\text { - Subject heading assigning }\end{array}$ \\
\hline Information services & $\begin{array}{l}\text { - Reference services: organising, delivering and managing } \\
\text { - Search strategies and skills: general skills, and OPACs, } \\
\text { internet and database searching } \\
\text { - Information literacy } \\
\text { - User education }\end{array}$ \\
\hline $\begin{array}{l}\text { IT knowledge and } \\
\text { computer skills }\end{array}$ & $\begin{array}{l}\text { - Advanced computer skills } \\
\text { - Working with integrated library systems }\end{array}$ \\
\hline Websites & $\begin{array}{l}\text { - Website planning } \\
\text { - Website design } \\
\text { - Website creation and maintenance } \\
\text { - Website management }\end{array}$ \\
\hline Digital libraries & $\begin{array}{l}\text { - Digital library creation } \\
\text { - Digital collection developing } \\
\text { - Copyright issues in the digital environment }\end{array}$ \\
\hline Communication skills & $\begin{array}{l}\text { - General communication skills } \\
\text { - Presentation skills } \\
\text { - Knowledge transfer skills }\end{array}$ \\
\hline English proficiency & - English proficiency \\
\hline Subject knowledge & $\begin{array}{l}\text { - Specific subject focus of universities } \\
\text { (for some libraries only) }\end{array}$ \\
\hline
\end{tabular}

Table 7.9: Learning content for operational staff based on staff's perceptions 
$\underline{\text { Cataloguing, subject analysis and information services }}$

Operational staff, except for some who had IT backgrounds, placed priority on core LIM knowledge and skills. They explained that, as practitioners, they needed to deal with their daily tasks; in addition, they wanted to perform well in the workplace, therefore, mastering professional knowledge and skills was crucial. Several instances of this point were found in group discussions from both multi-disciplinary and specialised universities. These views were representative:

Actually, we have to learn many things, but, first of all, as librarians we have to improve LIM knowledge and skills, especially now that many new things have become part of our profession. (DS-super3)

Cataloguing and information services are core knowledge of library science. We all need to learn and update these areas. (HK-staff2)

Similar to the managers' views, several operational staff who lacked a LIM degree agreed that they needed to possess core LIM knowledge and skills. For example, one said:

My educational background isn't in librarianship. I learn from my peers, and I only understand core LIM knowledge vaguely. I need to learn this content seriously in order to work more confidently. (TD-staff1)

Several operational staff who had a LIM degree also thought that they needed to update their professional knowledge and skills. This point was discussed in Section 5.2.2 which focused on professional education. Further, in all focus group discussions, participants emphasised changes in the profession as the requirement for them to keep learning professional knowledge and skills. This point was discussed in Section 5.2.1.2, which focused on changes in LIM.

In regard to particular learning areas, most operational staff highlighted the need to learn cataloguing standards. According to them, cataloguing knowledge is core to the library profession, and necessary for all library practitioners to deal with daily tasks. As a staff member in information services noted: 
Although I am not a cataloguer I need to know about cataloguing. Without an understanding of cataloguing, I don't feel confident when assisting clients to find materials in the library. (HT-staffl)

An IT staff member also noted, "My task now is establishing a digital collection so I need to learn how to catalogue digital materials." (TD-staff2)

Staff who worked in technical services seemed most able to point out specific topics they needed to learn. They mentioned current changes in bibliographic formats, descriptive rules and classification schemes as having an impact on their jobs. As a result, they indicated the ability to create and maintain catalogues, and working with MARC21, AACR2 and DDC as important CE topics. The following comments of participants in technical services in Hong Ha and Hoan Kiem, where DDC and MARC21 have been used for some years, were representative:

We have used DDC for few years. It has now been translated into Vietnamese and has become popular in many libraries. We need to learn about it in a more systematic way instead of learning it by ourselves. (HHsuper4)

We are using AACR2 and MARC21 but we still need to understand these standards thoroughly... How to catalogue digital materials? We need to learn cataloguing standards at advanced level. (HK-super3)

Participants in both the senior and operational staff focus groups in Ben Thanh, where DDC has not been applied, also mentioned DDC as their needs:

We now use BBK (Library-bibliographic classification), but we will use DDC and will have to assign subject headings to materials. Now many libraries apply these standards and our library will use them too. Therefore, we need to learn them now. (BT-super5)

Similar to the managers' views, staff across the libraries indicated subject heading analysis, indexing and abstracting skills as important learning areas. In some libraries, staff cited that knowing how to share bibliographic records also was an important topic. These are examples of their comments: 
For a long time indexing and abstracting weren't applied in our library; but currently we have a project to create bibliographies for specific subjects. Now we need to do indexing and abstracting for library materials. These tasks are a new challenge, thus requiring us to learn subject analysis content. (DS-super4)

We start talking about sharing bibliographic recorders and library resources so we need to understand standards relating these areas. (HKsuper3)

Operational staff also regarded information services as one of their most important learning areas. Many staff admitted that they had not acquired adequate search and information analysis skills in their university courses. This view was typical:

In university, we only learned to work with the card cataloguing system, so we now need to learn skills relating to the search for and analysis of information in electronic conditions. (HK-super1)

In addition, because of the increasing application of IT as reference tools and services, and the more complicated information demands of clients, staff pointed out the need to learn about assisting clients and providing suitable information for them. As one member reported:

Their questions can range from reference type, such as where they can get a particular title, to technical questions, such as how to attach photos... and to questions relating to their subjects, such as to find relevant articles on specific subject for them. It seems that we need to know everything. (HK-staff2)

Regardless of the availability of online sources in their libraries, staff of both multidisciplinary and specialised universities were aware that working in an electronic environment requires them to possess online searching skills. This comment of one staff member in a multi-disciplinary university represented the view of many other staff:

Now everything can be put online, and people also become skilful in using online sources. Sooner or later reference materials should be available as online resources. So we are librarians; we need to know how to search websites and databases. Otherwise, how can we serve clients? (BT-staff1) 
Similarly, a supervisor in a specialised university noted: "More and more materials are available online. This requires librarians like us to have an understanding of online sources" (HK-super3).

In particular, operational staff in information services indicated that skills in searching OPACs, and using search engines, databases and websites were required topics. This notion was typical: "My tasks are assisting clients using computers and searching databases. I need to master searching skills in web and database" (HTsuper1). In a specific case, one line staff member in Ben Thanh even reported:

I am even not skilful in using the OPAC. When users ask me to find a particular book, I don't really know how to do this. I need to learn this skill first. (BT-staff4)

Only operational staff in Hai Van and Hoan Kiem mentioned information literacy as an important CE topic. As one member noted:

Now people are talking about information literacy. I think we need to develop and use information literacy skills. Such skills will enhance our competencies and help us in assisting users to find information. However, I don't really fully understand this thing. (HV-staff3)

Staff in the remaining libraries did not directly discuss the needs of information literacy but they seemed to agree with the staff in Hai Van and Hoan Kiem when emphasising assisting clients as a learning need. This comment is an example:

We all know that librarians should assist students in searching relevant materials. It is certain that most of us can instruct them to use the library, such as using catalogues or finding the books on shelves. But how to find relevant documents isn't an easy task. I think we ourselves need to learn the use of difference sources and the use of materials from different sources before we can assist people. (TD-super4)

Developing high quality reference services also emerged as an important need in some libraries. As senior staff member in Hoan Kiem said:

We need to learn how to establish reference services, such as an "information desk" like the General Sciences Library [in HCMC] has 
done. To serve users better we should not only provide books from our storage but also satisfy their various information needs. (HK-super3)

The preceding data show that, regardless of their educational degrees or areas of work, operational staff across the sample libraries recognised that they need to learn and update LIM knowledge and skills. Dealing with daily tasks and requirements and changes in the profession mean they need to keep learning professional knowledge and skills. Cataloguing, subject analysis and information services were the main areas that most participants emphasised as their most important learning needs. It is recognised that staff and managers had similar emphases on the main learning areas; however, in terms of specific topics, staff indicated their needs in more detail.

\section{IT knowledge, computer skills, websites and digital libraries}

Operational staff from all libraries affirmed that, to perform well in the current library environment and in current society, IT knowledge and skills are crucial. They were aware that computer skills and IT knowledge has become part of LIM competency. A lack of these knowledge and skills means that library practitioners cannot deal with their daily tasks effectively. This point was discussed in Section 5.2.1.2, which focused on changes in LIM. Additional examples include the following:

Now IT is applied increasingly in our profession. We do everything by using computers: cataloguing, searching, statistics and so on. We have to understand and use the library integrated system as well as special software using in library activities... We do need to learn IT. (BT-super5)

Now everybody needs to know about computers and have certain IT knowledge. I didn't acquire IT knowledge in school and now I have to deal with IT tasks. Mostly I learn about IT on the job, and in fact I only partly understand it. I still haven't mastered my tasks. (HK-staff1)

At the same time, operational staff stressed that current projects in their libraries, as well as the Vietnamese universities' target of digital library creation, require them to learn IT-intensive areas. The evidence for this point can be found in Section 5.2.1.2. Here is another example: 
Now our library is in charge of many new tasks and they all relate to IT applications. To develop electronic curricula for lecturers we need to master using some software... IT skills and software are changing, so we need to update continuously. (DS-super4)

In terms of specific learning topics, computer skills, knowledge of IT applications in libraries, working with integrated library systems, websites and digital libraries emerged as the most important needs for operational staff across the libraries. These comments were typical:

We need to be good at online searching and first of all we need to possess advanced computer skills. (HK-staff5)

We work with an integrated system everyday; we need to understand it well. This means that we need to have basic IT knowledge and to be good at computer skills. (BT-super5)

Maybe we can't acquire expertise as the IT technical staff do but. at least, we need to understand basic IT knowledge or principles of IT application in libraries. These help us to work competently with the automated system and be able to give feedback to IT staff to make the system better. (DSsuper1)

Now most libraries have their own websites. People can put all kinds of information on the web. As library staff, we need to know basic knowledge and skills about websites... such as web searching and creating a simple personal website. (BT-staff1)

Website design, maintenance and management are essential for those who have tasks relating to IT. This comment was represented the view of IT staff:

Issues concerning websites are many. Each year many related issues arise. I can't list here all topics which I need to learn. However, I can say that specific skills to design, manage and plan for websites are essential for me. (TD-staff3)

Regarding digital libraries, the participants presented three distinct views concerning the degree of knowledge they felt they needed to possess: (1) the need to acquire basic understanding, (2) the need to learn specific skills and (3) no need. In five libraries, which had projects to develop digital collections or a digital library strategy, techniques to digitise documents, digital collection creation, copyright 
issues in digital libraries and cataloguing digital materials emerged as important needs. This comment of a supervisor was typical:

Like many university libraries, our library also tries to establish digital collections; therefore how to digitalise materials and how to maintain them... copyright issues are new to us. I myself have to deal with these issues. They are quite complicated for me but I have to learn. (BT-super3)

In the other four libraries, participants felt that a basic understanding of digital libraries was their first need. This was a typical view: "People are talking about digital libraries but I think that first we all need to understand what a digital library looks like" (HK-staff1).

The participants in the remaining library, which had a less developed infrastructure, did not see this area in particular or IT-intensive areas in general as important learning needs. As one staff member said, "We do everything manually now" (HGsuper2). Another noted, "We can't apply such things [skills in working with automated systems] under our conditions" (HG-super5). A third said, "A digital library is unrealisable for us" (HG-super1).

Thus, with the exception of one library, operational staff emphasised IT application areas including digital libraries among their most important learning needs. Analysis of the data again shows that the current infrastructure and particular projects in libraries affect the focus of the learning needs of practitioners. It is also recognised that participants appeared to keep in mind the requirements and conditions of their libraries, as well as their basic daily tasks, when identifying and assessing their own learning needs. This recognition of organisational needs by operational staff also reveals the nexus between the needs of practitioners and their organisations.

\section{Communication skills}

Communication skills emerged as important for staff, although there were a variety of views on this learning need. 
In the view of younger staff across the libraries, communication skills are crucial because these skills help them to become not only successful practitioners but also successful individuals in their community. This view represented the opinion of younger staff: "We all need to better ourselves. Communication skills help us. I am sure everybody needs to learn these skills" (DS-staff4). The following is another example:

I agree that communication skills are important. I used to work with a lady who is very clever in contact with others. She knew how to please others so people liked her and always supported her.... I try to learn from her... and I think it is wonderful if I have a chance to learn communication skills formally. (HK-staff1)

In particular, younger staff in several focus groups commented that, in order to explain or negotiate with clients, they needed to be skilful to speak in front of clients. Here are examples of comments. A supervisor said:

How to negotiate and convince people is important. Many students have bad behaviour when they come to use the library. They don't follow the library regulations. When we try to remind them about our regulations, some are ready to start a quarrel with us. So knowing how to negotiate with them is very important. (BT-super3)

A staff member in another library reported:

I have no confidence when I have to explain something to students [clients]. I think I don't have the ability to give a talk or teach others to do something. I need to learn. (HK-staff4)

In addition, by emphasising the lack of formal training opportunities to improve their communication skills, younger staff members appeared to indicate the need for formal CE programmes with this content. "Communication skills make us perform better, but the library never sends us on such courses" (KH-staff3) and "No such course is conducted for librarians" (HT-staff2) were comments that reappeared in the focus groups. 
However, in the view of some older senior staff and supervisors, practitioners need to learn communication skills through their work experience or on their own rather than by attending CE activities. They felt that libraries could not support the time and finance required for learning this content. This comment is an example:

Actually, communication skills are individual attributes. If people want to improve their communication skills, they'd learn better through their experiences. How could we improve such skills through learning activities? We can only focus on professional skills. (HS-super2)

Interestingly, in the focus groups consisting of senior and line staff in Thanh Da and Ho Tay, senior staff and supervisors agreed with line staff that communication skills were important learning content. As a supervisor in Ho Tay said, "They [managers] may think that spending time and money for staff to learn communication is a luxury but I think such skills are needed for staff' (HT-super1). More clearly, a supervisor in Thanh Da stated:

Working in information services, communication skills are the most important. In our library, staff with or without background in LIM all lack communication skills. (TD-super4)

The data analysis suggests that, because of the limitations of time and finance, older staff disregarded the need for improving communication skills. In contrast, because of their desire for self-improvement and doing the job better, the younger staff stressed their need for better communication skills. There were differing views from older and younger staff on learning communication skills; however, as seen in the above discussion, communication skills are very important for library practitioners.

\section{English proficiency}

Regardless of their tasks, staff agreed that foreign language proficiency, primarily English, is a requirement for effective practice and personal growth in present-day Vietnam. This view was typical: 
Not only us, but everybody now needs to learn English. Our country is now opening the door so poor English is a barrier for individuals in terms of becoming knowledgeable and successful. (DS-super2)

In particular, participants discussed various reasons for learning English. The following examples were representative of their ideas. A staff member in the IT section noted: "English is very important. All software, databases and IT programmes are in English" (HK-staff2). A staff member in technical services mentioned that they had to catalogue materials in English: "Our English proficiency isn't good. To read books in English in order to catalogue them is a struggle for us" (DS-staff1). A staff member in information services cited: "I think $85 \%$ of information in online sources is in English. To search and provide proper information to clients, we have to be able to read them" (TD-staff2).

Further, as mentioned in Sections 5.3.3.1 and 6.5.1 which discussed desire for higher education and sources for $\mathrm{CE}$ activities, there are even more reasons for practitioners to acquire English proficiency - most current professional literature is in English, and English proficiency is a prerequisite for further study opportunities overseas and a tool for strengthening collaboration with overseas organisations. All these reasons encourage operational staff across the libraries to learn and improve their English proficiency.

\section{Subject knowledge}

Similar to managers, operational staff in three specialised university libraries considered related subject knowledge as crucial. Cataloguers in two multidisciplinary university libraries also mentioned the need to acquire subject knowledge. This idea reappeared in the focus groups in these libraries:

Of course, we can't have insightful knowledge in a specific subject in the same way as an expert, but at least we need to have a basic understanding of the subject to provide proper information for clients. (TB-super3)

However, participants in the remaining libraries did not discuss subject knowledge as a learning need. It seems that subject knowledge was not seen as an important 
learning need for the operational staff in all libraries, but was important for those in specialised university libraries and for some who dealt with cataloguing tasks.

Taking into consideration all the comments of operational staff on their learning needs, it is recognised that staff across libraries identified very similar areas. The staff stressed the need to improve professional knowledge and skills as their priority. They also regarded generic skills, including communication skills and English proficiency, as essential for them to be successful in their careers as well as in modern society. When specifying particular learning topics, staff appeared to consider their daily tasks, the requirements from current projects and the degree of IT application in their libraries.

However, the data analysis reveals that operational staff across the libraries had different views concerning the degree of knowledge needed about digital libraries, due to different level of IT application in their libraries. There also was a difference between the perceptions of younger and older staff regarding the needs for communication skills. The younger staff seemed to be very interested in improving generic skills while older staff did not see this need as a priority. Finally, subject knowledge was indicated as learning need in almost specialised university libraries, but was not raised as a learning requirement for all staff in multi-disciplinary university libraries.

\subsubsection{Learning content identified for managers based on their perceptions}

In response to the question about their most important learning content, the interviewed managers began their discussions with the need to learn management knowledge and skills. They then emphasised that knowledge of the policies of the relevant organisations is necessary for their management tasks. Further, many managers mentioned understanding current professional issues as an important need. When specifying current issues, seven of the ten mentioned the management of IT application and the development of digital libraries as important learning areas. Some of them also indicated that, to lead a library, they needed to update knowledge of the management aspects of library areas, including cataloguing, collection 
management and information services. Table 7.10 a summary of the learning areas and specific topics for managers drawn from the managers' perceptions.

\begin{tabular}{|c|c|}
\hline Main areas & Specific topics \\
\hline $\begin{array}{l}\text { Management knowledge } \\
\text { and skills }\end{array}$ & $\begin{array}{l}\text { - General management knowledge and skills } \\
\text { - Management of human resources } \\
\text { - Communication skills for managers: developing and } \\
\text { maintaining workplace relationships } \\
\text { - Motivation: increasing motivation for staff } \\
\text { - Planning process: strategic planning, forecasting, } \\
\text { time scales for planning } \\
\text { - Collaboration skills } \\
\text { - English proficiency }\end{array}$ \\
\hline Policy knowledge & $\begin{array}{l}\text { - } \text { Government policies } \\
\text { - } \quad \text { Institutional policies }\end{array}$ \\
\hline IT applications & - Management of IT applications \\
\hline Digital libraries & - Digital library creation \\
\hline $\begin{array}{l}\text { LIM knowledge and } \\
\text { skills }\end{array}$ & $\begin{array}{l}\text { - Cataloguing management } \\
\text { - Collection management } \\
\text { - Information services management }\end{array}$ \\
\hline
\end{tabular}

Table 7.10: Learning content for managers based on managers' perceptions

Management knowledge and skills

Most managers cited that, to do their jobs effectively in this period of increasing change in the LIM profession and in Vietnamese society, managers need to be more knowledgeable and skilful in management. They had built up management skills primarily by learning on the job and had not had a chance to obtain formal management training. Therefore, they felt they were not very skilful in management and that $\mathrm{CE}$ would be an opportunity for them to improve these skills. As an example, one manager said:

By now, most managers, even the Rector of this university and many deans of faculties, haven't had any formal training in management. This is quite common in Vietnam.... Therefore, I think, first of all, as a manager we need to have knowledge of management, for example, the role, responsibilities and rights of a manager. (HH-manager) 
In terms of specific topics, a common theme among managers was the need to improve their ability to operate their libraries effectively and to create a supportive atmosphere in their libraries. Further, they needed to develop the ability to forecast and plan for the long-term development of their libraries as well as to establish collaboration with other institutions. For example, regarding the needs to improve management of human resources and communication skills, this statement was typical:

As a manager I need to have the ability to manage administrative tasks, human resources and even daily situations. I need to have the skills and abilities to convince staff and motivate them to keep focused on their work. We should create a warm atmosphere in the institution so that staff consider the workplace as their family. This will foster their love of the work and keep them with the institution. Such skills are very important to me. As you may know, $85 \%$ of staff are women, and women are very complicated. How can I encourage them to stand together and feel happy with the work? I need to learn skills that help me to deal with such things. (HS-manager)

In a specific case, a manager emphasised the need for staff management skills:

I see that in some cases, my staff appear to help each other if I am there but in fact they aren't willing to do that.... How to create a sharing and supportive atmosphere in the library? As manager, I need to have the ability to deal with this issue. (TB-manager)

Regarding the knowledge and skills to develop strategic plans for libraries, and improve collaboration among institutions, the following comment was very representative of managers' opinions:

I very much need to learn how to establish long-term strategies for our library development. Most library managers just patch together requirements in practice or just deal with a problem as it comes but don't have the ability to handle long-term plans for developing their libraries. Particularly, I need to propose a development plan for our library for the coming five and then ten years.... Of course, I can sit down and think and then write a proposal. However, I have never learned how to deal with such a task. (DS-manager)

Similarly, another manager noted: 
Currently, library managers in Vietnam don't have the ability to establish cooperation among our libraries.... We all have limited funding but we don't know how to cooperate and share our resources. (KH-manager

In addition, the managers across the sample libraries mentioned foreign language proficiency as a learning need. Three of them considered English proficiency as their own learning need.

You know, our managers lack communication skills, the ability to establish collaboration with partners and foreign language proficiency. We very much need to learn about these. In my case, because my English isn't good, I often hesitate to connect with overseas colleagues. (DS-manager)

However, foreign language proficiency was not an issue for six managers, who either had a background in English or had received higher education overseas. English proficiency was identified as one of the important learning areas for some managers interviewed, but in fact foreign language proficiency is important for every Vietnamese library manager.

\section{Policy knowledge}

As presented in Section 1.2.3, university libraries are under the administration of the parent university, functional ministries and central government. The managers confirmed that, to operate a library, managers have to follow the development path of the parent organisations, thus requiring them to understand the development strategies and policies of these organisations at different levels. This explanation of a manager was very typical:

As a manager I must determine development strategies for the library. To do this I have to know our possibilities, including human resources, facilities and finance. This means I have to understand the strategies and policies of our parent institutions. I need to understand what the university's priorities are in order to establish our action plans. (HTmanager)

Mentioning his experience, another manager said: 
Being a manager I need to know the duty and rights of a manager within our organisation. I need to understand particular policies of government as well as our university.... It used to be that, because I didn't know the relevant policies, I thought I didn't have rights to make decisions in some affairs - in fact I could do that. Therefore, in my opinion, an understanding of policies is necessary for managers. Further, our policies are changing quickly so we need to up with the changes. (HH-manager)

The data analysis suggests that policy knowledge, including the policies of government and parent institutions, is necessary for all managers.

\section{$\underline{\text { IT application and digital libraries }}$}

Interviewed managers regarded IT application in libraries, including digital libraries, as a practical requirement. As one manager summarised, the main issues concerning IT application in Vietnamese libraries emphasise the needs for this area:

IT is increasingly applied in libraries now. You can see that the internet and IT strongly impact on libraries.... Online sources are increasing... we have plans towards digital library development... So, I need to know about IT that can be applied to library activities. (TD-manager)

In particular, the managers in libraries with a modern infrastructure or a current digitisation project, such as Thanh Da or Ben Thanh, seemed more aware of the specific content they needed to learn. For example, the manager in Thanh Da pointed out particular topics necessary in his context. He said, "I want to know about establishing digital collections, metadata and establishing 'chat with librarian' services." However, in libraries with a less developed infrastructure or without particular digitisation projects, such as Ho Guom or Ho Tay, the managers recognised the importance of knowledge in IT application but seemed unsure about the specific topics they needed to learn. For instance, the manager in Ho Tay stated broadly, "I need to learn about trends or strategies or ways to develop the library towards a digital library."

Again, it is recognised that the infrastructure and particular projects of their libraries have impacted on the specific learning topics for practitioners. 
Management of cataloguing, collection management and information services

Finally, the data analysis shows that principles and issues in the management of LIM professional areas were among the most important learning needs for all managers. As one manager stated, "A manager needs to know new issues in professional knowledge, particularly management aspects of cataloguing, library collections and information services" (TD-manager). As an echo of this perception, another manager cited: "I am in charge of managing professional activities of the library. For me issues in development of library work and the ability to handle these issues are very important" (HT-manager).

The data analysis shows that the comments of managers across the sample libraries focused on their needs for management aspects rather than specific knowledge and skills in regard to LIM areas. The managers with a degree in LIM believed that they already had the LIM areas of knowledge. For example, the manager in Ho Guom said, "I think I have already mastered such things." The managers without a degree in LIM mentioned that they could rely on fellow managers or supervisors regarding technical issues in LIM. For example, the manager in Tan Binh said, "I consult with fellow managers who have a LIM background in regard to professional issues". The manager in Hai Van noted, "My duty is directing the library as a whole. Supervisors in each section are in charge of specific professional issues."

Taking together all the comments of managers about their learning needs, four main points emerge. First, the managers across libraries had similar needs. In particular, most of them placed the greatest emphasis on management knowledge and skills. Second, the infrastructures and particular development projects of their libraries affected the emphasis they placed on the levels of learning and specific topics in IT application. Third, in regard to professional knowledge, the managers mostly emphasised IT-intensive content and the management aspects of professional areas of work, due to awareness of the changing requirements of actual practice; but they placed much less emphasis on the working knowledge of particular areas of library work. Finally, there was not a significant difference between the learning needs of managers from multi-disciplinary and specialised university libraries. 


\section{2 Identifying preferred learning formats}

Learning formats are another aspect of learning needs. The identification of preferred learning formats is based on the perceptions of interviewees.

\subsubsection{Learning formats for operational staff}

Regarding important learning formats for operational staff, the data provided the perceptions of library managers and operational staff themselves. Their perceptions are examined as follows.

7.2.1.1 Managers' perceptions of learning formats for operational staff All the managers preferred intensive courses as the learning format for their staff. In addition, some of them mentioned visiting other libraries and overseas internships as effective ways of learning when libraries can afford these for staff.

\section{$\underline{\text { Intensive courses }}$}

All managers agreed that the best learning format for staff is intensive courses of one to two weeks' duration. Being released from their jobs allows staff to focus more on studying and, for these short periods, it is possible for other staff to absorb the workload of a trainee. The following are typical comments: "It is very good for staff to focus on study but it is very difficult to let staff be away for long. Two weeks is reasonable for us to arrange" (BT-manager) and "One week class focusing on a particular topic is a good format" (HS-manager).

Some managers added that, because of the lack of LIM degrees of many practitioners, and the need to upgrade the professional knowledge of LIM degree holders, intensive courses focusing on a particular topic and providing learners with both theoretical and practical aspects were their most important format for staff CE. In addition, the managers in some libraries suggested that all practitioners need to attend intensive $\mathrm{CE}$ courses periodically. For example, one manager said: 
Every three or four years, all staff need to attend CE courses to update their professional knowledge. They not only need update specific skills but also theoretical issues of the profession. (HV-manager)

To update and enhance professional knowledge and skills in both theoretical and practical aspects for operational staff, the managers identified intensive courses as the most preferred and important learning format.

\section{$\underline{\text { Visiting other libraries }}$}

In regard to visiting modern libraries as a learning format, there were two opposing views among managers. Three managers had a high opinion of this format. For example, the manager in Hong Ha believed that a person's perceptions are important in much that he or she does and that changing perceptions is harder than changing skills. He thought that visiting may change the perceptions of practitioners. He said:

Visiting is a good way to learn. You know, seeing is believing. A short visit is not enough for staff to know how to do particular tasks, but they can understand what a modern library should be. You know, it is not easy for people to change their views. By visiting they may change. This is quite good. You know, if they don't have a chance to see, they never want to change anything here.

However, the manager in Ben Thanh believed that "visiting has a low effectiveness." She noted, "Staff may change their views about library jobs but they don't know how to do the jobs." The manager in Hoan Kiem added that it was difficult to find financial support for staff to visit modern libraries, which made this format unfeasible.

The remaining five managers did not mention visiting as a learning format. The data analysis suggests that visiting may be effective in some ways and may be a useful learning format when libraries can afford it. However, for many managers, it was not a preferred learning format for their staff. 


\section{Overseas internships}

Only two of the participating libraries had provided overseas internship opportunities for their staff. The managers in these libraries assessed that this format was very effective. By being involved in daily work in a modern library for about three months, staff can learn from direct observations, asking colleagues and practising in real situations. These opportunities also motivate practitioners to improve their English proficiency, as well as their professional and communication skills. As the manager in Ben Thanh reported:

An overseas internship is a useful way of learning. Staff really like to do such activities. They dream about such opportunities and are very excited if they can get the chance. They can learn a lot by being involved in real modern working conditions.

Some other managers agreed that internships are a good opportunity for staff learning but they did not mention these as their preferred format for their staff. The lack of financial support from their universities made such a format unrealistic.

\subsubsection{Operational staff's perceptions of their learning formats}

Discussions from focus groups revealed that most operational staff preferred intensive courses. In addition, many staff mentioned learning from colleagues and using the internet to update as effective learning formats. In some libraries participants also mentioned visiting other libraries as a good way to learn, but, due to the lack of financial support, this format was not an option.

\section{$\underline{\text { Intensive courses }}$}

Similar to the managers, staff highlighted the features of intensive courses as an important learning format. This description represented the view of many staff:

Short intensive courses which can systematically provide us with particular skills are good. We need to be tutored in both theoretical and practical aspects of a skill. These help us to understand comprehensively and to apply the skill in our work. (HS-staff1) 
In addition, many participants emphasised that they particularly prefer learning in a step-by-step manner. This view was typical: "I really like short courses in which instructors teach us in a step-by-step way. This helps me to understand and remember easily" (TB-staff5).

Some participants added that they felt more committed to learning when they enrolled in intensive courses. They explained that, when libraries sent them on such courses and released them from their daily duties, learning became an obligation. In the particular context of intensive courses - for example, restricted time, specific requirements and direct feedback from instructors - they felt learners made more effort. As a supervisor noted:

I become more focused and more serious about learning when participating in intensive courses. I keep my mind on learning because I have to acquire particular knowledge in a limited time. Actually, when the library gives us opportunities to learn we should learn seriously. (HSsuper2)

It should be noted that a few staff did not see intensive courses as an effective learning format. For example, one member said:

For me, it doesn't make sense to sit in an intensive course to learn something about IT. I need to practise and apply new skills in a particular context and that takes time. So I'd rather do it through "trial and error" by myself than go to a short course and then not be able to absorb anything. (HH-staff3)

However, the majority of operational staff considered structured intensive courses as their best learning format.

\section{Learning from colleagues and using the internet}

As discussed in Section 6.3.4, in several focus groups, participants appreciated the support of colleagues because they were available to give prompt and detailed instructions, and feedback about daily tasks. Participants considered that learning from colleagues is both effective and a timesaver. The following are examples of operational staff opinions: 
I really like to learn from my peers. When I don't understand something I just ask and they show me everything in detail. This is very useful. (HSsuper3)

For me, learning from books or CE programmes isn't as easy as learning from peers. Peers can pass on particular skills in detail and in our particular context, therefore, I can easily understand. (BT-staff3)

Using the internet to learn and update is another method that many staff highlighted. Some participants even thought that they could find everything they needed on the internet. As an example, line staff in Hai Van shared this idea:

I think, self-learning, particularly learning through the internet, is very important. It is impossible that $\mathrm{CE}$ courses are always available for everybody, on every topic and at the right time. But by using the internet we can update regularly and learn particular and relevant skills for us. (HV-staff4)

However, as this method requires practitioners to possess English proficiency and libraries to have adequate internet access and capacity, none of operational staff in Ho Guom where internet access was not available, and only some in Hong Ha and Tan Binh where internet access was limited, preferred the internet as a learning format.

Regarding learning formats for operational staff, the findings show that both managers and staff emphasised intensive courses as the most important format. In addition, some staff considered learning from colleagues and using the internet as effective learning formats. Some managers cited visiting and overseas internships as useful methods; however, due to the lack of finance, these methods are not an option for many libraries.

\subsubsection{Learning formats for library managers based on their perceptions}

The managers reported that they had learned in different ways depending on available resources. Overall, many of them highlighted reading materials, visiting 
other libraries and participating in professional workshops as important learning formats for them.

\section{$\underline{\text { Reading materials }}$}

As mentioned in Section 4.2.1, many interviewed managers had part-time teaching work as secondary jobs. These managers appeared to be confident that they were learning-oriented and had a good ability to self-learn, particularly through reading. In addition, they mentioned that reading is the most opportune way to update knowledge to deal with their teaching as well as management jobs. As they said, "I learn by reading and it helps me to deal with my tasks" (HH-manager) and "I am a self-learning learner - reading and doing research are my primary ways to learn" (BT-manager) or, "Basically, I learn and update knowledge by reading books, journals and the internet" (HT-manager).

\section{Visiting other libraries}

Several managers mentioned that they found it useful to visit and learn from modern libraries, particularly overseas libraries. As the manager in Tan Binh said, "For me, listening and seeing are effective learning methods." The manager in Ho Tay noted that he could not directly apply what that he observed and learned through visiting, but in many cases he could modify the outside experiences to apply to his library. He concluded, "I learn a lot from visits."

\section{Participation in professional workshops}

As mentioned in Section 6.5.2, in general managers recognised that the current professional workshops and conferences held in Vietnam were still of low quality. However, in response to the question about the important format for their own $\mathrm{CE}$ programmes, three managers mentioned workshops. These managers had had opportunities to attend workshops conducted by overseas organisations, and believed that high quality workshops would be the perfect learning format for managers. They explained that it would be useful to engage in discussions of realistic issues, share practical experiences and build up networks among colleagues in a one to three-day workshop. As an example, one manager said: 
Actually, I learn very much about library work through participating in the professional workshops conducted by IFLA and ALA.... Being involved in discussions about activities and listening to colleagues have helped me learn and update my professional knowledge. This is a good way to learn. (HV-manager)

For the remaining managers, they did not use the term "workshop" to mention the important format for their own CE programmes but their preferences seemed to be very similar to workshops. They preferred brief classes where they have opportunities to learn from others and discuss their own cases. They mentioned that such a way is useful for them to find solutions for their situations. For example, one manager said, "I don't have much time for CE. A manager can't go away for long, so an activity lasting about two days is reasonable" (HG-manager). Another manager noted, "Basically I learn by reading. However, for CE programmes, a class for about two days focusing on a practical issue is useful" (HS-manager). A third manager said: "A short-time class where we can learn from experts and discuss our situations to find 'practical' suggestions is ideal for me" (DS-manager).

Hence, regarding learning formats for managers, the data analysis suggests that reading and visiting other libraries are the preferred learning formats for self-learning and attending workshops is the preferred format for CE programmes.

In summary, in Sections 7.1 and 7.2 the first step of the triage has been conducted. In this step, the most important learning needs for library practitioners were identified by examining documentary evidence and perceptions of interviewees. The results of this determination are used as the answer for the third research question ${ }^{6}$. These results are summarised in several tables as follows.

The most important learning content for operational staff from

- the organisational perspective is presented in Table 7.5;

- the managers' perspective is presented in Table 7.8;

- the operational staff perspective is presented in Table 7.9.

\footnotetext{
${ }^{6}$ What are the most important CE needs for Vietnamese university library managers and operational staff from the perspectives of managers, operational staff and organisations?
} 
The most important learning content for managers from

- the organisational perspective is presented in Table 7.7;

- the managers' perspective is presented in Table 7.10.

The preferred learning formats for operational staff:

- intensive courses are the most important format for CE programmes;

- visiting other libraries, overseas internships, learning from colleagues and through the internet are effective formats.

The preferred learning formats for managers:

- workshops are the most preferred mode for CE programmes;

- reading materials and visiting other libraries are the most preferred informal learning formats.

The results of this first step of the triage also provide a basis for the next two steps, which are identifying priorities for CE needs and assessing the priorities for these needs. In addition, the results of this step suggest that the next two steps should be divided into two parts - one for operational staff and another for managers. The reasons for this division are as follows.

First, as discussed in Section 7.1.1, the documentary evidence indicated no differences between the required learning content of the two types of university. Second, as discussed in Sections 7.1.2 and 7.1.3, the interview data revealed that, except for different views concerning the degree of knowledge and skills needed in digital library area and the fact that the needs for subject knowledge were verified in only some libraries, participants across the sample libraries shared very similar views. Third, the data revealed that the learning needs of managers differ from those of operational staff. Therefore, the next two steps of the triage in this study are conducted first for operational staff, then for managers. The results of these steps address the fourth research question ${ }^{7}$.

\footnotetext{
${ }^{7}$ What are the main CE priorities for Vietnamese university library managers and operational staff?
} 


\subsection{Priorities for operational staff}

\subsubsection{Identifying priorities}

In the first step of the triage, the most important learning needs for operational staff were identified from different sources (documentary evidence, perceptions of managers and perceptions of operational staff). In this second step of the triage, the priorities of these learning needs are identified by collating and combining them.

As suggested in the preliminary model in Section 2.5.1, through triage, CE providers identify priorities for the CE programmes that will satisfy the needs of individuals and organisations. Therefore, in this triage, the learning areas identified from different sources are collated to identify the level of their priority. The learning areas that were identified in all sources are considered priorities at level 1. The learning areas that were identified in only one or two sources are considered priorities at level 2. Under each of these areas, the indicative topics from all sources are combined and have the same priority level as the area to which they belong.

Based on the interviewees' perceptions discussed in Sections 7.1.2.1 and 7.1.2.2, the most important learning areas are grouped into two main categories: (1) professional knowledge and skills, and (2) generic skills. In addition to these two categories, a third category - namely "other knowledge" - is created to include learning areas identified in the documentary evidence which do not belong to the above two categories, plus the need for subject knowledge identified from interviews.

Table 7.11 illustrates the collation and combination of the learning areas with indicative content from various sources to identify the priorities for operational staff. The learning areas are presented in bold face, for example "Collection management". The indicated topics are presented in normal face, for example "Collection development", "Book storage and preservation" and "Interloan standards and skills". In the fourth column, using one asterisk (*) illustrates level 1 priorities, and using two asterisks (**) and italics illustrates the level 2 priorities. 


\begin{tabular}{|c|c|c|c|c|}
\hline & $\begin{array}{l}\text { Content identified in } \\
\text { documentary evidence } \\
\text { (from Table 7.5) }\end{array}$ & $\begin{array}{l}\text { Content identified from } \\
\text { perceptions of managers } \\
\text { (from Table 7.8) }\end{array}$ & $\begin{array}{l}\text { Content identified from } \\
\text { perceptions of operational staff } \\
\text { (from Table 7.9) }\end{array}$ & $\begin{array}{c}\text { Priority areas with indicative } \\
\text { content }\end{array}$ \\
\hline \multirow{7}{*}{ 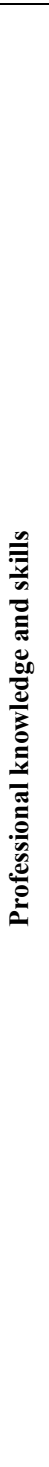 } & $\begin{array}{l}\text { Bibliographic control } \\
\text { - Indexing } \\
\text { - Data structures } \\
\text { - Cataloguing standards, skills } \\
\text { and systems }\end{array}$ & $\begin{array}{l}\text { Cataloguing and subject } \\
\text { analysis } \\
\text { - Classification skills } \\
\text { - Indexing and abstracting } \\
\text { skills } \\
\text { - Subject heading assigning }\end{array}$ & $\begin{array}{l}\text { Cataloguing and subject analysis } \\
\text {-AACR2 } \\
\text { - Classification skills } \\
\text {-DDC } \\
\text { - Catalogue creation and } \\
\text { maintenance } \\
\text { - Catalogue digital collections } \\
\text { - MARC21 } \\
\text { - Indexing and abstracting skills } \\
\text { - Subject heading assigning }\end{array}$ & $\begin{array}{l}\text { Bibliographic control * } \\
\text { - Using AACR2 } \\
\text { - Classification skills } \\
\text { - Data structures } \\
\text { - Using DDC } \\
\text { - Catalogue creation and } \\
\text { maintenance } \\
\text { - Catalogue digital collections } \\
\text { - Using MARC21 } \\
\text { - Indexing and abstracting skills } \\
\text { - Subject heading assigning }\end{array}$ \\
\hline & $\begin{array}{l}\text { Collection management } \\
\text { - Collection development } \\
\text { - Book storage and } \\
\text { preservation } \\
\text { - Interloan standards and skills }\end{array}$ & & & $\begin{array}{l}\text { Collection management ** } \\
\text { - Collection development } \\
\text { - Book storage and preservation } \\
\text { - Interloan standards and skills }\end{array}$ \\
\hline & $\begin{array}{l}\text { Digital libraries } \\
\text { - Developing digital collections } \\
\text { - Developing databases } \\
\text { - Intellectual property and } \\
\text { copyright }\end{array}$ & $\begin{array}{l}\text { Digital libraries } \\
\text {-Digital library creation } \\
\text {-Digital collection } \\
\text { development }\end{array}$ & $\begin{array}{l}\text { Digital libraries } \\
\text {-Digital library creation } \\
\text { - Developing digital collections } \\
\text { - Copyright issues in the digital } \\
\text { environment }\end{array}$ & $\begin{array}{l}\text { Digital libraries * } \\
\text { - Digital library creation } \\
\text { - Developing digital collections } \\
\text { - Copyright issues in the digital } \\
\text { environment }\end{array}$ \\
\hline & $\begin{array}{l}\text { Information services } \\
\text { - Reference services } \\
\text { - Nature of client base } \\
\text { - Information need analysis }\end{array}$ & $\begin{array}{l}\text { Information services } \\
\text { - Search strategies and skills } \\
\text { - Information need analysis }\end{array}$ & $\begin{array}{l}\text { Information services } \\
\text { - Organising, delivering and } \\
\text { managing reference services } \\
\text { - Search strategies and skills: } \\
\text { general skills, OPACs, database } \\
\text { and internet searching } \\
\text { - Information literacy } \\
\text {-User education }\end{array}$ & $\begin{array}{l}\text { Information services* } \\
\text { - Organising, delivering and } \\
\text { managing reference services } \\
\text { - Nature of client base } \\
\text { - Information need analysis } \\
\text { - Search strategies and skills: } \\
\text { general skills, OPACs, database } \\
\text { and internet searching } \\
\text { - Information literacy } \\
\text { - User education }\end{array}$ \\
\hline & Internet services & $\begin{array}{l}\text { Websites } \\
\text {-Website creation and } \\
\text { implementation }\end{array}$ & $\begin{array}{l}\text { Websites } \\
\text {-Website planning } \\
\text {-Website design } \\
\text {-Website creation and } \\
\text { implementation } \\
\text {-Website management }\end{array}$ & $\begin{array}{l}\text { Internet and website services * } \\
\text {-Website planning } \\
\text {-Website design } \\
\text {-Website creation and } \\
\text { implementation } \\
\text {-Website management }\end{array}$ \\
\hline & $\begin{array}{l}\text { IT knowledge, skills and } \\
\text { application/computer skills }\end{array}$ & $\begin{array}{l}\text { IT knowledge/computer } \\
\text { skills } \\
\text { •Advanced computer skills } \\
\text { • Working with integrated } \\
\text { library systems } \\
\end{array}$ & $\begin{array}{l}\text { IT knowledge/computer skills } \\
\text { - Advanced computer skills } \\
\text {-Working with integrated library } \\
\text { systems }\end{array}$ & $\begin{array}{l}\text { IT knowledge/computer skills * } \\
\text { - Advanced computer skills } \\
\text { - Working with integrated library } \\
\text { systems }\end{array}$ \\
\hline & $\begin{array}{l}\text { Research knowledge and } \\
\text { applications }\end{array}$ & & & $\begin{array}{l}\text { Research knowledge and } \\
\text { applications ** }\end{array}$ \\
\hline \multirow{3}{*}{ 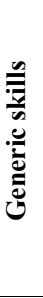 } & \multirow[t]{2}{*}{$\begin{array}{l}\text { Collaboration and } \\
\text { communication skills }\end{array}$} & $\begin{array}{l}\text { Collaboration/teamwork } \\
\text { skills }\end{array}$ & Collaboration/teamwork skills & Collaboration/teamwork skills * \\
\hline & & $\begin{array}{l}\text { Communication skills } \\
\text { - General communication } \\
\text { skills } \\
\text { - Presentation skills } \\
\text { - Knowledge transfer skills }\end{array}$ & $\begin{array}{l}\text { Communication skills } \\
\text { - General communication skills } \\
\text { - Presentation skills } \\
\text { - Knowledge transfer skills }\end{array}$ & $\begin{array}{l}\text { Communication skills * } \\
\text { - General communication skills } \\
\text { - Presentation skills } \\
\text { - Knowledge transfer skills }\end{array}$ \\
\hline & Foreign language proficiency & English proficiency & English proficiency & $\begin{array}{l}\text { Foreign language proficiency * } \\
\bullet \text { English proficiency }\end{array}$ \\
\hline \multirow{6}{*}{ 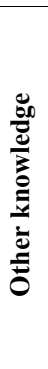 } & $\begin{array}{l}\text { Management knowledge and } \\
\text { skills }\end{array}$ & & & $\begin{array}{l}\text { Management knowledge and } \\
\text { skills ** }\end{array}$ \\
\hline & Marketing library services & & & Marketing library services ** \\
\hline & Reporting and statistical skills & & & $\begin{array}{l}\text { Reporting and } \\
\text { statistical skills ** }\end{array}$ \\
\hline & Government and Party policies & & & $\begin{array}{l}\text { Government and } \\
\text { Party policies ** }\end{array}$ \\
\hline & $\begin{array}{l}\text { Workplace safety and security } \\
\text { procedures }\end{array}$ & & & $\begin{array}{l}\text { Workplace safety and security } \\
\text { procedures ** }\end{array}$ \\
\hline & & Subject knowledge & Subject knowledge & Subject knowledge $* *$ \\
\hline
\end{tabular}

Note: $*$ = priority area at level 1; ** and italic = priority area at level 2

Table 7.11: Priority learning content for operational staff 
Table 7.11 shows that, when the learning needs are collated, several areas have been recognised as important by all sources. These areas are priorities at level 1. Specifically, in regard to professional knowledge and skills, documentary evidence, managers and operational staff all agreed on five priority areas:

- bibliographic control

- digital libraries

- information services

- internet and website services

- IT knowledge and computer skills.

In regard to generic skills all agreed on three priority areas:

- collaboration/teamwork skills

- communication skills

- foreign language proficiency.

However, regarding other knowledge and some other areas, the data did not provide a consensus among the participants and documentary evidence. Therefore, these areas are considered priorities at level 2. They include:

- collection management

- research knowledge and applications

- management knowledge and skills

- marketing library services

- reporting and statistical skills

- government and Party policies

- workplace safety and security procedures

- subject knowledge. 


\subsubsection{Assessing priorities}

Given that the priority level of identified learning needs in a triage process must take into consideration the affecting factors, in this third step of the triage, to assess the priorities for CE, the priority needs indicated in Table 7.11 are linked to the evidence of factors affecting CE discussed in Chapters 5 and 6. These needs are also linked to the organisational requirements and participants' perceptions of their learning needs. By doing so, the priority of particular learning areas is assessed not only based on the perceptions of participants but also on the factors affecting their $\mathrm{CE}$ and requirements from the organisations.

This step, which is discussed below, revealed that, within the level 1 priorities, professional knowledge and skills have a higher priority than generic skills. Therefore, professional knowledge and skills are Priority level 1-1, and generic skills are Priority level 1-2. Other knowledge, research knowledge and collection management are Priority level 2 .

\section{Priority level 1-1: Professional knowledge and skills}

Based on participants' perceptions of the learning needs for operational staff discussed in Section 7.1.2, possessing LIM knowledge and skills is a primarily requirement for all library staff. In fact, as the data on the effects of professional factors showed, many staff had not achieved this goal. This is because a number of staff do not have an educational background in LIM. In addition, because of rapid changes in the nature of library work in Vietnam, the gap between LIM curricula and the demands from current practice is quite big; accordingly many of LIM degree holders also have a need to update their professional knowledge core. Consequently, professional knowledge and skills are the primary priority for operational staff.

In particular, linking the needs for professional knowledge and skills to the impacts of the changes in professional standards (see Section 5.2.1.2), notably the translation of DDC into Vietnamese, the increasing application of AACR2, MARC21 and DDC, and 
the increasing establishment of indexing, abstracting and the assignment of subject headings for materials in university libraries, it is evident that operational staff continually need to learn and update their knowledge and skills on bibliographic control.

Similarly, the data discussed in Sections 5.2.1.2 showed that, due to the changes in information demands, libraries need to provide better services and meet the current needs of clients. Therefore, staff need to prioritise learning knowledge and skills in information services.

Also, linked to the objectives for university libraries in the 2007 Library Development Plan as well as to the effects of development plans of individual libraries (see Section 6.2.1), computer skills and IT application knowledge emerged as essential for library practitioners to operate in current library work. As a result, IT areas, including digital libraries, internet and website services, must also be part of the first priority for the $\mathrm{CE}$ of operational staff.

As shown in the discussion above, when learning needs are linked to evidence of the factors affecting $\mathrm{CE}$ and organisational requirements, LIM professional knowledge and skills emerge as the first priority for the CE of operational staff.

\section{Priority level 1-2: Generic skills}

Linking the needs for generic skills to the effects of the employment requirements, workplace features and individuals' desires, it is evident that generic skills must be priorities for operational staff because of the following reasons. First, dealing with students and academics who tend to be sophisticated clients requires staff to have good communication skills (see Section 5.2.1.2). Second, in creating collaborative relationships with co-workers, staff need collaboration skills (see Section 6.3.4). Third, gaining more opportunities to attend CE programmes, staff must have the ability to transfer knowledge to others. Finally, obtaining opportunities for promotion also 
requires staff to have the ability to express themselves (see Section 5.3.1). Accordingly, generic skills are very important for library staff.

At the same time, as discussed in Sections 5.2.1.2 and 5.3.3, English is crucial for staff in order to work and learn effectively. This is because internet use is becoming widespread and most internet content is in English, as is most up-to-date professional literature, and cooperation with overseas organisations in library activities and professional education has increased.

However, as discussed in Section 7.1.2, the majority of participants, including managers and staff, perceived that the foremost learning need for operational staff is to master professional knowledge and skills. Also, as stated in the 1993 Professional Criteria, the prerequisite for civil servants in librarianship is certification in LIM knowledge and skills. Therefore, in terms of CE for operational staff, generic skills have lower priority compared with professional knowledge and skills and, accordingly, are Priority level 1 2.

Priority level 2: Other knowledge, research knowledge and collection management Management knowledge and skills, research knowledge, policy knowledge, collection management and marketing library services are requirements of their organisations for all practitioners. However, as the data analysis shows, interviewees did not emphasise these areas as the most important learning needs for operational staff. Given that priority content for CE programmes must satisfy the needs of both individuals and organisations, these areas, therefore, are considered level 2 priorities.

It is noted that there are differences between the learning needs identified in the government documents and those identified from the perceptions of interviewees. Regarding collection management needs, the interview data did not reveal these needs for operational staff. As the data showed, interloan services have not yet been applied in most libraries. Participating supervisors who were in charge of collection development 
and line staff who were in charge of book storage did not comment on the learning needs within collection management areas.

Regarding marketing library services, it is noted that information services in most sample libraries were offering only basic services, such as looking up a title, lending printed materials or showing clients how to use catalogues. Therefore the participants probably did not see any reasons for learning how to market these services.

Regarding policy knowledge, as discussed in Section 6.1.1, operational staff conceded that policy knowledge was their focus only when they needed to pass the civil servant examinations. Also, no participant mentioned management knowledge or research knowledge as learning needs for operational staff. They likely did not see the importance of these areas for their daily tasks.

It should be also noted that, as the data discussed in Section 7.1.2.2 revealed, participants were aware of required learning areas from the government's strategies (such as the digital library area). However, in regard to their specific learning areas, participants focused on the knowledge and skills which would directly assist them in their daily tasks or in particular projects in their libraries rather than on those identified in the documents but not used on a basis daily.

Subject knowledge also is at Priority level 2 because, as discussed in Section 7.1.2, this need was not raised as a learning requirement in many libraries. Furthermore, it was not identified in the government documents.

Briefly, management knowledge and skills, research knowledge, policy knowledge, collection management and marketing library services, and subject knowledge are no emphasised by both practitioners and organisation, therefore, they are Priority level 2 for operational staff. 
The priority learning format for CE programmes: Intensive courses

As identified in the first step of the triage (see Section 7.2.1), the features of intensive courses, notably step-by-step instruction and short timeframe, are preferred for operational staff. Operational staff are more comfortable with direct instruction. The restricted timeframe makes it possible for libraries to release staff from daily tasks and to arrange for other staff to cover the work for a person who is away on CE. Therefore, intensive courses are the priority format for the CE of operational staff.

\subsection{Priorities for library managers}

\subsubsection{Identifying priorities}

To identify priorities for managers, their perceived needs identified from all sources (documentary evidence and perceptions of managers) are collated and combined in a similar way as the triage for operational staff in Section 7.3.1. As the data examined in Section 7.1.3 suggested, learning areas for managers are clustered into three categories: (1) management knowledge and skills, (2) policy knowledge, and (3) professional knowledge and skills.

Table 7.12 illustrates this collation and combination. Similar to Table 7.11, the learning areas are presented in bold face and the indicative topics are in normal face. In the third column, using one asterisk (*) illustrates the priorities at level 1, and using two asterisks $(* *)$ and italic illustrates the priorities at level 2. 


\begin{tabular}{|c|c|c|c|}
\hline & $\begin{array}{l}\text { Content identified in } \\
\text { documentary evidence } \\
\text { (from Table 7.7) }\end{array}$ & $\begin{array}{l}\text { Content identified from } \\
\text { perceptions of managers } \\
\quad \text { (from Table 7.10) }\end{array}$ & $\begin{array}{c}\text { Priority areas with indicative } \\
\text { content }\end{array}$ \\
\hline \multirow[b]{4}{*}{ 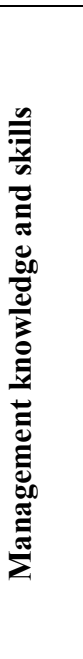 } & $\begin{array}{l}\text { Collaboration/ } \\
\text { communication skills }\end{array}$ & \multirow{4}{*}{$\begin{array}{l}\text { Management knowledge and } \\
\text { skills } \\
\text { - General management knowledge } \\
\text { and skills } \\
\text { - Management of human resources } \\
\text { - Communication skills for } \\
\text { managers: developing and } \\
\text { maintaining workplace } \\
\text { relationships } \\
\text { - Motivation: increasing motivation } \\
\text { for staff } \\
\text { - Planning process: strategies, } \\
\text { planning, forecasting, time scales } \\
\text { for planning } \\
\text { - Collaboration skills } \\
\text { - English proficiency }\end{array}$} & \multirow{4}{*}{$\begin{array}{l}\text { Management knowledge and } \\
\text { skills * } \\
\text { - General management knowledge } \\
\text { and skills } \\
\text { - Management of human resources } \\
\text { - Communication skills for } \\
\text { managers: developing and } \\
\text { maintaining workplace } \\
\text { relationships } \\
\text { - Motivation: increasing motivation } \\
\text { for staff } \\
\text { - Planning process: strategies, } \\
\text { planning, forecasting, time scales } \\
\text { for planning } \\
\text { - Collaboration skills } \\
\text { - Foreign language proficiency } \\
\text { - Training skills }\end{array}$} \\
\hline & Foreign language proficiency & & \\
\hline & $\begin{array}{l}\text { Management knowledge and } \\
\text { skills }\end{array}$ & & \\
\hline & Training skills & & \\
\hline \multirow{2}{*}{ 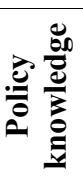 } & $\begin{array}{l}\text { Government and } \\
\text { Party policies }\end{array}$ & \multirow{2}{*}{$\begin{array}{l}\text { Policy knowledge } \\
\text { - Government policies } \\
\text { - Institutional policies }\end{array}$} & \multirow{2}{*}{$\begin{array}{l}\text { Policy knowledge * } \\
\text { - Government and Party policies } \\
\text { - Institutional policies }\end{array}$} \\
\hline & $\begin{array}{l}\text { Workplace safety and security } \\
\text { procedures }\end{array}$ & & \\
\hline \multirow{9}{*}{ 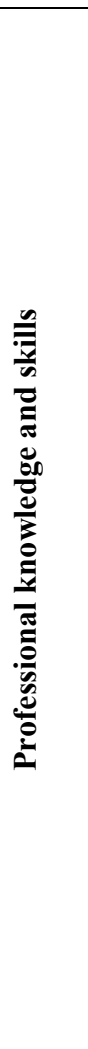 } & $\begin{array}{l}\text { Bibliographic control/ } \\
\text { cataloguing management } \\
\text { - Cataloguing standards } \\
\text { - Indexing library materials } \\
\text { - Data structures }\end{array}$ & Cataloguing management & $\begin{array}{l}\text { Bibliographic control/ } \\
\text { cataloguing management * } \\
\text { - Cataloguing standards } \\
\text { - Indexing library materials } \\
\text { - Data structures }\end{array}$ \\
\hline & $\begin{array}{l}\text { Collection management } \\
\text { - Collection development } \\
\text { - Interloan standards and skills } \\
\text { - Preservation of library } \\
\text { materials }\end{array}$ & Collection management & $\begin{array}{l}\text { Collection management * } \\
\text { - Collection development } \\
\text { - Interloan standards and skills } \\
\text { - Preservation of library materials }\end{array}$ \\
\hline & $\begin{array}{l}\text { Digital libraries } \\
\text { - Developing digital } \\
\text { collections } \\
\text { - Developing databases } \\
\text { - Intellectual property and } \\
\text { copyright }\end{array}$ & $\begin{array}{l}\text { Digital libraries } \\
\text { - Digital library creation }\end{array}$ & $\begin{array}{l}\text { Digital libraries * } \\
\text { - Digital library creation } \\
\text { - Developing digital collections } \\
\text { - Developing databases } \\
\text { - Intellectual property and } \\
\text { copyright }\end{array}$ \\
\hline & $\begin{array}{l}\text { Information services } \\
\text { knowledge, skills and } \\
\text { management }\end{array}$ & $\begin{array}{l}\text { Information services } \\
\text { management }\end{array}$ & $\begin{array}{l}\text { Information services knowledge, } \\
\text { skills and management * }\end{array}$ \\
\hline & Internet services & \multirow[t]{3}{*}{ Management of IT application } & \multirow{3}{*}{$\begin{array}{l}\text { Management of IT application } \\
\text { and emerging professional } \\
\text { practices * } \\
\text { - IT knowledge, skills, applications } \\
\text { - Internet services }\end{array}$} \\
\hline & $\begin{array}{l}\text { IT knowledge, skills and } \\
\text { application/computer skills }\end{array}$ & & \\
\hline & $\begin{array}{l}\text { Management of emerging } \\
\text { professional practices }\end{array}$ & & \\
\hline & Marketing library services & & Marketing library services ** \\
\hline & $\begin{array}{l}\text { Research knowledge, skills } \\
\text { and applications }\end{array}$ & & $\begin{array}{l}\text { Research knowledge, skills and } \\
\text { applications *** }\end{array}$ \\
\hline
\end{tabular}

Table: 7.12: Priority learning content for managers 
Table 7.12 indicates seven priorities at level 1 for managers:

- management knowledge and skills

- policy knowledge

- bibliographic control/cataloguing management

- collection management

- digital libraries

- information services management

- management of IT application and emerging professional practices.

Two learning areas are identified as priorities at level 2:

- marketing library services

- research knowledge, skills and applications

\subsubsection{Assessing priorities}

Similar to the part of the triage for operational staff in Section 7.3.2, to assess the learning needs of managers, the priorities indicated in Table 7.12 are linked to evidence of the factors affecting CE discussed in Chapters 5 and 6. These priorities also are linked to the managers' perceptions of their learning needs and the documentary evidence. This process, which is discussed below, revealed that, for the CE of managers, management knowledge and skills, and policy knowledge are Priority level 1-1, professional knowledge and skills are Priority level 1-2, and research knowledge, skills and applications, and marketing library services are Priority level 2.

Priority level 1-1: Management knowledge and skills, and policy knowledge

As discussed in Section 5.2.1 on the effects of professional factors, library managers face challenges in managing their libraries due to the changes in and evolving requirements of library work. In particular, as discussed in Section 6.4, the management abilities and styles of managers have a significant impact on library activities. The approaches of the managers to operate their libraries - how they arrange tasks for staff, 
assess staff and find learning opportunities for them - impact on staff's dedication to work and learning. In addition, the data examined in Section 7.1.3 revealed that none of the participating managers had formal training in management and they emphasised this in regard to their CE. Therefore, linked to the evidence of the effects of various factors on $\mathrm{CE}$, and the perceptions of managers on their learning needs, management knowledge and skills emerged as an important component of the first priorities for managers' CE.

At the same time, as discussed in Sections 6.1 and 6.2 on the effects of organisational factors on $\mathrm{CE}$, the policies and objectives of the government and parent universities affect all the activities in individual libraries. In fact, in a library, new policies are announced to managers and then the managers disseminate those policies to staff. They direct their libraries by following those policies and must base the development of library objectives on upper organisational policies. As a result, to handle the management role, it is necessary for managers to understand thoroughly the features of the administrative system in Vietnam, and the policies of organisations at different levels of the library system, including government and university. Therefore, linked to evidence of factors affecting CE, policy knowledge is another important component of Priority level 1-1 for managers.

\section{Priority level 1-2: Professional knowledge and skills}

As discussed in Section 5.2, due to the effects of professional factors, notably the changes in library work, it is necessary for managers to upgrade their professional knowledge. However, as discussed in Section 7.1.3, some managers considered that professional knowledge and skills were not their issue. Some mentioned that their main duty was operating the library as a whole rather than focusing on particular professional issues. In addition, some managers could rely on the supervisors as their LIM consultants. Managers primarily focused on IT issues and the management aspects in professional areas as their important learning needs, but were less focused on specific LIM knowledge and skills. Therefore, based on the perceptions of managers, professional knowledge and skills have lower priority compared with the needs for 
management knowledge and skills, and according are considered Priority level 1-2 for the CE of managers.

Priority level 2: Research knowledge, skills and applications, and marketing library services

As stated in the 1993 Professional Criteria, the ability to conduct research is a requirement for senior librarians, and, as drawn from the 2007 Library Development Plan, marketing library services is an expected learning area for all library practitioners. However, similar to the case of operational staff discussed in Section 7.3.2, the interviewed managers did not emphasise these needs for their CE. Given that priority content for CE programmes must satisfy the needs of both individuals and organisations, these areas, therefore, are considered priorities at level 2.

\section{The priority learning format for CE programmes: Workshops}

As discussed in Section 7.2.2, the managers pointed out three preferred learning formats: reading, visiting other libraries, and attending workshops. Of these preferences, the first two are informal self-learning formats, whereas workshops are formal learning formats and the preferred mode for CE programmes.

\subsection{Results of the triage}

The first step of the triage lists of the most important learning needs for library managers and operational staff from the organisational and individual perspectives. The second and third steps provide the priorities for the CE of library practitioners. These two steps address the fourth research question.

Together with the lists of priority learning needs, the triage suggests methods to identify and prioritise learning needs. The $\mathrm{CE}$ priorities for university library practitioners are summarised first, followed by the discussion on these priorities and the methods to conduct the triage. 


\section{Priority level 1-1}

For operational staff

- Bibliographic control

- using AACR2

- classification skills

- data structures

- using DDC

- catalogue creation and maintenance

- catalogue digital collections

- using MARC21

- indexing and abstracting skills

- subject heading assigning

\section{- Digital libraries}

- digital library creation

- developing digital collections

- copyright issues in the digital environment

\section{- Information services}

- organising, delivering and managing reference services

- nature of client base

- information need analysis

- search strategies and skills: general skills, OPACs, database and internet searching

- information literacy

- user education

- Internet and website services

- website planning

- website design

- website creation and implementation

- website management

- IT knowledge/computer skills

- advanced computer skills 
- working with integrated library systems

For managers

- Management knowledge and skills

- general management knowledge and skills

- management of human resources

- communication skills for managers: developing and maintaining workplace

relationships

- motivation: increasing motivation for staff

- planning process: strategies, planning, forecasting, time scales for planning

- collaboration skills

- foreign language proficiency

- training skills

- Policy knowledge

- government and Party policies

- institutional policies

Priority level 1-2

For operational staff

- Collaboration/teamwork skills

- Communication skills

- general communication skills

- presentation skills

- knowledge transfer skills

- Foreign language proficiency: English proficiency

For managers

- Bibliographic control/Cataloguing management

- cataloguing standards

- indexing library materials

- data structures

- Collection management 
- collection development

- interloan standards and skills

- preservation of library materials

\section{- Digital libraries}

- digital library creation

- developing digital collections

- developing databases

- intellectual property and copyright

- Information services

- Management of advanced professional techniques and IT application

- IT knowledge, skills, applications

- internet services

\section{Priority level 2}

For operational staff

- Collection management

- collection development

- book storage and preservation

- Interloan standards and skills

- Research knowledge and applications

- Management knowledge and skills

- Marketing library services

- Reporting and statistical skills

- Government and Party policies

- Workplace safety and security procedures

- Subject knowledge

For managers

- Marketing library services

- Research knowledge, skills and applications 


\section{Priority CE format for operational staff}

- Intensive courses

\section{Priority CE format for managers}

- Workshops

Regarding the content of learning needs, the results of this triage show some similarities to those indicated in other recent studies in LIM, for example, Dakshinamurti and Braaksma (2005), Fisher et al. (2005) and Larsen (2007). As presented in Section 2.3.1.2, these studies also provided lists of the learning needs that focused on both professional knowledge and generic capability. In particular, they also pointed out the need for development of competencies in the following areas: information organisation and management, information services, IT in libraries, teamwork skills and communication skills as main learning areas.

However, the priority learning content identified in this study appears to be more comprehensive and specific than that of others. The participants discussed learning needs within all LIM practice areas, including technical services, information services and IT. Under each priority area many specific topics were determined. In addition, the previous studies considered LIM areas and generic capability areas equally and did not point out the difference between the learning areas for managers and operational staff.

These differences reveal the distinctive learning needs of practitioners in the current Vietnamese context. Due to the lack of LIM background of a number of practitioners, the need to update core professional knowledge of many LIM degree holders and the embryonic digital environment within the Vietnamese library system, it is crucial for library practitioners in Vietnam to learn and continue learning in all areas of LIM knowledge. Plus, as financial support for CE is very limited, it is impossible to satisfy all the needs at the same time. Therefore, the first priority for operational staff must be professional knowledge and skills. 
The result of this triage also showed that although many of the respondents lacked formal LIM education, they did not appear to emphasis basic principles and philosophy of the LIM profession as their learning needs. In addition, for some learning areas such as research knowledge or marketing services the respondents did not identify specific priority topics.

Regarding the methods for conducting triage, the use of multiple methods (individual interviews, focus groups and documentary evidence) and various perspectives (government, managers and operational staff) allow this study to reach comprehensive and detailed findings. As mentioned in the literature review, most previous studies in LIM used only one method and one source of data. For example, they based their findings only on the library director perspective as with Larsen (2007), or only on library staff as with Swanson (1988) and Yang (2001), or they only used questionnaires to collect data as with Swanson (1988) and Yang (2001).

It should also be noted that, through this triage, the nexus between the needs of individual practitioners and their organisations again emerged as a significant effect on identifying and prioritising learning needs. The findings from the triage show that, when identifying important learning content, as discussed in Section 7.1.2, practitioners not only considered their own needs but also the requirements and conditions of their libraries and universities. The collation of learning needs identified from various sources shows that individuals and organisations recognised several similar learning needs (see Tables 7.11 and 7.12). These points reflect a nexus between the needs of individuals and their organisations.

In addition, examining the effects of the organisational factors in Section 6.2.1 showed that the needs of organisations drive the needs of individuals. In the triage, analysis of the data reveals that the individuals seem to be in the best position to point out the specific areas that particular libraries (organisations) need. For instance, the operational staff could specify topics (see Table 7.9) that the documents (see Table 7. 5) and 
managers (see Table 7. 8) could not. Similarly, the managers were the best at specifying their own needs. These points reflect the mutual interaction between individuals and their organisations. Thus, the triage confirms the nexus between the individual and organisation which was already identified in Sections 6.2.1, 6.3.4 and 6.4. This confirmation contributes to the assessment of the preliminary model which is conducted in the next chapter. 


\section{CHAPTER 8: MODEL REVISON AND CONCLUSION}

The CE needs and factors affecting the CE of Vietnamese university library practitioners were determined in the previous chapters. To accomplish the main goal of this study, this chapter uses the findings from the previous chapters to assess and revise the preliminary model for CE for university library practitioners. This chapter also includes the conclusion for this study with recommendations for implementing findings and suggestions for further research.

\subsection{Summary of factors affecting $\mathrm{CE}$}

Before the model is assessed and revised, all the factors found in the data are listed in Table 8.1 and then the effects of these factors are summarised.

\begin{tabular}{|l|l|}
\hline \multicolumn{1}{|c|}{ Main factors } & \multicolumn{1}{c|}{ Specific factors } \\
\hline Social factors & $\begin{array}{l}\text { • Society's perceptions of women's role } \\
\bullet \text { Society's views of library work } \\
\bullet \text { Society's perceptions concerning learning }\end{array}$ \\
\hline Professional factors & $\begin{array}{l}\bullet \text { Nature of employment } \\
\text { - Professional education } \\
\bullet \text { Professional leadership }\end{array}$ \\
\hline Organisational factors & $\begin{array}{l}\bullet \text { Government policies } \\
\bullet \text { University and library policies } \\
\bullet \text { Working climate } \\
\bullet \text { Managers' influences } \\
\bullet \text { Current CE conditions }\end{array}$ \\
\hline Individual practitioner factors & $\begin{array}{l}\bullet \text { Personal traits } \\
\bullet \text { Personal demographics } \\
\bullet \text { Individual goals and attitudes } \\
\bullet \text { Family conditions }\end{array}$ \\
\hline Practitioner and organisation nexus & Practitioner and organisation nexus \\
\hline
\end{tabular}

Table 8.1: Factors affecting CE for university library practitioners 


\section{Social factors}

\section{- Society's perceptions of women's role}

Although the development process in Vietnam encourages women to engage more in education, the traditional role of women is still adhered to by many people. The value of women is measured by how well they handle family and household obligations, affecting the meaning that female library practitioners assign to their lives. Family commitment is the first priority before professional success for most female practitioners. This is a significant barrier to the $\mathrm{CE}$ of female managers and operational staff. (Section 5.1.1)

\section{- Society's views of library work}

The low public regard for library work causes feelings of inferiority and doubts among practitioners about their professional careers. This demoralises them and discourages learning. However, this low regard also is a catalyst to CE for many practitioners in that the need to prove their value motivates them to engage in learning. (Section 5.1.2)

\section{- Society's perceptions concerning learning}

The perceptions of education as a privilege and learning as a duty of youth foster CE among young practitioners but limit the $\mathrm{CE}$ opportunities for older practitioners. The "degree hunger" of Vietnamese may have a two-sided effect - it can motivate people to pursue learning but may cause "diploma disease" where the worth of learning is questioned. Traditional teacher-centred teaching and learning methods do not value the library as a knowledge source, which discourages library practitioners from improving their competencies through CE. (Section 5.1.3)

\section{Professional factors}

\section{- Nature of employment}

The nature of LIM employment requires both managers and operational staff to update professional knowledge, master skills relating to their routine tasks and broaden related knowledge. In particular, the increasing application of IT in libraries and changes in the 
storage and retrieval of information and professional standards drive practitioners to continue their learning. (Section 5.2.1)

\section{- Professional education}

The limitations and inadequacies of current LIM education programmes, as well as the lack of formal LIM education among the majority of practitioners, causes both managers and operational staff to seek CE opportunities. (Section 5.2.2)

\section{- Professional leadership}

The lack of professional leadership has resulted in the lack of authorised CE providers and appropriate professional standards. Practitioners have no official guidance on the

learning resources, strategies and content for their career success, which disadvantages their CE. (Section 5.2.3)

\section{Individual practitioner factors}

\section{- Personal traits}

Self-confidence, self-esteem and learning orientation are traits which foster practitioners' desire to improve their knowledge and, therefore, to engage more in $\mathrm{CE}$. Without these traits, individuals are less likely to engage in learning. (Section 5.3.1)

\section{- Personal demographics}

Age: Age per se does not have a significant effect on CE, but, in association with other elements (social perceptions of learning, the government retirement and personnel policies, and working conditions), it may be a barrier to CE for older practitioners.

Gender: Male practitioners have more advantages in learning than female practitioners Society still considers family/household obligations as the role of women, and these commitments lessen their time, energy and motivation for CE. (See also "Society's perceptions of women's role" and "Family conditions").

Educational background: In general, LIM degree holders tend to pursue careers in LIM, therefore, have a high commitment to strengthening their competencies. But some of 
them find it hard to absorb IT skills and subject knowledge. Practitioners without a background in LIM are disadvantaged in dealing with the theoretical content of LIM.

However, some have advantages in updating knowledge relating to their own background (e.g., IT) that might assist them in improving professional skills. People with qualifications in other disciplines are more likely to pursue their initial background subject and consider library work as a temporary position, which leads them to pursue $\mathrm{CE}$ for their own interests rather than for improving LIM competencies. (Section 5.3.2)

\section{- Individual goals and attitudes}

Opportunities to earn higher degrees and be promoted inspire learning. For some, their passion and belief in the importance of their work encourage commitment and participation in $\mathrm{CE}$ activities. Conversely, those who lack dedication tend to engage in CE less. (Section 5.3.3)

\section{- Family conditions}

In general, family commitments are a barrier to CE for female practitioners, while male practitioners and young staff who still live with their parents usually receive support from their families. However, as male practitioners are usually the main breadwinners, they often feel pressure to seek secondary employment to supplement their income, reducing their time and energy for CE. (Section 5.3.4) (See also "Society's perceptions of women's role")

\section{Organisational factors}

\section{- Government policies}

The retirement and personnel policies limit the CE opportunities for older practitioners. The civil servant standardisation policy encourages learning participation and affects the learning objectives of practitioners; however, its effects on practitioners differ across university libraries due to its inconsistent implementation. The salary policy does not ensure a reasonable standard of living for library practitioners. As a result, many library practitioners supplement their low incomes through additional employment, limiting 
their time and energy for CE as well as their library jobs. This is also a reason for them to look for another career, thus further discouraging them from CE. Low income may also hinder staff from participating in CE programmes when they have to pay for themselves. The influences of government policies also reflect the influences of the political and economic systems on the CE of practitioners. (Section 6.1)

\section{- University and library policies}

The development plans of institutions drive the learning needs of practitioners. Bonus and promotion policies, including unwritten conventions, inspire the learning pursuits of practitioners. Library policies that specifically target $\mathrm{CE}$, such as staff selection for courses or the requirement to submit self-learning commitment plans, particularly impact on the learning enthusiasm and learning outcomes of practitioners. Time and financial support policies are enablers for practitioners' CE. Conversely, a lack of specific policies and support within institutions diminishes the learning engagement of practitioners. (Section 6.2)

\section{- Working climate}

Workload and lack of time: These elements are barriers to CE for all practitioners, but for managers in particular.

Infrastructure: This affects resources for learning as well as for applying learning in the workplace. In libraries with less-developed infrastructure, practitioners do not see the possibility or need for CE. In contrast, modern facilities are enablers for CE. They require practitioners to have the skills to work with them, allow practitioners to apply new work procedures and give practitioners pride in their workplace, which motivates them to learn so they can retain their jobs.

Working environment: Working in an academic environment pushes practitioners to improve their knowledge and qualifications. Working in a library with more up-to-date practices motivates learning, but, in libraries with a more traditional focus, practitioners seem to lose interest in learning. 
Relationships with colleagues: Collaborative relationships and an attitude towards perfection among practitioners encourage CE. Uncomfortable relationships and dissimilar attitudes towards change in libraries may diminish learning enthusiasm. (Section 6.3)

\section{- Managers' influences}

The management approach and managers' opinions regarding CE considerably affect staff CE. A manager's viewpoint influences the activities and policies of the library, and, in consequence, affects staff participation in CE. In particular, the proactive and assertive attitude of directive managers inspires learning enthusiasm and creates enablers for staff $\mathrm{CE}$. The support and trust given by decisive managers inspires staff to improve themselves. However, the encouragement alone of formalistic managers seems insufficient to motivate staff to learn. A lack of direction and assistance from managers is a barrier to staff CE. (Section 6.4)

\section{- Current CE conditions}

The shortcomings of current CE conditions in Vietnam are barriers to CE. They include shortcomings of reading materials and learning facilities, and the limitations of formal $\mathrm{CE}$ courses, in-house $\mathrm{CE}$ activities, professional activities and $\mathrm{CE}$ providers. However, the efforts of providers to conduct formal courses and the efforts of the libraries to conduct in-house activities are $\mathrm{CE}$ enablers to some degree, as they provide practitioners with opportunities to update and help create a learning climate. (Section 6.5)

\section{Practitioner and organisation nexus}

The interaction between library requirements and practitioners' attitudes to requirements (Section 6.2.1), the relationship between library needs and the perceived learning needs of practitioners (Sections 7.1.2 and 7.1.3), and the influence of colleagues in libraries as well as between staff and managers (Sections 6.3.4 and 6.4) create a nexus between practitioner and organisation that has an effect on CE. This factor particularly influences triage. 
As summarised above, analysis of the data indicates five main factors and several specific factors that significantly affect CE for university library practitioners in

Vietnam. This summary constitutes the complete answer to the first two research questions $^{1}$. The next section will assess and revise the preliminary contextual model using these findings.

\subsection{Model assessment and revision}

Before assessing the model and identifying where revision is needed, the factors suggested in the preliminary model and the factors found in the data are reviewed in Table 8.2.

\begin{tabular}{|c|c|}
\hline Factors in the preliminary model & Factors in the data \\
\hline $\begin{array}{l}\text { Social environment } \\
\text { • Social/cultural values }\end{array}$ & $\begin{array}{l}\text { Social factors } \\
\text { - Society's perceptions of women's role } \\
\text { - Society's views of library work } \\
\text { - Society's perceptions concerning learning }\end{array}$ \\
\hline $\begin{array}{l}\text { LIM profession } \\
\text { - Knowledge and skill base } \\
\text { - Competencies } \\
\text { - IT systems } \\
\end{array}$ & $\begin{array}{l}\text { Professional factors } \\
\text { - Nature of employment } \\
\text { - Professional education } \\
\text { - Professional leadership } \\
\end{array}$ \\
\hline $\begin{array}{l}\text { Organisations } \\
\text { - Central government } \\
\text { - } \text { Ministries } \\
\text { - Universities } \\
\text { - Libraries } \\
\end{array}$ & $\begin{array}{l}\text { Organisational factors } \\
\text { - Government policies } \\
\text { - University and library policies } \\
\text { - Working climate } \\
\text { - Managers' influences } \\
\text { - Current CE conditions }\end{array}$ \\
\hline $\begin{array}{l}\text { Practitioner characteristics } \\
\text { - Needs } \\
\text { - Aspirations } \\
\text { - Abilities }\end{array}$ & $\begin{array}{l}\text { Individual practitioner factors } \\
\text { - Personal traits } \\
\text { - Personal demographics } \\
\text { - Individual goals and attitudes } \\
\text { - Family conditions }\end{array}$ \\
\hline Practitioner and organisation nexus & Practitioner and organisation nexus \\
\hline
\end{tabular}

Table 8.2: Review of factors in the preliminary model and in the data

\footnotetext{
${ }^{1}$ RQ1: What are the contextual factors that affect CE for Vietnamese university library managers and operational staff?

RQ2: How do these factors affect CE for Vietnamese university library managers and operational staff?
} 
As shown in the table above, there are both similarities and differences between the factors in the preliminary model and the factors in the data. To assess the model, these similarities and differences are discussed in three parts: main factors, specific factors, and triage. This assessment points out where revision is needed. The significance of the findings is discussed further before a revised contextual model is provided for use in planning CE programmes for university library practitioners in Vietnam.

\section{Assessment 1: Main factors suggested in the preliminary model remain valid}

From Table 8.2, it can be seen that at a broad level the main factors found in the data appear similar to the main factors in the preliminary model. The data confirm that the features of the social environment in which practitioners live, requirements of the LIM profession, organisational features, individual characteristics and relationship between individuals and organisations have significant effects on the CE of practitioners. At this level, the preliminary model has suggested the appropriate main factors affecting $\mathrm{CE}$ for university library practitioners.

It should be noted that the preliminary model was based on a robust framework which considered theories from both adult education and $\mathrm{CE}$ in the professions. This framework allowed the selection of appropriate main factors for the model. Nevertheless, except for the practitioner and organisation nexus, the main factors need to be renamed to reflect more accurately the perceptions of participants of the factors affecting their CE. This point will be discussed in the revision of the model.

\section{Assessment 2: Specific factors suggested in the preliminary model need adjustment}

As shown in Table 8.3, for the first four main factors, the data provided more specific and comprehensive factors that impact on $\mathrm{CE}$ in the distinctive context of Vietnam. For example, in regard to influence of the social environment, the data were consistent with the suggestion about the influence of Vietnamese socio-cultural features on CE in the preliminary model. The data particularly provided evidence of specific effects which seem very significant in the Vietnamese context. These effects include society's 
perceptions concerning women's roles, library work and learning. Similarly, in the other three main factors, several of the specific factors suggested in the model remain appropriate, but many others are either too broad and require splitting or are too narrow and require merging. Thus, at the detailed level, specific factors suggested in the preliminary model need to be adjusted in order to reflect the data.

It should be noted that the preliminary model was based on Western literature and literature that is not focused on CE in LIM; therefore, it could not give completely accurate suggestions at a specific level. However, as mentioned above, its suggestions are close to the findings from the data. Indeed, the model had value as a springboard for the investigation.

\section{Assessment 3: Triage is appropriate}

The preliminary model suggested that triage is a process to identify and prioritise the learning needs of practitioners that would take into consideration the factors that affect $\mathrm{CE}$ and the needs of both individuals and organisations. Analysis of the data reveals that the changes in society, job requirements, organisation requirements, and individual circumstances drove CE needs of Vietnamese library practitioners. In other words, social factors, professional factors, organisational factors and individual factors affect CE needs of practitioners. At the same time, analysis of the data also reveals that, in Vietnamese university libraries, participants prioritised CE needs based not only on their own needs but on those of their organisations. These findings show a strong correlation between the triage suggested in the preliminary model and the findings from the study. Therefore, the triage has been a useful tool for identifying and prioritising the CE needs of the practitioners.

According to these three assessments, to improve the quality of the model, four of the five main factors need to be renamed and specific factors within them need adjustment. The revision of the model is discussed below. 
Revision 1: Renaming the Social environment factor and adjusting the relevant specific factors

As mentioned in Assessment 2, the data were consistent with the view in the preliminary model about the influence of socio-cultural features on $\mathrm{CE}$ and provided three specific factors. In order to reflect more accurately the data, the main factor is renamed and particular factors are specified as follows:

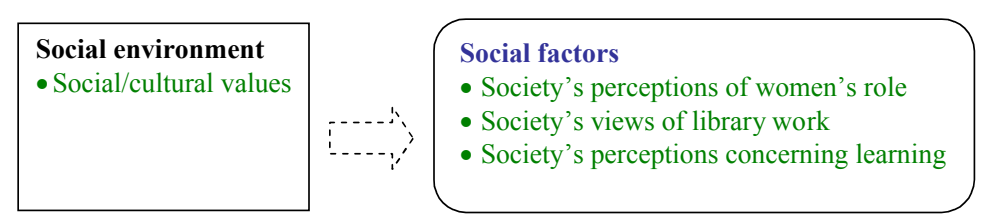

Figure 8.1: Revision of the Social environment factor

In general, the findings on the influences of social environment in this study support the theories in adult education and CE in professions as discussed by Houle $(1980,1996)$, Jarvis (2004, 2006), Merriam et al. (2007) and Nowlen (1988). Their theories suggest that the beliefs and values of society influence the development of individuals and the specific situations of the social system have an impact on the learning process of individuals. The findings particularly share Nowlen's (1988) opinion, by including influences of the environment in the variables that have a strong influence on triage.

More specifically, this study provides an understanding of the distinctive effects of social environment on CE within the LIM profession context in which the majority of practitioners are female. Also, it provides insight into the distinctive effects on CE in the Vietnamese context in which the public holds library work in low regard, the traditional fondness for higher education is prevalent, and the social development process is rapid. 
Revision 2: Renaming the LIM profession factor and adjusting the relevant specific

factors

The knowledge and skill base, competencies and IT systems within the LIM profession were originally included as particular factors that have an influence on the $\mathrm{CE}$ of practitioners. The effects of these elements were confirmed in the data. However, based on the perceptions of participants, all these elements were integrated into one single factor, named here "nature of employment". In addition, the data indicated the effects of two other factors - professional education and professional leadership. Accordingly, to ensure the completeness of the model, the main factor is renamed, specific factors are merged, and new specific factors are added.

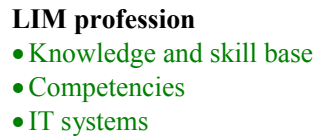

LIM profession

- Knowledge and skill base

- Competencies

- IT systems

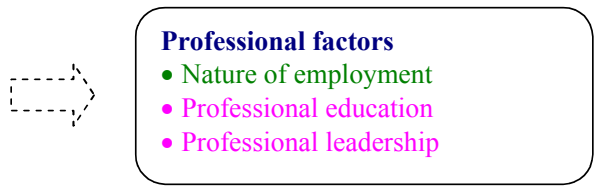

Figure 8.2: Revision of the LIM profession factor

The effects on CE of the specific professional factors found in this study support Houle's (1980) opinion that the characteristics of a profession, including performance and collective identity characteristics, influence the CE of practitioners. In particular, the study shares the findings of others, such as Li (2001) and Russett (1991), that the employment requirements strongly affect CE participation and learning needs. The findings also support Nowlen's idea (1988) when he included knowledge base, competencies and update requirements as variables affecting the learning agendas of practitioners.

However, this study indicates the considerable effects of professional education and leadership on $\mathrm{CE}$, which were not emphasised in previous studies. These effects seem very specific to the context of Vietnamese librarianship. 
Revision 3: Renaming the Organisation factor and adjusting the relevant specific

factors

The preliminary model was correct in suggesting that the features of the administration and policies of organisations - government, functional ministries, universities and libraries in the context of this study - are factors affecting CE for practitioners. However, an adjustment is needed because the data indicated more specific and comprehensive factors concerning organisational features: the effects of working conditions, working environments, relationships among colleagues and the management approach of managers. In addition, the study showed the effects of current CE conditions on learning participation. Accordingly, government, university and library policies, working climate, managers' influences and current CE conditions are included in the model to make it more comprehensive.

\begin{tabular}{l}
\hline Organisations \\
- Central government \\
- Ministries \\
- Universities \\
- Libraries \\
\hline
\end{tabular}

Organisational factors
$\bullet$ Government policies
$\bullet$ University and library policies
$\bullet$ Working climate
$\bullet$ Managers' influences
$\bullet$ Current CE conditions

Figure 8.3: Revision of the Organisations factor

The effects of the working environment on learning were emphasised in the Performance Model of Nowlen (1988) and have been discussed in many other studies concerning CE for practitioners, such as Mathieu and Martineau (1998), Ayres (2005) and Jennings (2007). This study shares findings with these previous studies on the effects of opportunities to apply learning and colleague support in the working environment.

Moreover, this study has identified the effects of the policies of several related organisations. As the lead organisation at the highest level, the central government 
strongly influences the motivation and the needs for $\mathrm{CE}$ of library practitioners through its policies, including those of civil servant standardisation, salary and retirement. These influences, at the same time, reflect the effects of the political and economic systems on the $\mathrm{CE}$ of practitioners. In addition, the policies of parent universities and libraries themselves directly affect the participation and needs of the CE of practitioners. The findings in this study also emphasise the influence of managers on CE. All these findings reflect the distinctive features of the Vietnamese administration system in government organisations.

Revision 4: Renaming the Practitioner characteristics factor and adjusting the relevant specific factors

Although the specific factors of practitioner characteristics are not stated as explicitly as those derived from the data, the preliminary model did include the significant points found in the data. To improve the precision of the model, the practitioner characteristics are specified as personal traits, personal demographics, individual goals and attitudes, and family conditions. The main factor is also renamed.

\begin{tabular}{|l|l|l|}
\hline $\begin{array}{l}\text { Practitioner } \\
\text { characteristics } \\
\text { - Needs } \\
\text { - Aspirations } \\
\text { - Abilities }\end{array}$ & $\begin{array}{l}\text { Individual practitioner factors } \\
\text { - Personal traits } \\
\text { - Personal demographics } \\
\text { - Individual goals and attitudes } \\
\text { - Family conditions }\end{array}$ \\
\hline
\end{tabular}

Figure 8.4: Revision of the Practitioner characteristics factor

Many theories in adult education and CE in professions (e.g., Houle, 1980, 1996; Jarvis, 2006; Merriam et al., 2007) and various models concerning CE for practitioners (e.g., Ayres, 2005; Facteau at al., 1995; Mathieu \& Martineau, 1997) have underlined the significance of the effects of individual characteristics on the learning process. This study is not an exception. However, the data in this study demonstrated that the way individuals determine their needs depends considerably on organisational policies. Similarly, the way individuals perceive their value, role and obligations depends 
considerably on social constraints. For instance, regarding the effects of age on learning, the findings showed that the behaviour of an individual is significantly affected by retirement policies and personnel policies, and social perceptions of learning. Therefore, this study emphasises that it is necessary to understand the effects of individual practitioner factors in the particular contexts of society and organisations. In addition, the findings also showed the distinctive effects of individual characteristics in respect to LIM, such as practitioners having different educational backgrounds.

Based on the perceptions of library managers and operational staff, the proposed contextual model for the $\mathrm{CE}$ of Vietnamese university library practitioners is illustrated in Figure 8.5. 


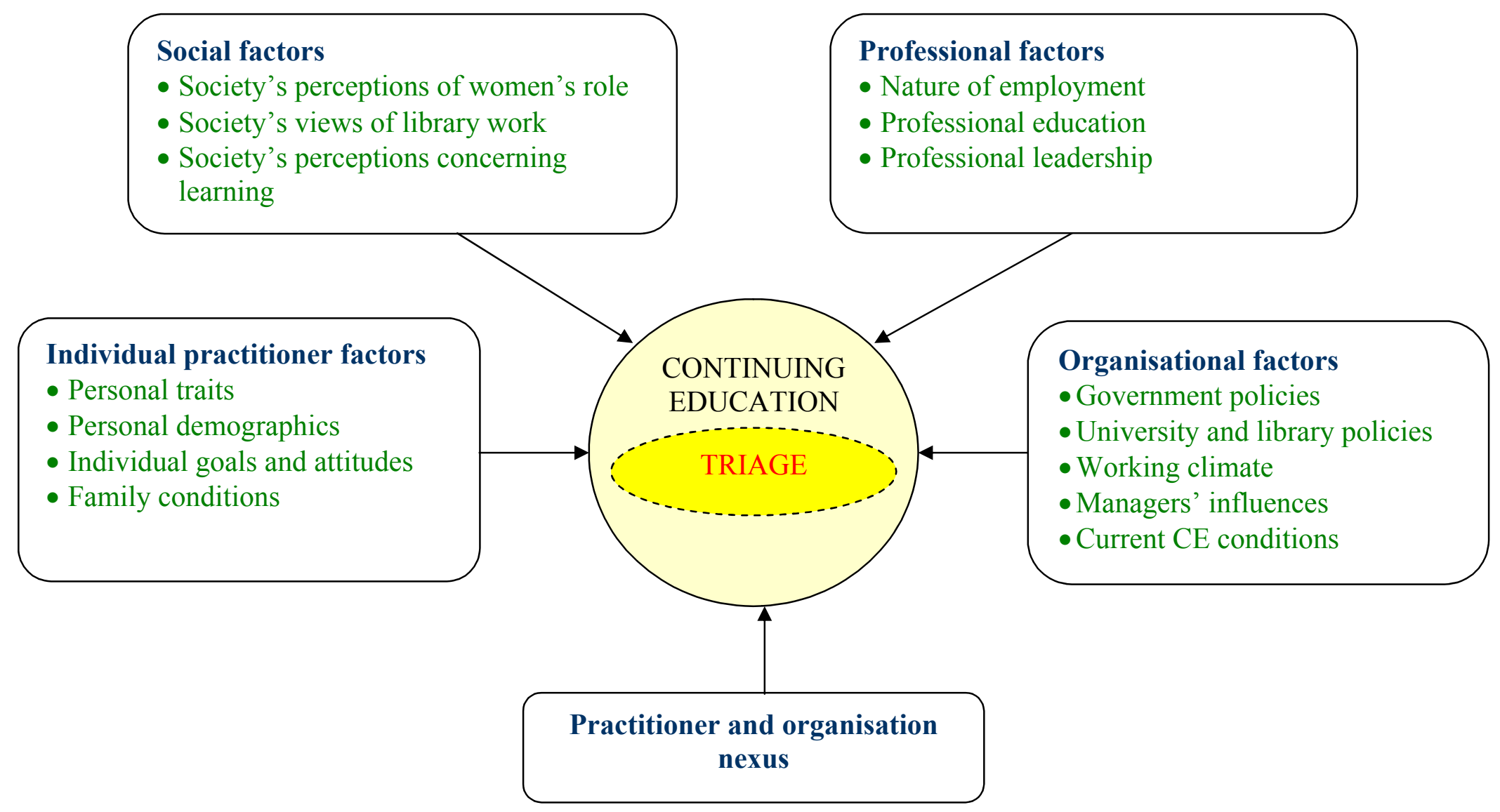

Figure 8.5: Contextual model for the CE of Vietnamese university library practitioners 
As discussed in the literature review, research on factors affecting CE for library practitioners is sparse in Western literature and absent in the Vietnamese literature. In other professions, several studies have focused on factors affecting CE for practitioners, however, most of them have focused on select variables rather than on developing a framework that includes comprehensive sets of factors (see Table 2.1). The model suggested in this study identifies comprehensive sets of factors affecting CE for library practitioners in Vietnam.

The model shows two levels of factors affecting CE. It designates broad, important factors which can be used as a framework to understand the effects to the CE of library practitioners, and indicates the specific factors affecting CE for university library practitioners in Vietnam. At the same time, it emphasises that these factors influence the identification and prioritisation of learning needs for practitioners.

The model can assist related government and professional organisations, CE providers and potential providers, university libraries and university library practitioners in Vietnam to understand the enablers, barriers and needs for CE for practitioners. It can help these organisations in planning CE programmes to ensure the growth of both individuals and organisations. Consequently, it enables the use of CE programmes as a valuable means to develop the LIM profession in Vietnam.

\subsection{Conclusion}

This study endeavours to strengthen CE activities, particularly to assist stakeholders in planning effective CE programmes for university library practitioners in Vietnam. It is obvious that $\mathrm{CE}$ is necessary for improving the quality of library services and accordingly improving the quality of teaching and learning in higher education; but it is not cheap. To identify and give insight into factors affecting $\mathrm{CE}$, this study helps stakeholders to recognise enablers and barriers for $\mathrm{CE}$ in order to increase $\mathrm{CE}$ possibilities for practitioners. To identify and prioritise learning needs for the CE of university library practitioners, this study helps stakeholders to invest time, energy and 
money appropriately on these needs in order to ensure the development of both organisations and individuals. In particular, the study provides a contextual model for use in planning $\mathrm{CE}$ programmes for Vietnamese university library managers and operational staff.

The study will be helpful to a variety of audiences. Administrators of libraries and universities, related government organisations and professional associations could find the information useful in gaining a deeper understanding of factors affecting CE for their members, which may in turn lead them to develop and apply policies for CE in their organisations. Potential CE providers could find the information helpful in planning, designing, modifying or expanding the $\mathrm{CE}$ programmes offered to library practitioners throughout the country. Individual practitioners could develop a comprehensive understanding of their $\mathrm{CE}$ and learning needs, which may help them to manage their own learning. Specific recommendations to implement the findings are given below.

\subsubsection{Recommendations}

Since the findings of this study are of value to several audiences, the recommendations are structured into five parts: for professional organisations, for libraries, for library managers, for CE providers and for library practitioners.

\section{Recommendations for leading organisations}

1. Establishing an organisation responsible for $\mathrm{CE}$

As discussed in Section 5.2.3, the lack of a lead organisation responsible for $\mathrm{CE}$ is a barrier for practitioners. This finding suggests that it is necessary to establish an organisation which is in charge of directing, coordinating, implementing and evaluating $\mathrm{CE}$ activities for university library practitioners. To fulfil these functions, such an organisation might start by preparing guidelines to ensure quality in $\mathrm{CE}$, creating a forum for discussing issues concerning $\mathrm{CE}$ and offering awards that recognise the efforts 
and achievements of institutions and individuals in professional training and development.

2. Reviewing the application and resetting the standardisation of civil servant ranks in librarianship

As the data in Section 6.1.1 showed, the inconsistent application and inadequate content of civil servant examinations in librarianship lessen the importance of the government civil servant standardisation policy in the eyes of library practitioners. As a result, for many practitioners learning in order to obtain professional rank is merely a reaction to the policy rather than a motivator to improve their competencies. This suggests that the Ministry of Culture, Sport and Tourism of Vietnam ${ }^{9}$ should review this policy in order to establish the rationale for such examinations as well as clear requirements for and procedures to attain each rank.

3. Articulating the standards and the core competencies for library practitioners

The data revealed that practitioners need guidelines to indicate the required knowledge and skills as well as to measure of their knowledge and skills (see Section 5.2.3). This finding poses that it is necessary to articulate standards that convey a collective vision of professionalism to guide the daily practices of practitioners. At the same time, in order to meet the standards, it is useful to create and regularly update core competencies or competency norms that are descriptions of the skills, knowledge and attitudes for practitioners in each kind of library (e.g., public libraries, university libraries, special libraries or school libraries). An organisation responsible for CE should be charged with addressing these issues.

\section{Investing in the development of professional materials}

As found in the data (see Section 7.1.2.1 and 7.2.2), reading and sharing experiences are perceived as effective learning methods. Accordingly, investment in professional literature as well as the creation of professional websites are recommended.

\footnotetext{
${ }^{9}$ Formerly the Ministry of Culture and Information. This ministry is in charge of policies concerning civil servant standardisations in librarianship in Vietnam.
} 
The lack of reading materials in Vietnamese is a barrier for CE (see Section 6.5.1). One of the methods to solve this problem is that Vietnamese scholars and experts be encouraged to publish their work to increase professional reading resources. Also, it is useful to work with existing professional journals such as the Journal of Information and Documentation or the Journal of Vietnamese Library to develop and maintain publications focusing on disseminating professional knowledge and on updating practical skills in the profession. Similarly, it would be useful to create a professional website or work with available websites or online resources such as Thuvientre (www.thuvientre.com) or the Online Newsletter of the Library of the University of National Science - HCMC to provide access to professional materials and to open forums for library practitioners to discuss and share information. These journals and online sources currently have a column for sharing professional reading materials; however, to ensure these publications provide reading materials in systematic manner and meet the current needs of practitioners, the leadership role of a professional organisation is crucial.

\section{Looking for overseas cooperation}

As discussed in Section 6.5.3, participants indicated that the cooperation of overseas experts in designing and implementing CE programmes is effective in educating practitioners. Plus, as the data showed, local CE providers and experts are limited in number as well as in ability. Accordingly, it would be useful to look for overseas cooperation to implement $\mathrm{CE}$ programmes as well as to publish and translate overseas professional materials for Vietnamese practitioners.

\section{Building up an image of modern libraries and library professionals}

Since the public in Vietnam is not aware of the importance of the library profession in society, the low regard for library work continues to demoralise practitioners (see Section 5.1.2). This reality requires lead organisations to be proactive and consistent in promoting the role and value of library work through different ways. Using public media such as newspapers and television may be a good way. High quality professional 
websites may also be a means to transmit the profession's image and market librarians as key players in the development of the country's education and socio-economics.

\section{Recommendations for libraries}

1. Identifying particular development plans and strategies for $\mathrm{CE}$ within libraries As the data discussed in Section 6.2.1 revealed, the specific requirements of particular projects or development plans and daily challenges inspire practitioners to strengthen their competencies. Moreover, these requirements drive staff in identifying and prioritising their learning content. Accordingly, it is suggested that each library should establish development plans and implement specific projects to improve their services, and at the same time, have strategies for $\mathrm{CE}$ based on the requirements of these plans and projects.

In addition, in Section 6.2.3 the data showed that equitable learning opportunities for all practitioners encourage library staff. Accordingly, strategies should provide incentives in order for all practitioners to have a chance to gain a professional education and keep upto-date on professional issues. Also, as discussed in Section 5.2.2, due to the lack of LIM degrees for many practitioners, the strategies should include goals to upgrade the professional degrees and competencies of their practitioners in a given time frame. This should be followed up with specific policies and plans to implement the strategies.

\section{Specific policies for $\mathrm{CE}$ activities}

- $\quad$ CE commitment policy

The data in Section 6.2.3 showed that practitioners are more engaged when they have self-commitment and libraries have a commitment to assist staff learning. Accordingly, it is proposed that each library should develop a policy that requires staff to set a selfcommitment plan for his or her CE in a given time. At the same time the library should make a commitment to support the individual in finding financial aid and in arranging time to participate, as his or her learning will assist in doing the job better. Implementing annual practitioner performance appraisals is one possible method to increase 
practitioner CE commitments. This suggestion is further discussed in the recommendations for managers.

\section{- Cost policy}

It is apparent that budgets for university library CE activities are limited. However, capable and up-to-date practitioners are essential for good library services and recognition of the value of libraries. In addition, the quality of library services is an important component of the quality of teaching and learning in universities. Accordingly, it is necessary for libraries and parent universities to make CE a budgeting priority and use funding allocations to achieve the goals of their $\mathrm{CE}$ strategies. In particular, as the data in Section 6.5.3 showed that regular internal activities lead practitioners to think about their learning and to create learning climate in their institutions, libraries and parent universities should allocate funds for in-house CE activities.

At the same time, as the data in Section 6.2.3 showed, in some sample libraries costsharing for degree courses is one way to increase opportunities for staff to achieve their learning needs. Therefore, libraries and parent universities should encourage staff to share CE costs, and a clear cost-sharing policy is recommended.

- Rethinking reward, promotion and practitioner assessment systems

As the data concerning university policies in Section 6.2.2 revealed, awards have a considerable impact on the work and learning efforts of practitioners in Vietnamese university libraries. This finding suggests that libraries should consider the meaning of rewards in regard to both income and recognition. Meaningful rewards would motivate practitioners to keep their professional competencies up-to-date and would create a competitive atmosphere that would push practitioners to greater efforts.

It may be a useful suggestion that libraries should include the learning progress of practitioners as a criterion for annual staff assessment. The results of the annual staff 
assessment should be considered as a base for increasing salary, promotion, allocation of scholarships for further education, and particularly for assigning supplementary tasks or jobs to increase income and reshuffling staff. Staff promotion should also be based on professional degrees and professional performance. This approach would create a greater motivation for practitioners to pursue learning. It would also have the effect of removing unmotivated and poor performers from the organisations.

\section{Supplementary income opportunities}

At present, the basic government salary is very low compared with living costs. The data in Section 6.1.2 showed that low income might diminish the enthusiasm for learning among library staff, particularly talented staff, and could lead them to change jobs. In other fields and sectors, employers improve the salaries of employees by offering supplementary work. This strategy seems to work well at the present time. As the data in Section 6.2.2 showed, in those few libraries which offered supplementary work, staff attempted to acquire the required competencies in order to take advantage of the additional work opportunities. However, such opportunities are not many in libraries.

This finding suggests that university libraries might offer fee-based information services to their clients. This strategy might help libraries to achieve two targets: offering better services for clients and providing supplementary income for staff. This in turn might motivate staff to improve their library competencies in order to satisfy clients.

\section{Adequate facilities and working conditions for practitioners}

This study has found that facilities and working conditions affect learning pursuits of practitioners (see Section 6.3.2). Library practitioners need to be provided with adequate facilities and working conditions, such as computers and internet access, and more adequate working space. Libraries should work to achieve these basic staff conditions. 


\section{Allocating responsibilities to managers}

In Section 6.4 the data demonstrated the important role of managers in the learning activities of staff. The ability of managers to find information and financial assistance, to set policies and conduct in-house CE activities, select learning topics and even force staff to participate in $\mathrm{CE}$ activities are enablers for staff $\mathrm{CE}$. This finding proposes that libraries should require managers to commit to $\mathrm{CE}$ for staff and clearly assign responsibilities for individual managers. How well the managers manage $\mathrm{CE}$ activities in their libraries, including establishing a learning climate, finding learning opportunities and organising CE activities for staff, should be a main factor in the performance appraisal and promotion for managers.

\section{Recommendations for library managers}

1. Being a champion of $\mathrm{CE}$ activities

As discussed in Section 6.4 on managers' influences, staff rely heavily on their managers' supervision, assessment and efforts in finding learning opportunities and creating a learning climate in the libraries. These findings address the issue that attitude and actions of managers become either enablers or barriers for CE of staff. As the data showed, staff are encouraged to pursue learning when their managers demonstrate visible leadership behaviour, dynamic style, fairness, and confidence in staff. Accordingly, it is important that managers should be champions for creating a learning environment in their libraries. Some suggested actions are discussed below.

\section{Motivating staff involvement in library development}

As introduced in Section 4.1.3 and in the data discussed in Section 6.4, in the centralised administration system in Vietnam, managers are informed of organisational policies before the policies are disseminated to staff. Therefore, it would be useful if managers thoroughly understood the policies of organisations at different levels and took responsibility for informing staff of the policies and strategies. Managers should make clear to staff the benefits and obligations of working in their organisations. This practice 
would lead staff to be more involved in library development and help them in prioritising their needs.

\section{Creating learning opportunities for staff}

Regarding managers' influence, the data analysis also showed that by searching for information on $\mathrm{CE}$ activities and arranging for staff to attend, the managers created enablers for staff's CE. Accordingly, it would be useful if managers could network with local CE providers as well as overseas libraries to search for CE programmes, professional activities and professional internships for their staff. Also, the managers should take responsibility for finding financial support and arranging time for staff CE.

\section{Promoting staff abilities}

As shown in Section 6.4.1, job challenges as well as proper staff assessment, high expectations and managers' confidence in staff are an inspiration for staff to learn. Accordingly, it is recommended that managers should assign jobs for staff based on individual skills and abilities, and with consideration for staff personal goals. Proper staff assessments and expectations of managers would promote staff to use their knowledge productively and stimulate them to enrich their knowledge. It also is recommended that managers consider the learning needs of both younger and older staff, and of both junior and senior staff in order to make sure that all staff have a fair opportunity to grow. By doing so, older staff would not simply bide their time until retirement, and young staff would not devote time and energy to other jobs for income supplementation.

\section{Conducting staff appraisal}

Together with opportunities to participate in CE, participants emphasised that staff commitment and individual goals also affect their CE (see Sections 5.3.31 and 6.2.3). To encourage the learning and self-commitment of staff as well as ensure that every staff member has opportunities to participate in appropriate CE, staff appraisal is a possible method and managers should be key persons in this method. 
It is recommended that, annually, managers should organise appraisal meetings to discuss learning needs with each member and set up an action plan for each. This would enable managers to better understand the needs of individual staff and assist them to set reasonable goals that meet both practitioner and library needs. Likewise, managers should work with individual staff to review the implementation of the plan and to evaluate achievement. This review would be a base for either staff promotion or relegation.

As discussed in Sections 6.4.1 and 6.4.2, it should be emphasised that managers' attitudes towards learning and their confidence in staff have a considerable impact on staff learning, so when conducting the appraisal managers need to demonstrate that they understand the needs of individual staff as well as make their expectations known.

\section{Recommendations for $C E$ providers and potential $C E$ providers}

This study found that organisations which can provide CE programmes for library practitioners are limited; however, some organisations, such as NACESTI and FESAL, have offered CE courses based on their resources. As the data showed, it is a barrier when current $\mathrm{CE}$ courses are not well-planned in terms of design and organisation. Based on participants' assessments of current CE courses discussed in Section 6.5.2, some recommendations are made as follows.

\section{Conducting needs assessment}

As the data showed, irrelevant content is among the weaknesses of the current $\mathrm{CE}$ courses. It is recommended that providers or potential providers (hereafter "CE providers" refers to both current and potential providers) should conduct needs assessment or triage to identify priority topics for design CE programmes. The nexus between the needs of practitioners and organisations, and the factors affecting the $\mathrm{CE}$ of practitioners should be considered when prioritising topics for CE programmes. 


\section{Building networks with libraries}

Arising from the claims of participants that the content of several CE courses is superficial and irrelevant, and does not meet their needs (see Section 6.5.2), it is recommended that providers should work closely with library managers to identify the learning needs and understand the characteristics of learners and the features of libraries in order to design achievable and effective programmes.

Since participants have claimed that weaknesses in the organisation of CE courses lessen their opportunities for quality CE (see Section 6.5.2), providers should plan and announce training programmes to libraries in a timely and regular fashion. Using existing professional websites or creating new websites to disseminate information about training programmes is possibly a good idea. Also, it is necessary for CE providers to consult with managers about the time, duration, location and expected outcomes for $\mathrm{CE}$ programmes. It is important for CE providers to collect feedback from the learners and libraries to improve future programmes. In addition, monitoring what happens when the learners return to the workplace would also help to improve future programmes.

\section{Taking initiative in designing and providing effective CE programmes}

As adult learners, practitioners usually have the ability to identify their preferred learning formats; however, they may not be aware of other formats that may be more effective for them. Therefore, educators should use the findings in this study regarding preferred learning formats and individual characteristics to try different educational formats and teaching methods. Also, providers should be aware that most library practitioners are women who have heavy family responsibilities as discussed in Section 5.1.1. Accordingly, it would perhaps improve the uptake of CE opportunities if programmes were scheduled during office hours, and did not involve long travel time so that female practitioners could fulfil their family responsibilities as well as benefit from CE. 
The data analysis also revealed that, because of the low percentage of LIM degrees among practitioners and the need to update professional knowledge among degree holders (see Section 5.3.2.3), interviewees indicated that operational staff had only basic knowledge and skills in professional practice (see Section 7.1.2). Consequently, it is proposed that $\mathrm{CE}$ providers consider systematic and sequential learning activities to ensure that $\mathrm{CE}$ programmes can provide practitioners with comprehensive knowledge, including the basic principles and philosophy of LIM as well as practical skills. In some cases, a single class might not be able to satisfy the needs fully and may be of only limited value to practitioners.

Finally, as the analysis in Section 6.5.2 has suggested, the quality of educators, teaching methods and evaluation methods are among elements affecting CE participation and outcomes of practitioners. Providers should have a strategy for recruiting qualified educators, make sure that $\mathrm{CE}$ programmes need to be designed in a standard manner including teaching and evaluating methods. CE programmes only are value to practitioners when they will learn and apply what they have learned in their practice. CE programmes will lose their value when they just provide practitioners a chance to take off from their daily tasks or to respond requirements from their institution formally.

\section{Recommendations for individual library practitioners}

1. Setting goals

As the data discussed in Section 5.3.3 showed, pursuing goals is an important motivation for learning. Particular goals, such as to gain a higher degree, position or rank, would give individuals concrete reasons why they need to learn and a guide to what they need to learn. Accordingly, it is recommended that each practitioner should set particular individual goals to pursue.

2. Showing learning commitment and fostering learning orientation

As indicated in Section 5.1.2.1, changes in society in general and in the profession in particular are rapid in Vietnam. The required knowledge and skills of library work 
become more diversified, including information management knowledge and skills, ITintensive areas, generic knowledge and skills. In addition, desire for success is an intrinsic need of all individuals as discussed in Section 5.3.3.1. Accordingly, CE should be no longer just an option but a part of life for all practitioners in Vietnam. Learning commitment and learning orientation become requirements for today practitioners. It is possible that showing enthusiasm, ability and commitment as well as a willingness to share the learning would enable individuals to gain learning opportunities within organisations. At the same time, being proactive in looking for learning opportunities through networking and seeking the assistance of managers, instead of passively waiting for a chance provided by the organisation, would increase CE opportunities for individuals.

\section{Managing own learning}

As the discussion in Section 5.3 has suggested, each practitioner is unique and has his or her unique working and living conditions. Some may have more opportunities for learning than others; however, it is important for all individuals to understand that learning makes a difference to their own future. It is a cumulative process that requires not only tenacious efforts but also proper arrangements to balance the responsibilities of other individuals. It is possible that making learning plans for specific periods would guide individuals to meet their goals, avoid making excuses and invest the energy and time for learning appropriately.

The discussion above addresses issues concerning enhancement CE for university library practitioners in Vietnam and gives several recommendations. It is emphasised that to implement effective $\mathrm{CE}$ requires a sharing of responsibilities among stakeholders: organisations at different levels, managers, and individual practitioners. All play important roles; however, each stakeholder should fulfil its particular responsibilities. 


\subsubsection{Further research}

To expand the knowledge gained from this study and to continue to strengthen $\mathrm{CE}$ activities for library practitioners in Vietnam, further research is needed on a variety of issues that arose from the data. Three main issues are recommended here for further study:

- Using the results of this study for further triages

- Further improving the model and applying the revised model in other environments

- Studying programming models for CE for library practitioners in Vietnam

\section{Using results of this study for further triages}

The results of the triage suggest further research in order to deepen and widen understanding on the learning needs of university library practitioners.

First, as discussed in assessing priorities for operational staff in Section 7.3.2, there are some differences between the perceived learning needs of organisations and those of practitioners. Learning needs were identified from the government documents related to the collection management area, marketing library services, policy knowledge and research knowledge and skills; however, the interviewees did not identify learning needs in these areas for operational staff. The data in this study did not provide clear evidence to enable understanding of these differences, so further exploration is required. Similarly, the participants in three specialised and two multi-disciplinary university libraries indicated subject knowledge as a learning need, while the participants in the remaining libraries and government documents did not raise this content as learning requirement. Further study is required to understand this point.

Second, as addressed in Section 7.5, both participants with and without formal LIM education did not identify basis principles and philosophy of the profession as a learning need. To learn more about this issue further study is needed. Also, further study is needed to complement specific learning topics in some areas such as research knowledge and marketing services. 
Third, in the triage of this study, linking the priority learning areas to evidence of the factors affecting $\mathrm{CE}$ enabled prioritisation of these areas based on the needs of both individuals and organisations. However, it is hard to rank the priority of each learning area by this method. To achieve specific ranking of priority learning needs, further research is needed. It is possible that a Likert-scale questionnaire based on the list of priority learning needs identified in this study could be designed to ask both managers and operational staff to rank priority learning areas and specific topics.

Further, learning needs for library practitioners can also be determined from other sources such as the libraries' clients or leaders in parent institutions, including universities, related ministries or professional organisations. The model suggested in this study can be used as a framework for further research to identify and understand the learning needs for library practitioners from other sources.

Finally, as mentioned in the literature review, many writers (e.g., Conroy, 1978; Monette, 1977; Noe, 2002; Puetz, 1987) emphasised that learning needs are dynamic, constantly shifting and evolving due to organisational, societal and technological changes. Therefore, the needs assessment process ought to be continual and regular. In the context of this study, it should be noted that changes in LIM practice and organisational policies in Vietnam are rapid and are altering the learning needs of library managers and operational staff. Therefore, research on needs assessment should be conducted continually to meet the new needs of individuals and the requirements of organisations.

2. Further improving the model and applying the revised model in other environments As mentioned in the conclusion of Chapter 5 (see p. 158), the available data did not permit examination of differences in interviewees' perceptions according to geographic location or women's role in society. Both points require further investigation through additional data collection. In addition, the model shows two levels of factors affecting $\mathrm{CE}$ for university library practitioners: broad, and specific. However, it does not show 
the degree or level of these factors; further research is required in this area to improve the reliability and usefulness of the model.

The focus of this study has been to provide a contextual model for planning CE programmes for university library practitioners in Vietnam. To assess the model the study was based solely on the perceptions of public university library practitioners and related documents. However, the model should have applicability across the Vietnamese library system. Therefore, testing and revising this model in other environments, such as in public libraries or libraries of schools or libraries of social-political organisations, should be the subject of future research.

3. Studying programming models for $\mathrm{CE}$ for library practitioners in Vietnam

Since identifying learning needs is only the first step for effective CE and the data revealed that poorly qualified instructors and inadequate course design discourage $\mathrm{CE}$ participation and result in poor outcomes for practitioners, to offer more effective CE programmes requires a study of practical models. Such models would help providers and instructors in understanding particular steps to organise and deliver effective courses in the Vietnamese context. 


\section{REFERENCES}

Aherne, M., Lamble, W., \& Davis, P. (2001). Continuing medical education, needs assessment, and program development: Theoretical constructs. Journal of Continuing Education in the Health Professions, 21, 6-14.

Alemna, A. A. (1995). Library associations in Africa and the case for professionalism. Library Review, 44(1), 56-59.

Allan, B. (2007). Supervising and leading teams in ILS. London: Facet.

Alreck, P. L., \& Settle, R. B. (2004). The survey research handbook. Boston: McGrawHill/Irwin.

American Library Association. (1970). Library education and manpower: A statement of policy adopted by the Council of the American Library Association, June 30, 1970. Chicago: American Library Association.

Anderson, D., Brown, S., \& Race, P. (1997). 500 tips for further and continuing education lecturers. London: Kogan Page.

Anwar, M. A. (1998). Continuing professional development of Malaysian Academic Librarians. Libri, 48(1), 26-34.

Auerbach, C. F., \& Silverstein, L. B. (2003). Qualitative data: An introduction to coding and analysis. New York: University Press.

Auster, E., \& Chan, D. C. (2004). Reference Librarians and keeping up-to-date: A question of priorities. Reference \& User Services Quarterly, 44(1), 57-66.

Avery, E. F., Dahlin, R., \& Carver, D. A. (Eds.). (2001). Staff development: A practical guide (3 ed.). Chicago, London: American Library Association.

Ayres, H. W. (2005). Factors related to motivation to learn and motivation to transfer learning in a nursing population. Unpublished doctoral thesis, North Carolina State University, Raleigh.

Babbie, E. (2001). The practice of social research. Belmont, CA.: Wadsworth Thomson Learning.

Bellanti, B. (2001). More than one way to learn: A leader's view [Electronic version]. Information Outlook, 5(6).

Bender, D. (1998). What's special about special libraries?- SLA and the continuing education challenge [Electronic version]. INSPEL, 32(4), 197-204.

Berg, B. L. (2007). Qualitative research methods for the social sciences. Boston Pearson/Allyn \& Bacon.

Berger, P. L., \& Luckman. (1991). The social construction of reality. London: Penguin.

Black, F. A., Dunn, J., Miller, R., \& Skrzeszewski, S. (2002). Continuing education for LIS professionals in Canada. In P. L. Ward (Ed.), Continuing professional education for the information society: The fifth world conference on Continuing professional education for the Library and Information science professions (pp. 167-181). Munchen: K.G.Saur.

Blank, J., \& Russell, J. D. (2000). The program planning model for adult and continuing education. Educational Technology, March-April, 47-51. 
Boucouvalas, M., \& Krupp, J.-A. (1989). Adult development and learning. In S. B. Merriam \& P. M. Cunningham (Eds.), Handbook of adult and continuing education (pp. 183-200). San Francisco: Jossey-Bass.

Boyd, R. D., Apps, J. W., \& associates (Eds.). (1980). Redefining the discipline of adult education San Francisco Jossey-Bass.

Brennan, B. (Ed.). (1990). Continuing Professional Education: Promise and Performance. Victoria: Australian Council for Educational Research.

Brennan, B., \& Dymock, D. (Eds.). (1995). CPE - An emerging professional practice: Selected papers from CPE conferences conducted between 1987 and 1994 by the University of New England. Armidale, New South Wales Dept. of Continuing Education, University of New England.

Brine, A. (2005). Continuing professional development: A guide for information professionals. Oxford: Chandos Publising.

Brockington, D., \& Sullivan, S. (2005). Qualitative research. In R. Scheyvens \& D. Storey (Eds.), Development fieldwork: A practical guide (pp. 57-74). London: Sage Publications.

Bryman, A. (2004). Social research methods. Oxford: Oxford University Press.

Buchanan, R. A. (2005). Library assistant training: Perceptions, incentives, and barriers [Electronic version]. The Journal of Academic Librarianship, 31(5), 421-431.

Bui, L. T. (1997). Hien trang va tuong lai phat trien khoa hoc thu vien o Viet Nam [Current condition and future development of Library science in Vietnam]. Hanoi: Nha xuat ban van hoa thong tin.

Bui, L. T. (2002). Van de dao tao can bo khoa hoc thong tin thu vien trong thoi ky cong nghiep hoa hien dai hoa dat nuoc [Library and information professional education in the period of industrialisation and modernisation]. Thong tin \& Tu lieu, 4, 5-12.

Central Library of Can Tho University. (2005). Co cau to chuc [Staff]. Retrieved 8 July, 2005, from http://www.ctu.edu.vn/library/gthieu/indext-gth.htm

Cervero, R. M. (1985). Continuing professional education and behavioural change: A model for research and evaluation. Journal of Continuing Education in Nursing, $16(3), 85-88$.

Cervero, R. M. (1988). Effective continuing education for professionals. San Francisco: Jossey-Bass Inc.

Cervero, R. M., \& Scanlan, C. L. (Eds.). (1985). Problems and prospects in continuing professional education. San Francisco: Jossey-Bass.

Chan, D., \& Auster, E. (2003). Factors contributing to the professional development of reference librarians. Library \& Information Science Research, 25(3), 265-286.

Chan, D. C. (2002). Maintaining professional competence: Impact of organizational and individual factors on the updating activities of public reference librarians. Unpublished doctoral dissertation, University of Toronto, Toronto.

Chatterjee, A. (1993). Continuing education for library and information workers: The India sense. In B. Woolls (Ed.), Continuing professional education and IFLA: Past, present, and a vision for the future. Papers form the IFLA CPERT section world conference on continuing professional education for the Library and Information Science Professions (pp. 342-352). Munchen: K.G. Saur. 
Cleveland, J. N., \& Shore, L. M. (1992). Self and supervisory perspectives on age and work attitudes and performance. Journal of Applied Psychology, 77(4), 469-484.

Committee of Governmental Organisation and Personnel. (1993). Quyet dinh so 428/TCCP-VC ve viec ban hanh tieu chuan nghiep vu ngach cong chuc nganh Van hoa - Thong tin [Decision No. 428/TCCP-VC on Professional Criteria for Civil Servant Ranks in Culture and Information Fields]. Hanoi, Vietnam: Author.

Communist Party of Vietnam. (1996). Van kien Dai hoi Dai bieu toan quoc lan thu VIII [Documents of the eighth National Congress of the Communist Party of Vietnam]. Retrieved 1 September, 2005, from http://www.dangcongsan.vn/details.asp?topic $=2 \&$ subtopic $=4 \&$ leader topic $=225$ \&id=BT1260353556

Communist Party of Vietnam. (1997). Chi thi so 14-CT/TW ngay 9-4-1997 cua Bo Chinh tri ve viec lanh dao, quan ly, su dung Internet o Viet Nam [Direction No. 14-CT/TW in 9-4-1997 of Vietnam Communist Party Politburo about management and utilizing Internet in Vietnam]. Retrieved 1 September, 2005, from http://www.dangcongsan.vn/details cd.asp?topic=51\&subtopic $=149 \&$ leader top $\mathrm{ic}=236 \& \mathrm{id}=\mathrm{BT} 730453204$

Communist Party of Vietnam. (2000). Chi thi so 58-CT/TW ngay 17-10-2000 cua Bo Chinh tri (khoa VIII) ve day manh ung dung va phat trien cong nghe thong tin phuc vu su nghiep cong nghiep hoa, hien dai hoa [Direction No. 58-CT/TW in 17/10/2000 of Vietnam Communist Party Politburo about development and application of informational technology]. Retrieved 5 August, 2005, from http://dangcongsan.vn/search/search result.asp?topic $=51 \&$ subtopic $=149 \&$ leader topic=236\&id=BT730452880\&str=đổi\%20mới

Communist Party of Vietnam. (2001). Van kien Dai hoi Dang toan quoc lan IX [Documents of the ninth National Congress of the Communist Party of Viet Nam]. Retrieved 5 August, 2005, from http://dangcongsan.vn/search/search_result.asp?topic $=2 \&$ subtopic $=8 \& \mathrm{id}=\mathrm{BT} 137$ 0321311\&str=đồi\%20mói

Communist Party of Vietnam. (2006). Van kien Dai hoi Dang toan quoc lan X [Documents of the tenth National Congress of the Communist Party of Vietnam]. Retrieved 6 November, 2007, from http://www.cpv.org.vn/details.asp?topic $=191 \&$ subtopic $=8 \&$ leader topic $=699 \& \mathrm{id}$ $=$ BT160635244

Conroy, B. (1978). Library staff development and continuing education: Principles and practices. Littleton, Colorado: Libraries Unlimited, Inc.

Cookson, P. S., Knowles, M. S., Nadler, L., \& Nadler, Z. (1998). Prototypical program planning models. In P. S. Cookson (Ed.), Program planning for the training and continuing education of adults: North American perspectives (pp. 29-56).

Malabar, Florida: Krieger Publishing Company.

Corrall, S. (2005). Developing model of professional competence to enhance employability in the network world. In P. Genoni \& G. Walton (Eds.), Continuing professional development-Preparing for new roles in libraries: $A$ voyage of discovery: Sixth World Conference on Continuing professional 
development and workplace learning for the library and information professions (pp. 26-40). München: K.G. Saur.

Creswell, J. W. (2003). Research design: Qualitative, quantitative, and mixed method approaches. Thousand Oaks, Calif. : Sage Publications.

Cross, K. P. (1981). Adults as learners: Increasing participation and facilitating learning. San Francisco: Jossey-Bass.

Curran, V. R., Fleet, L., \& Kirby, F. (2006). Factors influencing rural health care professionals' access to continuing professional education. The Australian journal of rural health, 14, 51-55.

Dakshinamurti, G., \& Braaksma, B. (2005). Preparing academic librarian for a changing role: A case of a Canadian information literacy programme. In P. Genoni \& G. Walton (Eds.), Continuing professional development - Preparing for new roles in libraries: A voyage of discovery: Sixth World Conference on Continuing professional development and workplace learning for the library and information professions (pp. 112-125). München: K.G. Saur.

Dall'Alba, G. (2004). Understanding professional practice: Investigations before and after an educational programme. Studies in Higher Education, 29(6), 679-692.

Danner, R. A. (1998). Redefining a profession. Law Library Journal, 90(3), 327.

Darke, P., Shanks, G., \& Broadbent, M. (1998). Successfully completing case study research: Combining rigour, relevance and pragmatism. Information Systems Journal, 8, 273-289.

Davis, J. R., \& Davis, A. B. (1998). Effective training strategies: A comprehensive guide to maximizing learning in organizations. San Francisco: Berrett-Koehler Publishers.

Denison, T., \& Robinson, M. (2004). Breaking ground: Library systems implementation in Vietnam. Retrieved 4 August, 2005, from www.vala.org.au vala2004 2004pdfs 38DenRob.PDF

Denscombe, M. (2007). The good research guide: For small-scale social research projects. Maidenhead, England; New York: Open University Press.

Dewey, M. (1898). Library instruction by correspondence. Library Journal, 23 (August 1898), 131.

Dillion, M. (1997). The OCLC institute: Genesis and prospectus. Ohio: OCLC.

Donaldson, J. F., \& Kuhne, G. W. (1997). Researching professional practice: The integrated practice perspectives model and continuing education. Retrieved 7 November, 2005, from http://www.edst.educ.ubc.ca/aerc/1997/97donaldson.htm

Doney, E. (1998). Developing opinions: The attitudes of ILS staff to continuing professional development. Library Management, 19(8), 486.

Dong, X. (1993). In-service training of Chinese public libraries in the 1990s. In B. Woolls (Ed.), Continuing professional education and IFLA: Past, present, and a vision for the future. Papers from the IFLA CPERT section world conference on continuing professional education for the library and information science professions (pp. 240-252). München: K.G. Saur. 
Dorner, D. G. (2004). The impact of digital information resources on the roles of collection managers in research libraries. Library Collection, Acquisitions, \& Technical Services, 28 (2004), 249-274.

Dorner, D. G., Chawner, B., \& Searle, S. (2002). Creating a digital Babylon? Results of a survey of digitisation activities in New Zealand: A report commissioned by The National Library of New Zealand. Wellington: School of Information Management. Victoria University of Wellington.

Duong, B. H. (1999). Lich su su nghiep thu vien Viet Nam trong tien trinh van hoa dan toc [Vietnamese libraries in the national culture history]. Hanoi: Van hoa Thong tin.

Education University of HCMC. (2005). Missions of University library. Retrieved 31 October, 2005, from http://lib.hcmup.edu.vn/default.asp?act $=\mathrm{cn}$

Elkin, J. (1997). Information navigators: Future professionals. Retrieved 14 July, 2005, from http://www.cni.org/regconfs/1997/ukoln-content/report 12.html.

Eraut, M. (1994). Developing professional knowledge and competence. London; Washington, D.C. : Falmer Press.

Esposito, N. (2001). From meaning to meaning: The influence of translation techniques on Non-English focus group research. Qualitative Health Research, 11(4), 568579.

Evans, G. E., Ward, P. L., \& Rugaas, B. (2000). Management basics for information professionals. New York Neal-Schuman Publishers.

Facteau, J. D., Doobins, G. H., \& Russell, J. E. A. (1995). The influences of general perceptions of the training environment on pretraining motivation and perceived training transfer. Journal of Management, 21(1), 1-25.

Feather, J., \& Sturges, P. (Eds.). (2003). International encyclopedia of information and library science. New York Routledge.

Fisher, B., Hallam, G., \& Partridge, H. (2005). Different approaches - Common conclusion: The skills debate of the 21 st century. In P. Genoni \& G. Walton (Eds.), Continuing professional development - Preparing for new roles in libraries: A voyage of discovery: Sixth World Conference on Continuing professional development and workplace learning for the library and information professions (pp. 41-52). München: K.G. Saur.

Flagello, J. R. (1998). Continuing education for the professions: The catalyst for workplace empowerment. In W. H. Young (Ed.), Continuing professional education in transition: Visions for the professions and new strategies for lifelong learning (pp. 43-57). Florida: Krieger

Foster, C. (1999). The professional growth of librarians: Small steps and giant leaps in providing information services. Kentucky Libraries, 63(3), 4-7.

Foxon, M. (1994). A process approach to the transfer of training - part 2. Australian Journal of Educational Technology, 10(1), 1-18.

Francke, A. L., Garssen, B., \& AbuSaad, H. H. (1995). Determinants of changes on nurses' behavior after continuing education: A literature review. Journal of Continuing Education in Nursing, 21(2), 371-377.

Freeman, M. (1994). A sense of direction: Librarianship and CPD. Librarian Career Development, 2(3), 26-28. 
Frey, J., \& Fontana, A. (1993). The group interview in social research. In D. Morgan (Ed.), Successful focus groups: Advancing the state of the art. Newbury Park, Calif.: Sage Publications.

Frost, N. (2001). Professionalism, change and politics of lifelong learning. Studies in Continuing Education, 23(1), 5-17.

General Statistics Office. (2006). Average population by sex and by residence. Retrieved 6 November, 2007, from http://www.gso.gov.vn/default_en.aspx?tabid=467\&idmid=3\&ItemID=6172

Gillam, S. J., \& Murray, S. A. (1996). Needs assessment in general practice. London: Royal College of General Practitioners.

Glesne, C. (2006). Becoming qualitative researchers: An introduction. Boston: Allyn \& Bacon.

Gorman, G. E., \& Clayton, P. (2005). Qualitative research for the information professional: A practical handbook. London: Facet Publishing.

Gorman, M. (2000). Our enduring values: Librarianship in the 21st century. Chicago [Ill.] American Library Association.

Government of Vietnam. (2003). Nghi dinh so 116/2003/ND-CP ve viec tuyen dung, su dung va quan ly can bo, cong chuc trong cac don vi su nghiep cua Nha nuoc [Decree No. 116/2003/ND-CP on the Recruitment, Employment and Management of Civil Servants]. Hanoi, Vietnam: Author.

Government of Vietnam. (2007). Quy dinh chuc nang, nhiem vu, quuyen han va co cau cua Bo Van hoa, The thao va Du lich [Decree No. 185/2007/ND-CP at 25 December 2007 on assigning functions, missions, authorities and organisational structure of the Ministry of Culture, Sports and Tourism]: Hanoi, Vietnam: Author.

Grant, J. (2002). Learning needs assessment: Assessing the need. British Medical Journal, 324, 156-159

Griscti, O., \& Jacono, J. (2006). Effective of continuing education programmes in nursing: Literature review. Journal of Advanced Nursing, 55(4), 449-456.

Grotelueschen, A. D. (1985). Assessing professionals' reasons for participating in continuing education. In R. M. Cervero \& C. L. Scanlan (Eds.), Problems and prospects in continuing professional education (pp. 33-46). San Francisco, London: Jossey-Bass Inc.

Guba, E. G., \& Lincoln, Y. S. (1994). Competing paradigms in qualitative research. In N. K. Denzin \& Y. S. Lincoln (Eds.), Handbook of qualitative research (pp. 105117). Thousand Oaks: Sage.

Gupta, D. K., \& Ghosh, S. B. (2002). Opportunities and strategies for continuing professional education in India through distance mode. In P. L. Ward (Ed.), Continuing professional education for the information society: The fifth world conference on Continuing professional education for the Library and Information science professions (pp. 49-60). Munchen: K.G.Saur.

Gupta, K. (1999). A practical guide to needs assessment. San Francisco JosseyBass/Pfeiffer.

Guy, S. C. (2002). Beyond degrees: Professional learning for knowledge services. Munchen: K.G. Saur. 
Hardesty, S., \& Sugarman, T. (2007). Academic librarians, professional literature, and new technologies: A survey [Electronic version]. The Journal of Academic Librarianship, 33(2), 196-205.

Hill, S. (1997). Meeting future challenges - Developing personal and professional skills for success [Electronic version]. Tidskrift for Documentation, 52(1-2), 57-66.

Hoang, L. M. (2003). Du an "He thong thong tin - thu vien dien tu lien ket cac truong dai hoc" va viec tang cuong tiem luc khoa hoc - cong nghe cho phat trien kinh te - xa hoi tai thanh pho Ho Chi Minh [Project "Digital library system of universities " and reinforce the potential of technology to social and economic development in Ho Chi Minh City]. Retrieved 3 September, 2005, from http://www.glib.hcmuns.edu.vn/fesal/bantin1203/bai4.pdf

Houle, C. O. (1961). The inquiring mind. Madison: University of Wisconsin Press.

Houle, C. O. (1967). The role of continuing education in current professional development. ALA Bulletin, 61, 256-267.

Houle, C. O. (1972). The design of education. San Francisco: Jossey-Bass.

Houle, C. O. (1980). Continuing learning in the professions. San Francisco: Jossey-Bass Inc.

Houle, C. O. (1981). Concept of adult education in continuing medical education. Continuing Medical Education Newsletter, 10 (February 1981), 5-11.

Houle, C. O. (1996). The design of education. San Francisco: Jossey-Bass.

Houle, C. O. ( 2003). Continued professional education (In The USA). In P. Jarvis \& C. Griffin (Eds.), Adult and continuing education: Major themes in education (Vol. III, pp. 195-207). London: Routledge.

Hurych, J. (2002). Continuing professional education as an ethical issue. In P. L. Ward (Ed.), Continuing professional education for the information society: The fifth world conference on continuing professional education for the library and information science professions (pp. 256-263). Munchen: K.G.Saur.

Institute of International Education. (2005). A sketch of tertiary education in Vietnam. Retrieved 28 September, 2005, from http://www.vef.gov/Report\%20\%20A\%20Sketch\%20of\%20Tertiary\%20Education\%20in\%20Vietnam.pdf

Jarvis, P. (1992). Paradoxes of learning: On becoming an individual in society. San Francisco: Jossey-Bass.

Jarvis, P. (1995). Adult and continuing education: Theory and practice. London: Routledge.

Jarvis, P. (1996). Continuing education in a late-modern or global society: Toward a theoretical framework for comparative analysis. Comparative Education, 32(2), 233-244.

Jarvis, P. (2002). International dictionary of adult and continuing education. London: Kogan Page.

Jarvis, P. (2004). Adult education and lifelong learning: Theory and practice. London: Routledge.

Jarvis, P. (2006). Towards a comprehensive theory of human learning. London : New York: Routledge. 
Jennings, M. E. (2007). Adult learning in a workplace setting: Key factors associated with the development of performance and efficacy. Unpublished doctoral dissertation, University of Connecticut, Connecticut.

Johnson, T. R. (1972). Professions and power. London: Macmillan.

Jordan, P., \& Lloyd, C. (2002). Staff management in library and information work. Aldershot: Ashgate.

Kanjilal, U. (2001). Continuing library and information science professional education through the virtual campus initiative. In B. Woolls \& B. E. Sheldon (Eds.), Delivering lifelong continuing professional education across space and time:

The fourth world Conference on Continuing Professional Education for the Library and Information Science Professions. Munchen: K. G. Saur.

Kanjilal, U. (2002). Developing a model for web enhanced continuing education programs for LIS professionals. In P. L. Ward (Ed.), Continuing professional education for the information society: The fifth world conference on continuing professional education for the library and information science professions (pp. 188-195). Munchen: K.G.Saur.

Keenan, S. (1996). Concise dictionary of library and information science. London: Kogan Saur.

Kenney, W. R. (1985). Progress planning and accreditation. In R. M. Cervero \& C. L. Scanlan (Eds.), Problems and prospects in continuing professional education (pp. 34-57). San Francisco: Jossey-Bass.

Klave, S. (1996). Interviews: An introduction to qualitative research interviewing. Thousand Oaks, Calif.: Sage Publication.

Knowles, M., Holton, E., \& Swanson, R. (1998a). The adult learner: The definitive classic in adult education and human resource development (5th ed.). Houston: Gulf Publishing.

Knowles, M. S. (1976). Model for assessing continuing education needs for a profession. In Continuing Library Education Network and Exchange Proceedings: First CLENE assembly, Palmer House, Chicago, IL., January 23-24, 1976. Chicago: CLENE.

Knowles, M. S. (1980). The modern practice of adult education: From pedagogy to andragogy. Englewood Cliffs, NJ: Prentice Hall Regents.

Knowles, M. S. (1990). The adult learner: A neglected species (4th ed.). Houston: Gulf Publishing Com.

Knowles, M. S., Holton, E., \& Swanson, R. (1998b). The adult learner: The definitive classic in adult education and human resource development (5th ed.). Houston: Gulf Publishing.

Knox, A. B. (1993). Strengthening adult and continuing education: A global perspective on synergistic leadership. San Francisco: Jossey-Bass.

Knox, A. B. (2000). The continuum of professional education and practice. New Directions for Adult and Continuing Education, 86, 13-22.

Knox, A. B., \& McLeish, A. B. (1989). Continuing education of the professionals. In C. J. Titmus (Ed.), Lifelong education for adults: An international handbook. Oxford; New York Pergamon 
Konn, T., \& Roberts, N. (1984). Academic librarians and continuing education: A study of personal attitudes and opinions. Journal of Librarianship, 16(4), 262-280.

Krailassuwan, S. (1988). A study of librarians' and administrators' opinions towards types of librarian development programs in university libraries. Unpublished master's thesis, Srinakharinwirot University, Bangkok, Thailand.

Krueger, R. A., \& Casey, M. A. (2000). Focus groups: A practical guide for applied research. Thousand Oaks, Cal.: Sage Publications.

Larsen, G. (2007). Preparing library staff for reference and information work in the hybird library - the need for skills and continuing professional development. Retrieved 23 September, 2007, from http://www.ifla.org/IV/ifla73/papers/151Larsen-en.pdf

Leedy, P. D., \& Ormrod, J. E. (2001). Practical research: Planning and design Upper Saddle River, N.J. : Merrill Prentice Hall.

Li, A. T. (2001). Librarians' learning in the workplace. Unpublished doctoral dissertation, Rutgers University New Brunswick.

Library and Information Center - VNU - Hanoi. (2005). Introduction to Library and Information Center Vietnam National University, Hanoi. Retrieved 31 October, 2005, from http://www.lic.vnu.edu.vn/chucnang_nv.htm

Lim, L., \& Firkola, P. (2000). Methodological issues in cross-cultural management research: Problems, solutions, and proposals. Asia Pacific Journal of Management, 17(1), 133.

Lipow, A. G., \& Carver, D. A. (Eds.). (1992). Staff development: A practical guide (2 ed.). Chicago, London: American Library Association.

Lonely Planet. (2007). Map of Vietnam. Retrieved 14 January, 2008, from http://www.lonelyplanet.com/maps/asia/vietnam/

Lonie, J. M. (2005). From counting and pouring to caring: How pharmacists learn empathic communication skills. Unpublished doctoral dissertation, Columbia University Teacher College, New York.

Machin, M. A. (1999). Understanding the process of transfer of training in the workplace. Unpublished doctoral dissertation, University of Southern Queensland, Toowoomba.

Maguire, M., Maguire, S., \& Felstead, A. (1993). Factors influencing individual commitment to lifetime learning: A literature review: Center for labour market studies University of Leicester.

Majid, S. (2004). Continuing professional development (CPD) activities organized by Library and Information Study Programs in Southeast Asia. Journal of Education for Library and Information Science, 45(1), 58-70.

Mann, K. V. (1994). Educating medical students: Lessons from research on continuing education [Electronic version]. Academic Medicine, 69(1), 41-47.

Mason, J. (2002). Qualitative researching. London: Sage Publications

Massis, B. E. (2004). The practical library trainer. New York: The Haworth Press Inc.

Mathieu, J. E., \& Martineau, J. W. (1997). Individual and situational influences on training motivation. In J. K. Ford, W. J. Kozlowski, K. Draiger, E. Salas \& T. M. S. (Eds.), Improving training effectiveness in work organisation (pp. 193-221). Mahwah, NJ: Lawrence Erlbaum Associates. 
McIntosh, N. E. (1979). To make continuing education a reality. Oxford Review of Education, 5(2).

Merriam, S. B., \& Caffarella, R. S. (1999). Learning in adulthood: A comprehensive guide. San Francisco: Jossey-Bass.

Merriam, S. B., Caffarella, R. S., \& Baumgartner, L. M. (2007). Learning in adulthood: A comprehensive guide. San Francisco: Jossey-Bass.

Miles, M. B., \& Huberman, A. M. (1994). Qualitative data analysis: An expended sourcebook. Thousand Oaks: Sage Publications.

Millerson, G. (1964). The qualifying association - A study of professionalization. London: Routledge and Kegan Paul.

Minichiello, V., Aroni, R., Timewell, E., \& Alexander, L. (1995). In-depth interviewing: Principles, techniques, analysis. South Melbourne Longman

Ministry of Culture and Information. (1995). Quyet dinh cua Bo truong bo Van hoa Thong tin quy dinh chuc nang nhiem vu, quyen han va to chuc bo may cua $\mathrm{Vu}$ Thu vien [Decision of the Ministry of Ministry of Culture and Information assigning functions, missions, authorities and organisational features of the Library Department] Hanoi, Vietnam: Author.

Ministry of Culture and Information. (2004a). Bao cao tong ket hoat dong cua he thong thu vien cong cong toan quoc nam 2001-2003. Phuong huong va nhiem vu trong tam nam 2004-2006 [Report on national public library system activities in 20012003. Visions and goals on 2004-2006]. Hanoi, Vietnam: Author.

Ministry of Culture and Information. (2004b). Quy hoach phat trien nganh thu vien Viet Nam den nam 2010 va dinh huong den nam 2020 [A plan to 2010 and strategic development to 2020 for library and information profession of Viet Nam]. Hanoi, Vietnam: Author.

Ministry of Culture and Information. (2005). So ket 5 nam hoat dong ung dung cong nghe thong tin cua he thong thu vien cong cong [Applying information technology in public library system in 5 years] Paper presented at the So ket 5 nam hoat dong ung dung cong nghe thong tin cua he thong thu vien cong cong. 24-25/5/2005 [Applying information technology in public library system in 5 years. 24-26/5/2005]. Quy Nhon, Binh Dinh.

Ministry of Culture and Information. (2007). Quyet dinh phe duyet quy hoach phat trien nganh thu vien Viet Nam den nam 2010 va dinh huong den nam 2020 [Decision No. 10/2007/QD-BVHTT on Approval of Vietnam's Master Library Development Plan until 2010 and Vision to 2020]. Hanoi, Vietnam: Author.

Ministry of Education and Training. (2003, October 2). Vietnam News, p. 1.

Ministry of Education and Training. (2007). So lieu thong ke giao duc [Statistics on education]. Retrieved 6 November 2007, from http://www.edu.net.vn/Data/ThongKe/dhcd.htm

Ministry of the Interior. (2004). Thong tu so 10/2004/TT-BNV huong dan thuc hien mot so dieu cua Nghi dinh so 11/2003/ND-CP ngay 10 thang 10 nam 2003 cua Chinh phu ve tuyen dung, su dung va quan ly can bo, cong chuc trong cac don vi su nghiep cua Nha nuoc [Circular No. 10/2004/TT-BNV on the Recruitment, Employment and Management of Civil Servants]. Hanoi, Vietnam: Author. 
Monette, M. L. (1977). The concept of educational need: An analysis of selected literature. Adult Education, 27(2), 116-127.

Morgan, D. L. (1997). Focus groups as qualitative research. Thousand Oaks, Calif. : Sage Publications.

Mott, V. W. (2000). The development of professional expertise in the workplace. New Directions for Adult and Continuing Education, 86, 23-31.

Moyo, L. (2002). CPE anywhere anytime: Online resources for the information society. In P. L. Ward (Ed.), Continuing professional education for the information society: The fifth world conference on continuing professional education for the library and information science professions (pp. 224-231). Munchen: K.G.Saur.

Muhamad, M., \& Associates. (2001). Adult and continuing education in Malaysia. Ampang: UNESCO Institute for Education, University utra Malaysia Press.

Murray, W. E., \& Overton, J. (2005). Designing development research In R. Scheyvens \& D. Storey (Eds.), Development fieldwork: A practical guide (pp. 17-37). London: Sage Publications.

Nasseh, B. (1996). Continuing professional education models. Retrieved 7 October, 2005, from http://www.bsu.edu/classes/nasseh/bn100/profess.html

National Council on Quality Continuing Education for Library and Media Personnel. (1980). A program for quality in continuing education for information, library, and media personnel, policy statement and criteria for quality. Washington, D.C.: CLNE.

Natural Sciences Library - VNU - HCMC. (2005). Introduction to Natural Sciences Library. Retrieved 31 October 2005, from http://www.glib.hcmuns.edu.vn/gioithieu.htm

Newton, S. (2001). Mastering your career [Electronic version]. New Library World, 102(1), 34-38.

Ngo, T. T. (2004). Hoat dong dao tao boi duong nghiep vu Thong tin - Thu vien o Viet Nam: Hien trang va kha nang phat trien [Information and library professional training activities in Vietnam: Present condition and perspective]. Khoa hoc Xa hoi va Nhan Van, October 2004, 32-41.

Nguyen, D. T. (2003a). Quan ly va thuc hien dao tao, boi duong nghiep vu thong tin-thu vien trong nganh van hoa-thong tin [Managing and implementing continuing education in the field of Culture and Information]. In National Centre for Scientific and Technological Information (Ed.), Tang cuong dao tao boi duong nghiep vu thong tin-tu lieu phuc vu cong nghiep hoa, hien dai hoa [Strenthening continuing education in the field of Information and Documentation to implement the industrialisation and modernisation]. Hanoi: National Centre for Scientific and Technological Information.

Nguyen, H. C. (2003b). Mot so y kien ve cong tac dao tao, huan luyen doi ngu can bo va nguoi dung tin [Suggestions for continuing education for information workers and users]. Paper presented at the Tang cuong dao tao boi duong nghiep vu thong tin-tu lieu phuc vu cong nghiep hoa, hien dai hoa [Strenthening continuing education in the field of Information and Documentation to implement the industrialisation and modernisation], Hanoi, National Centre for Scientific and Technological Information. 
Nguyen, H. C. (2005). Lich su hinh thanh va phat trien he thong thu vien - thong tin dai hoc My va dinh huong van dung mot so kinh nghiem vao thu vien dai hoc Viet Nam [History of development of American university library and information system and suggestions of applications of its experience in Vietnamese university libraries]. Unpublished doctoral dissertation, Vietnam National University Hanoi, Hanoi, Vietnam.

Nguyen, H. H. (2003c). Phat trien dao tao can bo thong tin thu vien o Viet Nam [Education for library and information staff]. Paper presented at the Nang cao chat luong dao tao can bo thu vien thong tin, Ha Noi, 29-30 thang 4 nam 2003 [Enhancing qualification of education for library and information staff, Hanoi, April 29-30, 2003]. Hanoi, Vietnam.

Nguyen, H. H. (2004). Nang cao chat luon dao tao can bo thong tin thu vien o Viet Nam [Strengthening qualification of library and information professional education]. Thong tin \& Tu lieu, 2, 1-5.

Nguyen, M. H. (2003d). Chien luoc dao tao nganh Thu vien - Thong tin o Viet Nam [Strategy of Library and Information education in Vietnam]. Paper presented at the Nang cao chat luong dao tao can bo thu vien thong tin, Ha Noi, 29-30/4/2003 [Enhancing qualification of education for library and information staff, Hanoi, April 29-30, 2003], Hanoi, Vietnam.

Nguyen, N. M. (2000a). Tim hieu su nghiep nganh thu vien - Luu tru ho so Viet Nam [Review of Vietnamese library and archives history]. Hanoi: The gioi.

Nguyen, T. H. (2000b). Trung tam thong tin tu lieu khoa hoc quoc gia voi cong tac dao tao, boi duong can bo [National Center for Scientific and Technological Information and continuing education for library and information staffs]. Thong tin \& Tu lieu, 4, 32-34.

Nguyen, T. L. T. (1993). Dam bao phuong phap luan huong dan nghiep vu cho he thong thu vien cong cong Viet Nam [Methodology of professional training for Vietnamese public libraries]. Unpublished candidate-doctoral dissertation, SaintPetersburg Institute of Culture, Saint-Petersburg.

Nguyen, T. L. T. (2001). Doi moi chuong trinh va phuong phap dao tao: Nhung giai phap chu yeu de phat trien giao duc dai hoc nganh Thu vien - Thong tin [Renewing curriculums and methods: Main solutions for library and information education]. Paper presented at the Dam bao chat luong dao tao chuyen nganh khoa hoc Thong tin - Thu vien, Ha Noi 12/12/2001 [The quality of Library and Information education, Hanoi December, 12, 2001], Hanoi, Vietnam.

Noe, R. A. (1986). Trainees' attributes and attitudes: Neglected influences of training effectiveness. Academic of Management Review, 11, 736-749.

Noe, R. A. (2002). Employee training and development (2nd ed.). New York: McGrawHill.

Noe, R. A., \& Colquitt, J. A. (2002). Planning for training impact: Principle of training effectiveness. In K. Kraiger (Ed.), Creating, implementing, and managing effective training and development (pp. 53-79). San Francisco: Jossey-Bass.

Nonmali, V. (1987). The needs for continuing education of academic librarians. Unpublished master's thesis, Chulalongkorn University, Bangkok, Thailand. 
Nowlen, P. M. (1988). A new approach to continuing education for business and the professions: The performance model. New York: Macmillan.

Oldroyd, M. (Ed.). (1996). Staff development in academic libraries: Present practice and future challenges. London: Library Association Publishing.

Orick, J. T. (2000). The virtual library: Changing roles and ethical challenges for librarians. International Information \& Library Review, 32(3/4), 313-324.

Orlikowski, W. J., \& Baroudi, J. J. (1991). Studying information technology in organisations. Research approaches and assumptions. Information Systems Research, 2, 1-28.

Parker, C. (1997). Professional development needs of CMA's in post-secondary education. The College Quarterly, 5(1).

Parson, L. C. (1988). Continuing professional education of academic librarians in Massachusetts: Practices, perceptions and preferences. Unpublished doctoral dissertation, Texas Woman's University, Denton.

Pors, N. O., \& Schreiber, T. (1997). Continuing education and information technology: A study of content and deliverables. In P. L. Ward \& D. E. Weingand (Eds.), Human Development: Competencies for the twenty-first century. Paper form the IFLA CPERT Third International Conference on Continuing Professional Education for the Library and Information Professions. Munchen: K.G. Saur.

Poteet, L. L. (1996). The training transfer process: An examination of the role of individual, motivational and work environmental factors. Unpublished Dissertation Abstracts International, 53 (04A), 2343. (UMI No. 9709051).

Powell, R. R., \& Connaway, L. S. (2004). Basic research methods for librarians. Westport, Conn.: Libraries Unlimited.

Prytherch, R. J., \& Harrod, L. M. (Eds.). (2000). Harrod's librarians' glossary and reference book : a directory of over 9,600 terms, organizations, projects and acronyms in the areas of information management, library science, publishing and archive management / compiled by Ray Prytherch. Aldershot: Gower.

Puetz, B. E. (1987). Contemporary strategies for continuing education in nursing. Maryland: Aspen publishers, Inc.

Punch, K. F. (2005). Introduction to social research: Quantitative and qualitative approaches. London; Thousand Oaks, Calif.: Sage Publication.

Queeney, D. S. (1992). Problems of content and delivery in continuing professional education. In E. S. Hunt (Ed.), Professional workers as learners: the scope, problems, and accountability of continuing professional education in the 1990s (pp. 35-55). Washington D.C.: Office of Educational Research and Improvement, U.S. Dept. of Education.

Queeney, D. S. (1995). Assessing needs in continuing education: An essential tool for quality improvement. San Francisco: Jossey-Bass Inc.

Queeney, D. S. (2000). Continuing educational education. In A. L. Wilson \& E. R. Hayes (Eds.), Handbook of adult and continuing education (pp. 375-407). San Francisco: Jossey-Bass.

Quinones, M. A. (1995). Pre-training context effects: Training assignment as feedback. Journal of Applied Psychology(80), 226-238. 
Qureshi, A. (1990). Continuing education of health sciences librarians: A national survey. Kent State University, Ohio.

Ramaiah, C. K., \& Moorthy, A. L. (2002). The impact of continuing education programmes on library and information science professionals. Library Review, 51(1), 24-31.

Roberts, N., \& Konn, T. (1989). Continuing education and training for academic library staff. Journal of Librarianship, 21(2), 109-128.

Roberts, N., \& Konn, T. (1991). Librarians and professional status: Continuing professional development and academic libraries. London: Library Association.

Robertson, M. K., Umble, K. E., \& Cervero, R. M. (2003). Impact studies in continuing education for health professions: Update [Electronic version]. The Journal of Continuing Education in the Health Professions, 23, 146-156.

Robinson-Pant, A. (2005). Cross-cultural perspectives on educational research. London: Open University Press.

Rogers, J. (1989). Adults learning. Philadelphia: Milton Keynes.

Rogers, J. (2001). Adults learning. Philadelphia: Open University Press.

Ross-Gordon, J. M. (1998). What we need to know about adult learners. In P. S. Cookson (Ed.), Program planning for the training and continuing education of adults: North American perspectives (pp. 207-250). Malabar, Florida: Krieger Publishing Company.

Rossman, G. B., \& Raills, S. F. (2003). Learning in the field: An introduction to qualitative research. Thousand Oaks, Calf.: Sage.

Rothstein, S. (1965). Nobody's Baby: A brief sermon on Continuing professional education. Library Journal, 90, 2226-2227.

Rubin, H. J., \& Rubin, I. S. (2005). Qualitative interviewing: The art of hearing data. Thousand Oak: Sage Publications.

Rugaas, B. (1993). Library/information science education for the 21st century: The Tromso conference. Conference on curriculum design for the information market place New York Neal-Schuman Publishers.

Russett, C. J. (1991). Factors that facilitate or impede information workplace learning among faculty in a large suburban New York state community college. Unpublished doctoral dissertation, Columbia University Teachers College, New York.

Saechan, C. (2001). The continuing education needs of academic librarians in the South of Thailand. Unpublished Doctor of Art Dissertation, Simmons College, Boston.

Sarantakos, S. (1998). Social research. Basingstoke, Hampshire: Macmillan.

Schensul, J. J. (1999a). Focused group interviews. In J. J. Schensul, M. D. Lecompte, B. K. Natasi \& S. P. Borgatti (Eds.), Enhanced ethnographic methods : audiovisual techniques, focused group interviews, and elicitation techniques (pp. 51-111). Thousand Oaks, Calif. : Altamira Press.

Schensul, J. J. (1999b). Focused group interviews. In J. J. Schensul, M. D. Lecompte, B. K. Natasi \& S. P. Borgatti (Eds.), Enhanced ethnographic methods: Audiovisual techniques, focused group interviews, and elicitation techniques (pp. 51-111). Thousand Oaks, Calif. : Altamira Press. 
Shuman, C. A. (2005). Perceptions of professional development by part-time faculty members in Kansas community colleges: An exploratory study. Unpublished doctoral dissertation, Kansas State University, Manhattan.

Siega, G. D. (1985). Continuing education for librarians in the Philippines. In E. E. Horne (Ed.), Continuing education: Issues and challenges. Papers form the Conference held at Moraine Valley Community College, Palos Hills, Illinois, U.S.A. August 13-16, 1985 (pp. 377-389). New York: K.G.Saur.

Smith, D. (1993). The greening of librarianship: Charting a new course for continuing library education. In B. Woolls (Ed.), Continuing professional education and IFLA: Past, present and a vision for the future. Papers from the IFLA CPERT second world conference on continuing professional education for the library and information science professions (pp. 11-23). Munchen: K.G. Saur.

Smith, D. (2001). Greening of librarianship: charting a new course for continuing library education. In B. Woolls \& B. E. Sheldon (Eds.), Delivering lifelong continuing professional education across time and space, the Fourth World Conference on Continuing Professional Education for the Library and Information Profession. (pp. 253-225). Munchen: K.G. Saur.

Song, Y. (2005). Continuing education in Chinese University Libraries: Issue and approaches. Libri, 55(1), 21-31.

Sproull, N. L. (1995). Handbook of research methods: A guide for practitioners and students in the social sciences. Metuchen, N.J. : Scarecrow Press.

Squires, G. (2005). Art, science and the professions. Studies in Higher Education, 30(2), 127-136.

Standing Committee of National Assembly. (2003). Phap lenh cong chuc [Ordinance of Civil Servants]. Hanoi, Vietnam: Author.

Stern, M. R., \& Queeney, D. S. (1992). The scope of continuing professional education: Providers, consumers, issues. In E. S. Hunt (Ed.), Professional workers as learners: the scope, problems, and accountability of continuing professional education in the 1990s (pp. 13-34). Washington D.C.: Office of Educational Research and Improvement, U.S. Dept. of Education.

Stewart, D. W., \& Shamdasani, P. N. (1990). Focus groups: Theory and practice Newbury Park, Calif.: Sage Publications.

Stolee, P., Esbaugh, J., \& Aylward, S. (2005). Factors associated with the effectiveness of continuing education in Long-Term Care. The Gerontalogist, 45(3), 399-405.

Stone, E. W. (1969). Factor related to the professional development of librarians. Metuchen: Scarecrow Press.

Stone, E. W. (1979). Model continuing education recognition system in library and information science. New York: K.G.Saur.

Stone, E. W. (1985a). Some historical antecedents of continuing library education. In W. G. Asp, S. H. Mahmoodi, M. L. Miller, P. O'Donnell \& E. W. Stone (Eds.), Continuing education for the library information professions (pp. 9-51). Hamden, Conn.: Library Professional Publications.

Stone, E. W. (1985b). Toward a learning community. In G. A. William, S. H. Mahmoodi, M. L. Miller, P. O'Donnell \& E. W. Stone (Eds.), Continuing 
education for the library information professions (pp. 52-82). Hamden, Conn.: Library Professional Publications.

Stone, E. W., Patrick, R., \& Conroy, B. (1974). Continuing library and information science: Final report to the National Commission on Libraries and Information Science. Washington D.C.: Government Printing Office.

Swanson, B. A. G. (1988). A needs assessment of professional development competencies for public school library media specialists. Unpublished doctoral dissertation, East Texas State University, Commerce.

Swanson, R. A., \& Holton, E. F. (2001). Foundations of human resource development. San Francisco: Barrett-Koehler.

Tepaya, T., Rongsavat, P., \& Daeponkran, S. (1997). Survey of the needs for the opening of the continuing education curriculum in the field of library and information science. Pattani: Department of Library and Information Science, Prince of Songka University.

Tharenou, P. (1997). Organisational, job and personal predictors of employee participation in training and development. Applied Psychology: An International Review, 46(2), 111-134.

Tharenou, P. (2001). The relationship of training motivation to participation in training and development. Journal of Occupational and Organisational Psychology, 74, 599-621.

The Library Association. (1986). Professional education and training for library and information work: A review by the Library and Information Services Council. London: Library Association Publishing Ltd.

The World Factbook. (2006). Vietnam Retrieved 21 May, 2006, from http://www.cia.gov/cia/publications/factbook/print/vm.html

Tracey, J. B., Hinkin, T. R., Tannenbaum, S., \& Mathieu, J. E. (2001). The influence of individual characteristics and the work environment on varying levels of training outcome. Human Resource Development Quarterly, 12(1), 5-22.

Tran-Nam, B., \& Pham, C. D. (Eds.). (2003). The Vietnamese economy: Awakening the dornant dragon. New York: Routledge.

Tran, A. D. (1999a). Thu vien Quoc gia Viet Nam voi viec dao tao, boi duong can bo nganh thu vien [Vietnamese National Library with education and training activities for library staff] Tap san Thu vien, 1/1999, 46-53.

Tran, L. A. (1999b). Recent library developments in Vietnam. Asian Libraries, 8(1), 516.

Tran, L. A., \& Gorman, G. E. (1999). Library and information science education in Vietnam. Asian Libraries, 8(3), 65-82.

Umble, K. E., \& Doole, L. M. (2004). Planning human resource development and continuing professional education programs that use educational technologies: Voices that must be heard. Advances in Developing Human Resources, 6(1), 86100 .

Vaughan, S., Schumm, J. S., \& Sinagub, J. (1996). Focus group interviews in education and psychology. Thousand Oaks: Sage Publication.

Venables, P. (1976). Report of the Committee on Continuing Education. Milton Keynes: Open University Press. 
Waddington, I. (1996). Professions. In A. Kuper \& J. Kuper (Eds.), The social science encyclopedia (pp. 650-651). London: Routledge \& Kegan Paul.

Walsh, M. E. (2003). Perceived continuing education needs of vascular nurses in caring for patients with peripheral arterial disease. Unpublished $\mathrm{PhD}$ thesis, The University of Toledo, Ohio.

Walsham, G. (1995). Interpretive case studies in IS research. Nature and method. European Journal of Information Systems, 4, 74-81.

Webb, R. (1995). Continuing education: Mandate or option? Journal of Education for Library and Information Science, 36(3), 261-264.

Weingand, D. E. (1991). The continuum of library education: Maintaining competence through the professional worklife [Electronic version]. IFLA Journal, 17(3), 266273.

Weingand, D. E. (1999). Describing the elephant: What is continuing professional education? [Electronic version]. IFLA journal, 26(3), 189-202.

Weingand, D. E. (2001). Training the trainer: A perspective from the ALA/CLENE-TR. In B. Woolls \& B. E. Sheldon (Eds.), Delivering lifelong continuing professional education across space and time: The fourth world conference on continuing professional education for the library and information science professions (Vol. IFLA publication 98, pp. 266-273). Munchen: K. G. Saur.

White, P. (2004). Medical professionalism and continuing professional development for medical specialists [Electronic version]. Australian and New Zealand Journal of Obstetrics and Gynaecology, 44, 186-190.

Wikle, T. A. (1998). Continuing education and competency programmes in GIS. International Journal Geographical Information Science, 12(5), 491-507.

William, G. A., Mahmoodi, S. H., Miller, M. L., O'Donnell, P., \& Stone, E. W. (1985). Continuing education for the library information professions. Hamden, Conn.: Library Professional Publications.

Williamson, C. C. (1923). Training for library service: A report prepared for the Carnegie corporation of New York. Boston: D. B. Updike.

Williamson, M. G. (1986). Guidelines for training in libraries. 7. Coaching and counselling skills. London Library Association.

Witkin, B. R., \& Altschuld, J. W. (1995). Planning and conducting needs assessments : A practical guide. Thousand Oaks: Sage Publications.

Wood, A. (2007). A comprehensive library staff training programme in the information age Oxford: Chandos.

Woolls, B. (2005). Continuing education professional education to continuing professional development and workplace learning: The journey and beyond. In P. Genoni \& G. Walton (Eds.), Continuing professional development - Preparing for new roles in libraries: A voyage of discovery: Sixth World Conference on Continuing professional development and workplace learning for the library and information professions (pp. 14-25). München K.G. Saur.

Xue, M. (2003). Strategy for surviving in 21st century: On knowledge librarian at the age of hybrid library. In China society for library science (Ed.), Librarians in the new century (pp. 331-336). Beijing: Beijing Library Press. 
Yang, Z. Y. L. (2001). An assessment of education and training needs for government documents librarians in the United States [Electronic version]. Journal of Government Information, 28 (2001), 425-439.

Yin, R. K. (2003). Case study research: Design and methods. Thousand Oaks: Sage publications.

Yun-Chou, S. (1991). Continuing professional education in China. In B. Woolls (Ed.), Continuing Professional Education: An IFLA guidebook; a publication of the Continuing Professional Education Round Table (CPERT) of the International Federation of Library Associations and Institutions (IFLA) (Vol. IFLA publication; 55, pp. 157). London, New York, Paris: K. G. Saur.

Zinn, L. F. (1997). Supports and Barriers to Teacher Leadership: Reports of teacher leaders. Unpublished doctoral dissertation, University of Northern Colorado, Greeley. 


\section{APPENDIX A \\ INFORMATION SHEET AND CONSENT FORM \\ FOR SAMPLE LIBRARIES}

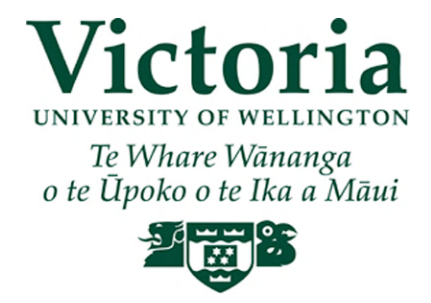

(Information sheet for libraries with a small number of staff)

\section{Research title: A contextual model for planning continuing education programmes for university library practitioners in Vietnam \\ Researcher: Nguyen Hong Sinh}

I am a PhD student in the School of Information Management at Victoria University of Wellington, New Zealand. My research is being carried out for my PhD thesis. This letter is to provide you with information about my study and to ask your permission to invite your staff to participate in my study.

The research focuses on determining factors affecting continuing education and on identifying and prioritising key learning needs among university library practitioners in Vietnam. The findings of my study will provide a contextual model for continuing education that will assist providers and university libraries in designing and implementing more effective learning programmes for university library practitioners in Vietnam.

I would like to collect data by conducting (1) an individual interview with a manager who has responsibilities for or an interest in continuing education and (2) one focus group interview with five operational staff in different parts of your library. Identity of your library and your staff will be kept confidential. A summary of research results will be sent to your library and the participants.

It is planned that the individual interview will last for up to one hour and the focus group interview for one and half hours. The interviews will focus on factors affecting continuing education, for instance, the changing nature of the Library and Information Management profession, the relationship between the practitioners' needs and the organisations' needs and the influences of the environment in which the practitioners live and practice. I also would like to ask participants about their own key continuing education needs. 
I would like to conduct interviews during the period of September-October 2006. Please note that the participants may withdraw from the study at any time until the end of the data collection period without having to give reasons. In these cases, the information contributed by them will be removed from the study.

In addition, I would like to ask you to provide me with documents from your institution that will help me to understand the institutional context. These include annual reports, training reports (last five years), promotion policies, decertification policies, human resource development plan, etc. The documents can be posted or given to me when I come to conduct the interviews.

My research, which has been approved by the Human Ethics Committee of Victoria University of Wellington, is under the supervision of Professor Gary Gorman and Dr. Dan Dorner from the School of Information Management, Victoria University of Wellington. Their contact details are:

Email: $\quad$ Gary.Gorman@vuw.ac.nz

Dan.Dorner@vuw.ac.nz

Postal Address:

The School of Information Management

Victoria University of Wellington

PO Box 600

Wellington

New Zealand

If you agree to your library's participation in this study please sign the attached Consent Form. If you have any questions about this study or the Information Sheet, please contact me by email sinh.nguyen@vuw.ac.nz or at the following postal address:

Nguyen Hong Sinh

333/14/4 Le Van Sy

Tp Ho Chi Minh

The participation of your library in this study is greatly appreciated. Thank you for taking the time to consider this invitation.

Your sincerely

Nguyen Hong Sinh 


\section{Victoria \\ UNIVERSITY OF WELLINGTON \\ Te Whare Wānanga \\ o te Ūpoko o te Ika a Māui

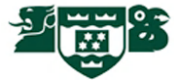

(Information sheet for libraries with a large or medium number of staff)

\section{Research title: A contextual model for planning continuing education programmes for university library practitioners in Vietnam Researcher: $\quad$ Nguyen Hong Sinh}

I am a PhD student in the School of Information Management at Victoria University of Wellington, New Zealand. My research is being carried out for my PhD thesis. This letter is to provide you with information about my study and to ask your permission to invite staff from your library to participate in the study.

The research focuses on determining factors affecting continuing education and on identifying and prioritising key learning needs among university library practitioners in Vietnam. The findings of my study will provide a contextual model for continuing education that will assist providers and university libraries in designing and implementing more effective continuing education programmes for university library practitioners in Vietnam.

I would like to collect data by conducting (1) an individual interview with a manager who has responsibilities for or an interest in continuing education and (2) two focus group interviews with operational staff from different parts of your library. One focus group will be with five supervisors or senior staff while the other will be with five line staff. Identity of your library and your staff will be kept confidential. A summary of research results will be sent to your library and the participants.

It is planned that the individual interview will last for up to one hour and the focus group interview for one and half hours. The interviews will focus on factors affecting continuing education, for instance, the changing nature of the Library and Information Management profession, the relationship between the practitioners' needs and the organisations' needs and the influences of the environment in which the practitioners live and practice. I also would like to ask participants about their own key continuing education needs.

I would like to conduct interviews during the period of September-October 2006. The participants may withdraw from the study at any time until the end of the data collection 
period without having to give reasons. In these cases the information contributed by them will be removed from the study.

In addition, I would like to ask you to provide me with documents from your institution that will help me to understand the institutional context. These include annual reports, training reports (last five years), promotion policies, decertification policies, human resource development plan, etc. The documents can be posted or given to me when I come to conduct the interviews.

My research, which has been approved by the Human Ethics Committee of Victoria University of Wellington, is under the supervision of Professor Gary Gorman and Dr. Dan Dorner from the School of Information Management, Victoria University of Wellington. Their contact details are:

Email: $\quad$ Gary.Gorman@vuw.ac.nz

Dan.Doner@vuw.ac.nz

Postal address:

The School of Information Management

Victoria University of Wellington

PO Box 600

Wellington

New Zealand

If you agree to your library's participation in this study please sign the attached Consent Form. If you have any questions about this study or the Information Sheet, please contact me by email sinh.nguyen@vuw.ac.nz or at the following postal address:

Nguyen Hong Sinh

333/14/4 Le Van Sy

Tp. Ho Chi Minh

The participation of your library in this study is greatly appreciated. Thank you for taking the time to consider this invitation.

Your sincerely

Nguyen Hong Sinh 


\section{Victoria \\ UNIVERSITY OF WELLINGTON \\ Te Whare Wānanga \\ o te Ūpoko o te Ika a Māui

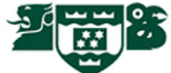

\section{Consent to Participation in Research}

\section{A contextual model for planning continuing education programmes for university}

library practitioners in Vietnam

I, Director of (name of university library) have read and understood the Information Sheet detailing the purposes and requirements of this study. I agree to our staff being involved in this research as outlined in the Information Sheet.

Name:

Signature:

Date 


\section{APPENDIX B \\ INFORMATION SHEET AND CONSENT FORM \\ FOR INDIVIDUAL INTERVIEWEES}

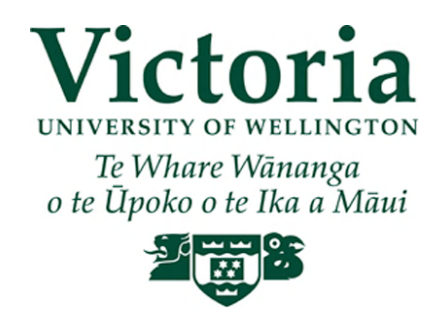

\section{Research title: A contextual model for planning continuing education \\ Researcher: programmes for university library practitioners in Vietnam Nguyen Hong Sinh}

I am a PhD student in the School of Information Management at Victoria University of Wellington, New Zealand. My research is being carried out for my PhD thesis. This letter is to provide you with information about my study and to invite you to participate in the study. I have already received permission from your director, to request your participation in my research.

The research focuses on determining factors affecting continuing education and on identifying and prioritising key learning needs among university library practitioners in Vietnam. The findings of my study will provide a contextual model for continuing education that will assist providers and university libraries in designing and implementing more effective continuing education programmes for university library practitioners in Vietnam.

I would like to ask you to be an interviewee for my data collection. The interview will focus on your perceptions of factors affecting continuing education, for instance, the changing nature of the Library and Information Management profession, the relationship between the practitioners' needs and the organisations' needs and the influences of the environment in which the practitioners live and practice. I also would like to ask about key continuing education needs for you and practitioners in your library.

It is planned that the average time for the interview will be one hour. We will discuss the date for the interview in subsequent communication.

In addition, I would like to ask you to provide me with documents from your institution that will help me to understand the institutional context. These include annual reports, training reports (last five years), promotion policies, decertification policies, human resource development plan, etc. The documents can be posted or given to me when I come to conduct the interviews. 
If you agree to participate in my study this means that:

- You allow me to record and transcribe the interview using an audio tape recorder. You may ask that the recorder be switched off at any time during the interview and you are free to refuse to answer specific questions.

- Information about you is confidential.

- You may withdraw from the study at any time until the end of the data collection period that is until the end of October, 2006. In this case the information contributed by you will be destroyed.

- You will receive a summary of research results that will also be sent to your library.

- You agree to the findings of this research being published in my PhD thesis and academic or professional journals, or being presented at relevant conferences.

My research, which has been approved by the Human Ethics Committee of Victoria University of Wellington, is under the supervision of Professor Gary Gorman and Dr. Dan Dorner from the School of Information Management, Victoria University of Wellington. Their contact details are:

Email: $\quad$ Gary.Gorman@vuw.ac.nz

Dan.Dorner@vuw.ac.nz

Postal address:

The School of Information Management

Victoria University of Wellington

PO Box 600

Wellington

New Zealand

If you agree to participate in this study please sign the attached Consent Form. If you have any questions about this study or the Information Sheet, please contact me by email sinh.nguyen@vuw.ac.nz or at the following postal address:

Nguyen Hong Sinh

333/14/4 Le Van Sy

Tp. Ho Chi Minh

Your participation in this study is greatly appreciated. Thank you for taking the time to consider this invitation.

Your sincerely,

Nguyen Hong Sinh 


\section{Victoria \\ UNIVERSITY OF WELLINGTON \\ Te Whare Wānanga \\ o te Ūpoko o te Ika a Māui

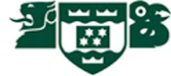

\section{Consent to Participate in Research (for individual interviews) A contextual model for planning continuing education programmes for university library practitioners in Vietnam}

I have read and understood the Information Sheet detailing the purposes and requirements of this study. I have had an opportunity to ask questions and have them answered to my satisfaction. I understand that

I may withdraw myself from this research without having to give reasons up to the end of October 2006 and the information contributed by me will be removed from the study.

My identity and that of university will be kept confidential and information or opinions which I have given will not be attributed to me in any reports on this research.

Information that I have told will be recorded.

A summary of the results of this research will be sent to my library and to me.

The data I provide will be only used for the publication of the researcher's $\mathrm{PhD}$ thesis and academic or professional journals or being presented at relevant conferences.

I agree to participate in this research.

Signed:

Date:

Participant's name:

Library's name: 


\section{APPENDIX C \\ INFORMATION SHEET AND CONSENT FORM \\ FOR GROUP FOCUS PARTICIPANTS}

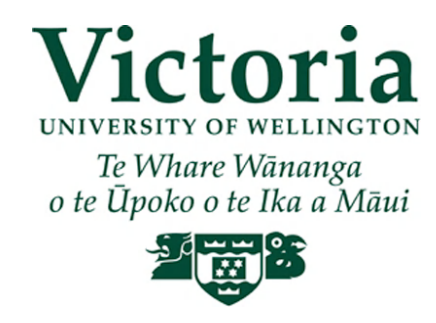

\section{Research title: A contextual model for planning continuing education programmes for university library practitioners in Vietnam Researcher: $\quad$ Nguyen Hong Sinh}

I am a PhD student in the School of Information Management at Victoria University of Wellington, New Zealand. My research is being carried out for my $\mathrm{PhD}$ thesis. This letter is to provide you with information about my study and to invite you to participate in the study. I have already received permission from your director to request your participation in my research.

The research focuses on determining factors affecting continuing education and identifying key learning needs among university library practitioners in Vietnam. The findings of my study will provide a contextual model for continuing education that will assist providers and university libraries in designing and implementing more effective continuing education programmes for university library practitioners in Vietnam.

I would like to ask you to be a participant in a focus group interview for my data collection. The focus group interview will focus on your perceptions of factors affecting continuing education, for instance the changing nature of the Library and Information Management profession, the relationship between the practitioners' needs and the organisations' needs and the influences of the environment in which the practitioners live and practice. I also would like to ask about your own key continuing education needs.

It is planned that the average time for the interview will be one and half hours. We will discuss the date for the interview in subsequent communication.

If you agree to participate in my study this means that:

- You allow me to record and transcribe the interview using an audio tape recorder. You may ask that the recorder be switched off at any time during the interview and you are free to refuse to answer specific questions.

- Information about you is confidential. 
- You may withdraw from the study at any time until the end of the data collection period that is until the end of October, 2006. In this case the information contributed by you will be destroyed.

- You will receive a summary of research results that will also be sent to your library.

- You agree to do not disclose information or opinions of other members in the focus group interview.

- You agree the findings of this research being published in my $\mathrm{PhD}$ thesis and academic or professional journals, or being presented in relevant conferences.

My research, which has been approved by the Human Ethics Committee of Victoria University of Wellington, is under the supervision of Professor Gary Gorman and Dr. Dan Dorner from the School of Information Management, Victoria University of Wellington. Their contact details are:

Email: $\quad$ Gary.Gorman@vuw.ac.nz Dan.Dorner@vuw.ac.nz

Postal address:

The School of Information Management

Victoria University of Wellington

PO Box 600

Wellington

New Zealand

If you agree to participate in this study please sign the attached Consent Form. If you have any questions about this study or the Information Sheet, Please contact me by email sinh.nguyen@vuw.ac.nz or at the following postal address:

Nguyen Hong Sinh

333/14/4 Le Van Sy

Tp. Ho Chi Minh

Your participation in this study is greatly appreciated. Thank you for taking the time to consider this invitation.

Your sincerely

Nguyen Hong Sinh 


\section{Victoria \\ UNIVERSITY OF WELLINGTON \\ Te Whare Wānanga \\ o te Ūpoko o te Ika a Māui

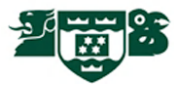

\section{Consent to Participate in Research (for focus group) A contextual model for planning continuing education programmes for university library practitioners in Vietnam}

I have read and understood the Information Sheet detailing the purposes and requirements of this study. I have had an opportunity to ask questions and have them answered to my satisfaction. I understand that

I may withdraw myself from this research without having to give reasons up to the end of October 2006 and the information contributed by me will be removed from the study.

My identity and that of university will be kept confidential and information or opinions which I have given will not be attributed to me in any reports on this research.

Information that I have told will be recorded.

I will not disclose information or opinions of other members in the focus group interview.

A summary of results of this research will be sent to my library and to me.

The data I provide will be only used for the publication of the researcher's $\mathrm{PhD}$ thesis and academic or professional journals or being presented at relevant conferences.

I agree to participate in this research.

Signed:

Date:

Participant's name:

Library's name: 


\section{APPENDIX D \\ INDIVIDUAL INTERVIEW PROTOCOL}

\section{Check-list of resources for interviews}

- Recorder

- Extra batteries for the recorder

- Pens

- Notebooks

- Copy of signed interview consent form

- Copies of letter of information, interview consent form to be provided to interviewees in case the researcher has not received signed consent form.

Interview schedule

\begin{tabular}{|l|l|l|l|l|}
\hline Time & Name of interviewee & $\begin{array}{l}\text { Organisation } \\
\text { and position }\end{array}$ & $\begin{array}{l}\text { Contact details } \\
\text { of interviewee }\end{array}$ & Note \\
\hline & & & & \\
\hline & & & & \\
\hline
\end{tabular}

\section{Procedure of interviews}

Before interviews are conducted the following tasks will be done

1. Contact the interviewees and schedule the time for interviews

2. Send the information sheet and consent form to them

Getting started

1. Introduce myself

2. Explain the purpose of the study and the purpose of the interview

3. Explain why the participant has been invited and why he or she is important to the study

4. Explain the term "continuing education"

Interviewing

1. Start with their opinions about factors (enablers and barrier) affecting CE

2. Ask their opinions about learning needs of university library practitioners and their individual needs

3. Based on the flow of discussion, ask follow-up questions

4. Check with the below list of themes concerning with factors in the preliminary model and check the list of preliminary learning needs in order to find out which factors and learning needs interviewees do and do not mention

5. Ask their opinions about factors in the preliminary model and learning needs which they do not mention

6. Ask their opinion about the process to conduct a triage

Drawing up

1. Ask the participant if there are any additional ideas

2. Thank the participant for participation and ask for their future help when needed After an interview

Review notes to formulate lessons learned to be applied in the next interviews. 


\section{APPENDIX E \\ THEMES FOR GATHERING EVIDENCE AND \\ SAMPLE OF INTERVIEW QUESTIONS}

\section{Themes}

1.a Enablers for and barriers to CE from:

- Social/cultural values, beliefs, and expectations

- Changes from the social/cultural system

- Economic system

1.b Influences from these systems and changes on CE needs of practitioners and of interviewees and what their needs are.

2.a Enablers for and barriers to $\mathrm{CE}$ from:

- Central government

- $\quad$ MOET and other ministries

- University

- Library

2.b Influences from these organisations on CE needs of practitioners and of interviewees and what their needs are.

3. Enablers for and barriers to $\mathrm{CE}$ from their own characteristics

- Age, physical condition, and family commitments

- Abilities, aspiration, and initial education

- Goals and needs

4. Enablers for and barriers to CE from nexus between organisations (library, university, and MOET) and practitioners:

- Fit and balance between requirements from the organisations and practitioners' needs

- Influences of manager support, peer support for their CE

5.a Barriers for practitioners to obtain:

- Knowledge and skill base

- Sets of competencies

- IT knowledge and skills

5.b Influences of changes in body of knowledge, competencies, ICTs on their CE and their CE needs and what their needs are.

6. Any other factors that need to be considered with regard to $\mathrm{CE}$

7. CE needs for practitioners and for participants including content and educational formats 


\section{Sample interview questions}

1. Would you please tell me, from your perceptions, what are enablers for CE of university library practitioners?

2. Would you please tell me, from your perceptions, what are enablers for CE of your own CE?

1. How do they affect CE?

2. What are barriers to CE of university library practitioners?

3. What are barriers to your own CE?

4. How do they barrier?

5. What are learning needs of practitioners in your library?

6. What are your learning needs?

7. How about the factor/s X (one in the preliminary model that interviewees do not mention so far)?

(Example: How about the enablers for CE from policies of your library, such as promotion policies, financial support or Human resource development? How do they affect CE?)

8. From your perceptions what are any other factors that should be considered with regard to CE? And why?

9. How do you think we can balance the needs of the library and university and your own needs? 


\section{APPENDIX F \\ A PRELIMINARY LIST OF LEARNING NEEDS}

\section{Group 1: information technology}

Internet

1. Overview of the internet

2. Internet security

3. Internet: issues and responsibilities

Web site creation

4. Fundamental web skills

5. HTML

6. SGML/XML

7. Information architecture

8. Web site planning

9. Web site design

10. Web site creation and implementation

11. Web site management

12. Creating virtual tour of library

Computer skills and IT application in library services

13. Using multimedia

14. Creating and using simple spreadsheets

15. Monitoring and enhancing information access

16. Sending and retrieving information over the internet using browsers and email

17. Developing and using complex databases

18. Using advanced feature of computer applications

19. Intranet communication

Digital libraries

20. Overview of digital library

21. Digital scanning

22. Image processing and management

23. Metadata

24. Management of electronic records and images

\section{Group 2: communication and management skills}

Management skills

1. Establish effective workplace relationships

2. Train small groups

3. Implement workplace health, safety and security procedures

4. Develop and maintain community/stakeholder relationships

5. Deliver information, activities and events

6. Develop a marketing program for your library

7. Evaluation of system and services

8. Legal issue in managing information

9. Creating a plan for information literacy

10. Understanding copyright issues 
11. Grant-writing

12. Information ethics

13. Marketing for information services

14. User education (Information literacy for users)

15. Current issues

16. Personal skills

17. Make presentation

18. Writing simple documents

19. Increase personal leadership

20. Leadership in library

21. Teamwork in library

\section{Group 3: information service skills}

1. Obtain information from external and networked sources to meet customer needs

2. Research and analysis information to meet customer needs

3. Search databases

4. Reference interview strategies

5. Develop and use information literacy skills

6. Assist customer to access information

7. Using and evaluating and extending own information literacy skills

8. Promote client access to literature

9. Developing search strategies

10. Deliver the information/information resources

\section{Group 4: collection development}

1. Process information resource order

2. Select and acquire information materials

3. Evaluate a library collection, library policy and client needs to select library material

4. Electronic collection development for the academic E-library

5. Electronic books and electronic publishing

\section{Group 5: preservation skills}

1. Process and maintain information resources

2. Identification of bookbinding styles and how a book is constructed

3. Care and handling of and other archive materials

4. Use of aids to reduce damage to books and archives

5. Storage and boxing

6. Housekeeping/Prevention

7. Digital preservation

\section{Group 6: cataloguing}

1. System and process to use to create and maintain the catalogs

2. Skill to create record for library catalogs

3. Skill in bibliographic description 
5. Skill subject analysis

6. Skill to provide classification numbers

7. Skill to index and abstract library materials

8. Skill to provide range of appropriate subject heading to the materials

9. Use LCSH

10. Use DDC

11. Use Vietnamese classification scheme 19 classes

12. Use ISBD

13. Use AACR2

14. Use MARC21

15. Cataloguing electronic resources 


\section{APPENDIX G \\ FOCUS GROUP INTERVIEW PROTOCOL}

\section{Check-list of resources for interviews}

- Recorder

- Extra batteries for the recorder

- Pens

- Notebooks

- Copy of signed interview consent form

- Copies of letter of information, interview consent form to be provided to interviewees in case the researcher has not received signed consent form

\section{Interview schedule}

\begin{tabular}{|l|l|l|l|l|l|}
\hline Library & Time & Name of interviewee & Position & Contact details & Note \\
\hline & & & & & \\
\hline & & & & & \\
\hline
\end{tabular}

\section{Procedure of focus group interviews}

Before interviews are conducted the following tasks will be done

1. Contact the interviewees and schedule the time for interviews

2. Send the information sheet and consent form to them

3. Ask for a room in the library in which to conduct interviews

Getting started:

1. Introduce myself

2. Explain the purpose of this study and the purpose of the focus group interview

3. Explain the term "continuing education"

4. Explain why the participants have been invited and why they are important to the study

5. Ask the participants to introduce themselves

6. Explain the ground rules for the group interview

- The researcher is a facilitator

- Everyone should participate

- All ideas, opinions or views are equally valid

- There are no right or wrong ideas

7. Ask for permission to record and take notes during the interview Interviewing

1. Start with their opinions about factors (enablers and barrier) affecting CE

2. Ask their opinions about learning needs of university library practitioners and their individual needs

3. Based on the flow of discussion, ask follow-up questions

4. Check with the below list of themes concerning with factors in the preliminary model in order to find out which factors interviewees do and do not mention 
5. Ask their opinions about factors in the preliminary model which they do not mention

6. Ask their opinion about the process to conduct a triage

Drawing up

10. Ask participants if there are any additional ideas

11. Thank participants for their participation and ask for their future help when needed

After interviewing

- Review notes to formulate lessons learned to be applied in the next interviews.

- Find out what it would take to get the participants to come to the discussion 


\section{APPENDIX H \\ HANDLING PROBLEMATIC GROUP BEHAVIOURS}

(Schensul, 1999a, p. 84-85)

\begin{tabular}{|c|c|}
\hline Problems & Solutions \\
\hline $\begin{array}{l}\text { Some members of the } \\
\text { group do not speak }\end{array}$ & $\begin{array}{l}\text { The facilitator calls on each group member one by one, } \\
\text { repeating the question or someone else's response. The } \\
\text { facilitator makes sure to ask individuals who have not } \\
\text { contributed, "What do you think about X?" }\end{array}$ \\
\hline $\begin{array}{l}\text { Some members of the } \\
\text { group speak too much }\end{array}$ & $\begin{array}{l}\text { The facilitator asks those individuals to wait for their turn, } \\
\text { to "hold your idea" for a moment, or to wait until others } \\
\text { have had an opportunity to speak. }\end{array}$ \\
\hline $\begin{array}{l}\text { One group member } \\
\text { dominates the conversation } \\
\text { by speaking to often, too } \\
\text { loudly, for too long or on a } \\
\text { coercive manner }\end{array}$ & $\begin{array}{l}\text { The facilitator reminds the group of the ground rules and } \\
\text { the purpose of the focus group. If the offending individual } \\
\text { does not understand or change behaviour, the facilitator } \\
\text { asks the participant directly to conform to the group rules, } \\
\text { either during the group session or during a break. }\end{array}$ \\
\hline $\begin{array}{l}\text { Group members talk to } \\
\text { people next them but not } \\
\text { with the group }\end{array}$ & $\begin{array}{l}\text { The facilitator first determines the cause of the problem: } \\
\text { some participants may feel uncomfortable speaking in a } \\
\text { group, participants may not have received enough } \\
\text { opportunity to express their opinions, the conversation } \\
\text { may difficult to follow, participants may not be able to } \\
\text { understand the way that others express themselves, } \\
\text { participants may feel uncomfortable with a subtopic, or } \\
\text { they may disagree with what someone said but feel uneasy } \\
\text { saying so in public. } \\
\text { The facilitator should take a few moments to observe and } \\
\text { discuss with the individuals what the problem is. A } \\
\text { solution then can be devised. }\end{array}$ \\
\hline $\begin{array}{l}\text { Group members begin to } \\
\text { take sides on an issue }\end{array}$ & $\begin{array}{l}\text { The facilitator reminds group member that everyone's } \\
\text { opinion is valued and that differences of opinion are } \\
\text { important as opportunities for learning. } \\
\text { The facilitator encourages participants to state their } \\
\text { opinions and to discuss and debate different points of } \\
\text { view, but to avoid open conflict, because it can divide a }\end{array}$ \\
\hline
\end{tabular}




\begin{tabular}{|l|l|}
\hline $\begin{array}{l}\text { Group discussion diverges } \\
\text { from the interview focus }\end{array}$ & $\begin{array}{l}\text { group and preclude further open discussion, which } \\
\text { disrupts the intention of the focus group. } \\
\text { polite reminder and/or a shift in questioning. If group } \\
\text { members do not wish to return to the topic scheduled for } \\
\text { discussion right away, they can be invited to postpone the } \\
\text { new topic until after the session is over, at which point } \\
\text { they can remain and continue to discuss the new topic for } \\
\text { as long as they wish. Divergence can happen very quickly. } \\
\text { The facilitator should exercise care when letting } \\
\text { discussion flow, even if she is trying to avoid offending } \\
\text { responding respondents by cutting off discussion. The } \\
\text { facilitator should remember that each formal focus group } \\
\text { interview member was selected because he or she was } \\
\text { known to have experience and opinions on the topic to be } \\
\text { discussed, and that because of their expertise, they } \\
\text { received incentives for their participation. }\end{array}$ \\
\hline $\begin{array}{l}\text { Participants have ideas } \\
\text { relevant to the topic, but } \\
\text { either have not thought } \\
\text { them out clearly or cannot } \\
\text { express themselves well }\end{array}$ & $\begin{array}{l}\text { The facilitator probes by asking additional questions but } \\
\text { avoids suggesting likely extensions of the respondent's } \\
\text { thoughts. Some people work best from the basis of } \\
\text { concrete examples, the facilitator can also ask such } \\
\text { respondents to give some examples of what they mean } \\
\text { and then question them for clarity. The facilitator can also } \\
\text { ask other group members to describe similar situations } \\
\text { that may stimulate the thoughts of the struggling group } \\
\text { member }\end{array}$ \\
\hline
\end{tabular}

